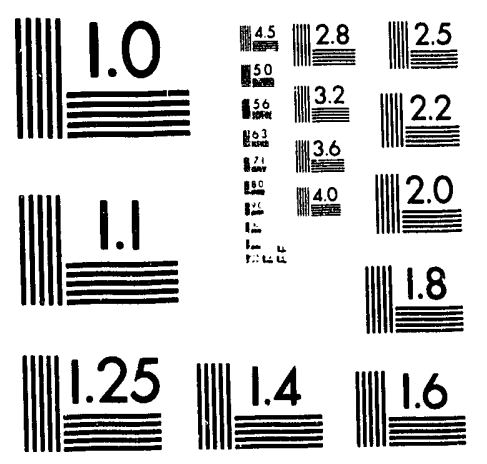



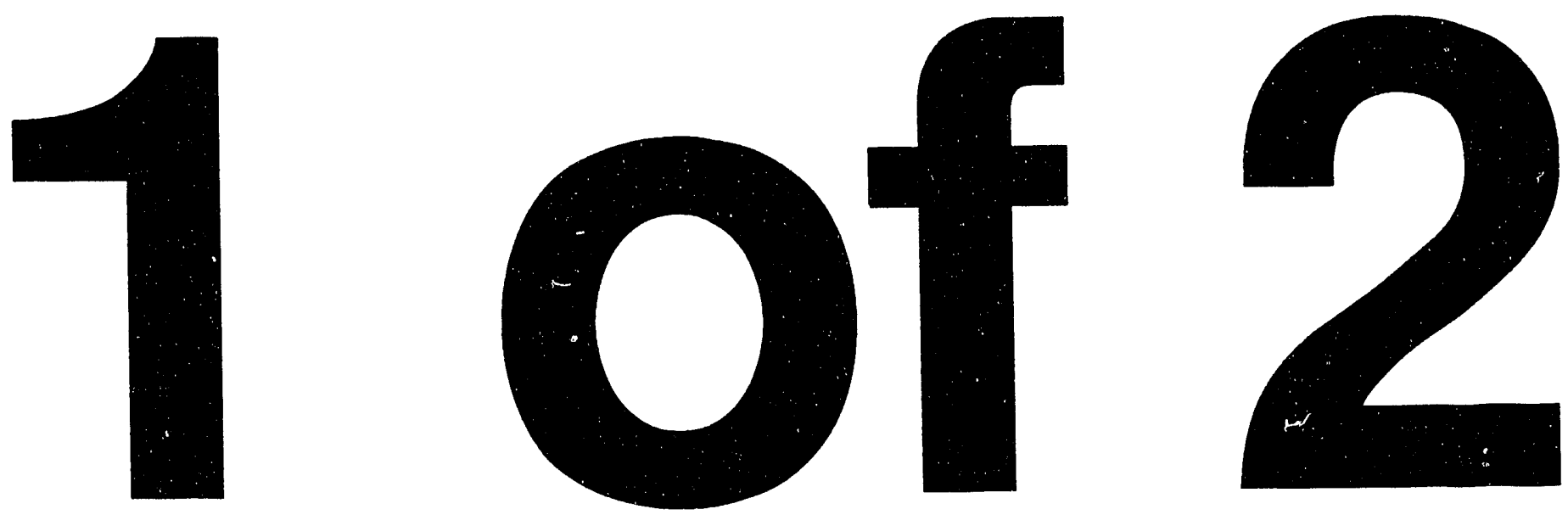


\section{Technical Evaluation: 300 Area Steam Line Valve Accident}

Technical Evaluation Team

D. J. Green, Chairman

Date Published

August 1993

Prepared for the U.S. Department of Energy

\footnotetext{
Q. Westinghouse P.O. Box 1970

(v) Hanford Company Richland, Washington 99352

Hanford Operations and Engineering Contractor for the

U.S. Departinent of Energy under Contract DE-AC06-87RL10930
}

Approved for Public Release 
WHC-EP-0667

\section{ACKNOWLEDGMENT}

The individuals listed below contributed to the text of this document.

Westinghouse Hanford Company
W. F. Brehm
B. A. Crea
L. E. Efferding
J. C. Guzek
R. K. Hansen
S. N. Huang
J. S. Huisingh
J. J. Irwin
D. L. Koreis

W. L. Knecht

M. R. Lindquist

T. B. McCal1

E. B. Schwenk

J. P. Strehlow

R. Valdiviez

Westinghouse Savannah River Company
P. Livengood
L. M. Polizzi

Westinghouse Science and Technology Center
R. M. Roidt
D. Squarer

Numerical Applications, Inc.

M. J. Thurgood 


\section{CONTENTS}

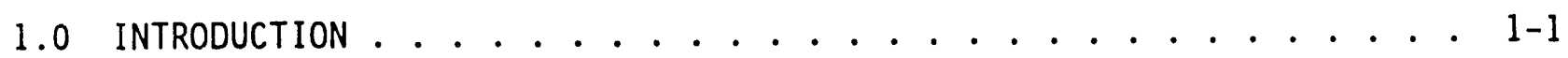

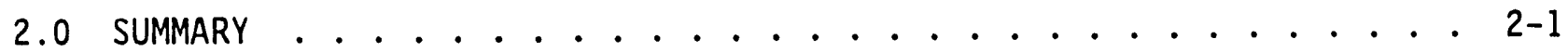

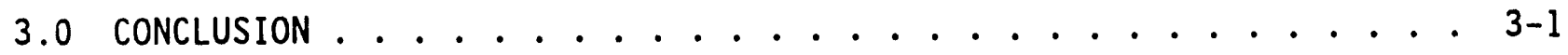

4.0 GENERAL DESCRIPTION OF EVENTS ................... . . .

5.0 BACKGROUND INFORMATION ............... 5-1

5.1 SYSTEM DESIGN AND SPECIFICATIONS . . . . . . . . . . 5-1

5.2 OPERATING CONDITIONS .............. . 5-3

5.3 OPERATIONAL PROCEDURES .............. 5-3

5.4 OPERATIONAL HISTORY ............... 5-3

5.5 MAINTENANCE HISTORY ................. . . 5-4

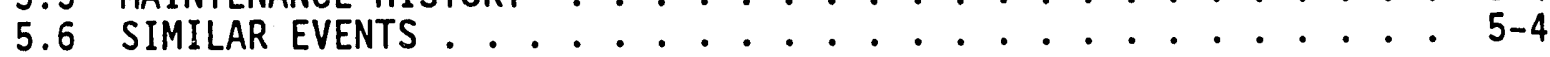

6.0 IN SITU INVESTIGATIONS . . . . . . . . . . . . 6-1

6.1 PRELIMINARY EXAMINATIONS ............. . . 6-1

6.1 .1 General Evidence of Damage . . . . . . . . 6-1

6.1.2 Component Identification/Description Data . . . 6-1

6.1.3 General Piping System Configuration ....... 6-2

6.1 .4 Pipe Supports and Anchors .......... 6-2

6.1.5 Measurements of the Exposed Shank of the ...... 6- 6-2

6.1.6 Description of Broken Valve .......... 6-2

6.2 ADDITIONAL EXAMINATIONS ............... 6-2

6.2 .1 General Evidence of Damage ........ 6-. 6-3

6.2.2 Component Identification/Description Data .... 6-3

6.2.3 General Piping System Configuration ....... 6-4

6.2.4 Pipe Supports and Anchors . . . . . . . . . . 6-4

6.2 .5 As-Built Configuration . . . . . . . . . 6-4

6.2.6 Slope Determinations of Selected Steam Lines.... 6-4

7.0 COMPONENT TESTING AND INVESTIGATIONS ............ . . . . .

7.1 VALVE MSS-25 ................ . . . . . .

7.1 .1 Examination .............. 7-1

7.1 .2 Air Testing . . . . . . . . . . . 7-1

7.1 .3 Disassembly ............. . . 7-1

7.2 STEAM TRAP . . . . . . . . . . . . 7-2

7.2 .1 Initial Tests . . . . . . . . . . 7-2

7.2 .2 Flow Tests............... . . . . .

8.0 THERMAL-HYDRAULIC ANALYSES . . . . . . . . . . 8-1

8.1 INTRODUCTION .......................... 8-1

8.2 SEQUENCE OF EVENTS PERTINENT TO THERMAL-HYDRAULIC EVALUATION . 8-1

8.3 DATA PERTINENT TO THERMAL-HYDRAULIC EVALUATION ....... 8-2

8.3.1 Steam System Description . . . . . . . . . 8-2

8.3.2 Steam System Process Parameters on June 7, $1993 \ldots$. 8-2

8.4 POSTULATED VALVE FAILURE MECHANISMS ......... 8-4

8.4.1 Geneial Failure Mechanisms . . . . . . . . . . 8-4

8.4.2 Description of Condensation-Induced Water Hammer . . 8-4 
8.5 THERMAL-HYDRAULIC ANALYSES .............. . . 8-5

8.5.1 Condensation in 8 -in. Pipe to Valve MSS-25 . . . . . 8-5

8.5.2 Condensation in 4-in. Pipe to Valve MSS-28 . . . . 8-6

8.5.3 Steam System Transient Analysis . . . . . . . . 8-6

8.5.4 Thermal Analysis of 6-in. Cast-Iron Valve . . . . 8-7

8.6 ANALYYSIS OF CONDENSATION-INDUCED WATER HAMMER . . . . . . . . 8-9

8.6.1 Introduction . . . . . . . . . . . . . . . . 8-9

8.6.2 General Information .............. 8-10

8.6.3 Analysis................... . 8-11

8.6.4 Conclusions ................ 8-17

8.7 THERMAL-HYDRAULIC EXPERIMENTS . . . . . . . . . . . . 8-18

8.7.1 Test Facility . . . . . . . . . . . . . . . 8-18

8.7.2 Test Procedure ................ . 8-19

8.7.3 Test Results .................. 8-19

8.7.4 Extrapolation of the Results to the Prototype . . . 8-21

8.7.5 Conclusions from Tests............. 8-21

8.8 CONCLUSIONS .................... 8-22

9.0 MATERIAL EXAMINATION AND ANALYSIS . . . . . . . . . . . . . . . 9-1

9.1 SCOPE OF INVESTIGATION . . . . . . . . . . . . . . . . . . . 9-1

9.2 SUMMARY . . . . . . . . . . . . . . . . . . . . . 9-1

9.3 ONSITE INSPECTION FOR REMOVAL OF TEE . . . . . . . . . . . . . . . $9-1$

9.4 VALVE DESCRIPTION ................... . . 9-2

9.5 INVESTIGATION METHODOLOGY . . . . . . . . . . . . 9 9-2

9.5.1 Removal from Pit ................ . 9-2

9.5.2 Initial Cleaning .. . . . . . . . . . . . . . . 9-3

9.5.3 Preliminary Examinations... . . . . . . . . 9-3

9.5.4 Nondestructive Examination . . . . . . . . . . . . 9-3

9.5.5 Specimen Preparation . . . . . . . . . . . . 9-4

9.6 RESULTS . . . . . . . . . . . . . . . . . . 9-5

9.6.1 Visual Examination .............. . 9-5

9.6.2 Nondestructive Examination . . . . . . . . . 9-6

9.6.3 Disassembly . . . . . . . . . . . . . 9-6

9.6.4 Microstructure . . . . . . . . . . . . . . . 9-7

9.6.5 Fractography .. . . . . . . . . . . . . . 9-8

9.6.6 Mechanical Properties . . . . . . . . . . . . . 9-9

9.6.7 Chemical Analysis . . . . . . . . . . . . . . 9-11

9.7 DISCUSSION . . . . . . . . . . . . . . . . . . 9-13

9.8 CONCLUSIONS . . . . . . . . . . . . . . . . . 9-15

10.0 STRESS ANALYSIS . . . . . . . . . . . . . . . . . 10-1

10.1 AS-BUILT CONFIGURATION . . . . . . . . . . . . . . 10-1

10.2 MATERIAL PROPERTIES . . . . . . . . . . . . . . . . . . . 10-1

10.3 STRESS ANALYSIS CRITERIA . . . . . . . . . . . . . . . . . 10-1

10.3.1 Allowable Stress for Normal Conditions . . . . . . 10-1

10.3.2 Failure Stress for Abnormal Conditions . . . . . 10-2

10.4 STRESS ANALYSIS ................ . . . 10-2

10.4.1 Normal Conditions . . . . . . . . . . . . 10-3

10.4.2 Abnormal Conditions . . . . . . . . . . . . . 10-3

10.4.3 Dynamic Analysis ............... . 10-4

10.4.4 Discussion ................. . . 10-5

10.5 FRACTURE MECHANICS ANALYSIS . . . . . . . . . . . 10-6

10.6 SUMMARY . . . . . . . . . . . . . . . . . . . . . . 10-7

11.0 REFERENCES . . . . . . . . . . . . . . . . . . . . 11-1 


\section{LIST OF FIGURES}

1-1. 300 Area Piping System Layout. . . . . . . . . . . . . . . IF-1

1-2. Steam Valve Pit U-3................. . . . . . . .

1-3. In-Pit Photo Showing Sand-Covered Broken 6-in. Valve. . . . . . 1F-3

5-1. Underground Steam Conduit Section. . . . . . . . . . . . . . 5F-1

5-2. Underground 10-in. Steam Line Section. . . . . . . . . . . . 5F-2

5-3. Underground 8-in. Steam Line Section. . . . . . . . . . . . . 5F-3

6-1. Isometric Sketch of Pipe Routing. . . . . . . . . . . . . . 6F-1

6-2a. U-3 Steam Valve Pit As-Built. . . . . . . . . . . . . . . . 6F-2

6-2b. Miscellaneous Details for U-3 Steam Valve Pit As-Built. . . . . 6F-3

6-3. Upper Elevation Piping to and from the U-3 Steam Valve Pit. . . . 6F-4

8-1. Plan View of Piping in U-3 Valve Pit. . . . . . . . . . . . . 8F-1

8-2. Valve Line-Up Before Accident, June 7, 1993. . . . . . . . . . . 8F-2

8-3. Valve Line-Up at Time of Accident $(\approx 7: 18$ p.m. $)$. . . . . . . . . 8F-3

8-4. First Attempt to Isolate Valve After Accident. . . . . . . . . . . 8F-4

8-5. Final Isolation of Valve After Accident. . . . . . . . . . . . 8F-5

8-6. Steam Pressure in Pipeline Before Valve Failure. . . . . . . . . . 8F-6

8-7. Schematic Illustrations of a Condensation-Induced Water Hammer. . 8F-7

8-8. Summary of Calculations Estimating Condensation. . . . . . . . 8F-8

8-9. Flow Rate, Valve MSS-25. . . . . . . . . . . . . . . 8F-9

8-10. Fluid Density at Location of Failed Valve. . . . . . . . . . . 8F-10

8-11. Flow Rate, Failed Valve Location. . . . . . . . . . . . . . . 8F-11

8-12. Hydrodynamic-Volume Temperature Transient at

Failed Valve Location. . . . . . . . . . . . . . 8F-12

8-13. Pressure of Hydrodynamic Volume at Failed Valve Location. . . 8F-13

8-14. Phase Velocities at Fluid Junction Upstream of

Hydrodynamic Volume. . . . . . . . . . . . . . . . 8F-14

8-15. Liquid and Vapor Void Fractions of Hydrodynamic Volume. . . . 8F-15

8-16. Transient Thermal Response of Valve Body at Failure Location. . 8F-16

8-17. Gray Scale Representation of Temperature Distribution at Valve

Failure Location at Times 1.0 second. . . . . . . . . . . . . . 8F-17

8-18. Transient Temperatures at Failure Location (First 5 seconds). . 8F-18

8-19. Transient Temperatures at Failure Location (First 60 seconds). . 8F-19

8-20. Time Required to Cool Lower Half of Valve to Temperature (55 ${ }^{\circ} \mathrm{F}$ ) of Entering Water. . . . . . . . . . . . . . . . 8F-20

8-21. Sectional View of Valve Body (Mode1) 8 seconds After

Cold Water Reaches Valve. . . . . . . . . . . . . . . . 8F-21

8-22. Sectional View of Valve Body (Model) 2.8 seconds After Cold Water Reaches Valve. . . . . . . . . . . . . . 8F-22

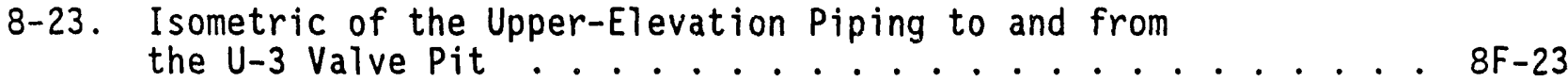

8-24. Postulated Condition of Valve Before Opened. . . . . . . . . $8 F-24$

8-25. Valve Condition Shortly After Opening, with Riser Filiing. . . 8F-24

8-26. Onset of Rapid Condensation ............. . 8F-25

8-27. Rapid Accelerätion of Water slug ............. . . . 8F-25

8-28. Slug Striking Reducer and Water-Filled 4-in. Line . . . . . . . 8F-26

8-29. Impact of Shorter Slug on Reducer and Water-Filled 4 -in. Line 8 . $8-26$

8-30. Water-Hammer Over-pressure as a Function of Slug Length . . . . 8F-27

8-31. Water-Hammer Over-pressure as a Function of Slug Length . . . . 8F-27

8-32. Duration of Pressure Pulse as a Function of Slug Length . . . . 8F-28

8-33. Duration of Pressure Pulse as a Function of Slug Length . . . . 8F-28 
8-34. Schematic of Pipe Condition Just Before Initiation of

Condensation-Induced Water Hammer. . .......... 8F-29

8-35. Photograph Showing Front View of Test Model ........ 8 . . . 30

8-36. Photograph Showing Side View of Test Model ......... $8 \mathrm{~F}-31$

8-37. Sketch of Test Model Piping Assemb7y . . . . . . . . . . . . 8F-32

9-1. Plan View Sketch of 6-in. Pipe Containing Broken Valve End. . . . 9F-1

9-2. View of Sand-Covered Broken Valve Still Attached

to the 6 -in. Tee Leg of the 8 by 4 Reducer ......... . 9F-2

9-3. Valve and Tee Section Banded to Pallet, after Arrival

at Building 272E, 200 Area. . . . . . . . . . . . . . 9F-3

9-4. Low-Pressure Water Washing of Broken Vaive. . . . . . . . . . . . 9F-4

9-5. 6-In. Valve, Cleaned, Forced-Air Dried and

Spray Coated with WD-40. ............... . . . . . F-5

9-6. Tee/Reducer Section Cleaned, Forced-Air Dried, and Spray-Coated

with WD-40. . . . . . . . . . . . . . . . . 9F-6

9-7. Cracked Vaive Bonnet Foot (one of four yoke legs shown

above cracked foot). ................. . . 9F-7

9-8. Location of an Additional crack Penetrating the Valve Body off the Major Circumferential Fracture Surface. . . . . . . . . . . 9F-8

9-9. Layout of Specimens in Fractured Valve for Metailographic

and Scanning Electron Microscope Observation and Surface

ihemica? Analysis. ............. . . . . . . . . . -9

9-10. View of Valve Fracture Face and Probable Impact Damage Region. 9F-10

9-11. View of Mating Flange Fracture Face Showing Reddish-Brown

Stained Regions. . . . . . . . . . . . . . . . . $9 F-11$

9-12. Close-Up View of Vaive Fracture Face and Additional Crack. . . 9F-12

9-13. Close-Up View of Back Side of Figure 9-12 Showing

Penetrating Crack. . . . . . . . . . . . . . 9F-12

9-14. Higher Magnification View of crack in Figure $9-13$ showing

Unbroken Ligament. . . . . . . . . . . . . . . . 9 9F-13

9-15. Cross Section of Fractured Vaive Showing Crack Path and

Microstructure ...................... 9F-13

9-16. Higher Magnification View (500X) of Figure 9-15 Showing

Graphite Flakes, Pearlite, and Ferrite . . . . . . . .. . 9F-15

9-17. Cross Section of Fractured Valve Showing Generai Microstructure 9F-15

9-18. Higher Magnification View (500X) of Figure 9-17 Showing

Typical Graphite Flakes, Pearlite, and Ferrite . . ..... 9F-16

9-19. Scanning Electron Microscope-2 Fracture Surface Near the

Interior Diameter Surface, 150x. . . . . . . . . . 9F-17

9-20. Higher Magnification View (500X) of Figure 9 -ig Showing

Particulate Deposits, Believed to be Mainly Oxides. . . . . . 9F-17

9-21. Scanning Electron Microscope-2 Fracture Surface Near the Center of SEM-2, 150X .............................. $9 F-18$

9-22. Higher Magnification View (500x) of Figure $9-21$ Showing Reduced Amount of Oxide Deposit ............... 9F-18

9-23. Fresh Fracture Surface, Specimen 3A-1, Near SEM-3 . . . . . . 9F-19

9-24. Fracture Surface, Characteristic of SEM-5, 300X. . . . . . . 9F-19

9-25. Tensile Test Specimen Geometry............. . . 9 . . . 20

10-1. Dimensions of the Failed 6-in. Valve. ........... 10F-1

10-2. Finite-Element Mode1. . . . . . . . . . . . . . . . 10F-2

10-3. Axial Stress pistribution as a Result of an Internai Pressure
of $125 \mathrm{lbf} / \mathrm{in}^{2}$ (Gauge). . . . . . . . . . . . . . . .

10-4. Axial Stress Distribution as a Result of an Internal Pressure
of $2,250 \mathrm{lbf} / \mathrm{in}^{2}$ (Gauge) 
10-5. Axial Stress Distribution as a Result of an Internal Pressure of $1,803 \mathrm{lbf} /$ in $^{2}$ (Gauge) ........... 10F-5

10-6. Axial Stress Distribution as a Result of an Internal Pressure of $1,803 \mathrm{lbf} /$ in $^{2}$ (Gauge) without Radial Pressure Component . . . 10F-6

10-7. Axial Stress Distribution as a Result of an Internal Pressure of $1,803 \mathrm{lbf} / \mathrm{in}^{2}$ (Gauge) without Axial Force Component . . . . 10F-7 


\section{LIST OF TABLES}

5-1. Documentation for 300 Area Steam System and U-3 Valve Pit. . . . 5T-1

5-2. Operational History of U-3 Pit. . . . . . . . . . . . . . 5T-2

5-3. Operational Record of U-3 Pit................ . . 5T-8

8-1. Power House Steam Flows. . . . . . . . . . . . . . . . . . 8T-1

9-1. Equivalence of A 126 to A 48 Class Gray Cast Irons for Three Tensile Specimen Diameters . . . . . . . . . . . . . . . 9T-1

9-2. Effect of Specimen Diameter on Tensile Strength, Class 20 and 30 Gray Irons . . . . . . . . . . . . . . . 9T-1

9-3. Effect of Carbon Equivalent on Gray-Iron Tensile Strength . . . . 9T-1

9-4. Effect of Graphite Maximum Flake Length on Strength . . . . . . 9T-2

9-5. Hardness and Ductility of Basic Cast-Iron Microconstituents . . . 9T-2

9-6. Hardness Ranges for Various Combination of Gray Iron Microstructures .. . . . . . . . . . . . . . . . . 9T-2

9-7. Room Temperature Tensile Strength and Brineil Hardness (BH) Values from Specimens Removed from the Broken Valve Flange . . . 9T-3

9-8. Alloy Chemical Analysis Results of Valve Flange Section B . . . . 9T-3

10-1. Pressure Loading for Maximum Calculated Stresses for Valve Body 10T-1 
TECHNICAL EVALUATION, 300 AREA STEAM LINE FAILURE, JUNE 1993

\subsection{INTRODUCTION}

On June 7, 1993, a journeyman power operator (JPO) was severely burned and 7 ater died as a result of the failure of a 6 -in. valve that occurred when he attempted to open main steam supply (MSS) valve MSS-25 in the U-3 valve pit. The pit is located northwest of Building 331 in the 300 Area of the Hanford Site. Figure 1-1 shows a layout of the 300 Area steam piping system including the U-3 steam valve pit. Figure 1-2 shows a cutaway view of the approximately 10 - by 13 - by $16-\mathrm{ft}$-high valve pit with its various steam valves and connecting piping. Valve MSS-25, an $8-i n$. valve, is located at the bottom of the pit. The failed 6-in. valve was located at the top of the pit where it branched from the upper portion of the $8-i n$. 1 ine at the 8 - by $8-$ by $6-$ in. tee and was then "blanked off" with a blind flange.

At some time during the opening of valve MSS-25, the downstream 6 -in. valve locateu overhead (top of Figure 1-1) failed completely. The valve's upstream-side flange remained attached to the flange near the tee while the rest of the valve body, bonnet, stem, yoke, handle, and the attached blind flange was jammed into its resting place between the vertical 8 -in. 1 ine and the south concrete wall of the pit, about 3 to $4 \mathrm{ft}$ to the west and 4 to $6 \mathrm{ft}$ below its original point of attachment (Figure 1-3).

The purpose of this technical evaliation was to determine the cause of the accident that led to the failure of the 6 -in. valve. The probable cause for the 6-in. valve failure was determined by visual, nondestructive, and destructive examination of the failed valve and by metallurgical analysis of the fractured region of the valve. The cause of the accident was ultimately identified by correlating the observed failure mode to the most probable physical phenomenon. Thermal-hydraulic analyses, component stress analy-es, and tests were performed to verify that the probable physical phenomenon could be reasonably expected to produce the failure in the valve that was observed. 
Figure 1-1. 300 Area Piping System Layout.

\section{AREA}

MAIN SERVICE STEAM (MSS)

(NOT DRAWN TO SCALE)

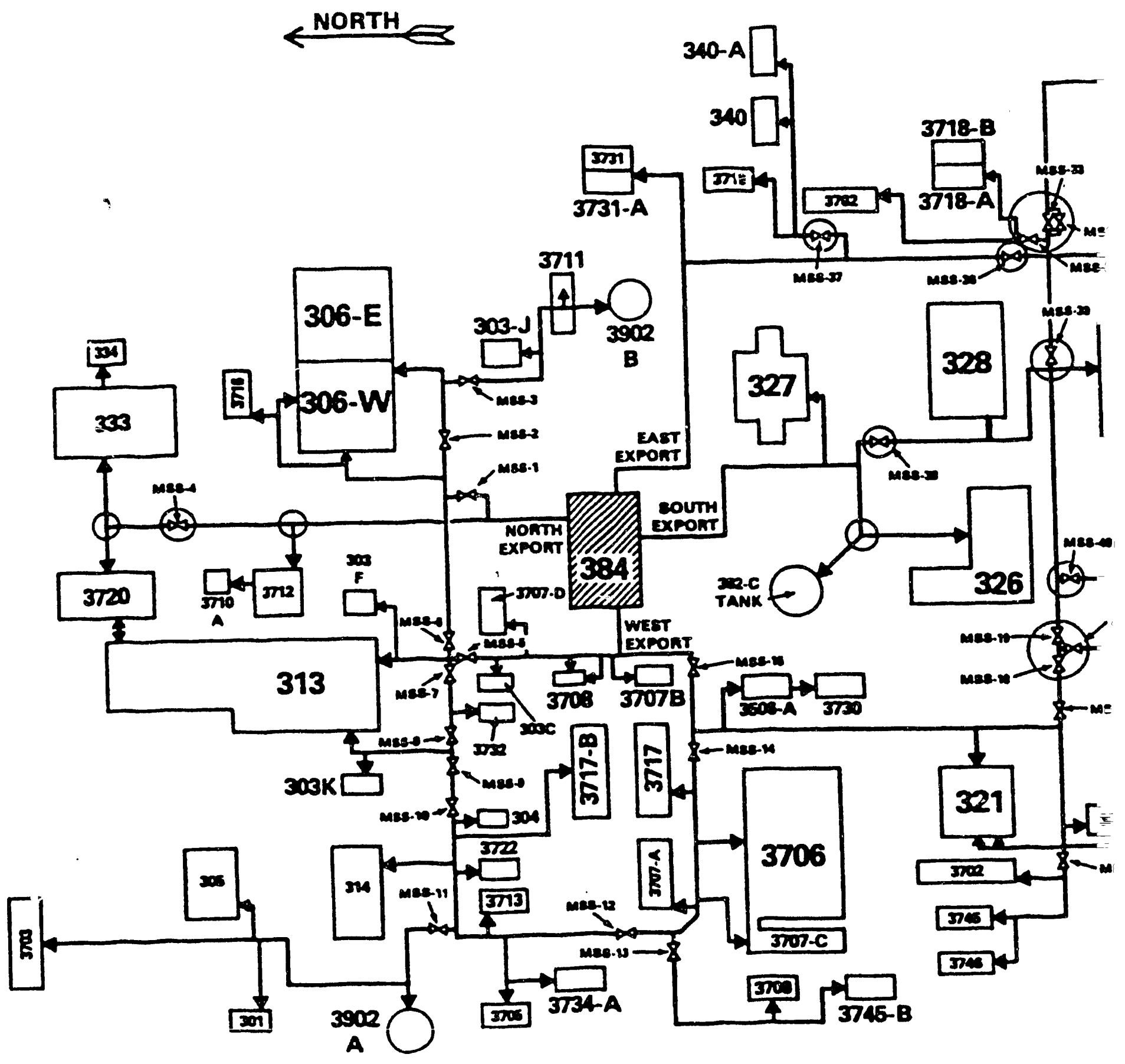


WHC-EP-0667

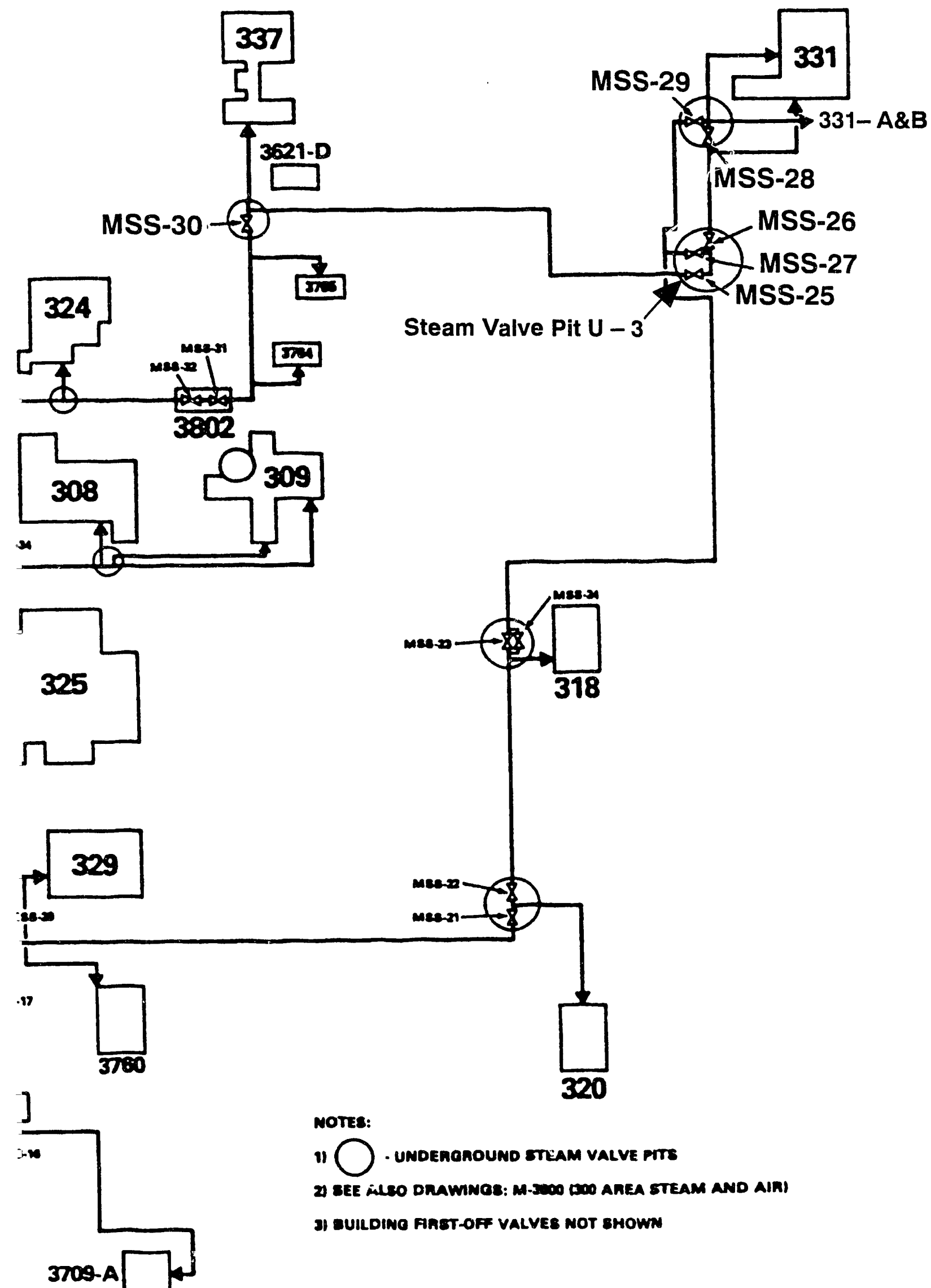


Fi- Ire 1-2. Steam Valve Pit U-3.

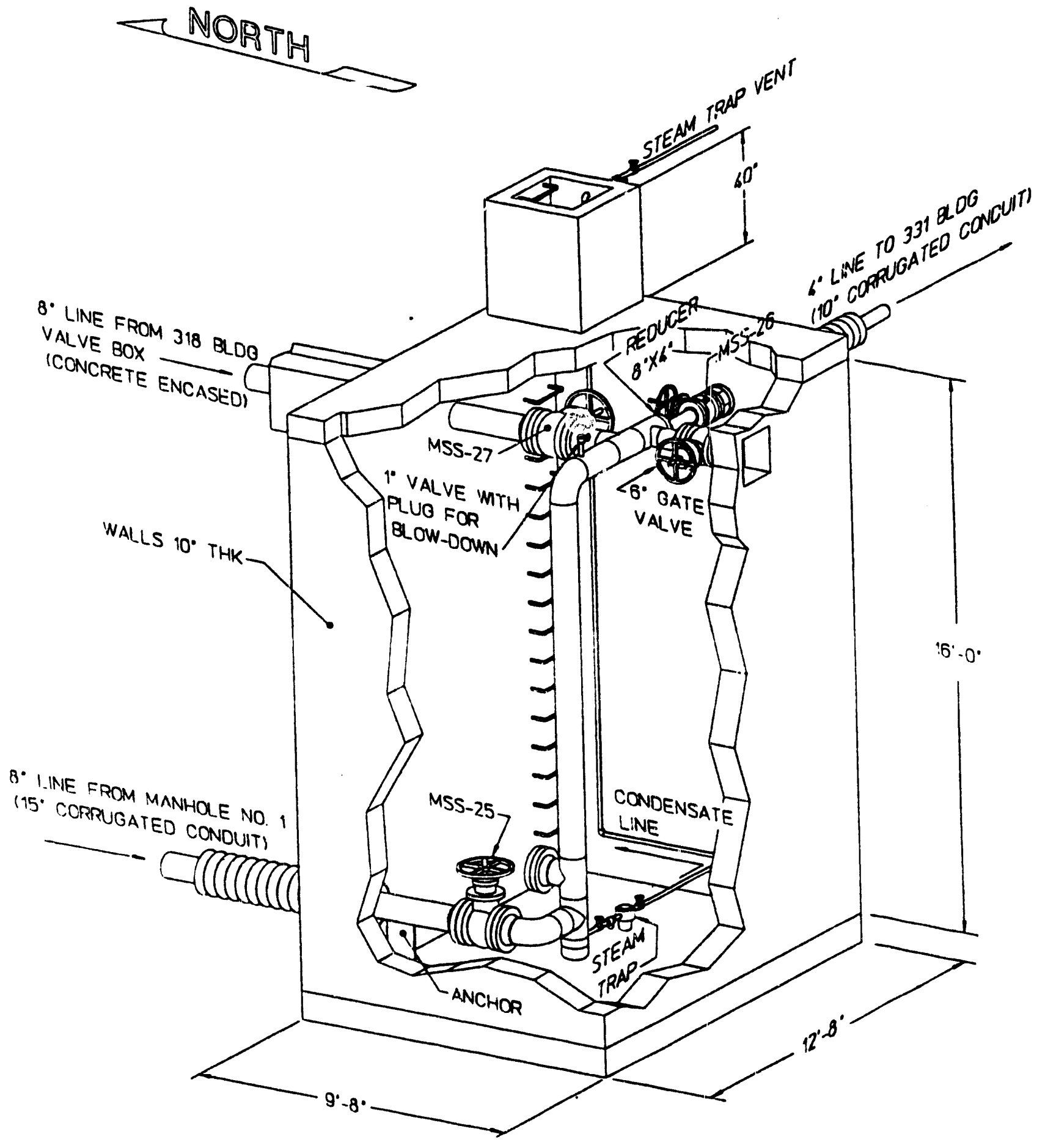

STEAM VALVE PIT U-3 
Figure 1-3. In-Pit Photo Showing Sand-Covered Broken 6-in. Valve.

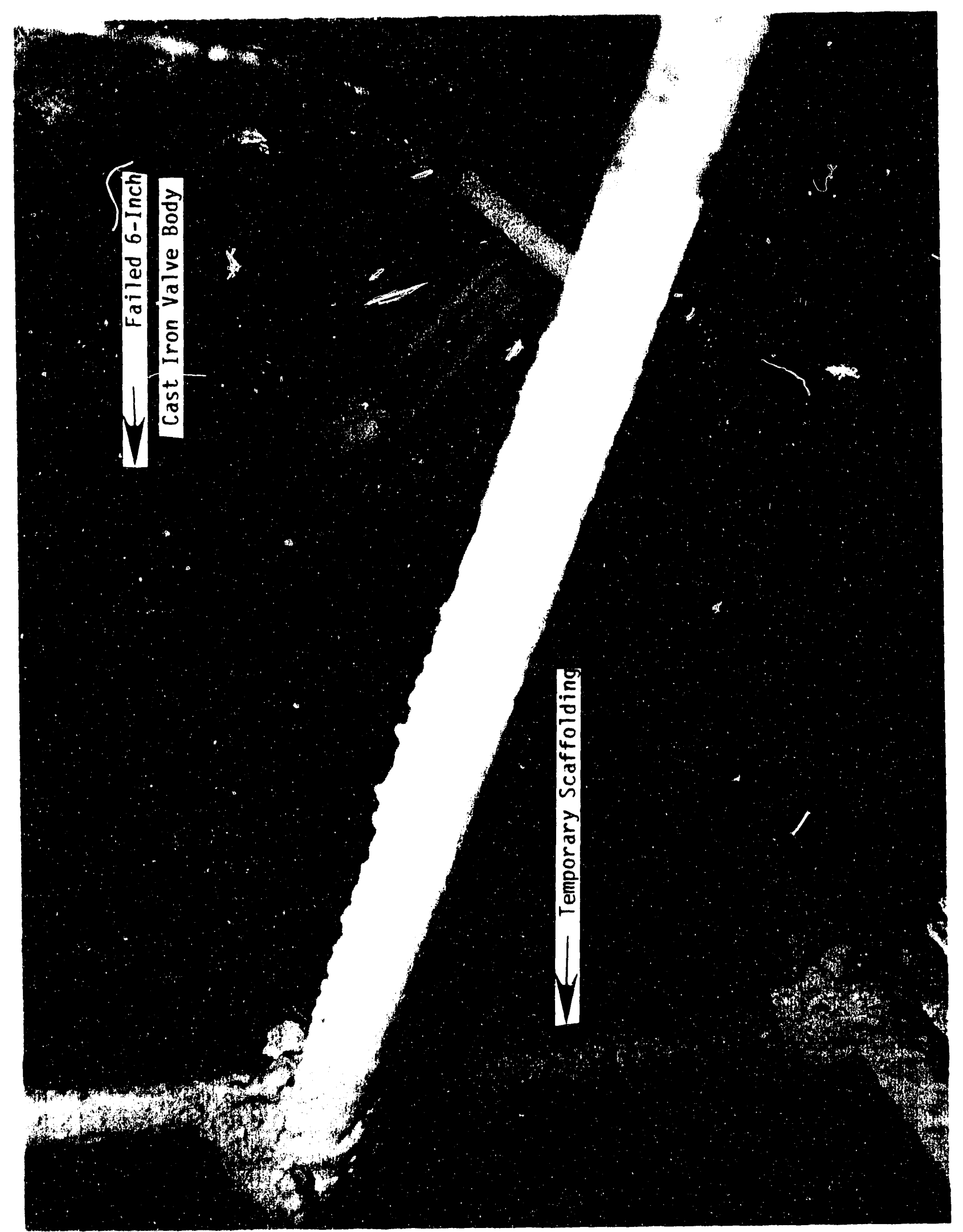




\section{WHC-EP-0667}

\subsection{SUMMARY}

Metaliurgical examinations of the failed valve indicated that the material was sound. It was free of any appreciable casting defects. There was no corrosion damage or evidence of stress-corrosion cracking, aild there were no apparent preexisting flaws or cracks that would have reduced the strength of the valve material. A fractographic analysis indicated that the fracture mechanism was essentially the same for all fractured surfaces. These fracture mechanism was essentially the failed because of over-pressure that was
results indicate that the 6 -in. valve faile
well beyond the pressure rating of the valve, not because of a material defect or degradation.

Results from tensile and hardness tests performed on samples taken from the valve material indicate that the actual strength of the valve material was less than the minimum value of $31,0001 \mathrm{bf} / \mathrm{in}^{2}$ specified in ASTM A-126 for Grade $B$ cast iron. Average tensile strength was found to be $15,9001 \mathrm{bf} / \mathrm{in}^{2}$.

In situ investigations, component testing, and a search of background In situ investigations, component testing, and a selated piping components were
information indicated that the 6 -in. valve and relate
in satisfactory working condition before the accident. Results from these investigations revealed no potential initiators for the accident other than an over-pressure of the 6-in. valve. However, the review of background information revealed a discrepancy between design pressure for the steam system and the pressure rating of the 6 -in. valve.

Detailed examinations (including disassembly) and testing were performed on major components taken from pit $U-3$ relating to the accident. These included $8-i n$. valve MSS-25 and the steam trap. There was no evidence of damage to either valve MSS-25 or the steam trap, and both components appeared to operate satisfactorily.

The design pressure and temperature of the 300 Area steam system is $50 \mathrm{lbf} / \mathrm{in}^{2}$ at $366^{\circ} \mathrm{F}$. The pressure rating for the failed 6 -in. valve is $125 \mathrm{lbf} / \mathrm{in}^{2}$, which corresponds to a saturated steam temperature of $353^{\circ} \mathrm{F}$. Although the valve did not meet the design pressure and rating for the system, the lower rating was not a contributing factor in the accident. The normal operating pressure and temperature at the steam-generating station is $125 \mathrm{lbf} / \mathrm{in}^{2}$ at $353^{\circ} \mathrm{F}$. At the time of the accident, the steam powerhouse was operating at $119 \mathrm{lbf} / \mathrm{in}^{2}$, and the pressure at the $U-3$ steam valve pit was estimated to be $1101 \mathrm{bf} / \mathrm{in}^{2}$. Therefore, the failed 6 -in. valve was operating within its allowable pressure and temperature rating. The difference in pressure between the valve pit and the powerhouse is due to friction losses as the steam flows through the pipe.

Based on these investigations and examinations, the phenomenon postulated as capable of causing an excessive over-pressure on the valve was condensation-induced water hammer in the piping system. A comparison of other potential initiators appears in Section 8.0 of this report.

Condensation-induced water hammer occurs when cold water is introduced into horizontal pipe sections that contain steam. The large surface area of

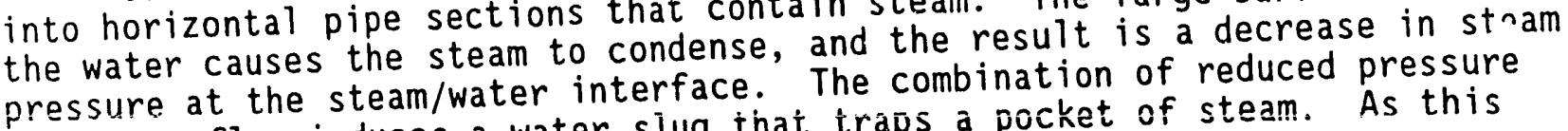
and steam flow induces a water siug that traps a pocket of steam. As this 
steam pocket continues to condense and reduce in pressure and volume, the slug of water accelerates until the steam pocket is gone. The moving slug of water then strikes the stationary water in the pipe and creates a pressure shock wave. As this shock wave travels through the piping system, it creates an over-pressure pulse, referred to as a water hammer, on the system and its components. The initial conditions in the steam system were such that a condensation-induced water hammer was possible. Because MSS-25 had been closed for about 9 months, a large amount of water (possibly completely filling the pipe upstream of MSS-25) at a low temperature (probably $55^{\circ} \mathrm{F}$ ) was available.

The capability of a condensation-induced water hammer to fracture the 6-in. va? ve in the observed manner was demonstrated by a thermal-hydraulic analysi: performed to predict the magnitude of the over-pressure and by component stress analyses performed to estimate the pressure required to cause the 6 -in. valve to fail. Results from these analyses show that a condensation-induced water hammer could induce pressures sufficient to fracture the valve.

Results of the thermal-hydraulic analysis indicate that the magnitude of the over-pressure from the condensation-induced water hammer is in the range of about 1,500 to $3,000 \mathrm{lbf} / \mathrm{in}^{2}$ for 0.01 seconds or $1,000 \mathrm{lbf} / \mathrm{in}^{2}$ for 0.37 seconds, depending on the location and mechanism generating the overpressure. Much higher pressure pulses are possible if the condensate upstream of MSS- 25 did not fill the entire line. The uncertainty in the magnitude and duration of the pressure pulse(s) reflects the uncertainty in initial conditions.

The relevant analytical results were confirmed by scaled laboratory experiments. These tests demonstrated that condensation-induced water hammer could occur and that large pressure pulses would be generated. Video and transient pressure test data were recorded simultaneously in five of the tests.

Results from the component stress analysis show that the over-pressure required to cause the 6 -in. valve to fail is approximately $2,3001 \mathrm{bf} / \mathrm{in}^{2}$ by the pressure load only. This pressure is based on a material tensile strength of $31,0001 \mathrm{bf} / \mathrm{in}^{2}$, the minimum value specified for ASTM A-126 Grade B cast iron, and does not include dynamic effects. This failure pressure will be significantly lower if the measured ultimate material strength $\left(15,900 \mathrm{lbf} / \mathrm{in}^{2}\right)$ and dynamic amplification of the load are used. Amplification of the load is caused by the structural respons: of the system to the rapid pressure transient, which generates additional iilertial loads on the valve. Because the pressure transient is essentially an instantaneous load, the maximum amplification that could theoretically be achieved would nearly double the effect of the pressure load for the pressire pulse durations stated above. Thus, the resulting pressure required to cause the valve to fail using a 20,000 $1 \mathrm{bf} / \mathrm{in}^{2}$ material strength and a dynamic amplification factor of 1.7 would be about $1,1001 \mathrm{bf} / \mathrm{in}^{2}$.

Temperature gradients created by thermal shock to the valve during the water hammer were not included in the estimate of the stress required to cause the valve to fail. The calculated pressure pulse is large enough to cause failure, and because cast iron is brittle, failure at one point will lead to failure across the entire valve section. 


\subsection{CONCLUSION}

The conclusion of this technical evaluation is that the 6 -in. cast-iron valve in valve pit U-3 failed from an over-pressure event in the piping system. This over-pressure event was caused by condensation-induced water hammer. When valve MSS-25 was opened, cold condensate $(1,500 \mathrm{gal})$ that had collected in approximately $840 \mathrm{ft}$ of underground 8 -in. line moved into the upper horizontal sections of the piping system containing high-temperature steam and created the conditions necessary for condensation-induced water hammer to occur. 


\subsection{GENERAL DESCRIPTION OF EVENTS}

On Monday, June 7, 1993, at approximately 7:18 p.m., a JPO was burned fatally while attempting to open main steam isolation valve MSS-25 at the bottom of the U-3 steam valve pit in the 300 Area.

The work being performed was in preparation for a scheduled steam outage to Building 324. Opening MSS-25, an 8-in. gate valve, was necessary to supply steam to Building 337 during the outage. This valve is located at the bottom of a steam valve pit that is $20 \mathrm{ft}$ below ground level. Valve MSS-25 had been left closed after a steam outage during September 1992. Although this valve normally was open during system operation, the decision was made after the September outage not to enter the U-3 steam valve pit to open it because it was not affecting system operation while closed, and a hazardous pit entry was avoided.

Leaving MSS-25 closed during normal system operation allowed steam pressure to be applied, without any flow, to both sides of the valve.

Valve MSS-25 is located at the low point at the end of a run of 8 -in. pipe approximately $840-\mathrm{ft}$ long. During the 8- to 9-month period in which this valve was closed, this $840-\mathrm{ft}$ run filled (or nearly filled) with condensate.

The JPO entered the U-3 steam valve pit. As he opened valve MSS-25, the condensate flowed from its wet side into the steam-filled pipe on its downstream side. A blanked-off 6-in. gate valve located approximately $10 \mathrm{ft}$ above MSS-25 failed circumferentially at its minimum diameter point adjacent to the flange attaching it to the 6 -in. pipe flange. This valve failure allowed approximately $1101 \mathrm{bf} / \mathrm{in}^{2}$ steam to escape via the 6 -in. pipe flange into the U-3 steam valve pit. 


\subsection{BACKGROUND INFORMATION}

\subsection{SYSTEM DESIGN AND SPECIFICATIONS}

No single site-specific set of design criteria has been identified that governs the entire evolution of the $U-3$ steam valve pit and its piping; what has been located are the general piping specifications that cover different phases of the current configuration. The construction specifications and design drawings pertaining to steam piping systems that run through the $U-3$ steam valve pit, listed in Table 5-1, are referred to in the discussion below.

The initial designs for the construction of the valve pit and the configuration of the steam lines were completed in late 1965. The 8-in. underground pipe that feeds into valve MSS-25 and the 4-in. underground pipe that exits the east wall perietration to supply steam to the 331 Buildings should conform to the requirements below, which are taken from drawings $\mathrm{H}-3-25791, \mathrm{H}-3-25792, \mathrm{H}-3-25794$, and from HWS-8449, "Specifications for Biology Laboratory Facilities, and Buildings 331A \& 331B, Projects CAH-977, $\mathrm{CAH}-982$, CAH-157." Page number $(s)$ in braces ( \{\}$)$ refer to pages(s) of HWS-8449 from which the requirements came.

- Pipe was to be ASTM A53, Schedule 40, black (carbon) steel pipe. "Type $F$ steel pipe shall not be used." \{pp. 58 and 77\}

- "All piping shall be fabricated and installed in accordance with ASA B31.1, with the drawings and these specifications." $\{p .80\}$

- "Underground steam and condensate return piping shall be prefabricated insulated pipe units." $\{p .60\}$

- Insulation on the steam lines in the prefabricated conduits shall have 2 in. of glass fiber insulation on pipe sizes 6 in. and greater. The insulation is to be per Federal Specification HH-I-562, "Insulation, Thermal, Mineral Wool, Block or Board and Pipe Insulation." This specification has been superseded by $\mathrm{HH}-\mathrm{I}-558$, "Insulation, Blankets, Thermal (Mineral Fiber, Industrial Type)." [pp. 59, 112, 113, and 117\}

- The 15-in. conduit for the 8-in. line and the 10-in. conduit for the 4-in. line is 16 gauge $(0.0625-i n$. thick) steel, spirally corrugated. It is to be hot-dip galvanized after the seam is welded. It is to be large enough to allow 1 in. of clear air space between pipe insulation and conduit. $\{p .60\}$

- The outside surface of the conduit is to be machine-coated with highmelting-point asphalt with one layer of asphalt-impregnated pipe-line felt. $\{p .60\}$

- At the entrance to the manholes, the conduit shall terminate at the inside face of the manhole. $\{p .60\}$

- Pipe was to be 'securely supported by means of approved pipe hangers' on 12-ft centers (for $21 / 2-i n$. pipe or larger). \{p. 53\} 
- "All pipe in conduit shall be ... free to expand and contract without stress or wear on the insulation. Pipe supports, spaced according to requirements, shall be furnished with the conduit." $\{p .60\}$

The 8 -in. underground pipeline that begins at the tee near valve MSS-27 and proceeds northward and then east to Building 331 was installed between 1968 and 1971. Drawing H-3-28157-A shows the concrete encasement of the pipe (Figure 5-1). The subsequent addition of the 10-in. line from Building 318 eastward to the anchor on the west side of the $U-3$ steam valve pit was installed in 1972. This addition was governed by specification HWS-9316, "Specifications for Steam Distribution System Addition, 300 Area, Project DAP-550." Drawing H-3-33546 shows the concrete encasement of this portion of the piping system (Figure 5-2) The $\varepsilon_{1}-i n$. underground piping added around 1979 includes the "dog leg" between the anchor west of the valve pit and the $8-i n$. tee north of the pit. This portion of underground piping is al so governed by HWS-9316 and is shown in drawing H-3-46220 (Figure 5-3).

The underground pipe governed by HWS-9316 should conform to the following selected requirements. Page number $(s)$ in braces $(\{\})$ refer to page(s) of HWS-9316 from which the requirements came.

- "Steam and condensate pipe shall be black steel, of the sizes shown on the drawings, and shall conform to ASTM A53, Type E or S, Grade B, or ASTM A106, Grade B. Steam pipe shall be Schedule 40 and condensate pipe shall be Schedule $80 . "\{p .8\}$

- "Fittings shall be wrought steel, buttwelded, conforming to ASTM A234, Grade WPA, and ANSI B16.9 with wall thickness to match pipe." $\{p .8\}$

- "Flanges shall be 150-1b forged steel, welding neck conforming to ASTM A181, Grade I or II, raised face, per ANSI B16.5." \{p.8\}

- "Steam trap, for replacement of trap in existing line in Manhole No. 2, shall be a cast iron, inverted bucket type with one inch side inlet and side outlet and a capacity of 2500 pounds of condensate per hour continuous discharge at an operating pressure of 150 psig. Trap shall be Armstrong No. 813, or approved equal." \{p. 8\}

- Expansion joints are addressed in Section 5.0 (of the specification). $\{p p$. 8-9 $\}$

- "Insulation for underground steam and condensate lines shall be lightweight, insulating concrete consisting of portland cement, vermiculite aggregate [conforming to ASTM C332], a liquid waterproofing admix and water." \{p.9\}

- The cured insulating concrete shall have the following properties:

(1) A dry density of not more than $30 \mathrm{lbf} / \mathrm{ft}^{3}$

(2) A compressive strength of not less than $751 \mathrm{bf} / \mathrm{in}^{2}$ at 28 days, per ASTM C495 requirements.

(3) A "k" factor of not more than 0.80 at $70^{\circ} \mathrm{F}$ mean temperature when tested per ASTM C177. \{p. 9\} 
- "Parting medium to encase the pipes shall be 'bubble' sheet material, formed from 0.002 inch thick polyethylene sheets, 'Air Cap SC-240,' as made by Sealed Air Corp., or approved equal." \{p. 9\}

- "Waterproof membrane to be used on the outside of the insulating colicrete shall be a high-temperature-resistant, stable, polyvinylchloride plastic sheeting not less than 0.020 inches thick." \{p. 9$\}$

- "Piping shall be fabricated and installed in accordance with ANSI B31.1.0, the drawings, and [HWS-9316]." \{p. 10\}

\subsection{OPERATING CONDITIONS}

The design pressure and temperature rating for the steam system is $150 \mathrm{lbf} / \mathrm{in}^{2}$ at $366^{\circ} \mathrm{F}$. The system operating pressure at the power plant at the time of the accident was $119 \mathrm{lbf} / \mathrm{in}^{2}$. The corresponding estimated pressure at the $\mathrm{U}-3$ pit is $110 \mathrm{lbf} / \mathrm{in}^{2}$ corresponding to a - team saturation temperature of $344^{\circ} \mathrm{F}$.

The failed 6-in. gate valve was rated for $125 \mathrm{lbf} / \mathrm{in}^{2}$ steam. All other values and $\mathrm{fl}$ anges in the pit were rated at $150 \mathrm{lbf} / \mathrm{in}^{2}$.

\subsection{OPERATIONAL PROCEDURES}

The following list contains the applicable procedures that existed at the time of the accident. Specific operational procedures that apply to the type of operation performed in the $U-3$ pit at the time of the accident do not exist.

-WHC-CM-4-40, Industrial Hygiene Manual, Section 2.3, "Asbestos Control Program," Rev. 0 and Section 3.1, "Confined Space Entry," Rev. 1.

- WHC-CM-4-3, Industrial Safety Manual, Vol. 1, Section A-3, "Pre-Job Safety Planning/Job Hazard Analys is," Rev. 3 and Section G-1, "Energy Control Program (Lock and Tag)," Rev. 3.

- WHC-IP-0384, Supplying Steam Service to a Facility, Vo1. II, SWU3-0-384-30, Rev. 0.

\subsection{OPERATIONAL HISTORY}

To better assess the events surrounding the steam line failure accident of June 7, 1993, it was necessary to evaluate the history of the operation of steam valve MSS-25. Historically, MSS-25 (the valve operated at the time of the event) was not manipulated on a frequent basis for two reasons. First, the valve provided a primary supply of steam to Building 331 . This building requires a supply of steam year-round. Second, MSS-25 was extremely difficult to reach. Access was restrained by the requirements for confined space entry, the heat inside the valve pit, and the belief that asbestos was present. Consequently, MSS-25 was closed only when steam outages were required for maintenance. 
On October 20, 1988, during outage A-986-S, valve MSS-25 was replaced. The configurations shown in Table 5-2 are the valve positions required by the tagout or outage permit. The return to normal positions is not shown, but discussions with Operations personnel indicate that valves were returned to normal positions. Steam header valves were opened and drain valves were closed.

From October 1988 until the present, there have been ten outage configurations during which MSS-25 was manipulated. Eight outages allowed the 6-in. failed valve to cool. All outages associated with MSS-25 and/or the cooling of the failed valve are shown in Table 5-2.

Operating evolutions were not documented consistently. However, of the ten instances when MSS-25 was actually manipulated, there were five instances when the shift supervisor's logbook specifically mentions cracking open valves before placing the steam lines completely in service. Of these, four logbook entries show specific times of pipeline warmup. The warmup times vary from 2 to $31 / 2$ hours. At another instance, th.e steam headers were cracked open on the day shift and opened completely on the swing shift.

\section{Conclusions}

- Although time entries were not consistently made in the supervisor's logbook, it appears that care was taken to log times associated with steam line operation. This indication suggests a sensitivity on the part of the Operations staff to warm the steam lines gradually.

- In all cases, the restoration involved the warming of cold steam lines; in contrast, the June 7 event involved the cooling by water of a hot steam line.

- It appears that at the end of every outage until September 18, 1992, the steam systems were completely restored to the normal configuration (valve open).

\subsection{MAINTENANCE HISTORY}

A search of Westinghouse Hanford Company (WHC) operational records (Table 5-3) showed that the steam trap in the $U-3$ pit was maintained on an annual basis.

Valve MSS-25 was replaced in 1988 without any indication of further maintenance on the valve.

\subsection{SIMILAR EVENTS}

A strainer was ruptured (Papenfuss 1982) during normal warmup to restore steam service for operational checkout of a preheat coil in Building 309 on the Hanford Site. This system had been placed in service each year for several years to the same procedure without recorded problems. 
Rupturing of the strainer was due to a case of severe water hanmer that subjected a vuinerable component to loads well beyond the normal working pressures.

The strairer was rendered vulnerable for the following reasons:

- No fericures were engineered to facilitate system warmup (i.e., a smallsize warmup bypass valve was not installed across the main steam isolating valve)

- The steam main pipe was sloped incorrectly; the steam flow was opposite to the pipe slope and thus trapped condensate with no means for draining; the reservoir then becomes a source of water slugs for water hammer

- The icolation valve was oversized: a 6 -in. diameter $(50,000-1 \mathrm{bf} / \mathrm{hr})$ valve serving a $2,500-1 b f / h r$ system

- The system increased the velocity of steam as it flowed through reducing pipe diameters (with a slug of water that remained at constant volume and thereby increased the force of impact from water hammer)

- A system configuration existed lirat was not capable of efficiently draining the condensate during warmup

- A system configuration existed that concentrated the impact of the water slugs into the area of a component that was the most vulnerable to high pressures.

Opening the main steam-isolating valve under existing operating procedures aggravated the situation because of the following.

- Turning the hand wheel one revolution (or $2.8 \%$ of the total lift) is more than required for the system's warmup needs; it takes 35 turns to open the valve $100 \%$.

- Water hammer cannot be detected in time to preverit an incident if only one operator performs all the work.

On October 10, 1986, at approximately 1:41 p.m. eastern daylight time, a steam line accident occurred in which four workers were injured, two of them fatally, at the U.S. Department of Energy (DOE) Brookhaven National Laboratory (BNL 1986). At the time of the accident, the workers were attempting to activate a newly constructed steam line. During the course of this operation, a series of powerful water hammer surges struck two blind flanges on the lines, causing their gaskets to extrude and release quantities of hot condensate and steam into the manhole where the men were working.

The DOE accident investigation board concluded that the probable cause of the BNL accident was operational error. This error was manifested in the failure of personnel to use available drains to drain water from a pressurized steam line, using instead a gate valve to perform that operation, an action inducing severe water hammer surges (BNL 1986). 
Figure 5-1. Underground Steam Conduit Section.

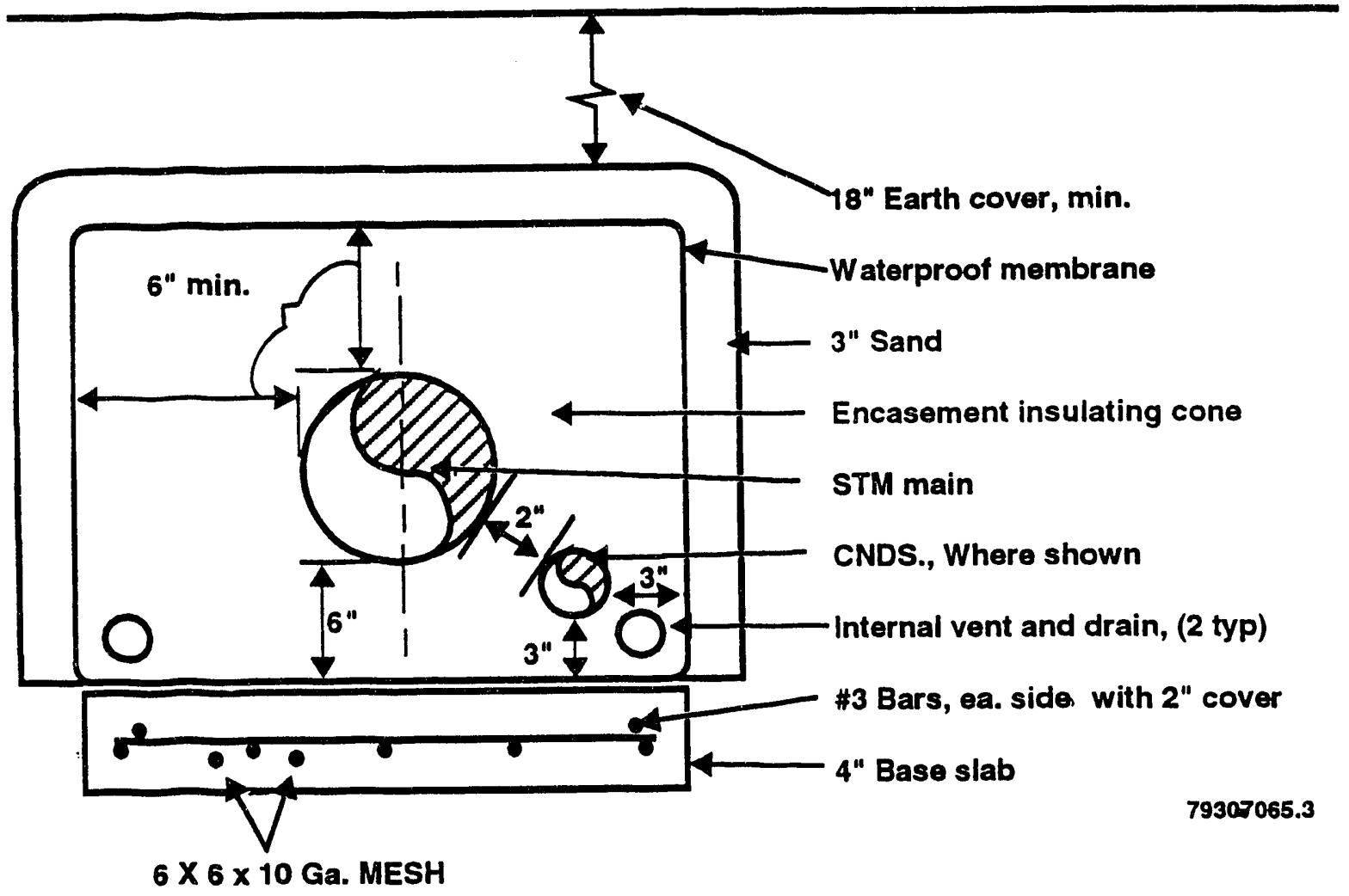


Figure 5-2. Underground 10-in. Steam Line Section.

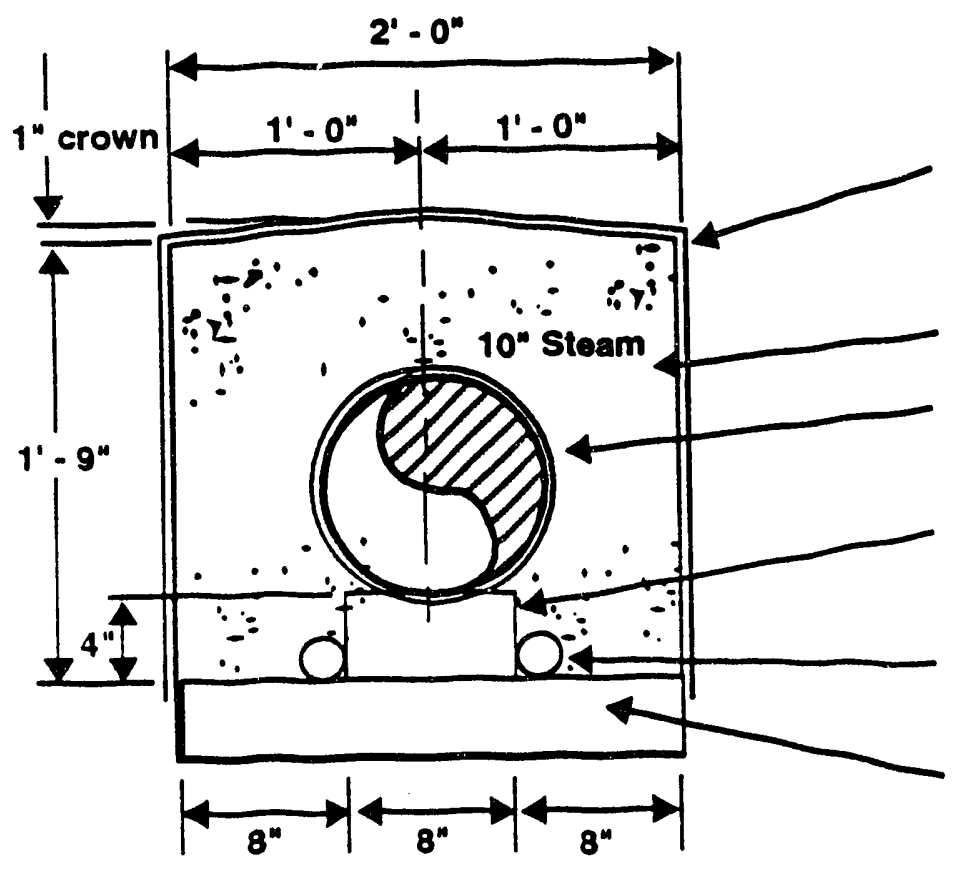

Membrane Drape-high Temp Resisiant PVC Plastic Sheoting .020 in. Thick-min (typ)

Insulating Concrete

Parting Medium-Polyethylene "Bubble" Sheeting 3/16" Thick (typ)

Ins Support Blocks - $6^{\prime \prime}$ Min Width 10' O" C to C Max (typ)

Internal vent-drains Continuous - 2" Min Dia. Formed Void (typ)

4" Base Pad 3000 PSI Cone

79307065. 5 
Figure 5-3. Underground 8-in. Steam Line Section.

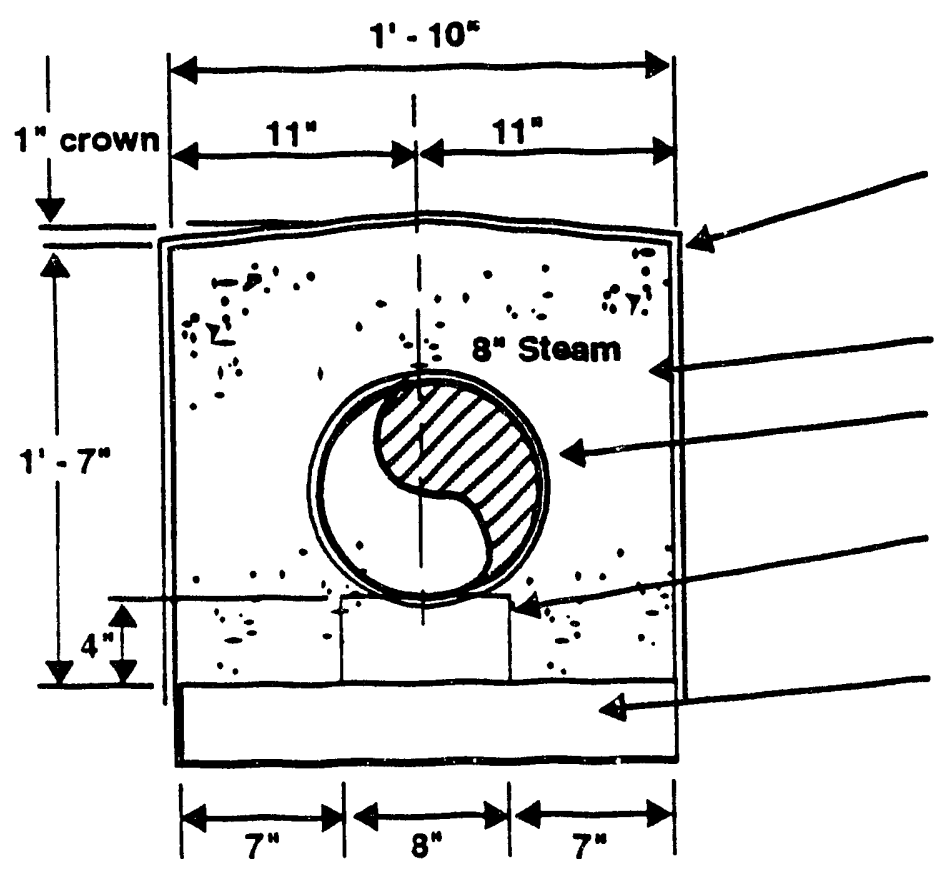

Membrane Drape-High Temp Resistant PVC Plastic Sheeting 020 in. Thick-min (typ)

\section{Insulating Concrete}

Parting Medium-Polyethylene "Bubble" Sheoting 3/16" Thick (typ)

Ins Support Blocks - 6" Min Width $10^{\prime}-0^{\prime \prime} C$ to $C$ Max (typ) Nom. 4" Base Pad 3000 PSI Conc. 
Table 5-1. Documentation for 300 Area Steam System and U-3 Valve Pit.

\begin{tabular}{|c|c|c|c|}
\hline Document no. & $\begin{array}{l}\text { Year } \\
\text { issued/ } \\
\text { revised }\end{array}$ & Originator & Title/description \\
\hline $\mathrm{H}-3-23702$, Sh 182 & $1966-1980$ & HEDL & 300 Area, Operating Plan, Outside Steam Lines \\
\hline$H-3-25791$ & $1965-1968$ & PNL & Steam and Hater Distribution \\
\hline$H-3-25792$ & $1965-1968$ & PNL & steam Profile $($ M.H.\#1 $\rightarrow$ M.H.\#2 $\rightarrow 331)$ \\
\hline$H-3-25794$ & $1965-1968$ & PNL & $\begin{array}{l}\text { Steem and Weter Details (no blind flange on riser nor } \\
\text { on } 8 \text {-in. line from } 318 \text { ) }\end{array}$ \\
\hline $\mathrm{H}-3-25917$, Sh 182 & 1984 & HEDL & 300 Area Steam Lines \\
\hline$H-3-28157-A$ & $1968-1971$ & MBBJ & Mechanical Profiles and Details \\
\hline$H-3-28157-8$ & $1968-1979$ & NBB J & $\begin{array}{l}\text { Mechanical \& Electrical Details: Abbreviations, } \\
\text { Symbols, and Legend }\end{array}$ \\
\hline$H-3 \cdot 33545$ & $1972-1979$ & vitro & $\begin{array}{l}\text { Civil Steam Line } P \text { lan and Profile ( } w / \text { "new" } 10-\text { in. } \\
\text { line from } 318 \text { and general notes) }\end{array}$ \\
\hline$H \cdot 3 \cdot 33546$ & $1972-1979$ & vitro & $\begin{array}{l}\text { Civil Steam Line Sections and Details (w/ "new" 10-in. } \\
\text { line from 318) }\end{array}$ \\
\hline$H \cdot 3 \cdot 33563$ & $1972-1979$ & vitro & $\begin{array}{l}\text { Civil Steam Line Sections and Details (expansion } \\
\text { joints, anchor details) }\end{array}$ \\
\hline $11-3-46220$ & 1979 & HEDL & $\begin{array}{l}\text { Steam Manhole No. } 2 \text { Bypass ( } 10 \text {-in. line from } 318 \\
\text { replaced by new iine. Current configuration.) }\end{array}$ \\
\hline $\begin{array}{l}+3-47433, \text { shs } 1 \\
7=11\end{array}$ & $1980-1981$ & HEDL & $\begin{array}{l}\text { Process and Service Piping, Service Index and } \\
\text { Procedures; Steam. Medium Pressure, Service Type } \\
H-12 B ; \text { Condensate, Service Type H-18 }\end{array}$ \\
\hline$M-3800$, Sh 16 & $1966-1984$ & HEDL & 300 Area, Outside Lines, Steam and Air, Section 16 \\
\hline H. 3-53413 & 1984 & HEDL & Steam System, 300 Area, By Year Installed \\
\hline$H \cdot 3.60766$ & $1989-1990$ & WHC & 300 Area, Main Service Steam (MSS) \\
\hline HWS - 8449 & 1965 & $\begin{array}{l}\text { Leo A. Daly } \\
\text { Company }\end{array}$ & $\begin{array}{l}\text { Specifications for Biology Laboratory Facilities, } \\
\text { Buildings } 331 \text { and } 3318 \text {, Projects CAH-977, CAH-982, } \\
\text { CAH- } 157 \text { (information on piping, insulation, support's, } \\
\text { conduit, etc.) }\end{array}$ \\
\hline HWS - 8729 & 1968 & L. F. Reilly & 300 Area Steam Distribution System Additions \\
\hline HWS-9316 & 1972 & vitro & $\begin{array}{l}\text { Specifications for Steam Distribution System Addition, } \\
300 \text { Area, Project OAP }-550\end{array}$ \\
\hline CAT. NO. 60 & 1960 & Crane co. & Crane Catalog No. 60 \\
\hline CAT. NO. VC- 1200 & $=1976-1977$ & Crane co. & Crane Iron Valve Catalog No. VC- 1200 \\
\hline CAT. $L-6 A$ & 1971 & $\begin{array}{l}\text { Armstrong } \\
\text { Machine } \\
\text { Works }\end{array}$ & The Armstrong Steam Trap Book \\
\hline
\end{tabular}

HEDI. = Hanford Engineering Development Laboratory

M.H. = Manhole

NBBJ = Naramore, Bain, Brady and Johanson, Architects

PNL = Pacific Northwest Laboratory

Vitro = Automation Industries, Inc., Vitro Engineering Division

$W H C=$ Westinghouse Hanford Company 
Table 5-2. Operational History of U-3 Pit.

(6 Sheets)

\begin{tabular}{|c|c|c|}
\hline Outage permit number: A-986-S & Date: $10 / 20 / 88$ & Duration: $16 \mathrm{~h}$ \\
\hline Válve configuration & \multicolumn{2}{|c|}{ Position } \\
\hline MSS-26 & \multicolumn{2}{|c|}{ Closed } \\
\hline MSS-27 & \multicolumn{2}{|c|}{ Closed } \\
\hline MSS-28 & \multicolumn{2}{|c|}{ Closed } \\
\hline MSS-30 & \multicolumn{2}{|c|}{ Closed } \\
\hline MSS-31 & \multicolumn{2}{|c|}{ Closed } \\
\hline Vents in MSS- $30 \& 30$ valve pit & \multicolumn{2}{|c|}{ Open } \\
\hline \multicolumn{3}{|c|}{ Restoration: No restoration information available. } \\
\hline \multicolumn{3}{|c|}{$\begin{array}{l}\text { Remarks: MSS- } 25 \text { was not manipulated, but the failed } 6-\text { in. valve would have } \\
\text { cooled during this outage. Valve MSS }-25 \text { was replaced during this outage. }\end{array}$} \\
\hline
\end{tabular}

\begin{tabular}{|c|c|c|}
\hline Outage permit number: $A-1141-\varsigma$ & Date: $09 / 17 / 90$ & Duration: $4.5 \mathrm{~h}$ \\
\hline Valve configuration & \multicolumn{2}{|c|}{ Position } \\
\hline MSS-25 & \multicolumn{2}{|c|}{ Closed } \\
\hline MSS-31 & \multicolumn{2}{|c|}{ Closed } \\
\hline MSS-32 & \multicolumn{2}{|c|}{ Closed } \\
\hline Blowdown in 337 Equip $\mathrm{Rm}$ & \multicolumn{2}{|c|}{ Open } \\
\hline \multicolumn{3}{|c|}{$\begin{array}{l}\text { Restoration: No pertinent information available for the restoration of the } \\
\text { steam system. }\end{array}$} \\
\hline Remarks: & & \\
\hline
\end{tabular}


Table 5-2. Operational History of U-3 Pit (cont.)

\begin{tabular}{|c|c|c|}
\hline Outage permit number: $A-1142-S$ & Date: $09 / 18 / 90$ & Duration: $4 \mathrm{~h}$ \\
\hline Valve configuration & \multicolumn{2}{|c|}{ Position } \\
\hline MSS-25 & \multicolumn{2}{|c|}{ Closed } \\
\hline MSS-31 & \multicolumn{2}{|c|}{ Closed } \\
\hline MSS-32 & \multicolumn{2}{|c|}{ Closed } \\
\hline 337 Equip $\mathrm{Rm}$ freeblow & \multicolumn{2}{|c|}{ Open } \\
\hline \multicolumn{3}{|c|}{$\begin{array}{l}\text { Restoration: No pertinent information available for the restoration of the } \\
\text { steam system. }\end{array}$} \\
\hline Remarks: & & \\
\hline
\end{tabular}

\begin{tabular}{|c|c|c|}
\hline Outage permit number: $A-1163-S$ & Date: $03 / 22 / 91$ & Duration: $52 \mathrm{~h}$ \\
\hline Valve configuration & \multicolumn{2}{|c|}{ Position } \\
\hline MSS-25 & \multicolumn{2}{|c|}{ Closed } \\
\hline MSS-26 & \multicolumn{2}{|c|}{ Closed } \\
\hline MSS-27 & \multicolumn{2}{|c|}{ Closed } \\
\hline MSS-31 & \multicolumn{2}{|c|}{ Closed } \\
\hline MSS-32 & \multicolumn{2}{|c|}{ Closed } \\
\hline \multicolumn{3}{|c|}{$\begin{array}{l}\text { Restoration: Removed } L / 0 \text { for steam outage for } 337,3764 \text {, and } 3765 \text { and put } \\
\text { back in service. No pertinent information about the evolution. }\end{array}$} \\
\hline \multicolumn{3}{|c|}{ Remarks: This outage cooled the 6 -in. failed valve. } \\
\hline
\end{tabular}


Table 5-2. Operational History of U-3 Pit (cont.)

\begin{tabular}{|c|c|c|}
\hline Outage permit number: A-1169-S & Date: $05 / 10 / 91$ & Duration: $72 \mathrm{~h}$ \\
\hline Valve configuration & \multicolumn{2}{|c|}{ Position } \\
\hline MSS-25 & \multicolumn{2}{|c|}{ Closed } \\
\hline$M S S-26$ & \multicolumn{2}{|c|}{ Closed } \\
\hline MSS-27 & \multicolumn{2}{|c|}{ Closed } \\
\hline MSS-31 & \multicolumn{2}{|c|}{ Closed } \\
\hline MSS-32 & \multicolumn{2}{|c|}{ Closed } \\
\hline \multicolumn{3}{|c|}{$\begin{array}{l}\text { Restoration: Log entry: "3621-D, } 337-0830 \text {-cracked in steam from steam } \\
\text { outage. } 1200-\mathrm{L} / 0 \text { removed and steam is back in service." }\end{array}$} \\
\hline \multicolumn{3}{|c|}{ Remarks: This outage cooled the 6 -in. failed valve. } \\
\hline
\end{tabular}

\begin{tabular}{|c|c|c|}
\hline $\begin{array}{l}\text { Outage permit number: A-1174-S } \\
\text { Tagout number: } 3 G-91-00414\end{array}$ & Date: $08 / 14 / 91$ & Duration: $13 \mathrm{~h}$ \\
\hline Valve configuration & \multicolumn{2}{|c|}{ Position } \\
\hline MSS-22 & \multicolumn{2}{|c|}{ Closed } \\
\hline MSS-23 & \multicolumn{2}{|c|}{ Closed } \\
\hline MSS-24 & \multicolumn{2}{|c|}{ Closed } \\
\hline MSS-25 & \multicolumn{2}{|c|}{ Closed } \\
\hline MSS-26 & \multicolumn{2}{|c|}{ Closed } \\
\hline MSS-27 & \multicolumn{2}{|c|}{ Closed } \\
\hline \multicolumn{3}{|c|}{$\begin{array}{l}\text { Restoration: Day shift log entry: "opened MSS-27 \& } 23 \text {. Cracked MSS } 22 \& \\
\text { 25." Swing shift log entry: "331 opened up MSS } 22 \& 25 \text { steam I/S." }\end{array}$} \\
\hline Remarks: This outage cooled the $f$ & led 6-in. valve. & \\
\hline
\end{tabular}


Table 5-2. Operational History of U-3 Pit (cont.)

\begin{tabular}{|c|c|c|}
\hline $\begin{array}{c}\text { Outage permit number: A-1175-S } \\
\text { Tagout number: 3G-91-60441 }\end{array}$ & Date: 08/27/91 & Duration: 39 $\mathrm{h}$ \\
\hline Valve configuration & Position \\
\hline \hline MSS-22 & Closed \\
\hline MSS-23 & Closed \\
\hline MSS-25 & Closed \\
\hline MSS-26 & Closed \\
\hline MSS-27 & Closed \\
\hline $\begin{array}{l}\text { Restoration: Swing shift log entry: "@ 2220 began bringing steam into } 331 \\
\text { as per outage A-1175-S graveyard to finish." Graveyard shift log entry: } \\
\text { "secured from steam outage A-1175-S } 0300 . "\end{array}$ \\
\hline Remarks: This outage cooled the failed 6-in. valve. \\
\hline
\end{tabular}

\begin{tabular}{|c|c|c|}
\hline Outage permit number: $A-1185-S$ & Date: $10 / 04 / 91$ & Duration: $48 \mathrm{~h}$ \\
\hline Valve configuration & \multicolumn{2}{|c|}{ Position } \\
\hline MSS-25 & \multicolumn{2}{|c|}{ Closed } \\
\hline MSS-31 & \multicolumn{2}{|c|}{ Closed } \\
\hline MSS-32 & \multicolumn{2}{|c|}{ Closed } \\
\hline \multicolumn{3}{|c|}{$\begin{array}{l}\text { Restoration: Log entry: "steam outage A-1185-S opened MSS-25, MSS-31, } \\
\text { MSS-32 began cracking steam in a 1830. Completed full service blds } \\
\text { @ 2030." }\end{array}$} \\
\hline Remarks: & & \\
\hline
\end{tabular}


Table 5-2. Operational History of U-3 Pit (cont.)

\begin{tabular}{|c|c|c|}
\hline Outage permit number: & Date: $10 / 10 / 91$ & Duration: $12 \mathrm{~h}$ \\
\hline Valve configuration & \multicolumn{2}{|c|}{ Position } \\
\hline MSS-22 & \multicolumn{2}{|c|}{ Closed } \\
\hline$M S S-23$ & \multicolumn{2}{|c|}{ Closed } \\
\hline MSS-25 & \multicolumn{2}{|c|}{ Closed } \\
\hline MSS-26 & \multicolumn{2}{|c|}{ Closed } \\
\hline MSS-27 & \multicolumn{2}{|c|}{ Closed } \\
\hline \multicolumn{3}{|c|}{$\begin{array}{l}\text { Restoration: Log entry: "331 pit - } 0430 \text { - cracked in steam to warm up } \\
\text { lines." Suspect that } 0430 \text { entry is a mistake. } 1630 \text { is the likely time. } \\
\text { "331 deep pit - removed L/0 } 00532 \text { and valved in steam } 02100 \text {. }\end{array}$} \\
\hline \multicolumn{3}{|c|}{ Remarks: This outage cooled the failed 6-in. valve. } \\
\hline
\end{tabular}

\begin{tabular}{|c|c|c|}
\hline Outage permit number: A-1204-S & Date: $04 / 14 / 92$ & Duration: $4 \mathrm{~h}$ \\
\hline Valve configuration & \multicolumn{2}{|c|}{ Position } \\
\hline MSS-23 & \multicolumn{2}{|c|}{ Closed } \\
\hline$M S S-25$ & \multicolumn{2}{|c|}{ Closed } \\
\hline MSS-26 & \multicolumn{2}{|c|}{ Closed } \\
\hline$M S S-27$ & \multicolumn{2}{|c|}{ Closed } \\
\hline MSS-29 & \multicolumn{2}{|c|}{ Closed } \\
\hline \multicolumn{3}{|c|}{$\begin{array}{l}\text { Restoration: Log entry: "removed lockout from Bldg. steam outage and } \\
\text { cracked in steam at } 1630 . "\end{array}$} \\
\hline \multicolumn{3}{|c|}{ Remarks: This outage cooled the failed 6-in. valve. } \\
\hline
\end{tabular}


Table 5-2. Operational History of U-3 Pit (cont.)

\begin{tabular}{|c|c|c|}
\hline $\begin{array}{l}\text { Outage permit number: } \\
\text { Tagout number: } 3 G-92-00594 \\
\text { Tagout number: } 3 G-92-00595 \\
\end{array}$ & Date: $09 / 18 / 92$ & Duration: $16 \mathrm{~h}$ \\
\hline Valve configuration & \multicolumn{2}{|c|}{ Position } \\
\hline MSS-25 & \multicolumn{2}{|c|}{ Closed } \\
\hline MSS-26 & \multicolumn{2}{|c|}{ Closed } \\
\hline MSS-27 & \multicolumn{2}{|c|}{ Closed } \\
\hline MSS-31 & \multicolumn{2}{|c|}{ Closed } \\
\hline MSS-32 & \multicolumn{2}{|c|}{ Closed } \\
\hline Blowdown $3802 \mathrm{~A}$ valve pit & \multicolumn{2}{|c|}{ Open } \\
\hline \multicolumn{3}{|c|}{$\begin{array}{l}\text { Restoration: Log entry: "removed L/0 3G-92-00594 and L/0 3G-92-00595 to } \\
\text { repair steam leaks. (Complete)-MSS-25 - is still closed. Unable to cool } \\
\text { down to open valve." }\end{array}$} \\
\hline
\end{tabular}

\begin{tabular}{|c|c|c|}
\hline Outage permit number: $A-1229-S$ & Date: $10 / 17 / 92$ & Duration: $23 \mathrm{~h}$ \\
\hline Valve configuration & \multicolumn{2}{|c|}{ Position } \\
\hline Entrance to 331 deep pit & \multicolumn{2}{|c|}{ Tagged } \\
\hline MSS-31 & \multicolumn{2}{|c|}{ Closed } \\
\hline Basement 331 mainstream blowdown & \multicolumn{2}{|c|}{ Open } \\
\hline \multicolumn{3}{|c|}{$\begin{array}{l}\text { Restoration: Log entry: "tour - removed lockout } 3 G-92-00656 \text { installed for } \\
\text { steam outage to reinsulate piping in } 36210 \text { pit. Opened MSS-31. They did } \\
\text { complete installing insulating block on large pipes, however they did not } \\
\text { cover it with lagging cloth or install metal covering. MSS-25 is still } \\
\text { closed." }\end{array}$} \\
\hline \multicolumn{3}{|c|}{$\begin{array}{l}\text { Remarks: Valve MSS- } 25 \text { was still closed and locked in accordance with } \\
\text { tagouts } 3 G-92-00594 \text { and } 3 G-92-00595 \text {. It was not manipulated. Therefore, } \\
\text { it is not counted as a manipulation of the valve. }\end{array}$} \\
\hline
\end{tabular}


Table 5-3. Operational Record of U-3 Pit.

\begin{tabular}{|c|c|c|c|c|}
\hline ID & $\begin{array}{l}\text { Base } \\
\text { Date }\end{array}$ & $\begin{array}{c}\text { PM } \\
\text { Date }\end{array}$ & $\begin{array}{l}\text { Hours } \\
\text { Used }\end{array}$ & Comments \\
\hline $331000 F 0002$ & 8008 & 8008 & 5.0 & OK DLS \\
\hline $331000 F 0003$ & 8108 & 8108 & 0.5 & CEN OK \\
\hline $331000 F 0004$ & 8209 & 8209 & 0.0 & BYPASSED TO HOT TO ENTER J. 0. ALDEREDGE \\
\hline $331000 \mathrm{~F} 0005$ & 8310 & 8310 & 1.0 & RSL BYPASSED TO HOT TO ENTER PIT \\
\hline $331000 \mathrm{~F} 0006$ & 8410 & 8508 & 0.0 & CED $* *$ BYPASSED \\
\hline $331000 \mathrm{~F} 0007$ & 8510 & 8510 & 0.5 & $\begin{array}{l}\text { NEUMAN ** TRAP WORKING FINE * INLET VALVE } \\
\text { TO TRAP NEEDS TO BE PACKED. SEE } \\
\text { WR \# } 023046 .\end{array}$ \\
\hline $331000 \mathrm{~F} 0008$ & 8610 & 8610 & 0.5 & $\begin{array}{l}\text { PEEBLES ** STEAM TRAP STATION REPLACED } \\
9-26-86 * \text { WORKING PROPERLY }\end{array}$ \\
\hline $331000 F 0009$ & 8709 & 8711 & 0.0 & $\begin{array}{l}\text { JN STACY } \star * \text { BYPASSED. UNABLE TO ENTER PIT } \\
\text { DUE TO STEAM LEAKAGE. SEE WR } 036892 . \\
\text { RESET FOR APRIL 1988. }\end{array}$ \\
\hline $331000 \mathrm{~F} 0010$ & 8811 & 8812 & 2.0 & R GATES ** EQUIPMENT OPERATIONAL \\
\hline $331000 \mathrm{~F} 0011$ & 8911 & 9001 & 1.0 & WCS * COMPLETE \\
\hline $331000 \mathrm{~F} 0012$ & 901101 & 9102 & 1.0 & BN PERFORMED PM \\
\hline $331000 R 0013$ & 911101 & 930125 & 0.0 & PM SUSPENDED PER PMCR \\
\hline $331000 F 0014$ & 921001 & & & \\
\hline
\end{tabular}




\subsection{IN SITU INVESTIGATIONS}

\subsection{PRELIMINARY EXAMINATIONS}

The U-3 steam valve pit was inspected on June 12, 1993. The primary purpose of this preliminary inspection was to assess the existing condition of the piping visually and to gather as much data as possible on its condition, its components, and the fractured valve surfaces before anything in the pit was disturbed (e.g., removing insulation, washing mud from walls and equipment, removing segments of pipe). Two engineers entered the pit for the visual examination, but because of the mud spray that covered much of the pit and its contents, their findings were limited.

\subsubsection{General Evidence of Damage}

The piping displayed no visual sign of plastic deformation such as ovality, crimping, differential displacements, crushed insulation at pipe penetrations, or abnormal bends that might suggest violent pipe motion from water hammer types of phenomena. However, much of the piping, except at penetrations, was covered with insulation or mud, the presence of which hampered the investigation.

The only visible evidence of damage that might have helped to define the trajectory and behavior of the failed valve was the torn insulation on the vertical 8-in. riser, a tear made by the valve handle as it was propelled between the riser and the wall.

\subsubsection{Component Identification/Description Data}

The eastern half of the lowest horizontal run of the trap line was covered by the mud on the bottom of the pit. As for the steam trap itself, only its upper portion and valve handles extended above the surface of the mud. If there were any markings or tags on the components, they were not readable because they were coated with mud and the engineers inspecting the equipment had to stand some distance away. Access was not permitted to the floor of the pit, but was confined to the ladder near the floor of the pit.

Valves MSS-26 and -27 and the failed valve were so covered with mud and insulation that no information about their manufacture could be seen.

Valve MSS-25 displayed the following information on its body:

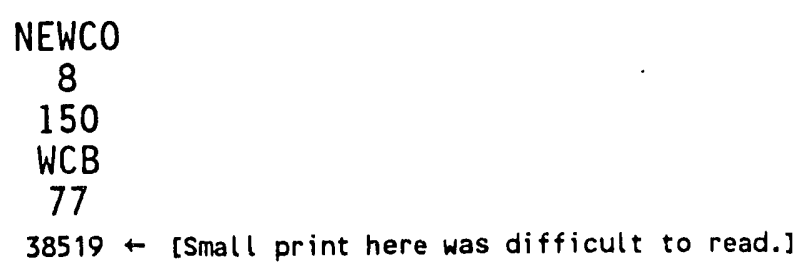

The flange of the failed valve, a 6 -in. gate valve, had a 6 -in. inside diameter (ID) and an 11-in. outside diameter (OD). 


\subsubsection{General Piping System Configuration}

The general pipe routing visible during this inspection was just as shown in the preliminary isometric sketch developed from Site drawings (Figure 6-1). It appeared likely that the dimensions of tha piping configuration read or scaled from the drawings would provide a reasonabiy realistic description of the actual configuration.

\subsubsection{Pipe Supports and Anchors}

The only large-bore pipe support in the pit appeared to be the concrete pedestal anchor shown in drawing H-3-25794. The pedestal was located beneath the 8-in. line between valve MSS-25 and the penetration at the north wall. The pedestal was approximately $1 \mathrm{ft}$ in length (along the direction of the pipe) and located approximately $5 \mathrm{in}$. from the north wall of the pit.

\subsubsection{Measurements of the Exposed Shank of the Valve-Operating Screw}

Outside screw and yoke valves, such as those in the pit, are operated by a threaded screw along which a handie moves toward and away from the valve itself. The degree to which a valve is open can be judged from the amount (length of the screw) that is exposed between the outside end of the screw and the handle. Measurements made of the lengths of exposed screws on the valves inspected were as follows:

Valve MSS-25: Length not measured; valve inaccessible from

Valve MSS-26: $\quad 4.5$ in.

Valve MSS-27: $\quad 9.5$ in.

Failed valve: Essentially closed; water might have been able to pass around the seat but not directly through the valve.

\subsubsection{Description of Broken Valve}

The casting of the 6 -in. gate valve failed at the point of the smallest cross section of the body nearest the 8 -in. run of pipe. The failure surface visible on the portion of the valve that remained on the piping is jagged but is consistently located close to $0.25 \mathrm{in}$. from the face of the outermost flange.

\subsection{ADDITIONAL EXAMINATIONS}

Another visual inspection of the $U-3$ steam valve pit occurred on June 21, 1993; its purpose was to gather as much information as possible about the condition of the piping and its components. On this occasion, the insulation had been removed, walls and equipment had been cleaned of most of the mud and water, and segments of the piping had been removed for evaluation. 
Field measurements were taken to prepare an as-built configuration of the piping system. In addition to the two engineers who entered the pit, a video photographer also was present to record the condition of the pit, the piping, and components before the inspection began.

In addition to the removal of the insulation, valve MSS-25 had been removed, along with the tee section adjacent to the failed valve and the steam trap and its adjacent valves. Although approximately 1 in. of water remained in the pit, inspectors had access to the floor of the pit.

\subsubsection{General Evidence of Damage}

As in the preliminary inspection, there was no visual evidence of pipe ovality or plastic deformation of the piping. The only visible evidence of damage that might have helped to define the trajectory and behavior of the failed valve were a few scrapes and a couple of gouges along the concrete of the south wall of the pit in the vicinity between the location of the 6 -in. valve before the accident and where it came to rest between the wall and the vertical pipe. The gouges most likely resulted when the valve body jammed into place while its handle dug into the insulation on the 8-in. riser. It is unlikely that the scrapes were caused by the trajectory of the valve because long scrapes such as these require that a material be forced along the wall for some distance. The failed valve, however, had been blown suddenly from its place and hurled to its resting place without anything to guide it along the surface of the wall.

The pipe at each of the upper two penetrations was grouted into place. The lower penetration showed another, softer material around the pipe where it entered the pit. The only notable evidence of spalling concrete around the penetrations that might suggest violent pipe motion was at the 4 -in. 1 ine penetration: a 4-in.-wide portion of the concrete grout had been dislodged at some point in time. The grout at this penetration appeared to have degraded over time; overall, it was in poor condition. The grout around the upper penetration in the north wall appeared to be in good condition.

\subsubsection{Component Identification/Description Data}

Valve MSS-26 displayed the following information on its body:

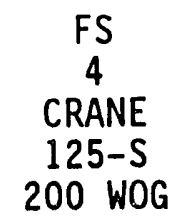

The valve operator of MSS-26 had the number "46838" cast into it. The flanges were rated at $1501 \mathrm{~b}$. 
Valve MSS-27 displayed the following information on its body:

$$
\begin{gathered}
46831 \\
\text { FS } \\
8 \\
\text { CRANE } \\
125-S \\
200 \text { WOG }
\end{gathered}
$$

The flanges for MSS-27 were also rated at $150 \mathrm{lb}$.

\subsubsection{General Piping System Configuration}

The pipe routing is just as shown for the large-bore steam piping on the preliminary isometric sketch in Figure 6-1. However, the route of the condensate line at the bottom of the pit was slightly different. Details appear on the as-built dimensions on the revised isometric sketch of Figures $6-2(a)$ and $6-2(b)$.

\subsubsection{Pipe Supports and Anchors}

According to drawing H-3-25794, the only large-bore pipe support in the pit was a concrete pedestal anchor located beneath the $8-i n$. steam pipe between valve MSS-25 and the penetration in the north wall. However, closer inspection showed there was no concrete pedestal. The support consisted of a 12- by 17- by 1/2-in. plate located $3.5 \mathrm{in}$. from the north wall that extended from the floor to the bottom of the 8-in. pipe. Both sides of the bottom $12-$ in. edge felt as if they were welded to an embedded plate in the floor. (Muddy water covered the floor of the pit and the bottom edge of the plate.) The upper 12-in. edge was welded to the bottom of the pipe.

\subsubsection{As-Built Configuration}

The as-built dimensions taken during this inspection are summarized pictorially in Figures 6-2(a) and 6-2(b).

\subsubsection{Slope Determinations of Selected Steam Lines}

On June 25,1993 , a third inspection was performed to determine the slopes of the steam 1 ine between valves MSS -30 and -25 where the line exits the 3621-D pit (manhole \#1) and enters the U-3 steam valve pit (manhole \#2). Despite the presence of insulation on the steam line in the 3621-D pit, measurements indicated that it was horizontal (i.e., had zero slope). This line enters the penetration approximately $3 \mathrm{ft} 4 \mathrm{in}$. below its surrounding grade, then enters the U-3 steam valve pit approximately $17 \mathrm{ft} 6$ in. below the surrounding grade and slopes downward toward valve MSS-25 at approximately $1.61 \mathrm{in}$. per $20-\mathrm{ft}$ length of pipe (equating to approximately a $4 \mathrm{ft} 10 \mathrm{in}$. gain in elevation if extrapolated over the 720 linear $\mathrm{ft}$ between the two pits). 


\section{WHC-EP-0667}

Also measured was the slope of the 8 -in. 1 ine that enters the $U-3$ steam valve pit at the upper north wall. Between the penetration and valve MSS-27, a slope of $6.44 \mathrm{in}$. per $20 \mathrm{ft}$ down and to the south was measured.

No slope could be measured where the 4-in. line exits the U-3 steam valve pit.

See Figure 6-3 for an isometric sketch incorporating these data. 


\section{WHC-EP-0667}

Figure 6-1. Isometric Sketch of Pipe Routing.

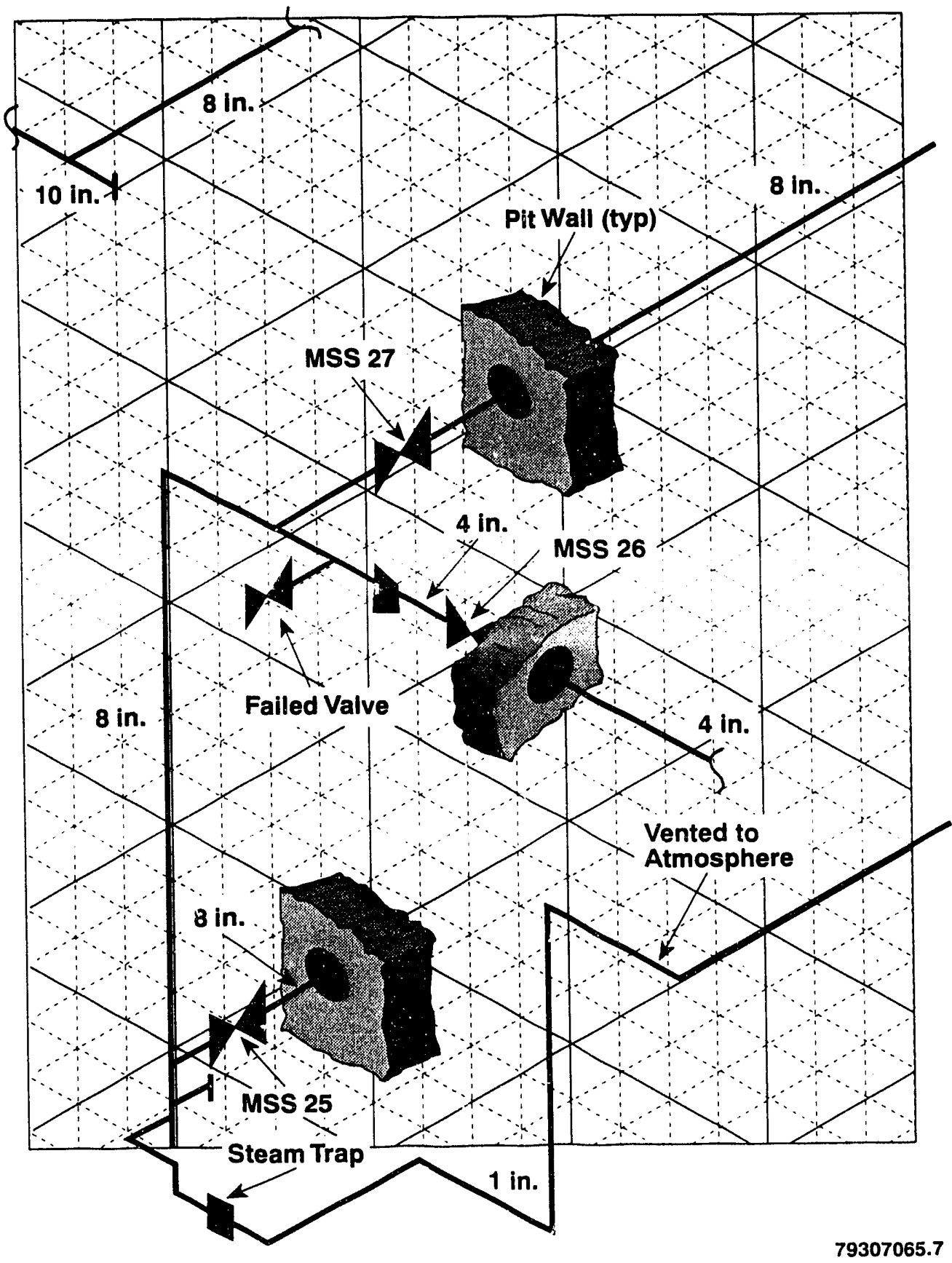


Figure 6-2a. U-3 Steam Valve Pit As-Built.

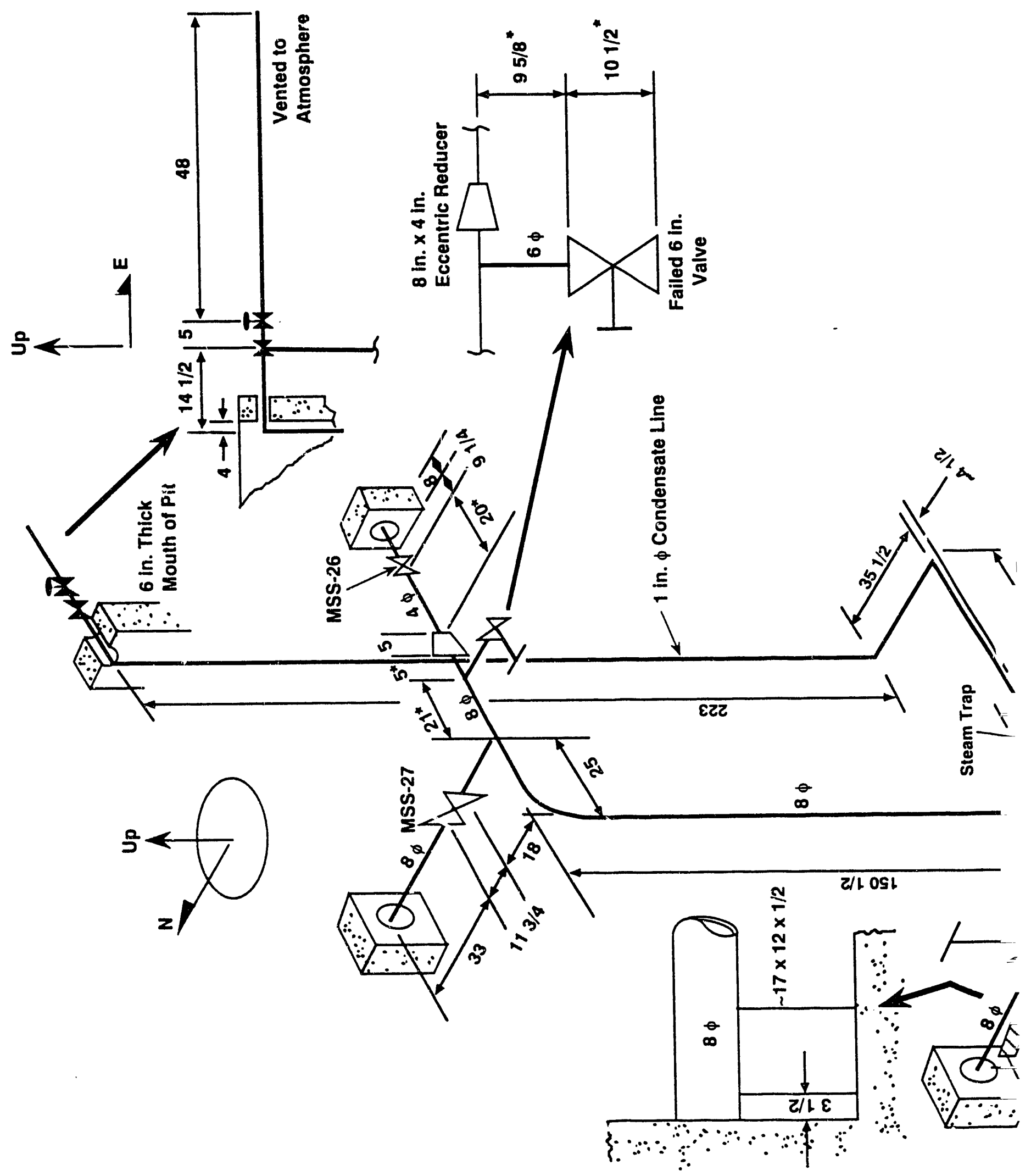



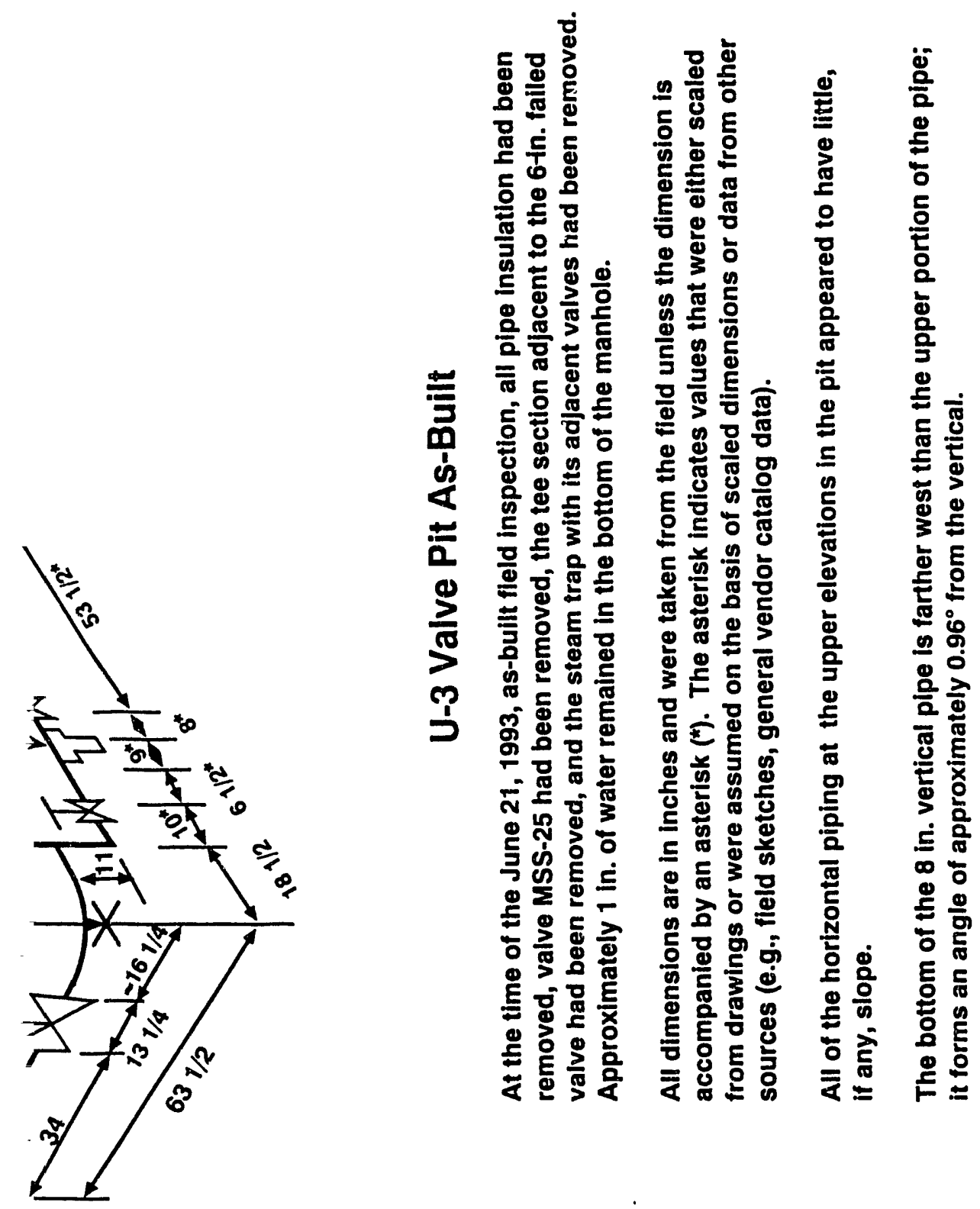
Figure 6-2b. Miscellaneous Details for U-3 Steam Valve Pit As-Built.

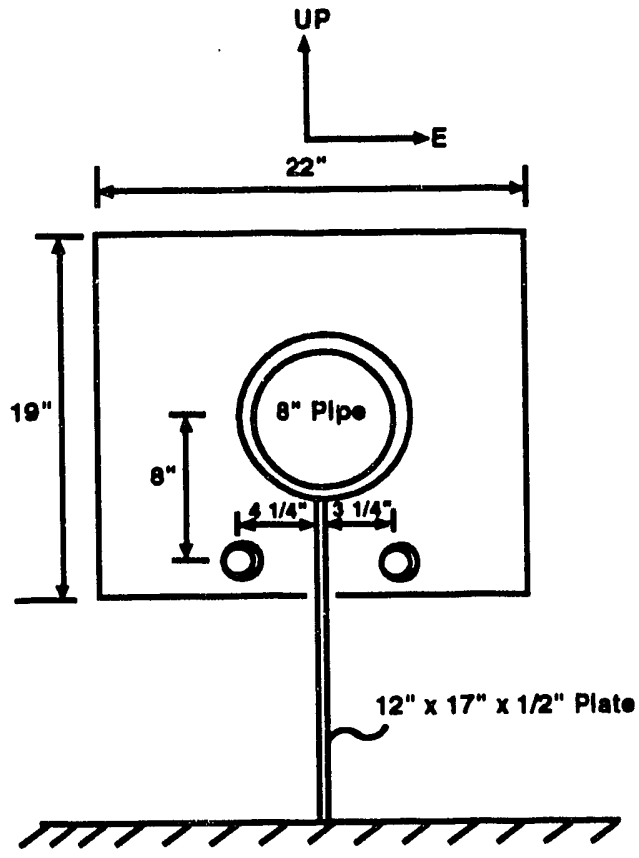

North Wall Penetration and Anchor Near MSS-25

Height of PIt Mouth From GR+UE

= Average Each SIde

$=\frac{15(N)+12(E)+11(J)+13(W)}{4}$

$=12.75^{\prime \prime} \approx 13^{\prime \prime}$

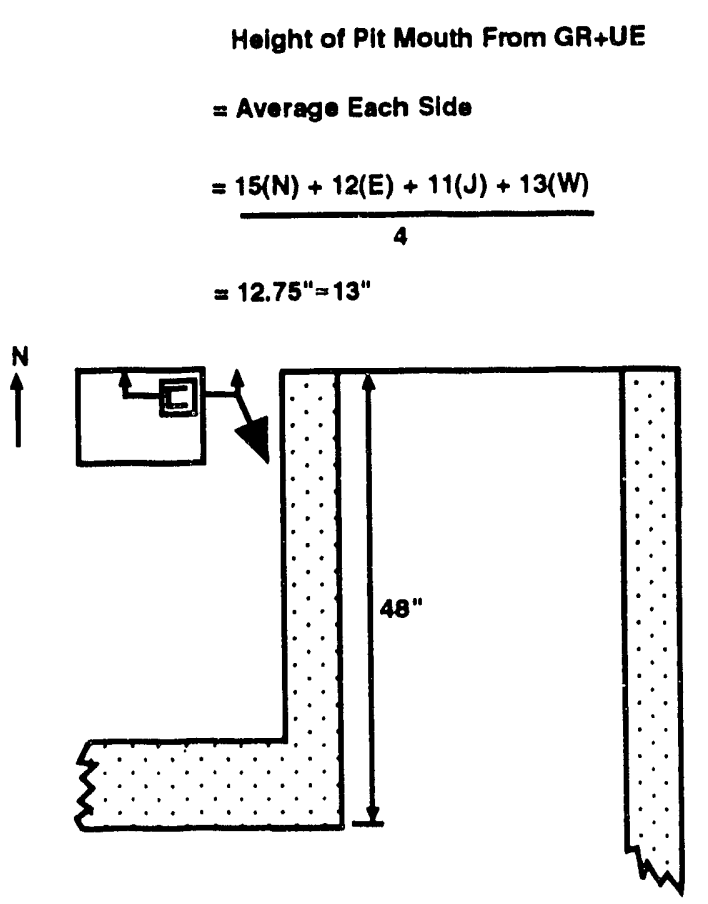

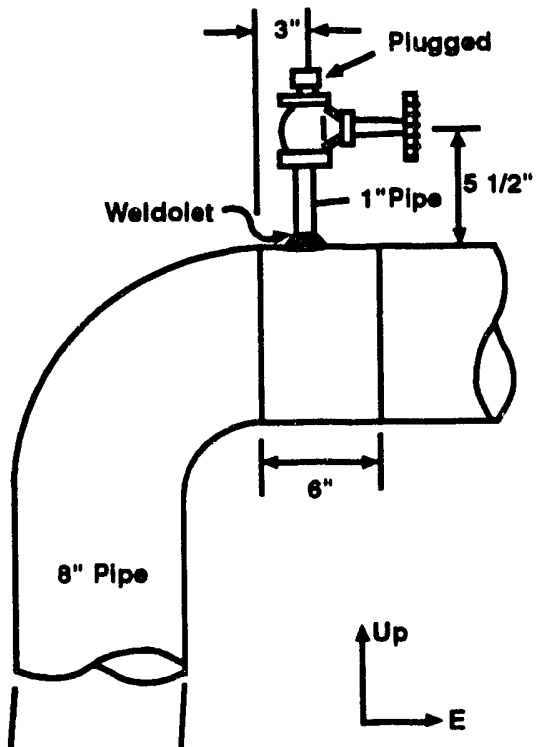

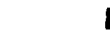

1
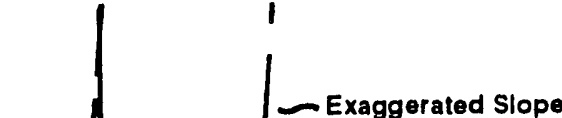
of Riser 
Figure 6-3. Upper Elevation Piping to and from the U-3 Steam Valve Pit.

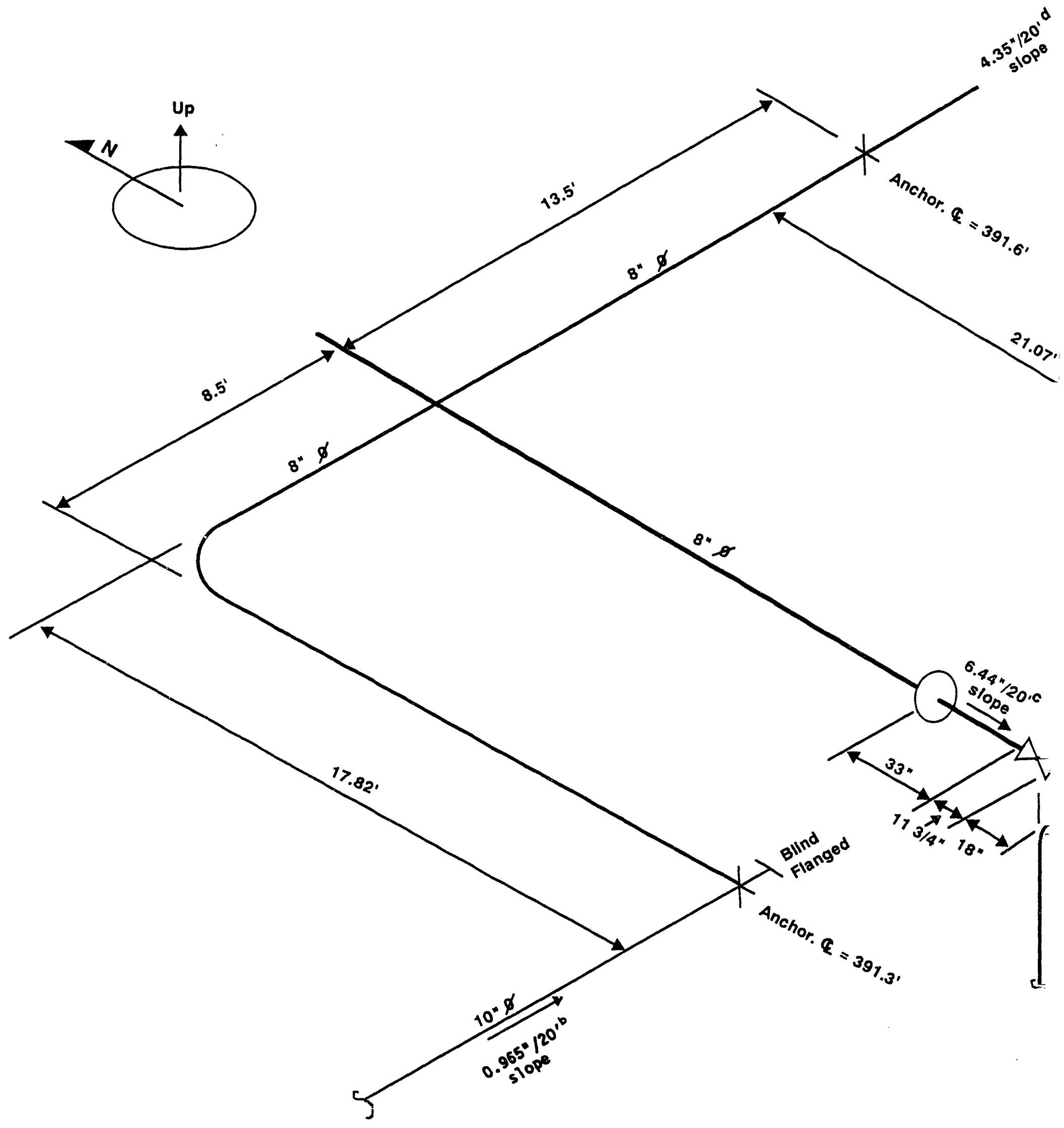




\subsection{COMPONENT TESTING AND INVESTIGATIONS}

\subsection{VALVE MSS-25}

\subsubsection{Examination}

On June 17, 1993, valve MSS-25 was removed from storage and brought to Building 272-E for physical measurements and airflow testing of the stem packing. Before the airflow test, the valve stem height above the handwheel was measured by WHC Quality Assurance (QA) personnel to be 4.938 in. (about 25 threads). The valve disk opening was measured from the bottom of the valve seat and from the inside diameter of the valve. The openings were 4.701 in. and 3.551 in., respectively. Blind flanges were then installed on the valve, and a soap bubble test was performed on the valve stem near the packing gland. The test was conducted at several pressures, with $101 \mathrm{bf} / \mathrm{in}^{2}$ (gauge) the maximum. The quantity of air passing through the stem was not measured, but visual and auditory observations of the bubble test concluded that the flow was significant. The results of this test led to the conclusion that measurements should be made to evaluate the airflow leakage rate as a function of pressure.

On June 18, 1993, the valve was marked with a vibro-etcher to identify component locations and orientations (i.e., nuts, bolts, bonnet). The nuts on the packing-follower flange then were untorqued and the break-away torque recorded. The break-away torques were 21 and $32 \mathrm{ft} \cdot 1 \mathrm{~b}$, respectively, for the two nuts. The follower was loosened to allow visual observation of the relationship of the packing to the stem. The packing appeared to be intact. The depth of the packing in the housing then was measured as $0.535 \mathrm{in}$.

\subsubsection{Air Testing}

On June 24, 1993, an air leak test to $251 \mathrm{bf} / \mathrm{in}^{2}$ (gauge) was performed on the valve stem with the follower-flange nuts retorqued to $101 \mathrm{bf} \cdot \mathrm{ft}$. The test involved gradually increasing the pressure in increments between 1 and $21 \mathrm{bf} / \mathrm{in}^{2}$ (gauge) until the maximum test pressure was obtained. The results showed a flow of $2.15 \mathrm{ft}^{3} / \mathrm{min}$ at $25 \mathrm{lbf} / \mathrm{in}^{2}$ (gauge) based on a reading uncorrected for ambient temperature and pressure.

\subsubsection{Disassembly}

On June 28,1993 , the valve was prepared for disassembly. The disassembly was witnessed by representatives of NEWCO, the valve manufacturer. All break-away torques on nuts were recorded. The lock and chain on the valve handle were removed and the bonnet assembly lifted off the valve housing to expose the disk. The disk appeared to be in good condition. The valve stem was removed from the bonnet to expose the packing. The packing appeared to have deteriorated somewhat, but showed no evidence of steam undercut. The deterioration in the packing was oriented $360^{\circ}$ around the packing and in the upper half of the packing toward the valve handle. 
On June 29, 1993, the valve was reassembled to its original configuration with the original packing still in the valve. The followerflange packing nuts were retorqued to $101 \mathrm{bf} \cdot \mathrm{ft}$ in preparation for a subsequent air test of the stem packing.

On June 30,1993 , the reassembled valve MSS-25 was subjected to an additional airflow test to determine leakage past the stem packing. The packing gland nuts were retorqued to $10 \mathrm{lbf} \cdot \mathrm{ft}$ and the valve disk location was reset to the accident condition. Air was applied to the valve in increments of $2 \mathrm{lbf} / \mathrm{in}^{2}$ to a pressure of $25 \mathrm{lbf} / \mathrm{in}^{2}$. The resulting flow of $3.65 \mathrm{ft}^{3} / \mathrm{min}^{2}$ past the stem exceeded the first airflow packing test by about $70 \%$ for the same $10 \mathrm{lbf} \cdot \mathrm{ft}$ torques. The two packing gland nuts then were torqued to the break-away torque levels of 21 and $321 \mathrm{bf} \cdot \mathrm{ft}$. The air pressure test was repeated with a resulting leakage rate at the packing of $2.8 \mathrm{ft}^{3} / \mathrm{min}$ at $25 \mathrm{lbf} / \mathrm{in}^{2}$ (uncorrected for atmospheric pressure and temperature).

An ergonomics test was performed to determine the ease with which the valve handle could be operated and the number of turns required to seat the valve disk from the accident condition position. It took 20 turns of the valve handle to seat the disk into the bottom of the valve. The required effort to perform this task appeared to be relatively easy for an operator using two hands. This task took approximately 1 minute.

After the ergonomics test, the valve was connected to water at a gauge pressure of $75 \mathrm{lbf} / \mathrm{in}^{2}$. The purpose of this test was to determine the number of turns of the valve handle required to initiate flow from a fully closed valve position. The downstream side of the valve was fitted with a tapped flange to allow water to flow through the valve and into a container. The valve first was opened $1 / 2$ turn from the fully seated condition without flow being achieved. The valve was then turned in increments of $1 / 4$ turn to $11 / 4$ turns before flow began. The resulting flow rate out of the valve was approximately $3.5 \mathrm{gal} / \mathrm{min}$. The packing stem leaked considerably at this position. The test then ended.

It is concluded that the MSS-25 valve was in good working condition except for some leakage past the valve stem. The valve stem packing, which was graphite-impregnated steel mesh, showed evidence of loss of surface graphite. This condition was observed by representatives of the valve manufacturer, who indicated that this was normal for that type of packing.

\subsection{STEAM TRAP}

\subsubsection{Initial Tests}

On June 21, 1993, the inlet and outlet piping and associated valves were removed from the steam trap and examined visually to determine whether they were plugged with any debris. Isolation valves were checked to determine whether they were fully open, and check valves and strainers were checked visually for functionality. The piping/components were marked to record their position in the steam-trap piping system. The visual inspection confirmed that all pipe and valves were fully open and operational. The screen on the strainer had accumulated some rust particles but appeared to be $70 \%$ open. 


\subsubsection{Flow Tests}

On June 25, 1993, an operational verification test was performed on the $Y$-strainer, the steam trap, and the check valve. The test consisted of pressurizing these components with steam at $1001 \mathrm{bf} / \mathrm{in}^{2}$ and collecting the discharge condensate in a plastic bag. The initial pressurization resulted in approximately $2 \mathrm{gal}$ of condensate dumped from the trap in less than a minute. The condensate then was filtered through cloth to collect any foreign particles. The residue left on the cloth consisted of small amounts of rust and sand. The steam trap was repressurized and allowed to continue to discharge condensate and steam for several more cycles. From all observations, the steam trap appeared to operate satisfactorily. This operational test was recorded on videotape. 


\subsection{THERMAL-HYDRAULIC ANALYSES}

\subsection{INTRODUCTION}

This section presents the results of a thermal-hydraulic evaluation of the steam line failure. The following major topics are covered:

- Sequence of events pertinent to thermal-hydraulic evaluation

- Steam system data pertinent to thermal-hydraulic evaluation

- Postulated valve failure mechanisms

- Thermal-hydraulic analyses

- Analysis of condensation-induced water hammer

- Thermal-hydraulic scaled experiments.

Accidents in 300 Area steam 1 ines occurred in 1972, 1979, and 1982. A11 appear to have involved steam/water reactions (Papenfuss 1982). A steam system accident also occurred at Brookhaven National Laboratory (BNL) in 1986 in which two workers were fatally injured; the probable cause was identified as a steam/water reaction (BNL 1986).

\subsection{SEQUENCE OF EVENTS PERTINENT TO THERMAL-HYDRAULIC EVALUATION}

Presented elsewhere in this report is a detailed history of the events that led to and followed the valve failure accident. This section focuses on those events most pertinent to determining the mechanism that caused the valve to fail.

- In September 1992, valve MSS-25 was closed; closure cut off the steam flow from the north through the line containing valves MSS-30 to MSS -25 . The cut off resulted in a stagnant steam condition in approximately 840-ft of 8-in. pipe. Drawing information indicates that over the $840 \mathrm{ft}$ length of this pipe, the elevation decreases by $11 \mathrm{ft}$.

- In October 1992, valve MSS-28 was closed; closure would have cut off steam flow east to Building 331 in approximately $500 \mathrm{ft}$ of 4 -in. pipe. However, other information indicates that there may have been steam flow in the pipe through an alternate path. (Investigation showed that the steam trap in the 4-in. line is operational. Therefore, it is unlikely that there was water in the 4-in. pipe.)

- On June 7, 1993, a JPO cracked open valve MSS-25 and waited to hear flow in the pipe. After an indeterminate period of time, the JPO rapidly moved the valve gate to approximately $50 \%$ open. After hearing indications of water hammer in the piping, the JPO attempted to close the valve, but was unable to do so. Subsequently, the 6 -in. valve above the JPO failed and separated from the piping, releasing steam and water to the valve pit.

The first piece of important information that can be drawn from this series of events is that there was ample time for steam to condense in the 8-in. pipe through which no steam had flowed for approximately 8 to 9 months. If there had been no flow in the 4-in. pipe, there was also ample time for condensation to occur in it. 
The fact that the JPO apparently heard water-hammer noises in the piping and reported that he had attempted to close the valve indicates that a cyclical phenomenon may have been initiated and that more than one pressure pulse may have occurred before the valve failed.

\subsection{DATA PERTINENT TO THERMAL-HYDRAULIC EVALUATION}

This section includes data from drawings and discussions with WHC staff pertinent to the thermal-hydraulic evaluation. This information is presented in the subsections below that describe the steam system and the system process parameters at the time of the accident.

\subsubsection{Steam System Description}

Steam is supplied to the 300 Area complex from a single steam plant located in the west-central region of the area. The piping system consists of four main piping networks. These are identified at the steam plant as north, east, south, and west exports. The June 7, 1993, steam line failitre of a valve occurred near the end of the west export piping in valve pit $U-3$ which is located about $500 \mathrm{ft}$ from the outermost valving of steam to Building 331 .

Figure 1-2 shows the 300 Area steam line piping network. The accident occurred when the JPO began opening valve MSS-25 (in pit $U-3$ ) to activate a 840-ft-long, 8-in.-diameter branch 1 ine that connects near valve MSS-30 and leads northward to the east export pipe line. From valve MSS-30, the $840-\mathrm{ft}$ long 8-in.-diameter branch 1 ine slopes downward from valve MSS-30 to an elevation of $11 \mathrm{ft}$ at valve MSS-25 (pit U-3).

Figure 1-1 illustrates the piping arrangement in the $U-3$ valve pit. Figure 8-1 shows the plan view piping of $U-3$; see Figure $6-2 a$ for an isometric description of piping dimensions from field measurements taken after the accident. Figure 6-3 similarly shows an isometric description of the $U-3$ upper-region piping and includes piping inclines.

Figures 8-2 through 8-5 show the distribution of open and closed valves before and after the accident and subsequent isolation.

\subsubsection{Steam System Process Parameters on June 7, 1993}

Figure 8-6 shows measured, saturated steam pressure at key locations at the east and west export grid pipelines. The pressure difference between active steam locations at MSS -30 and the steam side of MSS-25 (pit U-3) is indicated to be about $5 \mathrm{lbf} / \mathrm{in}^{2}$.

Table 8-1 lists steam flow rates recorded before and after the incident. Based on comparisons before and after isolation of the west export pipe line, estimates are that the steam flow rate in the active 8 -in. 1 ine at the $\mathrm{U}-3$ valve pit was about $1,000 \mathrm{lb} / \mathrm{h}$. 


\section{Steam Conditions} follows:

The steam pressures and temperatures at saturated conditions were as

$\begin{array}{lll}\text { Steam supply boiler } & 119 \mathrm{lbf} / \mathrm{in}^{2} \text { (gauge) } & 349^{\circ} \mathrm{F} \\ \text { MSS-30 } & 115 \mathrm{lbf} / \mathrm{in}^{2} \text { (gauge) } & 347^{\circ} \mathrm{F} \\ \text { Building } 331 & 110 \mathrm{lbf} / \mathrm{in}^{2} \text { (gauge) } & 344^{\circ} \mathrm{F}\end{array}$

Bașed on these data, the nominal steam pressure across valve MSS-25 was $5 \mathrm{lbf} / \mathrm{in}^{2}$. To this number must be added the gravity head resulting from the slope of the 8-in. pipe. The degree of accuracy that can be ascribed to the measured pressure data is uncertain. Experience indicates that the accuracy might be approximately $+/-21 \mathrm{bf} / \mathrm{in}^{2}$.

$\begin{array}{ll}\text { Valves } & \text { Valve positions } \\ \text { MSS-25 } & \text { closed } \\ \text { MSS-26 } & \text { open } \\ \text { MSS-27 } & \text { open } \\ \text { MSS-28 } & \text { closed } \\ \text { MSS-30 } & \text { open } \\ \text { Failed valve } & \text { closed (and biocked) }\end{array}$

MSS-25 Gate Position versus Time

The JPO is reported to have "cracked open" the steam valve to permit a small amount of flow. This operation reportedly took approximately 25 seconds. After the accident, the valve was removed from the piping system and a flow test was conducted with the valve in a "cracked open" position. At a pressure difference of $75 \mathrm{lbf} / \mathrm{in}^{2}$, the valve flow rate was measured to be $3.5 \mathrm{gal} / \mathrm{min}$. At a pressure difference of $101 \mathrm{bf} / \mathrm{in}^{2}$, the flow rate would be approximateiy $2 \mathrm{gal} / \mathrm{min}$. Therefore, during the 25 seconds that the JPO had the valve in the "cracked open" position, only a gallon of liquid, approximately, would have flowed past the valve. (This information may explain why the power operator [PO] observer outside the valve pit saw a small amount of water/steam emanating from the steam trap pipe.) This initial flow was inconsequential as the capacity of the vertical riser inside the pit is about 20 gal.

The valve operated by the UPO was found to be approximately $50 \%$ open. Investigation indicated that 20 revolutions of the handle were required to fully seat it. The time required to close the valve 18 turns to the crackedopen position was less than a minute. 


\subsection{POSTULATED VALVE FAILURE MECHANISMS}

\subsubsection{General Failure Mechanisms}

Familiarity with events and failures of hydraulic networks and heat transport systems leads to the frequent causes and/or contributors to component failures.

- Classical water hammer--This phenomenon typically is due to the sudden deceleration of a liquid column caused by closing a valve. Commonly observed in poorly designed homes, it involves single-phase liquid systems.

- Condensation-induced water hammer--Recently this phenomenon has been studied extensively in connection with the steam generators in pressurized-water reactors. Examined for the case of $\mathrm{N}$ Reactor (Thurgood 1987), this mechanism is discussed in Section 8.4 .2 in greater detail.

- Thermal transient caused by the exposure of a hot valve to cold water-This mechanism is likely to have occurred in this instance; however, thermal stresses alone would not cause the valve to fail.

- Combination of the above--A combination of mechanically and thermally induced stresses could cause failure.

\subsubsection{Description of Condensation-Induced Water Hammer}

Condensation-induced water hammer caused by admitting subcooled water into horizontal piping geometries containing steam is a subject area that has been investigated extensively. In the mid-1970s, condensation-induced water hammer produced damaging results in steam-generator feedwater systems in water reactors. Although other mechanisms leading to the steam valve failure are plausible, condensation-induced water hammer appears to be the likely mechanism, based on the available evidence. Figure 8-7, a through $\mathrm{g}$, is a schematic illustration of a condensation-induced water hammer.

The phenomena described below represent the frequent causes of or contributors to the kinds of component failures that can lead to the failure of hydraulic networks and transport systems.

- Steam contained in or flowing in horizontal piping

- Subcooled water admitted in such a manner as to provide stratified flow

- Steam/water interface area of a size to promote rapid steam condensation

- Two-phase transition between stratified and slug flow regimes caused by wave formation following a collapse in steam pressure

- Geometric restrictions that contain the resulting water-hammer hydrodynamic transient and sustain a repetitive formation of slug flow alternating with steam condensation. 
Experiments reflecting the above conditions and events have been performed at pressure levels ranging from 1 to 70 atmospheres (absolute). Resulting water-hammer peak over-pressures were observed to range up to $2,500 \mathrm{lbf} / \mathrm{in}^{2}$ for initial steam conditions of $100 \mathrm{lbf} / \mathrm{in}^{2}$ (absolute). The pulse duration is a function of geometry. In the 331 valve pit, the scenario is described by acoustic propagation bounded by the eccentric reducer, the riser elbow, and the tee junctions.

\subsection{THERMAL-HYDRAULIC ANALYSES}

\subsubsection{Condensation in 8-in. Pipe to Valve MSS-25}

This calculation is of fundamenisl importance because the existence of liquid in the 8-in. pipe sets up the conditions for classical water hammer and condensation-induced water hammer. The north end of this pipe tees into a line containing steam flowing at a gauge pressure of approximately $115 \mathrm{lbf} / \mathrm{in}^{2}$. This flowing steam provided the supply of steam that condensed in the isolated 8-in. line.

The pipeline that branches northward from valve MSS-25 in pit U-3 slopes upward for a distance of $840 \mathrm{ft}$, at which point it connects to the east export pipel ine near valve MSS-30. The difference in elevation between valves MSS -30 and MSS-25 is $11 \mathrm{ft}$. Before the accident, MSS-25 at the lower elevation was closed, and MSS-30 was open, so that the upper end of the 8-in. branch line was open to active steam and, as such, was exposed to condensate accumulation. Over a period of months, the condensate flowed downward toward MSS-25 and filled the $840-\mathrm{ft}$ pipeline. The rate of condensation is determined by heat loss from the pipe.

This pipeline is underground and inside a 15-in.-diameter steel conduit. The 8 -in. schedule 40 pipe is also insulated with a 2 -in. thickness of fiberglass. Boundary conditions for the heat transfer calculations assumed internal steam temperature at $340^{\circ} \mathrm{F}$ and soil temperature at $55^{\circ} \mathrm{F}$. The resulting calculation indicates a linear heat loss-rate of $167 \mathrm{Btu} / \mathrm{h} / \mathrm{ft}$. The estimated rate of condensation is based on this heat loss and the assumption that at least $15 \mathrm{ft}$ of the $840-\mathrm{ft}-1$ ong pipeline at the upper end is supplied with active steam. On these bases, condensate would have been generated at the rate of about $2 \mathrm{lb} / \mathrm{h}$ and would have flowed downward to valve pit U-3 (valve MSS-25), filling the branch pipeline at a rate of about $75 \mathrm{ft} / \mathrm{month}$. At this rate, the pipeline would fill within the 8- to 9-month period between the time MSS- 25 was last opened and the time of the failure. Soon after filling, the condensate would have reached equilibrium with the ground temperature of $55^{\circ} \mathrm{F}$.

Figure 8-8 summarizes the calculations of estimated condensation. 


\subsubsection{Condensation in 4-in. Pipe to Valve MSS-28}

A comparison of the calculations for conditions in the 8-in. pipe with those for the 4-in. pipe leads to the conclusion that condensation in the $4-i n$. pipe is at least as likely, if not more likely, if valve MSS-28 indeed was closed and if no other route existed through which steam could flow. However, a small by-pass pipe around vaive MSS-28 allowed some steam to flow through the 4-in. line toward MSS-28.

\subsubsection{Steam System Transient Analysis}

Engineers at Westinghouse Savannah River Company (WSRC) were enlisted to perform a system analysis with the RELAP 5 computer code to determine the system transient response to the opening of valve MSS-25. The RELAP 5 Mod 3 code has been used extensively to analyze water-reactor accidents and can be applied to obtain bulk system conditions in complex systems.

\section{RELAP5 Model}

A RELAP model based on the data summarized in Section 8.3.1 was set up to include both a detailed representation of the piping geometry within the valve pit and an equivalent simplified model of the piping outside the valve pit. The pressure boundary conditions were those given in Secticn 8.3.2.

RELAP5/MOD3/V7J was used to simulate the thermal-hydraulic transient resulting from the opening of valve MSS-25. The piping upstream of the valve, containing the condensate slug, was modeled by a source reservoir, maintained at constant temperature and pressure (including a hydrostatic pressure head to , account for the slope of the pipe), that was connected to a pipe and then to a valve. The piping system within the U3-pit was modeled accurately to maintain the geometry of the piping system. The 4-in. pipe was modeled for a length of $60 \mathrm{ft}$ ending in a sink of constant pressure and temperature. The $21 \mathrm{ft}$ of 8-in. cross-over piping was also modeled, connected to a source reservoir maintained at constant pressure and temperature.

Valve MSS-25 was modeled with the RELAP5/MOD3 motor valve component. One preliminary run of RELAP code was made with valve MSS-?5 cracked open for 20 seconds, and then another in which the valve opened linearly up to a valve flow area of $0.2 \mathrm{ft}^{2}$. Subsequent runs of the code were made with the crackedopen time period deleted since it did not influence the results.

The subsequent RELAP cases are simulations with the valve MSS-25 cracked open for 5 seconds and then opened linearly in flow area during the following 20 seconds.

Figure 8-9 shows the valve flow rate as evaluated by RELAP.

\section{RELAP Analysis Results}

The next group of figures are graphs showing the properties of the fluid at the location of the 6 -in. failed valve. 
Figure 8-10 shows the void-average mixture density and the hydrodynamic volume rate of fill. The flattening of the curve at approximately 11 to 15 seconds reflects flow stratification, as predicted by RELAP.

Figure 8-11 shows the mass flow rate (1iquid phase + vapor phase) at the same location, as calculated by RELAP.

Figure 8-12 shows the hydrodynamic-volume temperature transient (Tempf). The curve labeled Tempg is plotted only to show the actual saturation temperature of the vapor at the pressure of the hydrodynamic volume.

Figure 8-13 shows the pressure of the hydrodynamic volume. Pressure spike caused by rapid condensation are not shown because RELAP5 algorithms smooth out excessive spikes of pressure. However, RELAP predicts the proper environment for condensation-induced water hammer.

Figure 8-14 shows the phase velocities (Velgj = vapor velocity, $v: l f j=$ liquid velocity) at the fluid junction upstream of the hydrodynamic volume.

Figure 8-15 shows the liquid (Voidf) and vapor (Voidg) void fractions at the hydrodynamic volume; this figure is included to assist in the interpretation of Figure 8-14.

Within 11.5 seconds from the time at which valve MSS-25 starts to open, the water rises to the top of the vertical piping section. Thereafter RELAP predicts flow stratification in the horizontal pipe toward the 8- by $4-i n$. reducer pipe that includes the 6 -in. failed valve. At about 15 seconds the flow regime is predicted to change to bubbiy flow. Simultaneously, the subcooled fluid begins to enter the 8 -in. sloped branched pipe that tees into the horizontal pipe, and the flow in this branch changes from stratified to bubbly. This change indicates that the conditions are such to initiate condensation-induced water hammer.

\subsubsection{Thermal Analysis of 6-in. Cast-Iron Valve}

A thermal analysis of the cast-iron valve has been performed to provide steady-state and transient temperature distributions for the stress analysis. Three thermal analyses were done. The first and second analyses were performed with a full length axisymmetric $(r, z)$ model of the valve and a small portion of the attached piping. The third analysis, of the axial section of the valve at the failure location, provided azimuthal and radial temperature variation.

8.5.4.1 Axisymmetrical Analys is of Cast Iron-Valve. Transient temperatures for the failed steam valve were predicted with a numerical thermal model of the valve. These predicted results support the initial structural assumption of a 55 to $325^{\circ} \mathrm{F}$ temperature gradie t from the inside to the outside surface of the wall of the valve body at the failure location.

In the first case, the steam valve was modeled as insulated and at an initiai temperature of $340=F$, the upper iimiting temperature for the sieami supplied from the boiler. For cunservatism, any thermal loss in the piping from the boiler to the location of the failed valve was ignored. The 
temperature of the water on entering the valve was assumed to be $55^{\circ} \mathrm{F}$. The numerical model reduces the temperature of the inner surface of the valve linearly with time from 340 to $55^{\circ} \mathrm{F}$ over a period of 1 second. The time required for the temperature reduction is an assumption to account for the behavior of the water entering the valve.

Figure $8-16$ is a plot showing the predicted transient response of the wall of the valve body at the location of the failure. The upper curve is a transient temperature plot of the surface of the outer wall. The lower curve is the transient temperature plot of the surface of the inner wall. The most severe temperature gradient occurs at 1.0 second when the valve experiences the full 1 effect of water at $55^{\circ} \mathrm{F}$. The temperature gradient is $285^{\circ} \mathrm{F}$ through the wall of the valve body. The majority of this gradient occurs through the inner half of the wall thickness. The wall thickness at the failed location is nominally $5 / 8 \mathrm{in}$. The temperature gradient through the inner $5 / 16 \mathrm{in}$. of the wall is $247^{\circ} \mathrm{F}$. The outer $5 / 16$ in. of the valve wall has a temperature gradient of $38^{\circ} \mathrm{F}$. This effect can be seen in Figure $8-17$, a gray scale representation of the temperature distribution at the failure location.

The second case modeled the valve as uninsulated and at an initial temperature of $300^{\circ} \mathrm{F}$. This value is the lower limiting temperature for the steam supplied from the boiler. The water was assumed to enter the valve at $55^{\circ} \mathrm{F}$. The numerical model reduces the temperature of the surface of the inner valve linearly with time from $300^{\circ} \mathrm{F}$ to $55^{\circ} \mathrm{F}$ in 1 second.

Figure 8-18 is a plot of the transient temperatures predicted for the first 5 seconds at the failure location. Figure 8-19 is a plot of the same location for the first 60 seconds of the transient. The plots show that the through-wall temperature gradient predicted is approximately $245^{\circ} \mathrm{F}$ at a time of 1 second. The failed section of the valve cools throughout to below $100^{\circ} \mathrm{F}$ within approximately 45 seconds after the water enters.

This analysis indicated that the time constant of the valve in the failure location is approximately five seconds.

\subsubsection{Analysis of Cast-Iron Valve Considering Azimuthal Temperature}

Variation. Analysts suspect that the water that first reached the top of the riser above valve MSS-25 spread out readily on the bottom of the 8-in.-diameter horizontal piping. The result would have been open channel flow that quickly spilled over into the bottom of the 6 -in. cast-iron valve. Thus, the bottom of the hot $\left(340^{\circ} \mathrm{F}\right)$ valve would have been exposed to cold $\left(55^{\circ} \mathrm{F}\right)$ water first.

For a transient thermal analysis, the model represented the section of the valve body that broke. This analysis shows that, when cold water is introduced into the lower portion of the valve body, the portion of the valve body that is in contact with the water cools rapidly. Figure 8-20 shows the time required to cool the lower portion of the valve body to the temperature of the entering water. This case assumes that the water level in the valve is 1.5 in. 

follows.

Two of the more conservative assumptions used in this analysis are as

- The temperature of the water introduced into the valve is not raised as the valve heats up.

- The heat transfer cosfficient during the course of the transient is maintained at $3,000 \mathrm{Btu} / \mathrm{h}-\mathrm{ft} \star \star 2{ }^{\circ} \mathrm{F}$.

Figures 8-21 and 8-22 are section views of the model used for this analysis. One quadrant of the valve has been translated 6 in. in the $X$ direction for improved visibility of the through-wall gradients. These figures show the temperature distributions in the valve at 8 seconds after the water reached the valve location and at 28 seconds after the water reached the valve location, respectively.

\subsection{ANALYSIS OF CONDENSATION-INDUCED WATER HAMAER}

To determine whether condensation-induced water hammer could have occurred, WHC obtained the services of Numerical Applications, Inc. (NAI), of Richland, Washington. The MAI has analytical models that treat the phenomenon of the formation of water slugs caused by the interaction of water and steam and calculate the resulting pressure pulses caused by the dynamics of such water slugs. These methods have been applied in the past to $\mathrm{N}$ Reactor safety analyses (Thurgood 1987).

\subsubsection{Introduction}

This section provides an analysis of the possibility for and the magnitude of the condensation-induced water hammer that may have resulted in the failure of the closed $6-i n$. gate valve in the $U-3$ steam valve pit. The analysis is based primarily on the use of the CHOP (Countercurrent HOrizontal Pipe) program developed at The Massachusetts Institute of Technology by Bjorge and Griffith (1984) and the SLUGDYN (SLUG DYNamics) ${ }^{1}$ program based on work performed at CREARE, INC., by Block (1977).

Three cases are considered as scenarios that could have resulted in condensation-induced water hammer. The analysis predicts the magnitude and duration of the pressure pulses resulting from each of the following cases.

Case 1 - The condensate filling the pipe behind valve MSS-25 rapidly accelerated up the riser and down the horizontal 8-in. line until it struck. the 8- by 4-in. reducer. The magnitude and duration of the resultant pressure pulse is a function of the following.

- The initial length of the water slug

- The pressure difference across the slug

- The end condition at the 4-in. reducer, i.e., was the 4-in. line filled with condensate or was it filled with steam?

${ }^{1}$ CHOP and SLUGDYN are crademarks of Numerical Applications, Inc. 
- The condition of the 8-in. cross-over line at the time of slug impact, i.e., did it partially fill with water as the slug accelerated down the line?

Case 2 - After water filled the 8-in. riser, the water flow rate was such that the water flowed into the 8-in. horizontal iine in a stratified flow. This stratified flow went into the 8 -in. cross-over line and continued down the line through the 8- by 4-in. reducer into the 4-in. line. Because the 8-in. cross-over line slopes upward from valve MSS-27 and on the assumption that not all of the flow could be handled by the $4-i n$. line, the $8-i n$. line from the riser to the reducer would fill with water as the water flowed along the incline of the 8-in. cross-over line. As the length of the stratified interface increased, the condensation rate of steam on the horizontal interface would increase. Eventually the steam flow induced by condensation would be large enough to induce unstable wave growth on the liquid surface, resulting in the formation of a water slug that would accelerate down the pipe until it encountered the liquid-filled portion of the 8-in. line. The magnitude of the resulting pressure pulse is a function of the following:

- The volume of water in the 8-in. cross-over line

- The pressure difference across the slug

- The piping system geometry.

Case 3 - This case is the same as case 2 except for the assumption that the water flow is such that the flow in the 4-in. line is stratified and the 4-in. line does not completely fill with water. This case also assumes that the downstream end of the 4-in. line has access to an unlimited steam supply, a condition that apparently did not exist but was not conclusively ruled out. In this case, condensation on the interface in the 4-in. Tine results in unstable wave growth and slug formation. The slug accelerates back up the 4-in. line until it encounter's the water-filled riser. The magnitude and duration of the resulting pressure force is a function of the following:

- The liquid level in the 4-in. Tine

- The pressure difference across the slug

- The geometry of the piping system.

\subsubsection{General Information}

The general layout of the piping is shown in the isometric sketch in Figure 8-23. All of the piping consists of schedule 40 pipe. Line sizes and slopes are shown, as is the direction of steam flow during normal operation. Valve MSS-25 was closed initially, and the assumption is that the piping on the upstream side of this valve was filled with condensate. This line, extending approximately $840 \mathrm{ft}$ from valve MSS -25 to a live steam line, is buried; the ground temperature is assumed to be approximately $55^{\circ} \mathrm{F}$ year'round. The line drops approximately $11 \mathrm{ft}$, from the 1 ive steam 1 ine to valve MSS-25. Because the valve had been shut for several months and the line is connected to a live steam line on the other end, it is reasonable to assume that steam would condense in the line and that the line would fill with condensate. The condensate is assumed to have been in the line long enough for the water in the line to reach thermal equilibrium with the ground, i.e., the temperature of the condensate was $55^{\circ} \mathrm{F}$. When the valve was opened, the steam pressure on the upstream end of the water-filled pipe is assumed to have 
forced the water through the valve and into the 8-in. riser pipe. The water then would flow horizontally into the 8 -in. and 4 -in. 1 ines at the top of the steam pit. The horizontal flow of water as well as the turbulence induced by flow around bends and through tees would result in condensation of the steam in contact with the cold water, reducing the steam pressure and increasing the flow of both steam and liquid in the direction of the condensation site.

\subsubsection{Analysis}

Three possible scenarios for the formation of condensation-induced water hammer have been postulated:

- Acceleration of the condensate behind MSS-25 after the valve is opened. The acceleration of the slug could have increased as a result of condensation on the downstream end of the slug

- Condensation-induced formation of a slug on the stratified liquid flow in the horizontal 8-in. cross-over line

- Condensation-induced formation of a slug on the stratified liquid flow in the horizontal 4-in. line.

Each of these cases is examined in the following sections.

8.6.3.1 Acceleration of Condensate Slug through Piping. The first scenario postulated for an event causing a pressure pulse that would break the 6 -in. valve is that condensate that had accumulated behind the closed MSS-25 valve was pushed through the valve into the 8 -in. riser 1 ine as the valve was opened. As the slug of water was pushed along the 8 -in. 1 ine and flowed around the bend at the top of the riser, the increased disturbance of the liquid/steam interface caused by flow around the bend and through the tee accelerated the condensation rate of the steam. The increased rate of condensation caused the pressure on the downstream end of the water slug to decrease rapidly, accelerating the slug. If the 4 -in. line were closed at the far end and filled with steam, once the slug face crossed the tee connecting the 8 -in. horizontal line to the 8 -in. horizontal cross-over line, the 4 -in. line would have been cut off from the steam supply and the trapped steam would condense rapidly, dropping the pressure on the downstream end of the slug to zero and rapidly accelerating the slug toward the 8 - by $4-i n$. reducer. If the 4-in. line were filled with condensate, the depressurization would occur even faster. When the water slug reached the reducer, it would decelerate rapidly because of the flow restriction and would stop when it reached the condensate. Either condition would result in a pressure pulse that could cause the valve to fail. This scenario is depicted in the figures described below.

Figure 8-24 illustrates the condition likely before the valve was opened. The piping behind MSS-25 is filled with water and the 4-in. Tine is filled with condensate with a sloping interface 19.08-ft long ending at the 8-in. riser pipe. If the 4-in. line was connected to a steam trap, then the line would not have had water in it. Which of these circumstances was the case is not known. The length of the water slug upstream of MSS-25 is not known. Other analyses have indicated that the valve was closed long enough for condensate to fill the entire line. If this indeed were the case, then the slug would accelerate very slowly because of its mass ( $840 \mathrm{ft} 1 \mathrm{ong}$ ) and 
its velocity would not be sufficient to create significant water-hammer pressures. On the other hand, the duration of the pressure pulse could be long. If condensate did not fill the entire line but only a short portion near the valve, then higher water slug velocities could be achieved.

Figure 8-25 illustrates the condition shortly after valve opening began. The water flows through the valve and begins to fill the riser. Rapid acceleration at this time is not likely because the interface between the liquid and the steam is relatively stable in this position and the liquid at the surface is probably saturated.

Figure 8-26 illustrates the onset of rapid condensation resulting from the disturbance caused by flow around the bend in the pipe. Rapid condensation results in rapid decompression on the downsteam end of the water slug and acceleration of the water slug toward the 8- by 4-in. reducer (see Figure 8-27).

In Figure 8-28, the slug strikes the reducers and the water that fills the 4-in. line. This impact generates a pressure pulse that travels in both directions from the point of impact. As the pressure wave passes the 6-in. tee connecting to the 6 -in. valve (closed), a fraction of the pressure wave is transmitted into the valve. When this pressure wave reaches the valve disc, it reflects off the disc as a decompression wave equal in magnitude to the incoming wave, doubling the magnitude of the pressure wave. This pressure pulse could cause the failure of the valve. When the pressure wave in the 8-in. line reaches the 8 -in. tee, it will reflect as a decompression wave back toward the reducer, reducing the magnitude of the pressure in the line.

Figure 8-29 shows the impact of a shorter slug. In this instance, the velocity of the slug at impact would be much higher than in the cases

described above; however, the duration of the pressure pulse would be shorter.

The magnitude of the water-hammer over-pressure and the duration of the pressure pulse at the location of the 6-in. valve for this scenario have been calculated with the SLUGDYN program (Block 1977). See Thurgood 1987 and Block 1977 for a complete description of the methodology used to calculate the water-hammer over-pressure. For the simple case of the acceleration of a slug with a constant length under a constant pressure gradient, the equations are as follows:

$$
\rho_{1}:=62.28 \mathrm{1bm} / \mathrm{ft}^{3} \text {. }
$$

The slug length is

$$
1_{\mathrm{s}}:=800.0 \mathrm{ft} \text {. }
$$

The system steam pressure is

$$
\mathrm{p}:=128 \mathrm{lbf} / \mathrm{in}^{2} .
$$

The length of voided pipe is

$$
l_{p}:=20.24 \mathrm{ft} \text {. }
$$


The slug velocity at impact is given by

$$
v_{s}(1):=\sqrt{\frac{2 \cdot 1_{p} \cdot p}{\rho_{1} \cdot 1}} .
$$

The bulk modulus of elasticity for the water is

$$
K_{L}:=3.208 \times 10^{5} \mathrm{lbf} / \mathrm{in}^{2} \text {. }
$$

Young's modulus for the pipe wall is

$$
E:=30.0 \times 10^{6} \mathrm{lbf} / \mathrm{in}^{2} \text {. }
$$

The 8-in. pipe wall thickness is

$$
\varepsilon:=0.0268 \mathrm{ft} \text {. }
$$

The inside diameter of the 4 -in. pipe is

$$
D_{8}:=0.665 \mathrm{ft} \text {. }
$$

The wave speed in the $8-i n$. pipe is

$$
a_{w 8}:=\left(\frac{\frac{K_{L}}{\rho_{1}}}{1+\frac{K_{L} \cdot D_{8}}{E \cdot \epsilon}}\right)=4343 \frac{\mathrm{ft}}{\mathrm{s}} .
$$

The water-water impact over-pressure is

$$
\Delta p(1):=\rho_{1} \cdot a_{w 8} \cdot \frac{V_{s}(1)}{2} .
$$

The 4-in. pipe wall thickness is

$$
\varepsilon_{4}:=0.237 \text { in }=0.01975 \mathrm{ft} \text {. }
$$

The 4-in. pipe inside diameter is

$$
D_{4}:=4.026 \mathrm{in} .=0.3355 \mathrm{ft} \text {. }
$$

The wave speed in the 4-in. pipe is

$$
a_{w 4}:=\left(\frac{\frac{K_{L}}{\rho_{1}}}{1+\frac{K_{L} \cdot D_{4}}{E \cdot \epsilon_{4}}}\right)=4494 \frac{f t}{s} .
$$


The magnitude of the pressure wave transmitted into the 4-in. pipe is

$$
\begin{aligned}
& A_{8}:=\pi \cdot \frac{D_{8}^{2}}{4}=0.3473 \mathrm{ft}^{2} \\
& A_{4}:=\pi \cdot \frac{D_{4}^{2}}{4}=0.0884 \mathrm{ft}^{2} \\
& S:=\frac{2 \cdot \frac{A_{8}}{a_{w 8}}}{\frac{A_{8}}{a_{w 8}}+\frac{A_{4}}{a_{w 4}}}=1.605 \\
& \Delta p_{4}:=\Delta p\left({ }^{1 s}\right) \cdot s=1028 \mathrm{lbf} / \mathrm{in}^{2} .
\end{aligned}
$$

The magnitude of the pressure wave transmitted back along the 8-in. line is

$$
\begin{aligned}
& \Delta p_{8}(1):=(s-1) \cdot \Delta p(1)+\Delta p(1) \\
& \Delta p_{8}\left({ }^{1 s}\right)=10281 b f / i n^{2} .
\end{aligned}
$$

The duration of the pressure wave will be

$$
\begin{aligned}
& t_{w}(1):=2 \cdot \frac{1}{a_{w 8}} \\
& t_{w}\left({ }^{1 s}\right)=0.3684 \mathrm{~s} .
\end{aligned}
$$

As the exact length of the water slug upstream of the valve is not known, the water-hammer over-pressure is represented best as a function of slug length (see Figures 8-30 and 8-31).

The duration of the pressure pulse can also be plotted as a function of the slug length (see Figures 8-32 and 8-33).

The magnitude of the pressure pulse will be reduced by the following factor when it passes the 8-in. tee:

$$
\text { s8 }:=\frac{2 \cdot \frac{A_{8}}{a_{w 8}}}{\frac{A_{8}}{a_{w 8}}+2 \cdot \frac{A_{8}}{a_{w 4}}}=0.682 .
$$


The magnitude of the pressure in the 8 -in. line in the vicinity of the failed valve will be reduced by a factor of 1.0 minus this ratio each time a pressure wave is transmitted from the tee to the reducer and back. Therefore, the actual duration of the pressure pulse at the failed valve will be reduced from the time given in the above equations by this effect.

Conclusion: This calculation assumes the longest possible length of voided pipe during rapid condensation; to provide a conservative estimate of the magnitude and duration of the pressure pulse, the reduction of the magnitude and duration of the pressure wave by reflections at the 8 -in. tee have not been included. Because it is likely that the entire length of the pipe upstream of MSS-25 was filled with condensate, the best estimate for the water hammer for this case is approximately 1,000 $\mathrm{ibf} / \mathrm{in}^{2}$ and the duration of the pressure pulse is approximately 0.37 seconds. Higher pressure pulses for shorter durations are possible if smaller amounts of condensate were in the line when the valve was opened.

\subsubsection{Condensation-Induced Formation of A Water Slug in the 8-in. Cross-} over Line. The conditions for this case are similar to those in the previous case except that the liquid flow rate is assumed to be low enough that the liquid flows through the horizontal lines at the top of the riser in stratified flow. Under this condition, water will flow into both the 8-in. cross-over line and the 4-in. line, filling the 8-in. line connected to the failed valve and the 4-in. line with water as the level in the upward sloping 8 -in. cross-over line increases. At some point, condensation on the stratified interface in the 8 -in. cross-over 1 ine will become sufficiently large that the steam flowing over the interface will develop unstable wave growth. This process results in the formation of a water slug in the 8 -in. cross-over line. The sudden increase in condensation caused by the formation of the unstable interface will sweep the water in the cross-over line into a slug that will travel back up the 8-in. cross-over line and strike the waterfilled $8-i n$. line to which the failed 6 -in. valve is attached. Figure $8-34$ schematicaliy shows the condition in the piping system just before siug formation.

The CHOP program (Bjorge and Griffith 1984) was used to calculate the liquid flow rates where slug formation can be expected to occur, as well as the liquid fraction in the 8-in. cross-over line when slug formation occurs. This liquid fraction determines the final slug length and the velocity with which it strikes the water solid piping (filled) and therefore determines the magnitude and duration of the condensation-induced water hammer. The equations solved in CHOP are not presented here. See Thurgood 1987 and Bjorge and Griffith 1984 for a complete discussion of the equations. Only the results of the analysis are presented here. The liquid fraction in the 8 -in. cross-over line at the time of slug formation and the length of the 8-in. cross-over line are used in SLUGDYN to calculate the magnitude of the water hammer over-pressure and the length of the slug at impact. The slug length then is used to calculate the duration of the water hammer over-pressure. CHOP predicts that condensation-induced water hammer will occur in the 8-in. cross-over line if the liquid flow rate is between 1 and $21 \mathrm{~b} / \mathrm{s}$. This value corresponds to a liquid velocity between 0.05 and $0.1 \mathrm{ft} / \mathrm{s}$. 
The liquid fraction in the pipe under these conditions is predicted to be 0.6051 . Using this value, SLUGDYN produces a water-hammer over-pressure of $2,255 \mathrm{ibf} / \mathrm{in}^{2}$ with a duration of

$$
t_{c}:=2 \cdot \frac{21.08 \mathrm{ft}}{a_{w 8}}=0.009708 \mathrm{~s} .
$$

This pressure wave will be reduced by a factor of

$$
s 8=0.6667
$$

when it passes through the tee connection to the 8 -in. line connecting to the 6 -in. valve. The pressure seen at the 6-in. valve should be on the order of

$$
P_{6}:=2255 \mathrm{lbf} / \mathrm{in}^{2} \cdot s 8=1503 \mathrm{lbf} / \mathrm{in}^{2} .
$$

8.6.3.3 Condensation-Induced Formation of A Water Slug in the 4-in. Line. The mechanism causing formation of a water slug in the 4-in. line is similar to that for slug formation in the 8-in. cross-over line if water flows down this line in stratified flow. However, the current understanding is that the 4-in. line is not connected to a significant steam supply at the downstream end, a necessary condition for the formation of a slug that would be driven toward the section of piping containing the 6 -in. valve that failed. Therefore, this case is not considered feasible for the cause of the water hammer. However, condensation induced by water first running down the 4-in. line could act as the trigger to generate a slug in both the 4-in. line and the 8-in. cross-over line.

A slug may accelerate down the 4-in. line if the liquid level in the 8-in. line rises high enough to cover the top of the 4-in. line at the reducer. With no steam source at the downstream end of the 4 -in. line (i.e., the line ends at a valve), the trapped steam bubble would condense rapidiy, accelerating liquid down the line until it strikes the closed end. This process would produce a pressure pulse that would travel back up the 4-in. line to the reducer. If the 8 -in. line has filled with water, a fraction of this pressure pulse would be transmitted into the 8 -in. 1 ine at the reducer; this fraction travels to the location of the tee connecting to the failed 6 -in. gate valve. This scenario would require that the equivalent of a 4-in.-diameter slug the length of the 4-in. line accelerate down the 4-in. line. SLUGDYN has been used to calculate the velocity of this slug and the resulting pressure pulse in the 4-in. line. The magnitude of the pressure pulse in the 1 ine would be $2,477 \mathrm{lbf} / \mathrm{in}^{2}$. When the pressure pulse reaches the tee, only a fraction of the pulse is transmitted into the 8-in. 1ine:

$$
s 48:=\frac{2 \cdot \frac{A_{4}}{a_{w 4}}}{\frac{A_{4}}{a_{w 4}}+\frac{A_{8}}{a_{w 8}}}=0.3948 .
$$


Therefore, the magnitude of the pressure wave transmitted into the 8 -in. line is

$$
\Delta p_{48}:=s 48 \cdot 2477 \mathrm{lbf} / \mathrm{in}^{2}=978 \mathrm{lbf} / \mathrm{in}^{2}
$$

The duration of this pressure pulse would be similar to, but shorter than, the duration of the pressure pulse in case 1 above. Because this pressure pulse is smaller in magnitude and because the first case is likely to occur if this case occurs, the first case is the controlling load. Because both cases can occur (one shortly after the other), some additive effect of the two pressure pulses may occur. No attempt has been made to estimate this effect. Its maximum effect would be the sum of the two pressure pulses, or

$$
p_{\text {add }}:=P_{6}+\Delta p_{48}=2481 \mathrm{lbf} / \mathrm{in}^{2}
$$

Once the 4-in. line and the 8-in. line connected to the failed $6-$ in. gate valve have filled with water, they will drain back into the 8 -in. cross-over line connecting them to the main steam supply line. As they drain, a steam bubble propagates up the 8 -in. Iine connected to the valve and down the 4-in. line. Once the total exposed length of the horizontally stratified interface in both the $8-$ and the 4 -in. Iines reaches a critical value, unstable wave growth occurs and condensation increases sharply. The horizontally stratified water in the 8 -in. cross-over line is swept into a water slug that strikes the tee connecting the 8-in. 1ines, generating a pressure pulse on the order of the pressure pulse given by equation 29 above. The nearly simultaneous impact of a slug in the 4 -in. 1 ine could produce $a$ pressure pulse of $3,824 \mathrm{lbf} / \mathrm{in}^{2}$ in the 4 -in. Iine that would transmit a pulse of

$$
\Delta p_{4 \text { to } 8}:=s 48 \cdot 3824 \mathrm{lbf} / \mathrm{in}^{2}=1510 \mathrm{lbf}, \mathrm{in} \mathrm{n}^{2}
$$

This force, combined with the pressure pulse generated in the 8 -in. cross-over line, could produce a combined effect of

$$
\text { padd2 }:=P_{6}+\Delta p_{4} \text { to } 8=30311 \mathrm{bf} / \mathrm{in}^{2} \text {. }
$$

\subsubsection{Conclusions}

Results of these analyses should be considered approximate, as there are a number of unknowns concerning the conditions in the piping just before the event. Analysis results indicate that the magnitude of the condensationinduced water-hammer over-pressure is in the range of approximately 1,500 to $3,000 \mathrm{lbf} / \mathrm{in}^{2}$ for 0.01 seconds or approximately $1,000 \mathrm{lbf} / \mathrm{in}^{2}$ for 0.37 seconds, depending on its location and the mechanism generating it. Much higher pressure pulses could have occurred if the condensate upstream of MSS-25 did not fill the entire line or if the slug lengths occurring in the 8-in. cross-over line were shorter than those that have been estimated in this analysis. The figures provided in the report can be used to estimate the magnitude and duration of pressure pulses resulting from shorter slug lengths. 
The phenomena that have been analyzed in this report have been demonstrated to occur in scale model tests conducted at the Westinghouse Science and Technology Center in Pittsburgh, Pennsylvania (see Section 8.7).

\subsection{THERMAL-HYDRAULIC EXPERIMENTS}

\subsubsection{Test Facility}

Tests were conducted at the Westinghouse Science and Technology Center (STC) July 12-15, 1993, on a 1/6-scale model of the piping involved in the June 7, 1993, steam 1 ine accident at WHC. The model, which is built of glass tubes (see Figures 8-35 and 8-36) simulates the geometry of the 8- and 4-in. lines shown in the schematics in Figure 8-37. It includes the 8-in. riser, the 21-ft-long, 8-in. south-north cross-over pipe, the 8-in. 1ine joining the 4-in. line through an 8 - by 4 -in. eccentric reducer, and the tee on which was mounted the 6-in. valve that failed. The model includes a gate valve before the 8 -in. riser, simulating the 8 -in. valve that was opened, a steam-bleed valve at the end of the 4-in. line, and another steam-bleed valve at the bottom of the riser.

In the model, water is admitted from a small water reservoir containing enough water to fill twice the volume of the piping. The water is driven from the reservoir by pressurized air kept at a constant set pressure of 2,3 , or $4 \mathrm{lbf} / \mathrm{in}^{2}$. This pressure is maintained by a pressure regulator. The steam, generated by a steam generator, is admitted directly into the simulated 8-in. line through a reducer made to fit the hose of the steam generator.

Two views of the test apparatus are shown in Figure 8-35, a front view through a protective transparent plate, and a side view in Figure 8-36. In the front view, from left to right are the steam generator, the hose connecting the steam generator and the glass tube, the glass test section, a 12-in. scale for measuring the rate of water rise in the riser, a vertical copper water reservoir connected to the water supply and to the house air supply, drain valves and drain pan, and a support structure.

Figure 8-35 shows the simulated 8 - by 4-inch reducer in the glass test section, the steam trap at the bottom of the riser, the pressure transducer at the tee of the failed valve (note that this arrangement for the pressure transducer did not allow the pressure transducer to record reliably, so the pressure transducer was relocated as described below), and a transparent protective plate. At the far left of the figure, the visicorder can be seen; it records the output of the pressure transducer. On top of the visicorder are two digital readout devices that read the water and steam temperatures.

The measurements were taken as follows: by two thermocouples, one at the steam inlet to the simulated $8-i n$. line and a second at the water inlet; by a pressure transducer at the tee, by a video recorder, and by timing the rate of water rise in the vertical riser along a distance of $12 \mathrm{in}$.

The data recorded by the pressure transducer at the time when the video cassette was made are not reliable because the pressure transducer was exposed to fast temperature transients during the condensation and to a direct current (DC) drift. To rectify this problem, the transducer was removed from the tee 
near the failed $6-i n$. valve and a $90^{\circ}$ elbow was installed in its place; a vertical 6-in.-long stainless steel tube, 3/4-in. in diameter, was connected to this elbow, and the transducer was installed at the bottom of this tube. Filling the tube with water protected the transducer from the rapid thermal transients but allowed the pressure pulse to reach the transducer. This modification resolved the thermal transients at the transducer and allowed reliable pressure data to be obtained. High positive pressure pulses can be recorded when the pressure transducer is exposed to a continuous water column. However, when the water column is interrupted by steam or by air bubbles, the high pressure pulse will be dampened by the compression of the bubbles, and the transducer will measure a reduced pressure.

The thermocouple measuring the steam temperature is located near the inlet where the steam enters the simulated 8-in. piping and is affected by the temperature of the water and the condensing steam.

\subsubsection{Test Procedure}

The cold-water storage was filled with water at approximately $72^{\circ} \mathrm{F}$, and was pressurized with a set air pressure of $2-41 \mathrm{bf} / \mathrm{in}^{2}$. When the $501 \mathrm{~b} / \mathrm{h}$ steam generator was turned on, steam flowed for a few minutes through the piping, venting through two bieed valves, one at the bottom of the riser and the second at the end of the simulated 4-in. piping.

Before the water flow was started, the bleed valve at the bottom of the riser was shut, allowing the steam to continue to bleed through the end of the simulated 4-in. piping. Next, the gate valve at the bottom of the riser was opened to allow the water to fill the riser before it flowed into the piping. The rate at which the water rose in the riser varied in the tests from approximately 0.25 to approximately $1 \mathrm{in} / \mathrm{s}$.

The water and steam temperatures were read by digital recorders, the pressure transducer was recorded on a visicorder, and the events were recorded by a video/audio recorder. The test ended when the cold-water storage was emptied. Depending on the water flow rate, the duration of each test was a few minutes.

At the conclusion of each test, the water was drained from the test section, steam flow was resumed through the test section as mentioned above, and a new test was begun.

On occasion, the initial steam temperature and pressure were too high to allow the water to enter the test section, and the test had to be aborted and restarted at a steam temperature close to $214^{\circ} \mathrm{F}$, approximately. Variations in steam temperature and the associated steam pressure affect the flow rate of the water into the test section. Thus, the tests were conducted with a transient water-inlet flow resulting from the transient driving head.

\subsubsection{Test Results}

Eleven tests recorded by video camera were obtained. Five additional tests were conducted with pressure transducer data. of the 11 tests recorded on video, the first five were conducted with a sloping (simulated) 8-in. pipe 
having a rise of 1.25 in. along a 48.75-in. length of tube. Tests 6 through 11 were conducted with a horizontal simulated 8-in. pipe. Two distinct phenomena appeared from these two conditions. For the sloping pipe, the water hammer occurred along the east-west 8- and 4-in. pipes, initiated at the 8- by 4-in. reducer when the reducer was covered with water. Repeated pulses were recorded. The waves traveled back and forth along the 8- and 4-in. piping.

When the 8-in. pipe was horizontal, the condensation event began at the reducer near the steam generator. This reducer does not exist in the prototype, but had to be manufactured into the model to connect the steam line. A better representation of the prototype would have resulted from connecting the 8-in. pipe to an 8-in. tee that, in turn, was connected to the steam generator.

The events that occurred during tests conducted with the pipes horizontal were more violent than those in the tests with the pipes sloping because the slug of water along the north-south 8-in. pipe was accelerated against the tee near the top of the riser.

When the water flow rate was low, the water hammer began in a steamwater stratified pipe, whereas at a high flow rate, the condensation events occurred after the pipe filled with water. Repeated water-hammer pulsations were observed, some of them quite strong.

The data from each test include a video/audio recording, temperatures, air pressure, rates at which water rose in the riser, pressure transducer information (which is unreliable for tests 1 through 11), and piping slope. The pressure data obtained from tests 12 through 16 are reliable, indicating a peak pressure for horizontal piping of approximately $201 \mathrm{bf} / \mathrm{in}^{2}$ and a pulsating frequency of 0.3 to $1 \mathrm{~Hz}$. Three tests (12, 13, and 14) were performed on July 14, 1993, with horizontal piping, at a water fill rate of $0.6 \mathrm{in} / \mathrm{s}, 0.69 \mathrm{in} / \mathrm{s}$, and $0.1 \mathrm{in} / \mathrm{s}$ respectively, and two additional tests (15 and 16) were performed on July 15, 1993, with sloping pipe (1.25-in. rise in 48.75-in. along the 8 -in. north-south pipe). At a very low fill rate of $0.1 \mathrm{ft} / \mathrm{s}$, not much happened. The fill rate in test 15 was $0.67 \mathrm{in} / \mathrm{s}$ and in test $16,0.33 \mathrm{in} / \mathrm{s}$.

In general, the events in tests with sloped piping registered only the negative pressure generated by the condensing steam, whereas with horizontal piping, positive pressures were recorded because of a continuous water column near the transducer. There was one exception, in test 16, when rapid venting through the valve at the bottom of the water reservoir suddenly increased the pressure driving the water and accelerated a water slug into the test section, which in turn generated a positive pressure pulse of approximately $201 \mathrm{bf} / \mathrm{in}^{2}$. The data indicate that the maximum pressure pulse was approximately $201 \mathrm{bf} / \mathrm{in}^{2}$ and that the frequency of pulsation was between $0.3 \mathrm{~Hz}$ and $1 \mathrm{~Hz}$ (time period of 1 to 3 seconds). A corresponding pressure pulse can be estimated from the expression:

$$
\Delta P=C^{\prime} \rho C W
$$

where $\Delta P$ is the magnitude of the pressure pulse; $C^{\prime}$ is a coefficient that depends on the pipe geometry, the steam-water flow pattern at the moment of 
condensation, and the pipe cross section through which the wave is transmitted; $\rho$ is the density of water; $c$ is the acoustic velocity in water $(4,800 \mathrm{ft} / \mathrm{s})$; and $W$ is the velocity of the condensing surface. The data indicate that for $W=2 \mathrm{ft} / \mathrm{s}$ and $C^{\prime}=0.5$, we obtain $\Delta P=64.5 \mathrm{ibf} / \mathrm{in}^{2}$.

For $W=1 \mathrm{ft} / \mathrm{s}$, which is withir the data range, $\Delta P=32.21 \mathrm{bf} / \mathrm{in}^{2}$. This value is within the range of the data and can be matched to the data by changing the coefficient $C^{\prime}$. An estimate of $C^{\prime}$ ' and $W$ for the prototypic conditions would allow extrapolation of the data from the model to the prototype.

The pressure pulses in tests 12,13 , and 14 indicate a negative pressure of 1 tn $2 \mathrm{lbf} / \mathrm{in}^{2}$. These events 1 asted 0.1 and 0.2 seconds. Test 14 shows some s...rious signal that interfered with the pressure pulse. The pressure pulses $i_{1}$ tests 15 and 16 (sloped pipes) show only negative pressures, of a magnitude of approximately $2 \mathrm{lbf} / \mathrm{in}^{2}$.

Other variables that could affect the phenomena are stopping the steam deneration before the introduction of water, closing the bleed valve at the nd of the 4-in. line, and replacing the reducer with a tee at the inlet of the steam generator to the 8 -in. pipe.

\subsubsection{Extrapolation of the Results to the Prototype}

The primary purpose of the testing was to verify whether a given geometry is susceptible to condensation-induced water hammer. The use of these results to predict the magnitude of the pressure pulse would require : carefuliy de-aerated system and steam supply.

Work related to various geometric configurations has been performed by Westinghouse for problems related to steam generators (Roidt 1980). However, this work has not been applied directly to predicting pressure-pulse magnitude. Instead, the results of other experiments with different geometries in which the supply steam was de-aerated have been used for extrapolation. The reason is that the above expression for $\Delta P$, with $C^{\prime}=0.5$, gives the impulse pressure generated by the impact of two columns of water on the assumption that a perfect vacuum exists between the two impacting faces. Although the presence of non-condensible gases in the steam has little effect on the condensing coefficients (Roidt 1980), its presence as a cushion between the two impacting columns of water has a large degrading effect on the magnitude of the maximum pressure wave. For this reason, we predict a maximum pressure-pulse multiplier of approximately 18, yielding a peak pressure pulse, after bubble collapse, of approximately 2,260 $1 \mathrm{bf} / \mathrm{in}^{2}$ in the actual system.

\subsubsection{Conclusions from Tests}

- Condensation-induced water hammer began at the 8- by 4-in. reducer when the 8 -in. south-north pipe was sloped; the pulses travelled along the e-st-west 8- and 4-in. pipes.

- When the south-north 8-in. pipe was horizontal rather than sloped, water hammer occurred in the $\overline{8}-i n$. pipe, and the water siug accelerated against the $8-i n$. tee at the south end of the 8 -in. pipe. 
- The pressure pulses measured indicate a peak positive pressure of approximately $20 \mathrm{lbf} / \mathrm{in}^{2}$ for horizontal piping and a peak negative pressure pulse of approximately $4 \mathrm{lbf} / \mathrm{in}^{2}$ for sloped piping.

- The presence of non-condensible gases in the system makes it difficult to extrapolate the measured pressure pulses to prototypic conditions. Instead, the magnitude of the prototypic pressure pulse was estimated from the work of others; the tests verified that condensation-induced water hammer did occur.

- The magnitude of the pressure pulses caused by condensation-induced water hammer is drastically reduced in the presence of non-condensible gases. Introducing non-condensible gases into the actual system may be one way to reduce the peak pressures anticipated when condensation-induced water hammer is of concern.

\subsection{CONCLUSIONS}

This evaluation led to the conclusion that the probable initiator of this accident was a condensation-induced water hammer exacerbated by a thermal transient in the cast-iron valve. 
WHC-EP-0667

Figure 8-1. Plan View of Piping in U-3 Valve Pit.

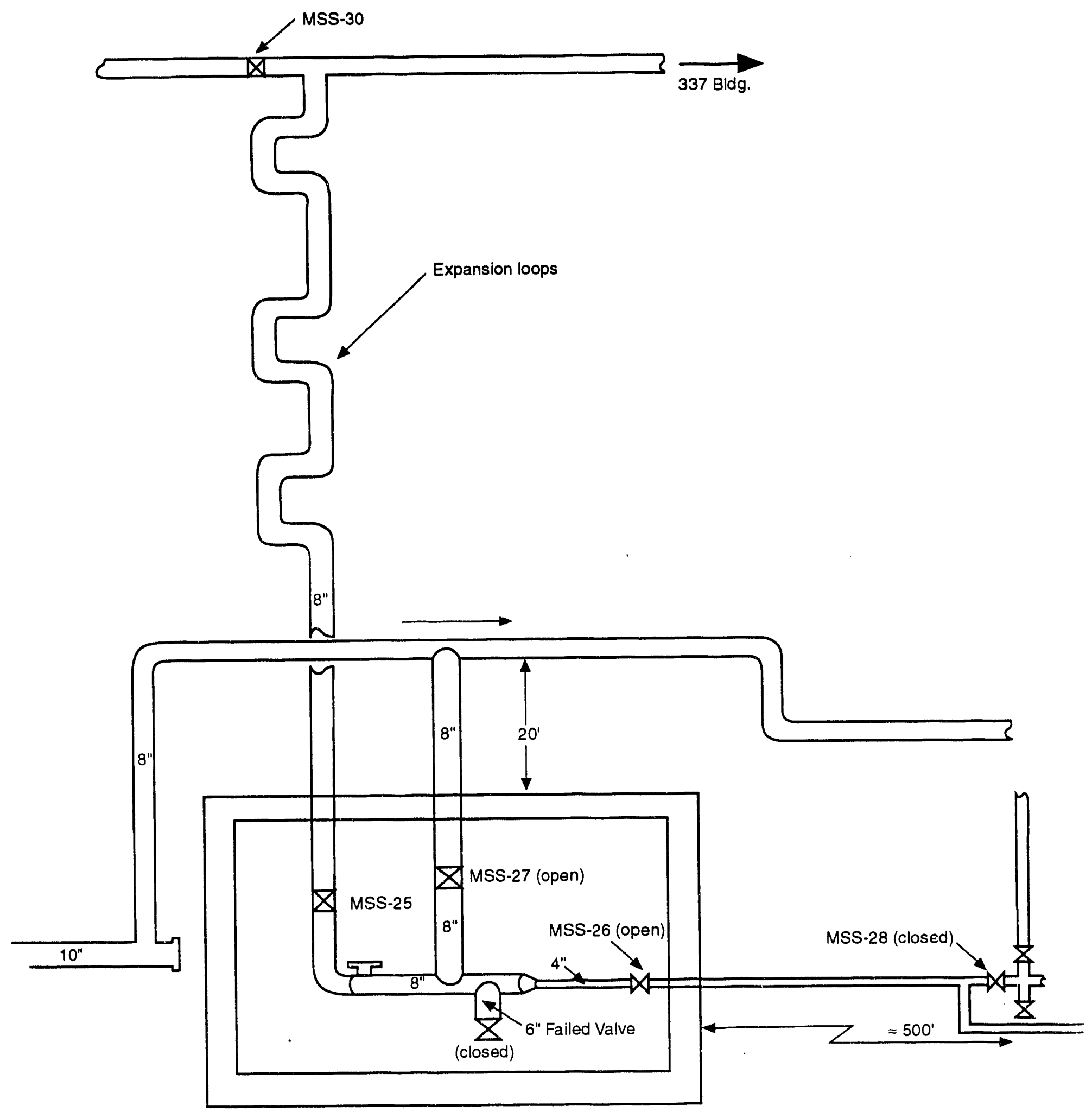

79307065.1 
Figure 8-2. Valve Line-Up Before Accident, June 7, 1993.

See Detail 'A'

Drawing No. 1 of 4

Valve line up prior

to $\approx 7: 18 \mathrm{pm}$

accident on $6 / 7 / 93$

All four valves

ocated in $12 \mathrm{ft}$

shaliow pit at 331
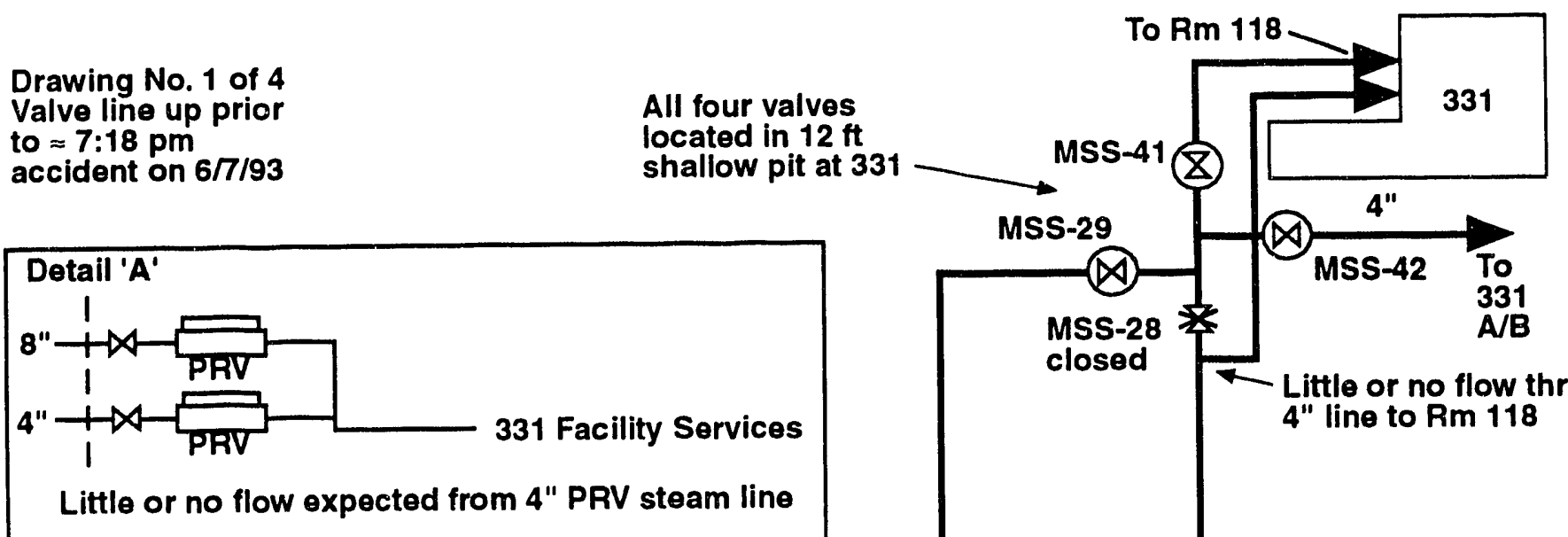

Tittle or no flow thru closed

4 " line to Rm 118

To Bldg. 337

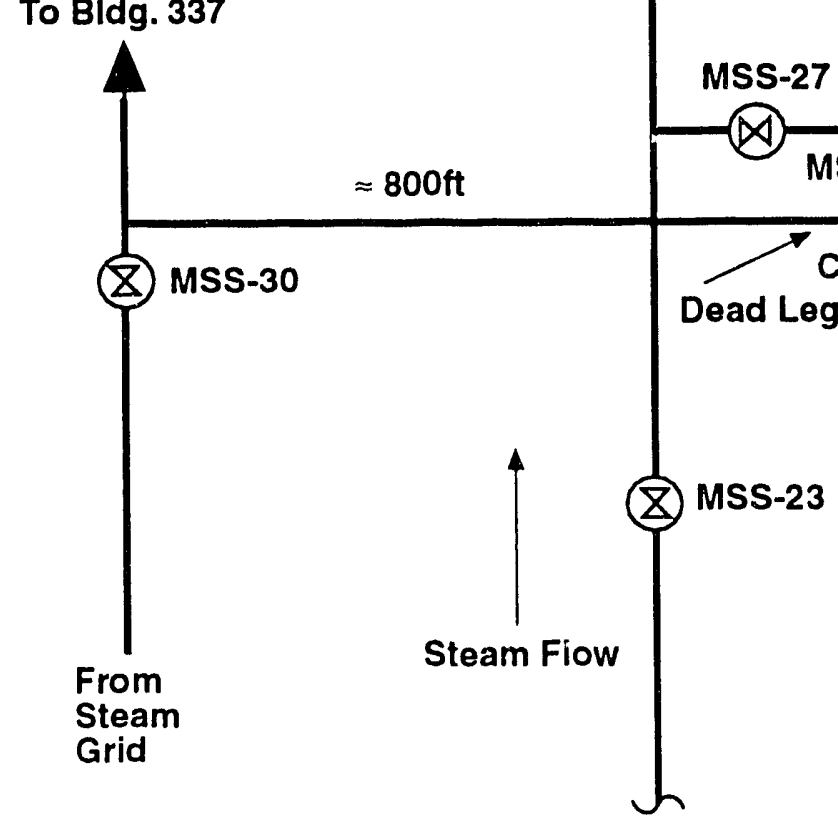

All valves located in

Flow to 331

estimated at

$2000 \mathrm{lb} / \mathrm{hr}$

U-3 valve pit

From Steam Grid

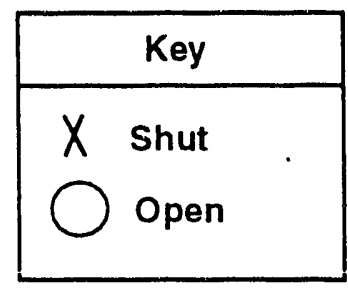

Ref: WHC Drawing H-3-60706

79307065.8 
Figure 8-3. Valve Line-Up at Time of Accident $(\approx 7: 18 \mathrm{p.m.})$.

Drawing No.2 of 4

Valve line-up at time of accident

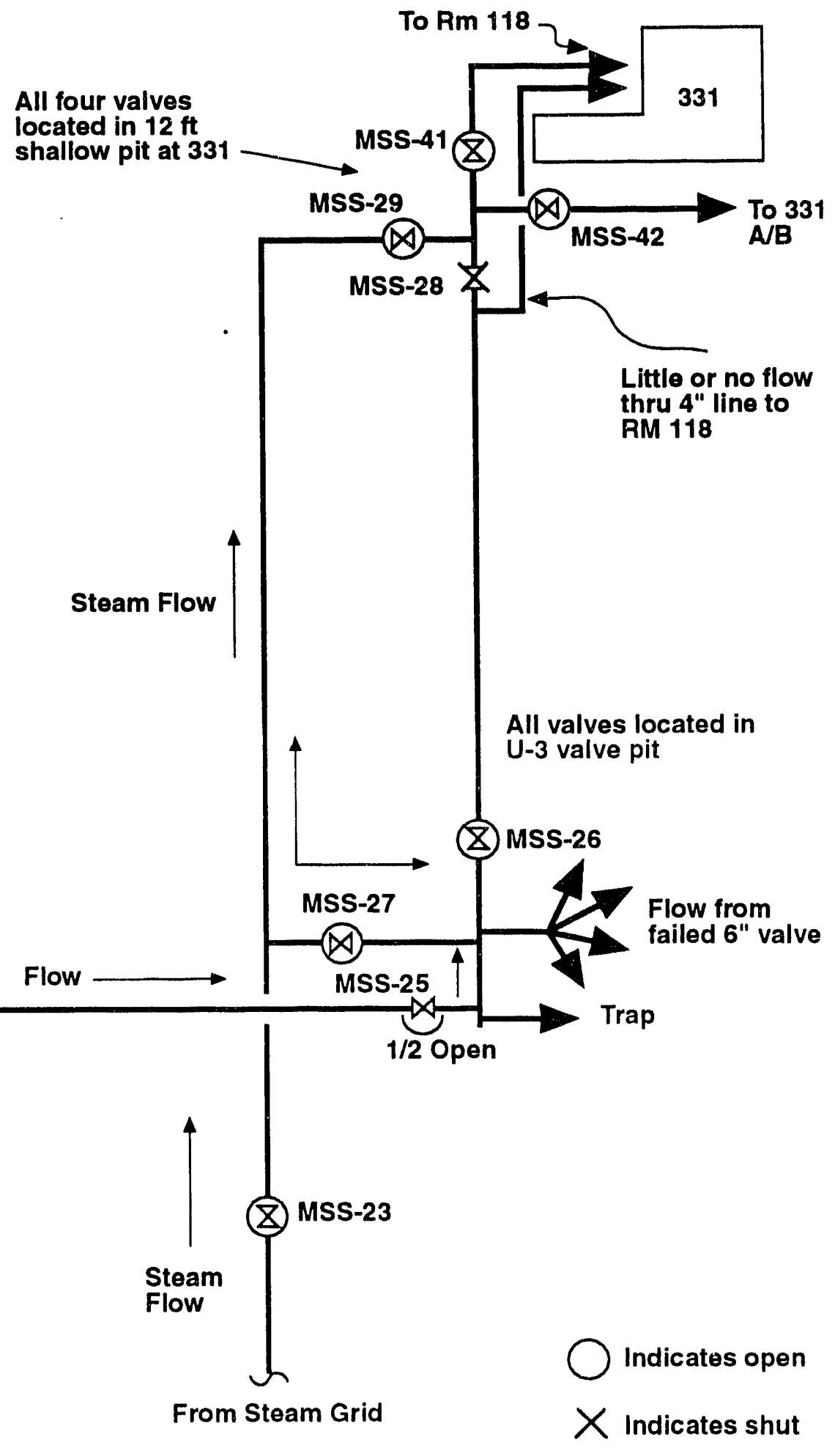


Figure 8-4. First Attempt to Isolate Valve After Accident.

Drawing No.3 of 4

First valve isolation attempt after accident

NOTE:

Valves MSS-30 and 23 were shut $\approx 20$ to 30 minutes after accident. They were not Lock and Tagged until graveyard shift. (A shift)
To Bldg. 337

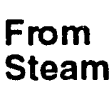
Steam

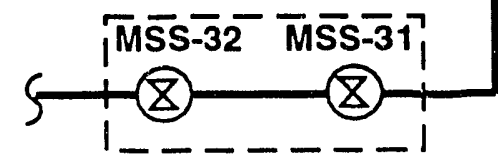

Ref: WHC Drawing H-3-60706

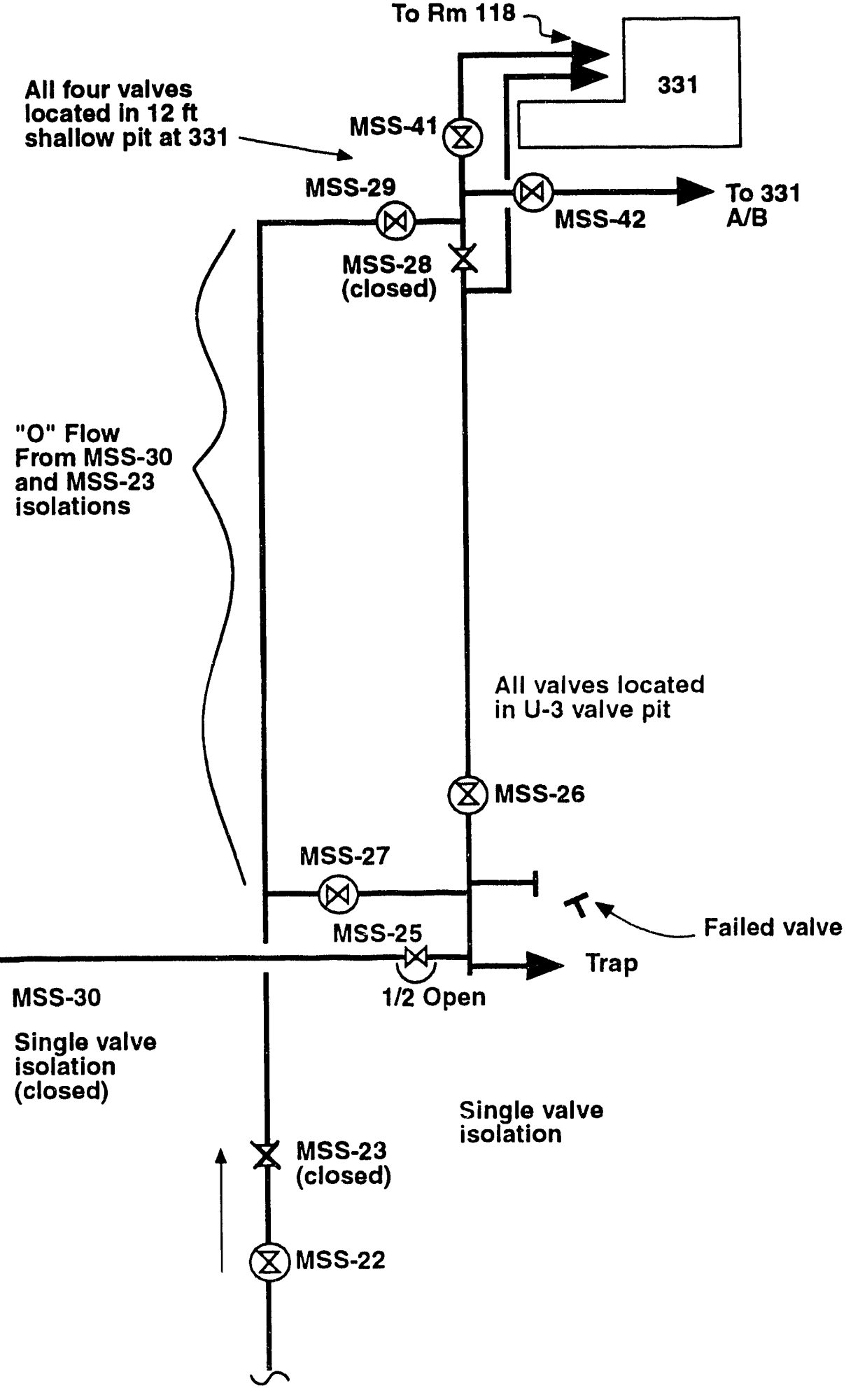

From Steam Grid 
Figure 8-5. Final Isolation of Valve After Accident.

Drawing No. 4 of 4

Final valve

isolation after

accident

Note:

Valves MSS-22 and MSS-31 were added to

lock and tag during day shift on $6 / 8 / 93$ to achieve two valve isolation - in

preparation for U-3 entry at later time

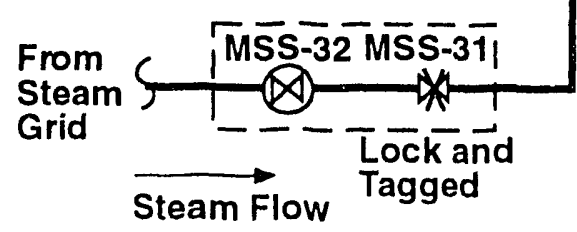

Ref: WHC Drawing H-3-60706

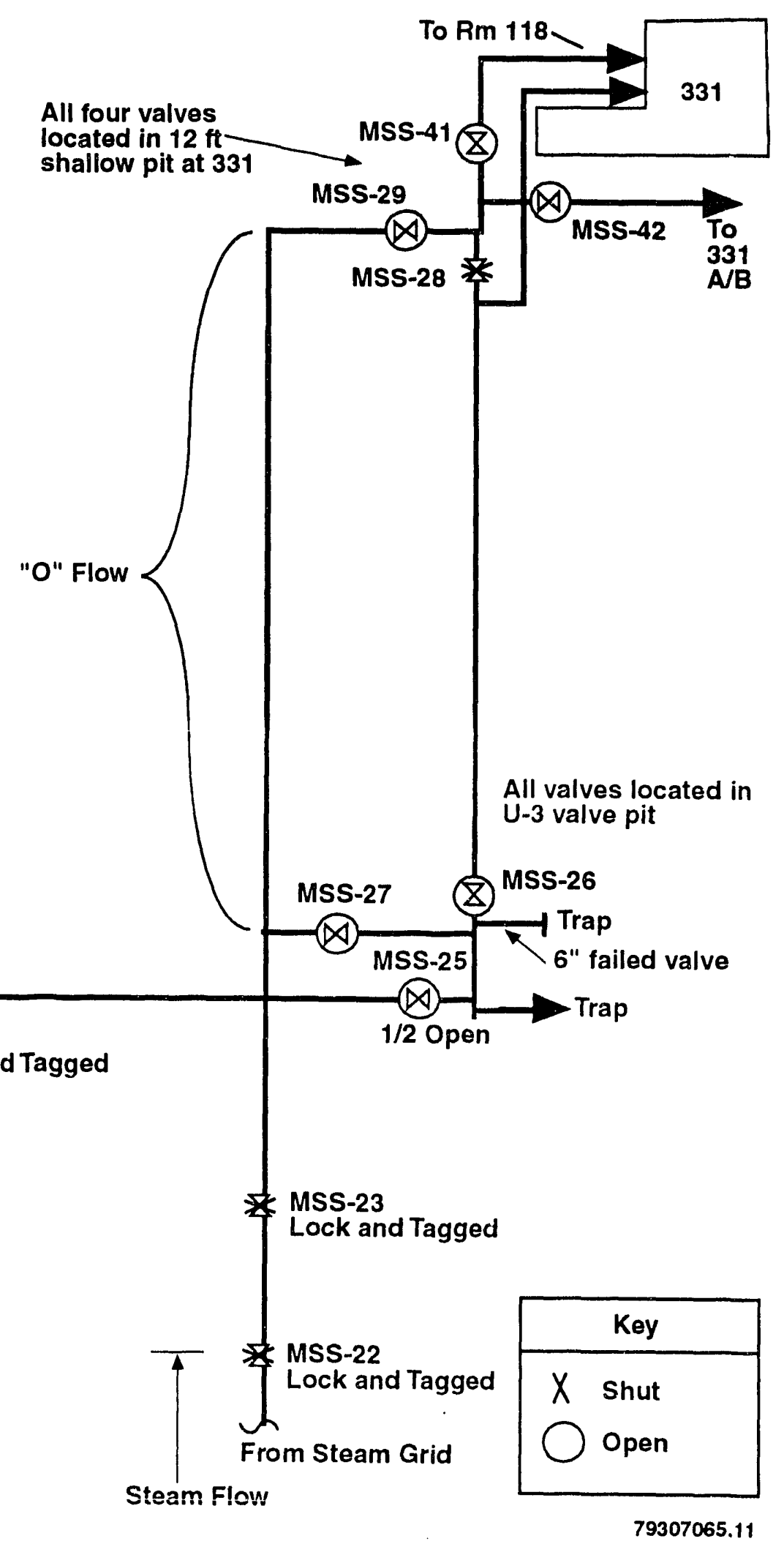




\section{WHC-EP-0667}

Figure 8-6. Steam Pressure in Pipeline Before Valve Failure.

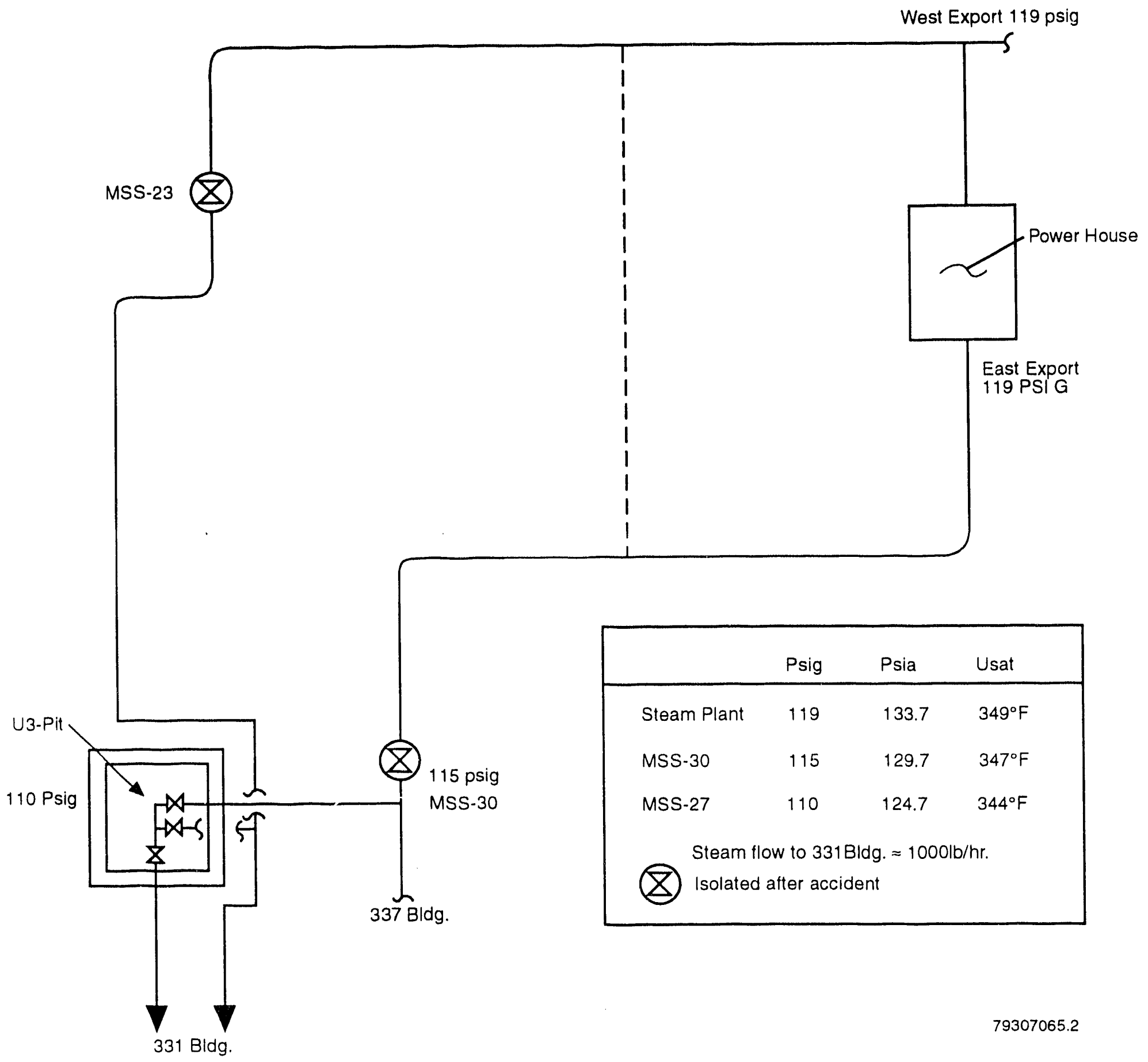


Figure 8-7. Schematic Illustrations of a Condensation-Induced Water Hammer. (Illustrations a through $\mathrm{g}, 4$ sheets)

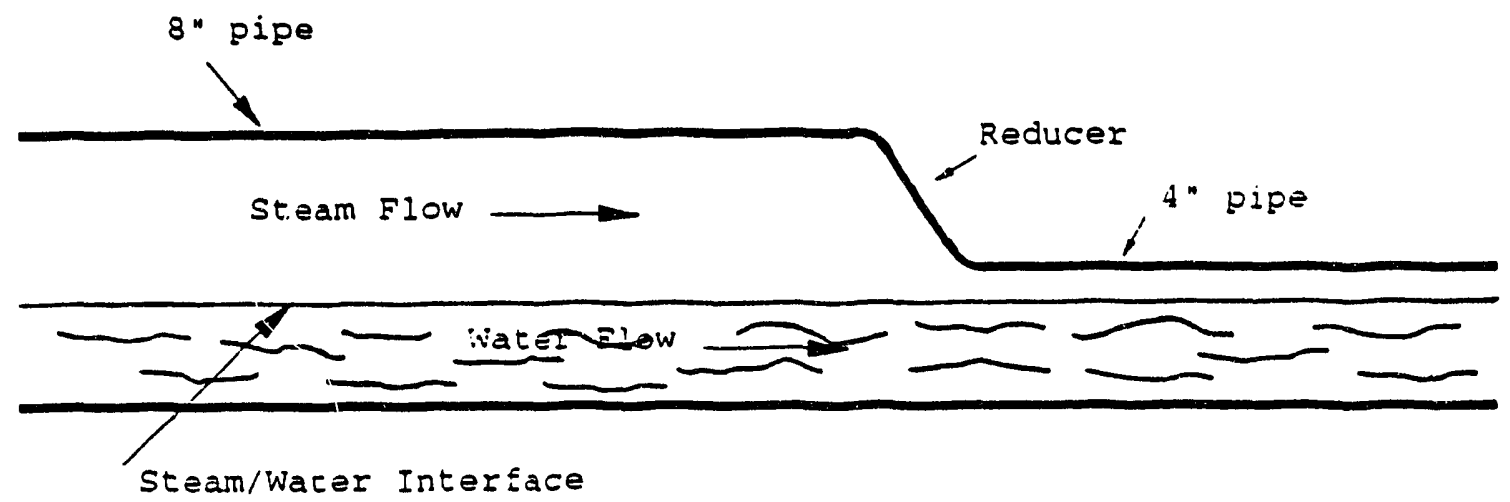

(a) Initial Stratified Flow in Piping.

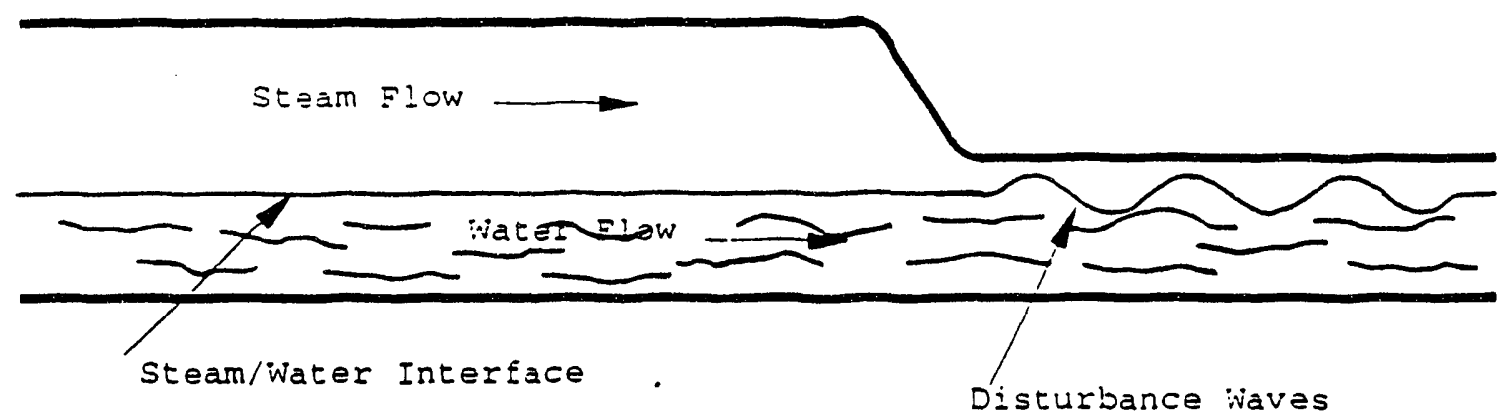

(b) Initiation of Disturbance Waves. 
Figure 8-7. Schematic Illustrations of a Condensation-Induced Water Hammer. (cont)

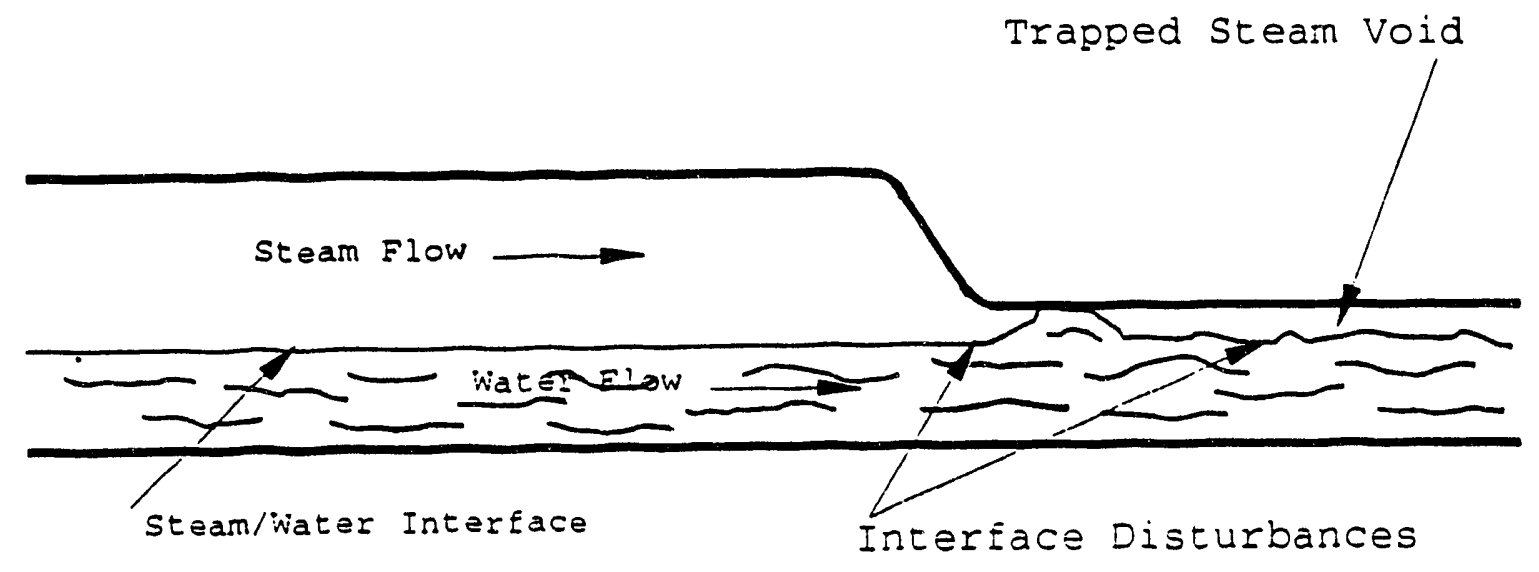

(c) Unstable Wave Growth.

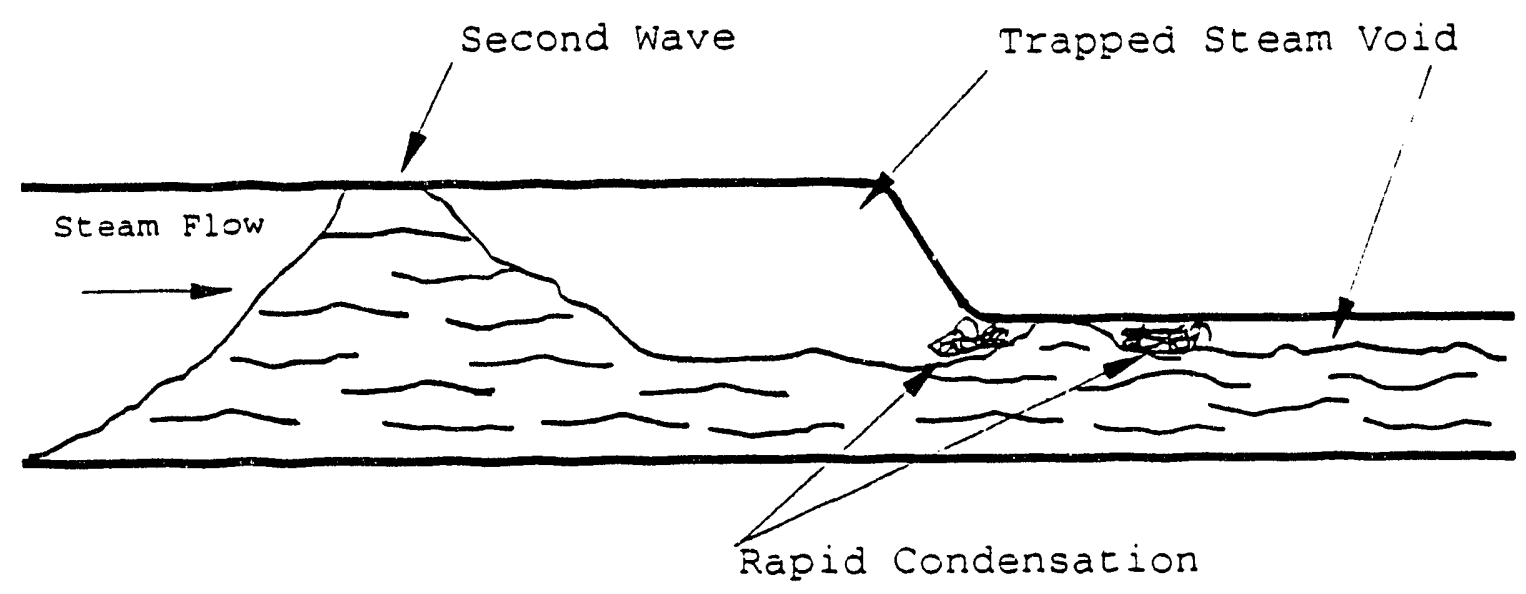

(d) Slug Formation. 
Figure 8-7. Schematic Illustrations of a Condensation-Induced Water Hammer. (cont)

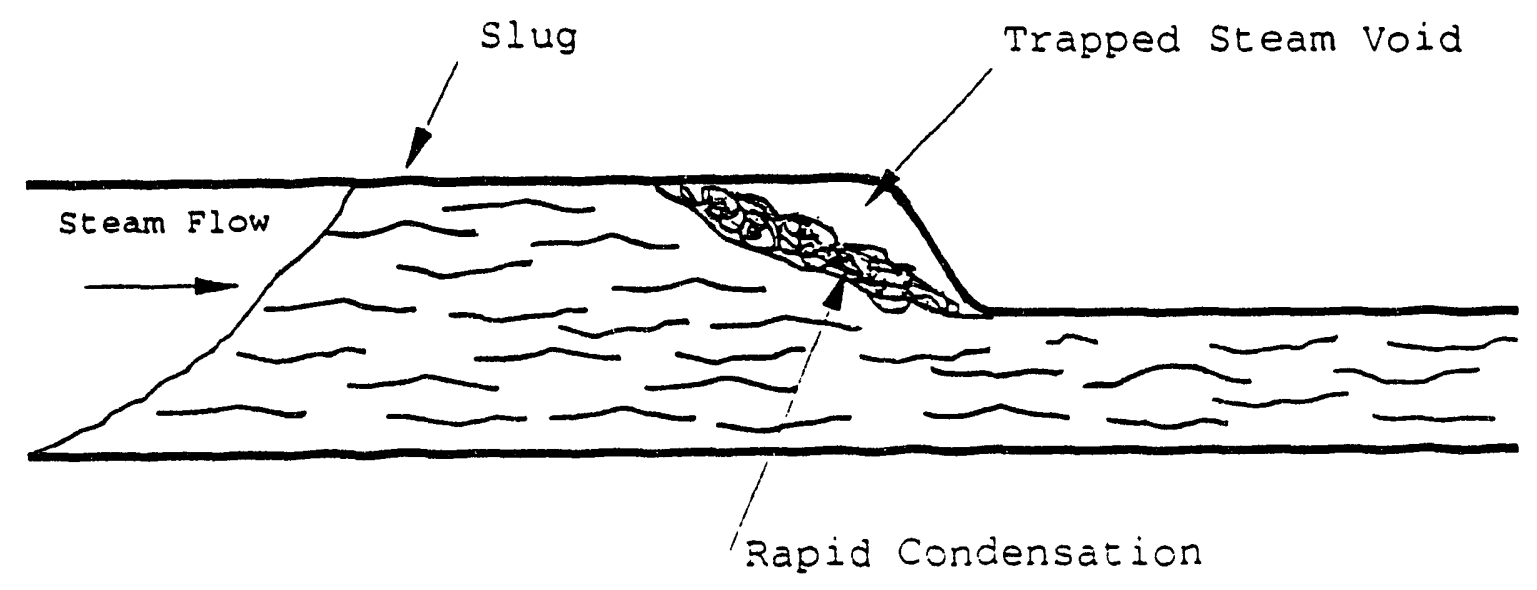

(e) Slug Growth and Acceleration.

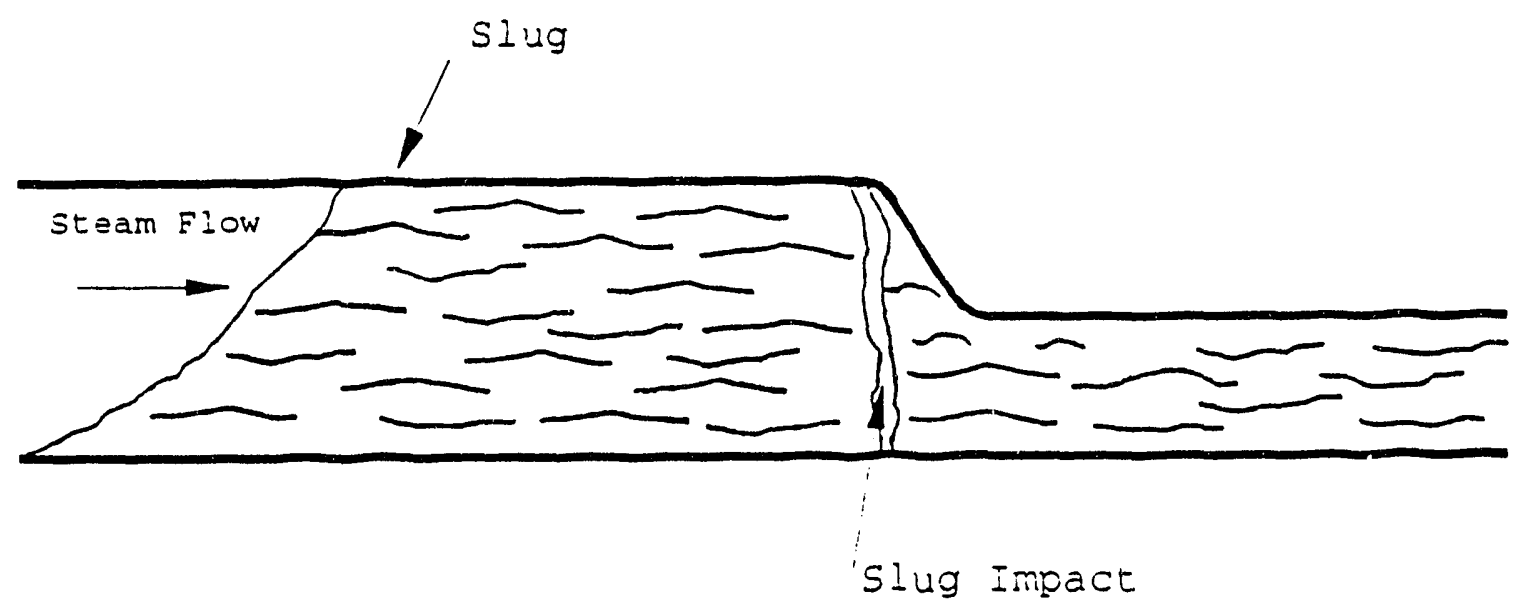

(f) Slug Impact and Pressure-Pulse Generation. 
Figure 8-7. Schematic Illustrations of a Condensation-Induced Water Hammer. (cont)

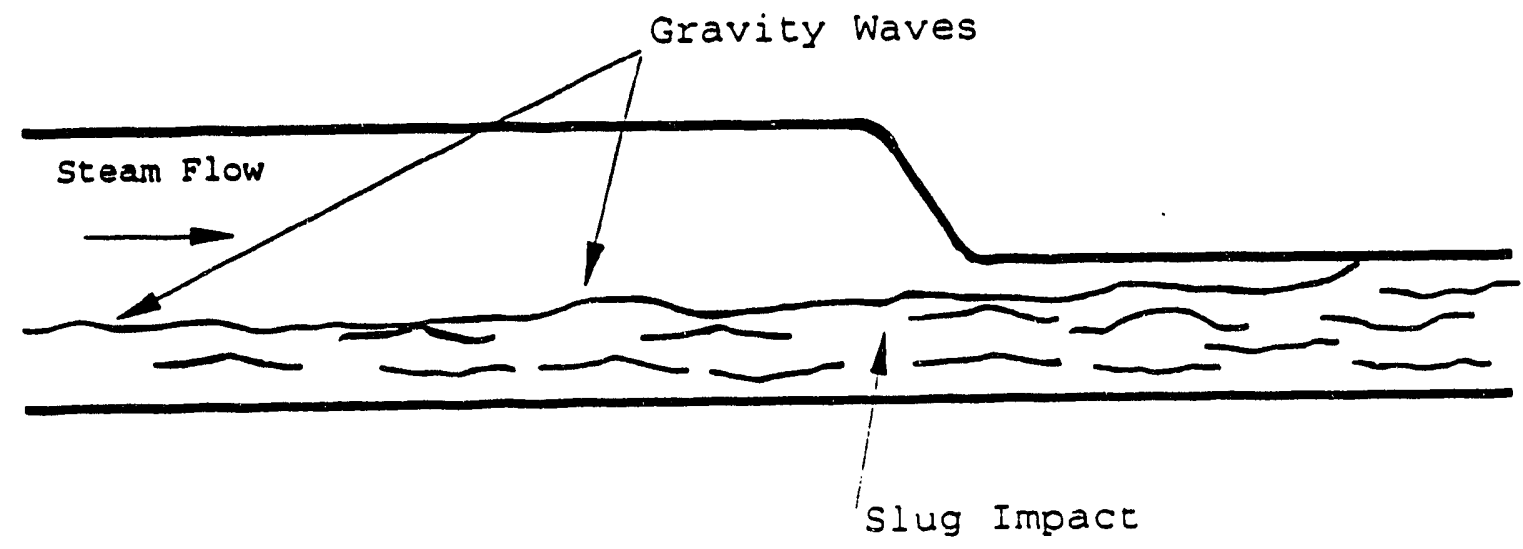

(g) Slug Decay. 
Figure 8-8. Summary of Calculations Estimating Condensation.

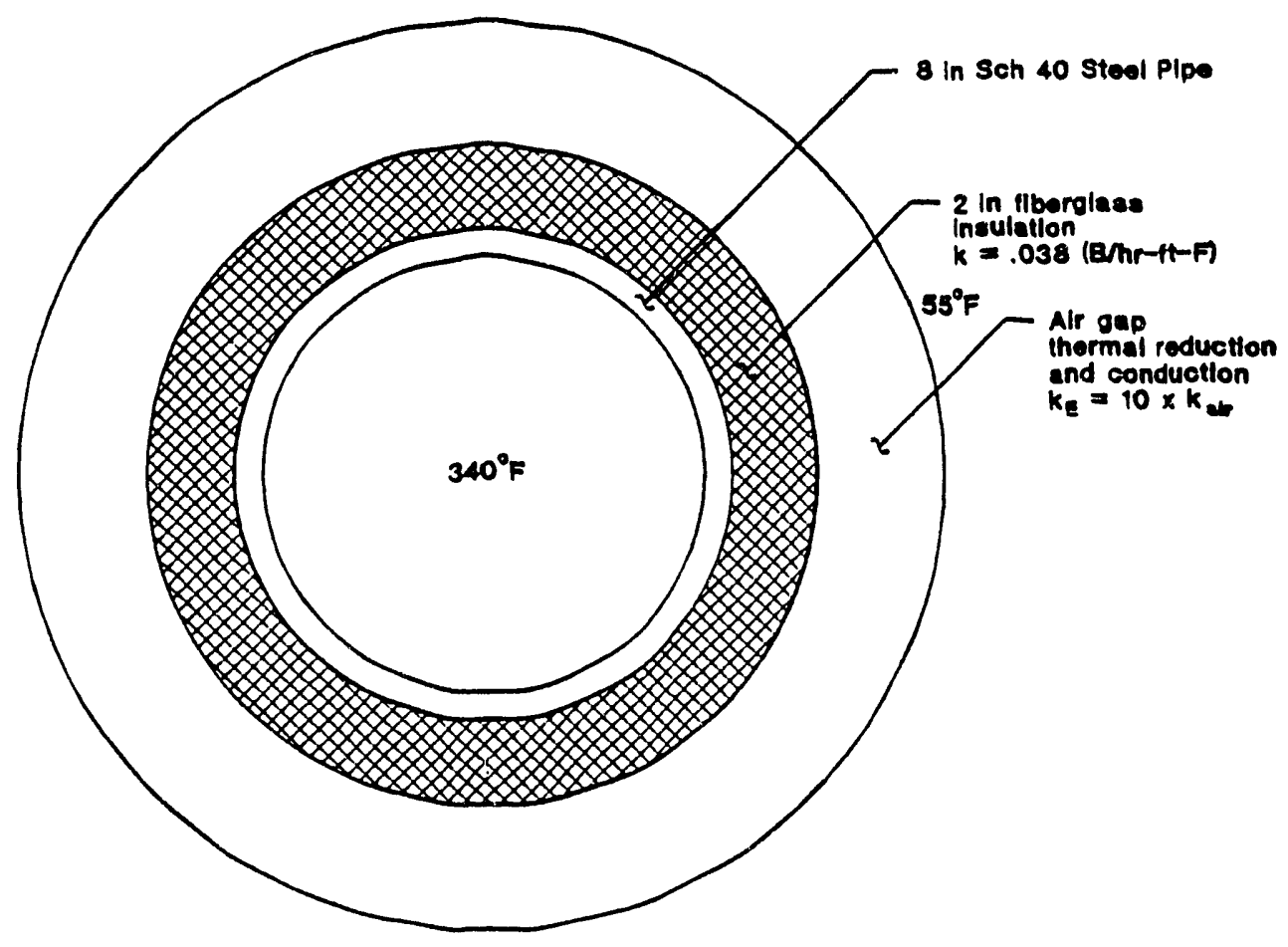

Heat Loss $=167 \mathrm{Btu} / \mathrm{h} / \mathrm{ft}$

Assume steam condensate in a $15 \mathrm{ft}$ length

Heat loss for condensate $=167 \times 15=1754 \mathrm{Btu} / \mathrm{h}$

Steam at $115 \mathrm{lbf} / \mathrm{in}^{2}$ (gauge) (130 $\mathrm{lbf} / \mathrm{in}^{2}$ (absolute))

$h_{f g}=873 \mathrm{Btu} / \mathrm{lb}$

pounds condensate $=1754 / 873=2.1 \mathrm{lb} / \mathrm{h}$

Monthly rate $=2.1(24)(30)=1512 \mathrm{lb} /$ month

$=\frac{1512}{62}=24.4 \mathrm{ft}^{3} /$ month

Volume in 8 " pipe $/ \mathrm{ft}=0.35 \mathrm{ft}^{3} / \mathrm{ft}$

Fill rate $=24.4 / .35=70 . \mathrm{ft} /$ month

In 9 months $70(9)=630 \mathrm{ft}$

Total water $=0.35(700)=245 \mathrm{ft}^{3}$

$$
=\frac{245}{.134}=1840 \mathrm{gal}
$$


Figure 8-9. Flow Rate, Valve MSS-25.

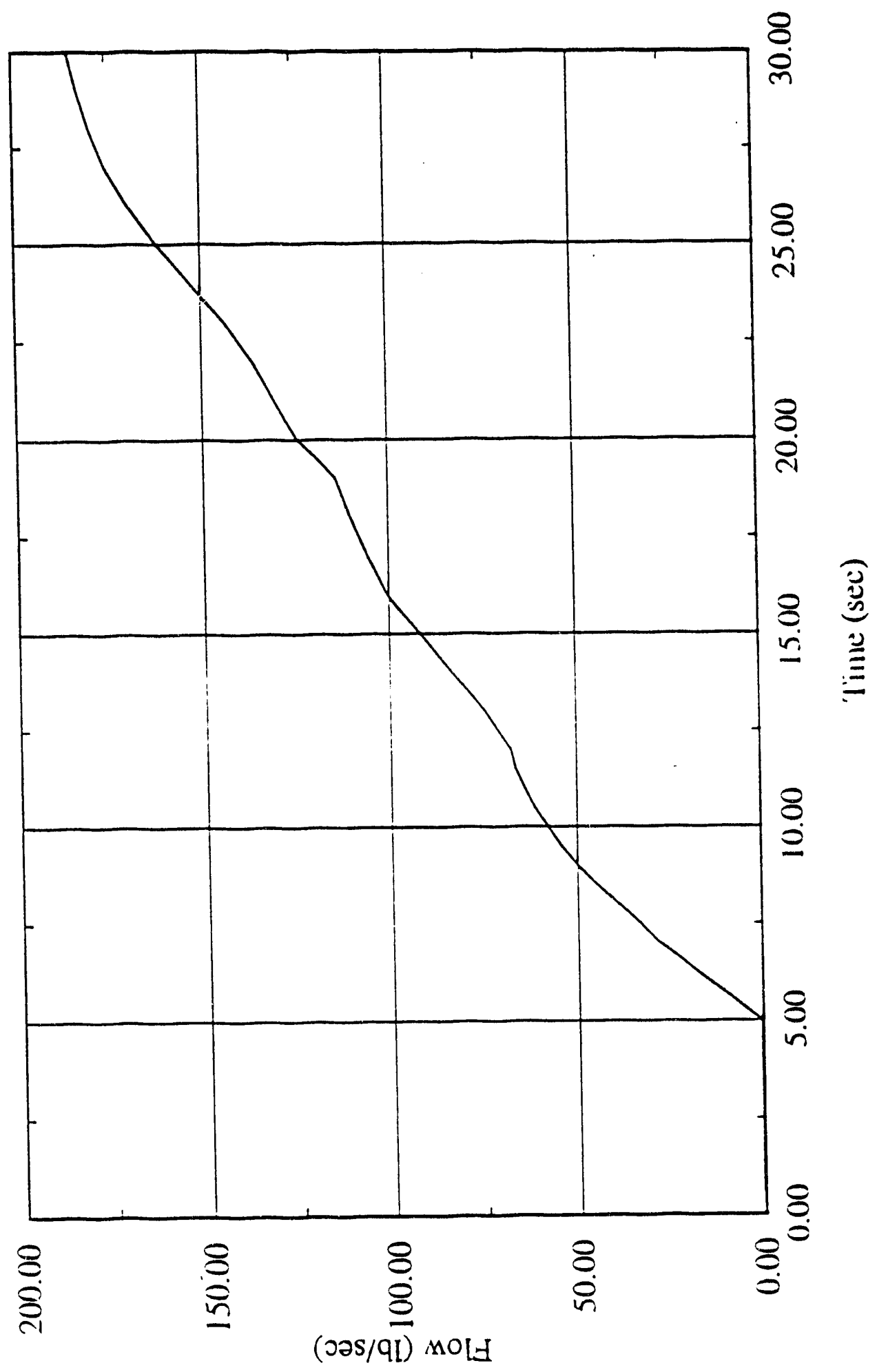


Figure 8-10. Fluid Density at Location of Failed Valve.

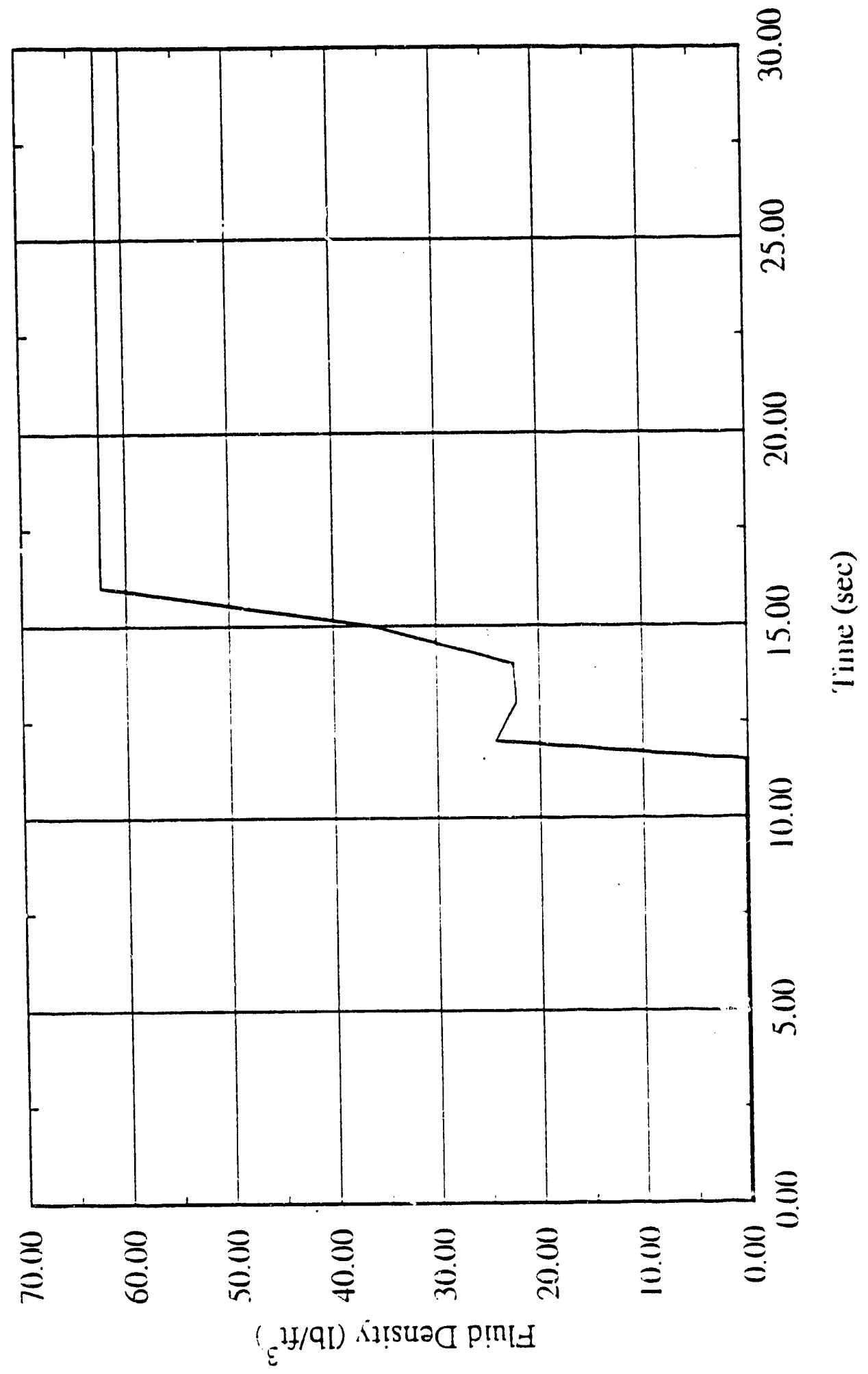


Figure 8-11. Flow Rate, Failed Valve Location.

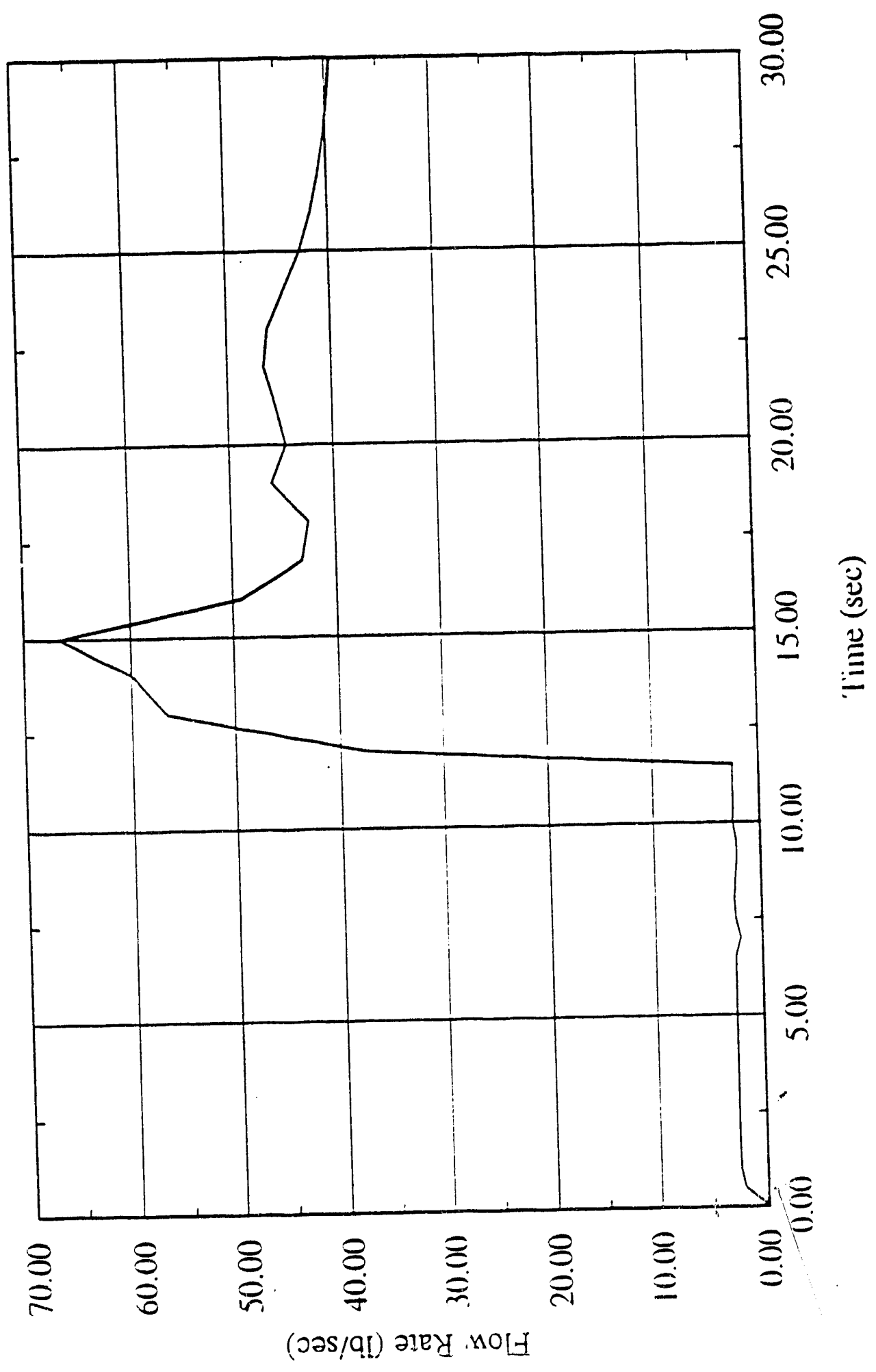


Figure 8-12. Hydrodynamic-Volume Temperature Transient at Failed Valve Location.

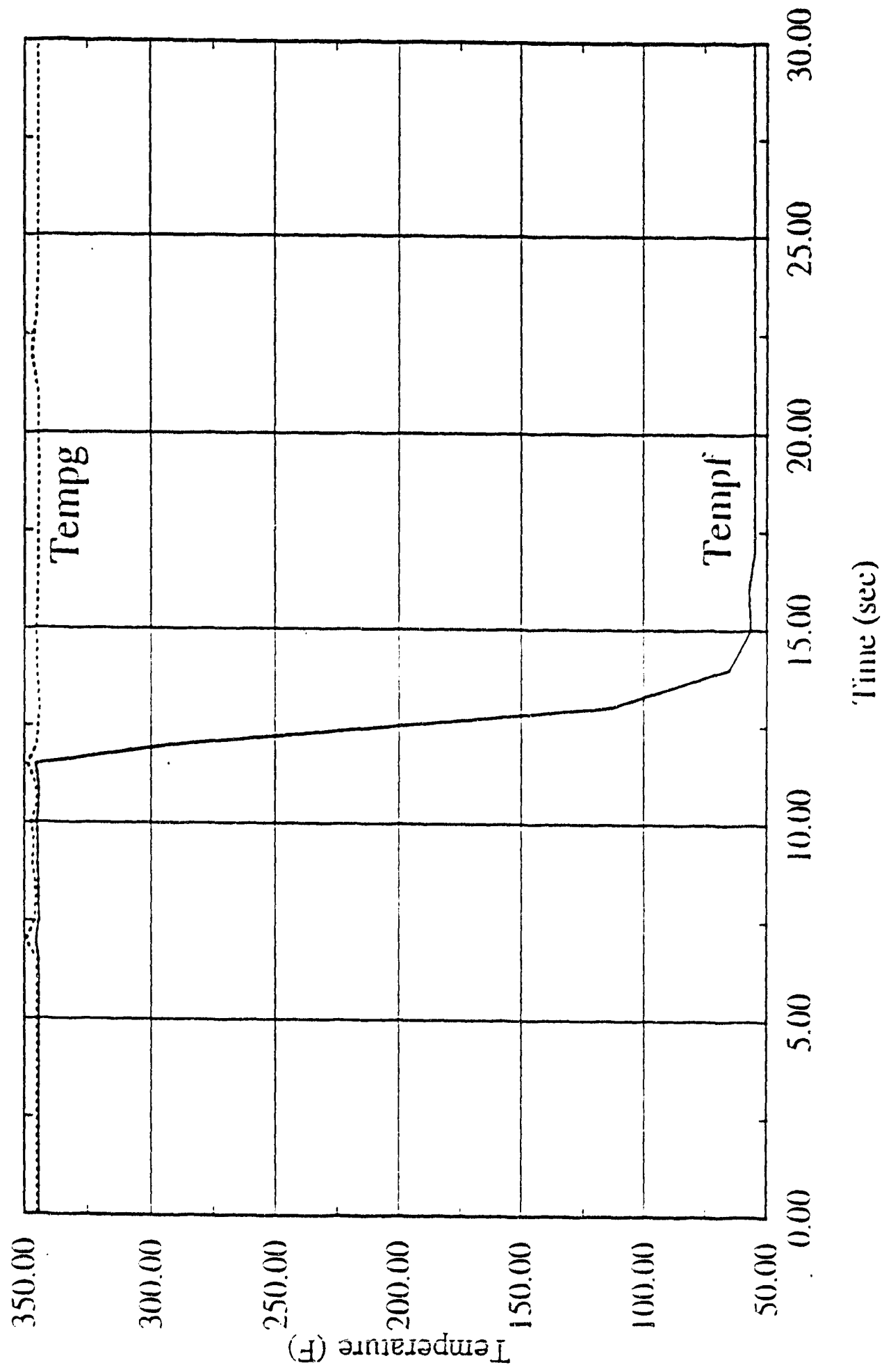


Figure 8-13. Pressure of Hydrodynamic Volume at Failed Valve Location.

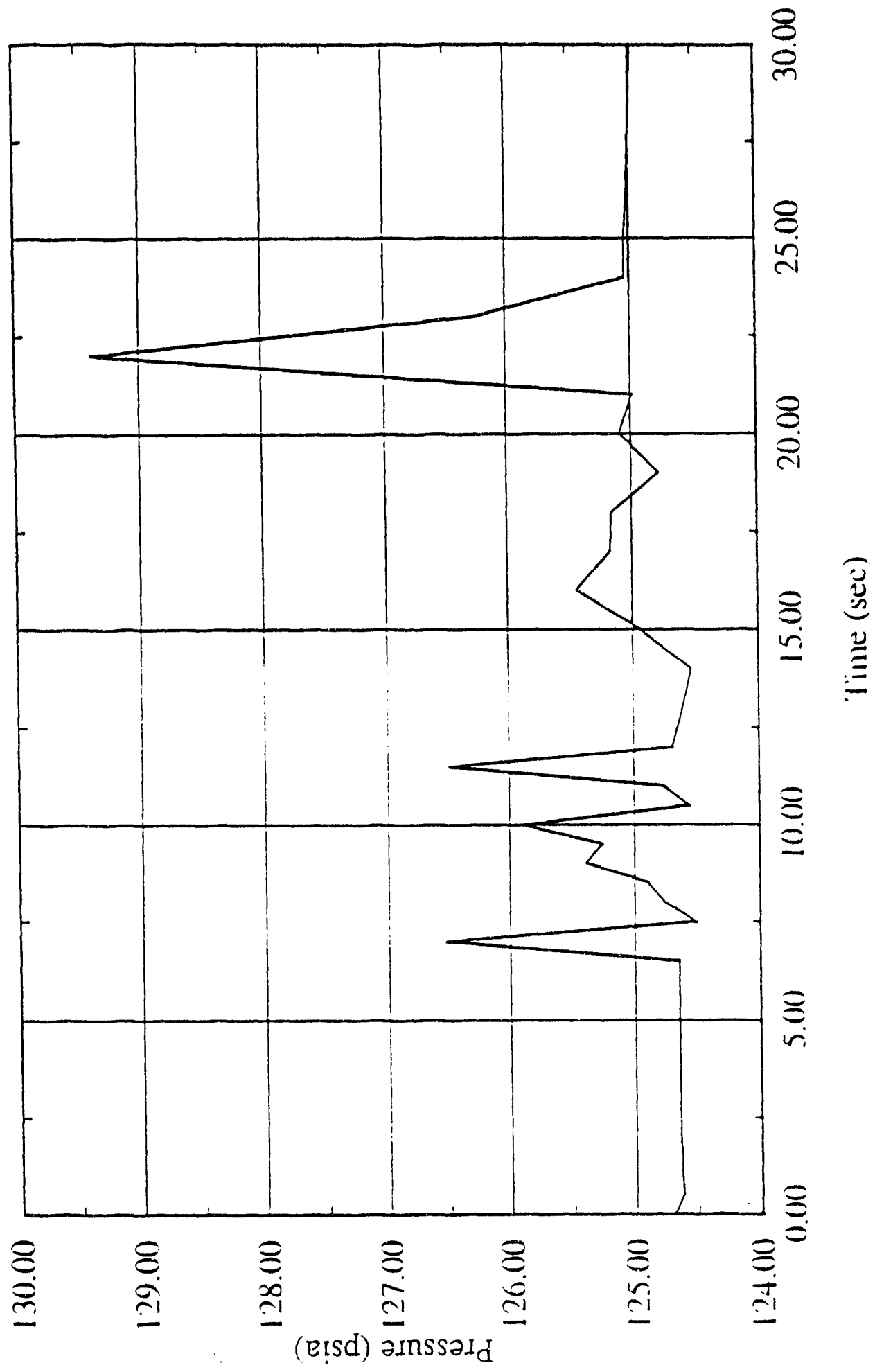


Figure 8-14. Phase Velocities at Fluid Junction Upstream of Hydrodynamic Volume.

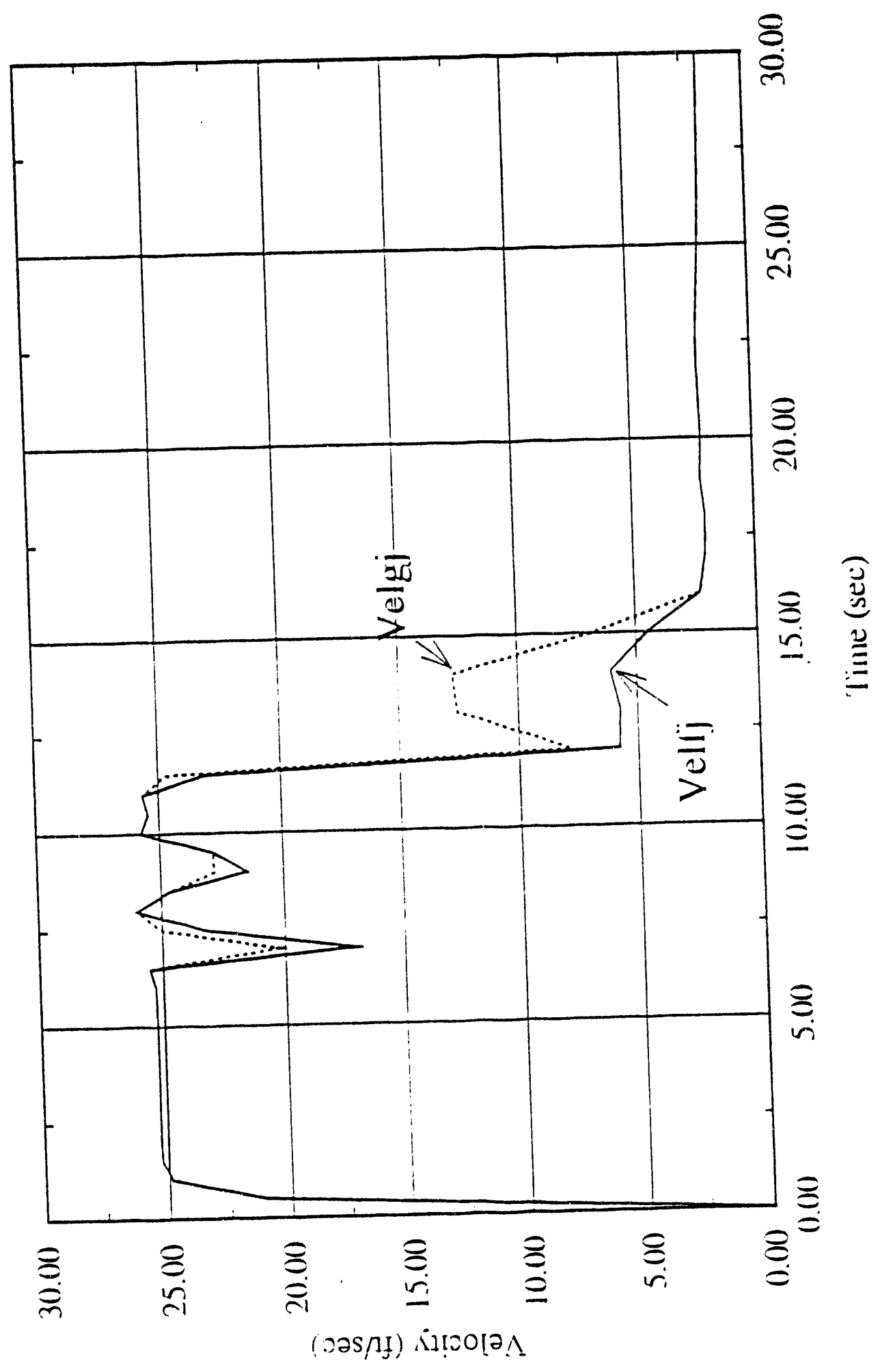


Figure 8-15. Liquid and Vapor Void Fractions of Hydrodynamic Volume.

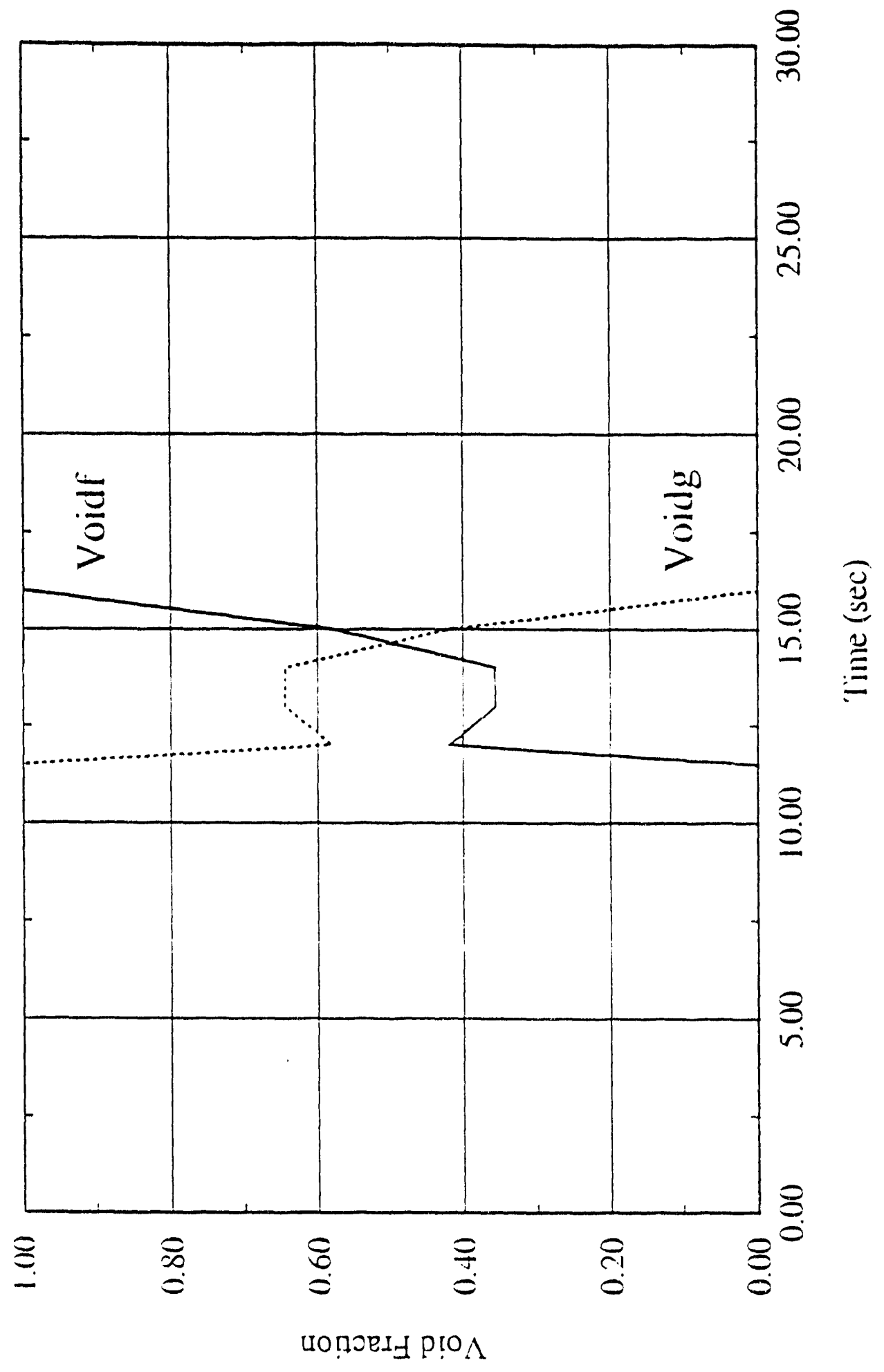


Figure 8-16. Transient Thermal Response of Valve Body at Failure Location.

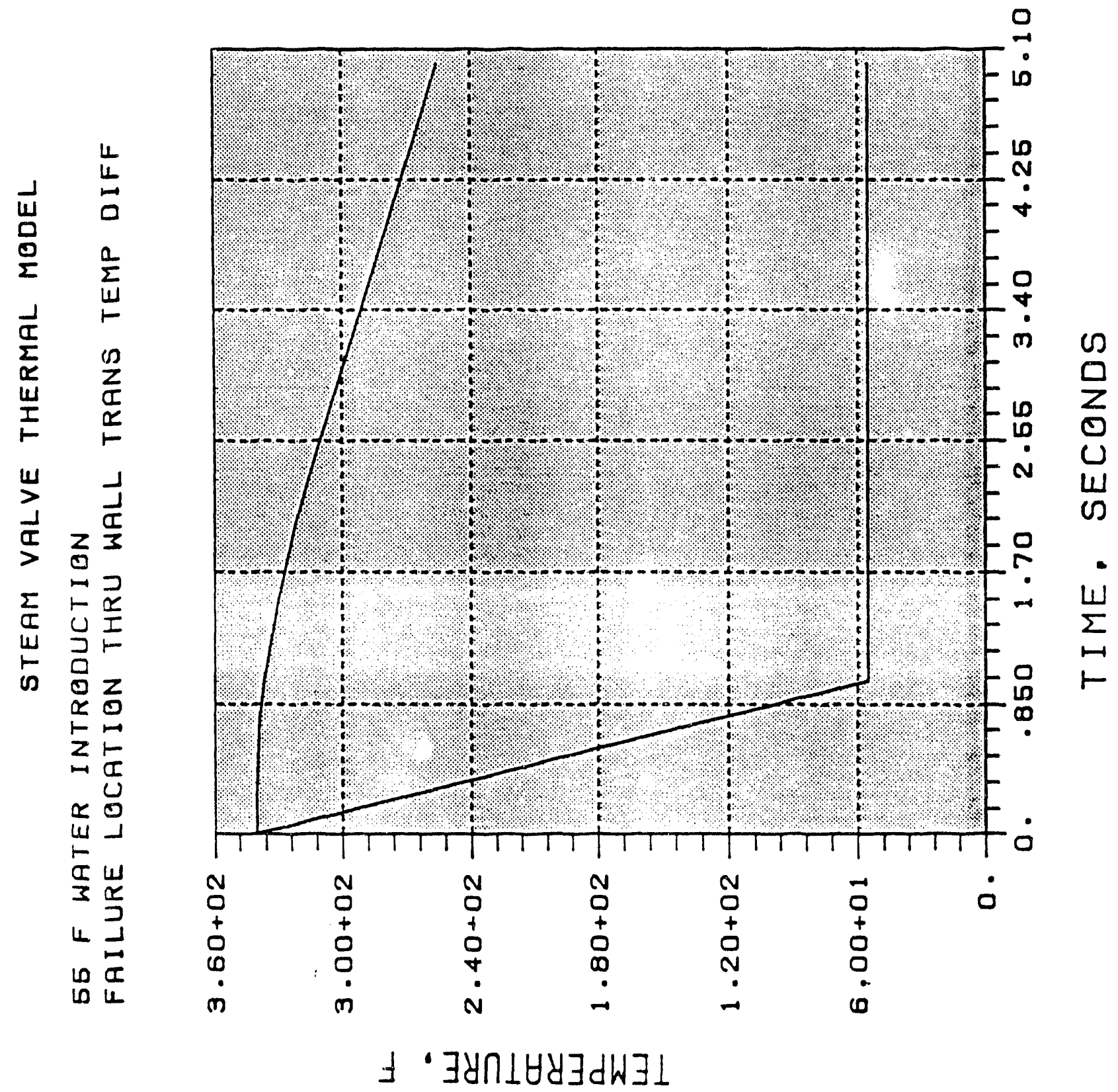


Figure 8-17. Gray Scale Representation of Temperature Distribution at Valve Failure Location at Times 1.0 second.

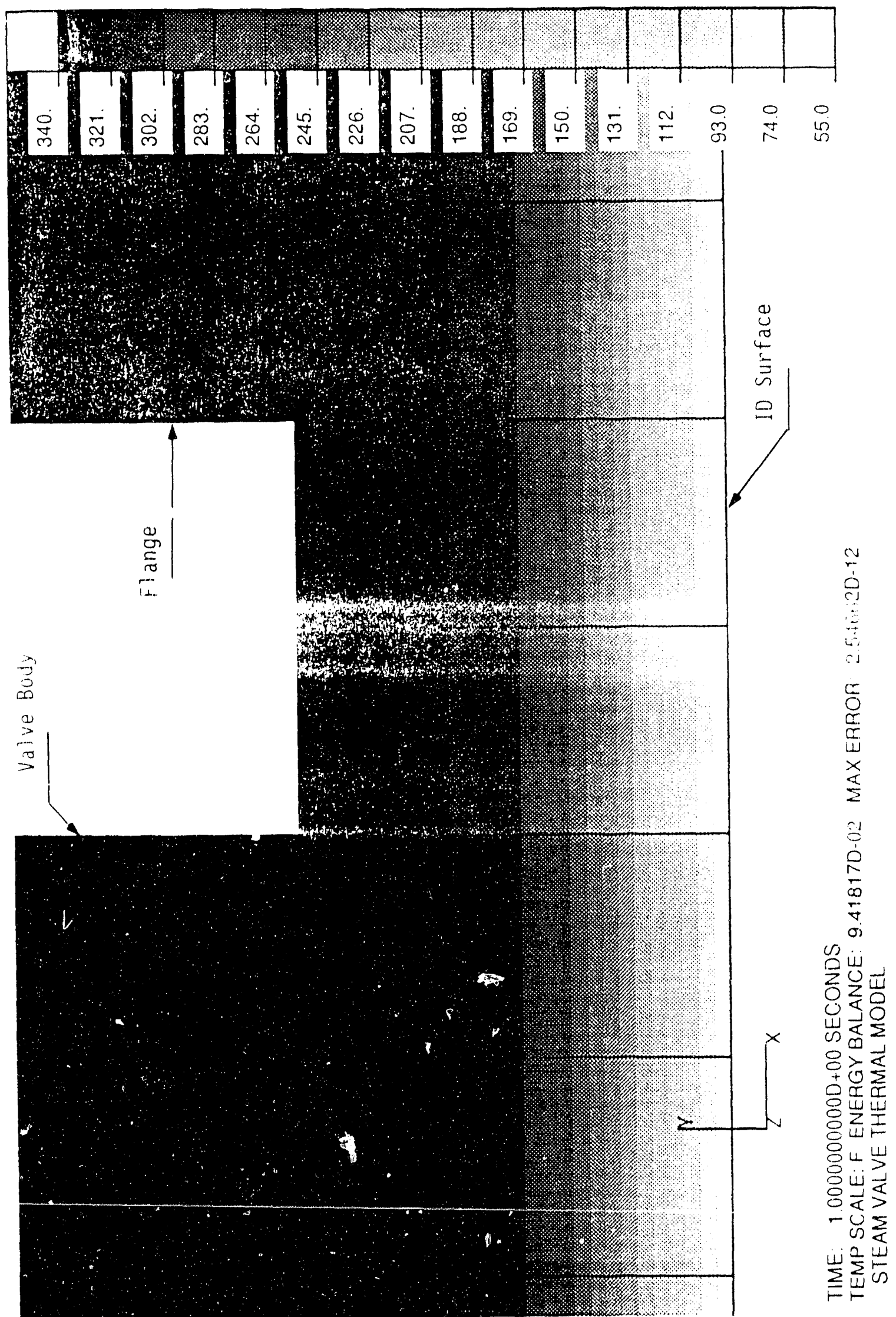


Figure 8-18. Transient Temperatures at Failure Location (First 5 seconds).

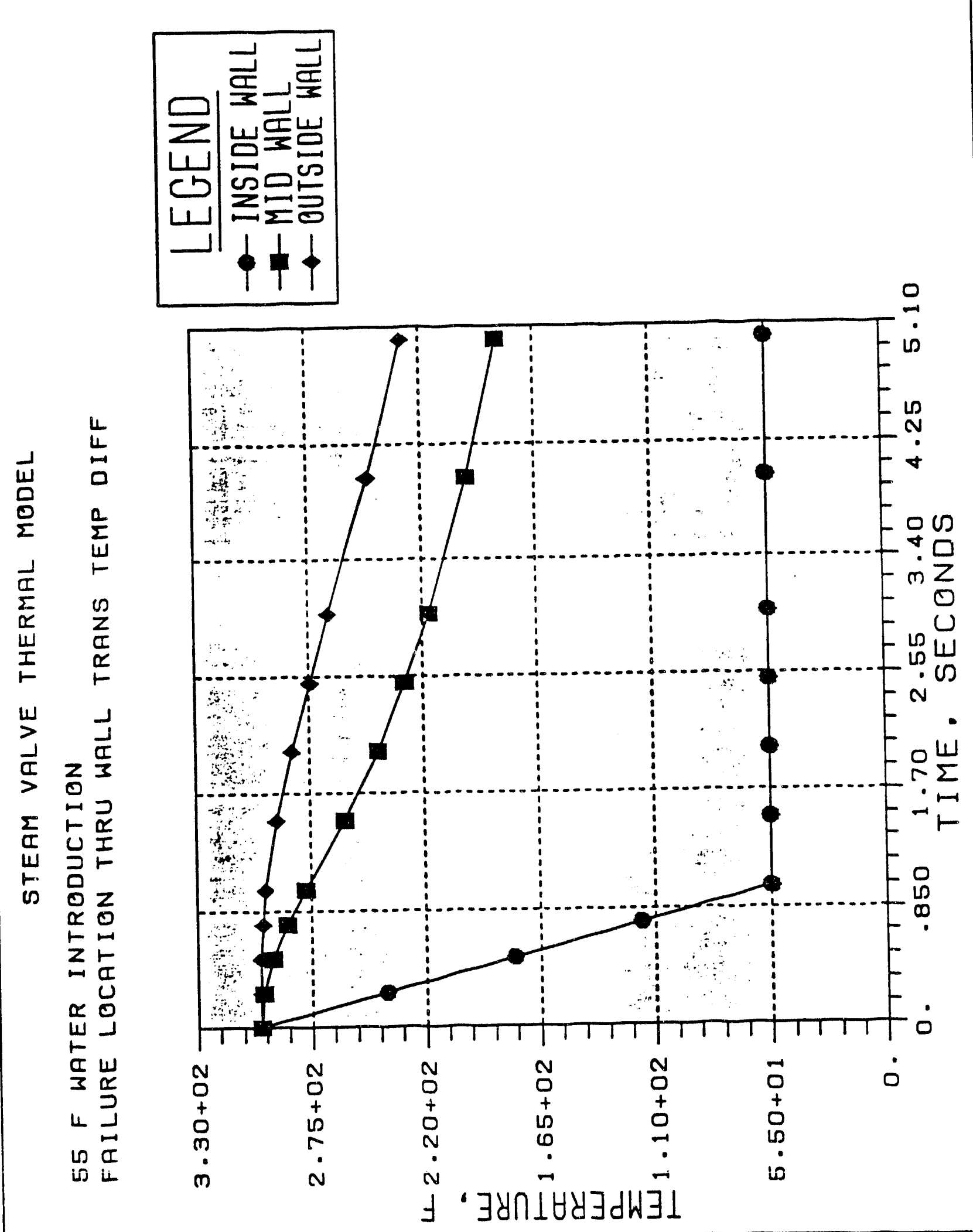


Figure 8-19. Transient Temperatures at Failure Location (First 60 seconds).

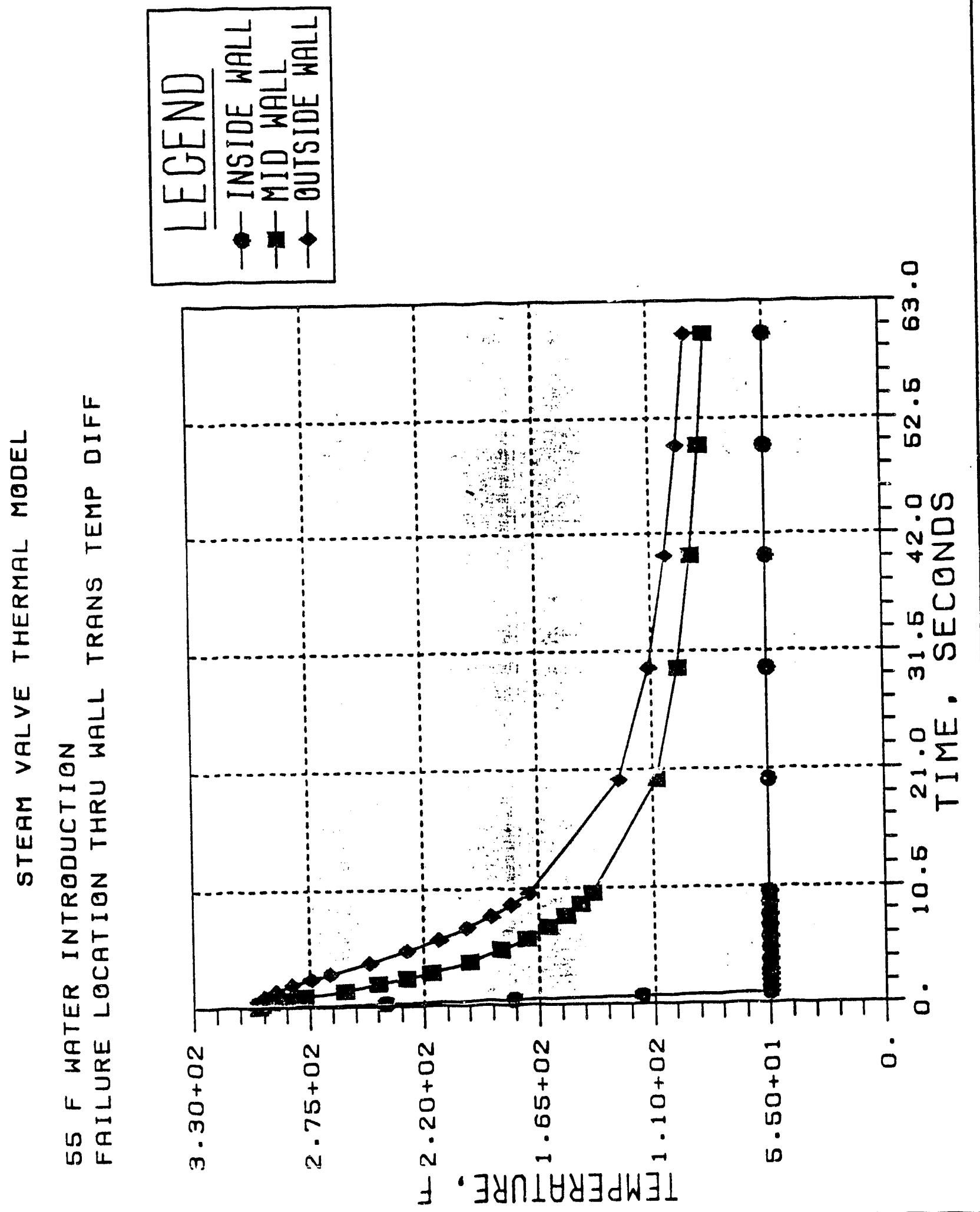


Figure 8-20. Time Required to Cool Lower Half of Valve to Temperature $\left(55^{\circ} \mathrm{F}\right.$ ) of Entering Water.

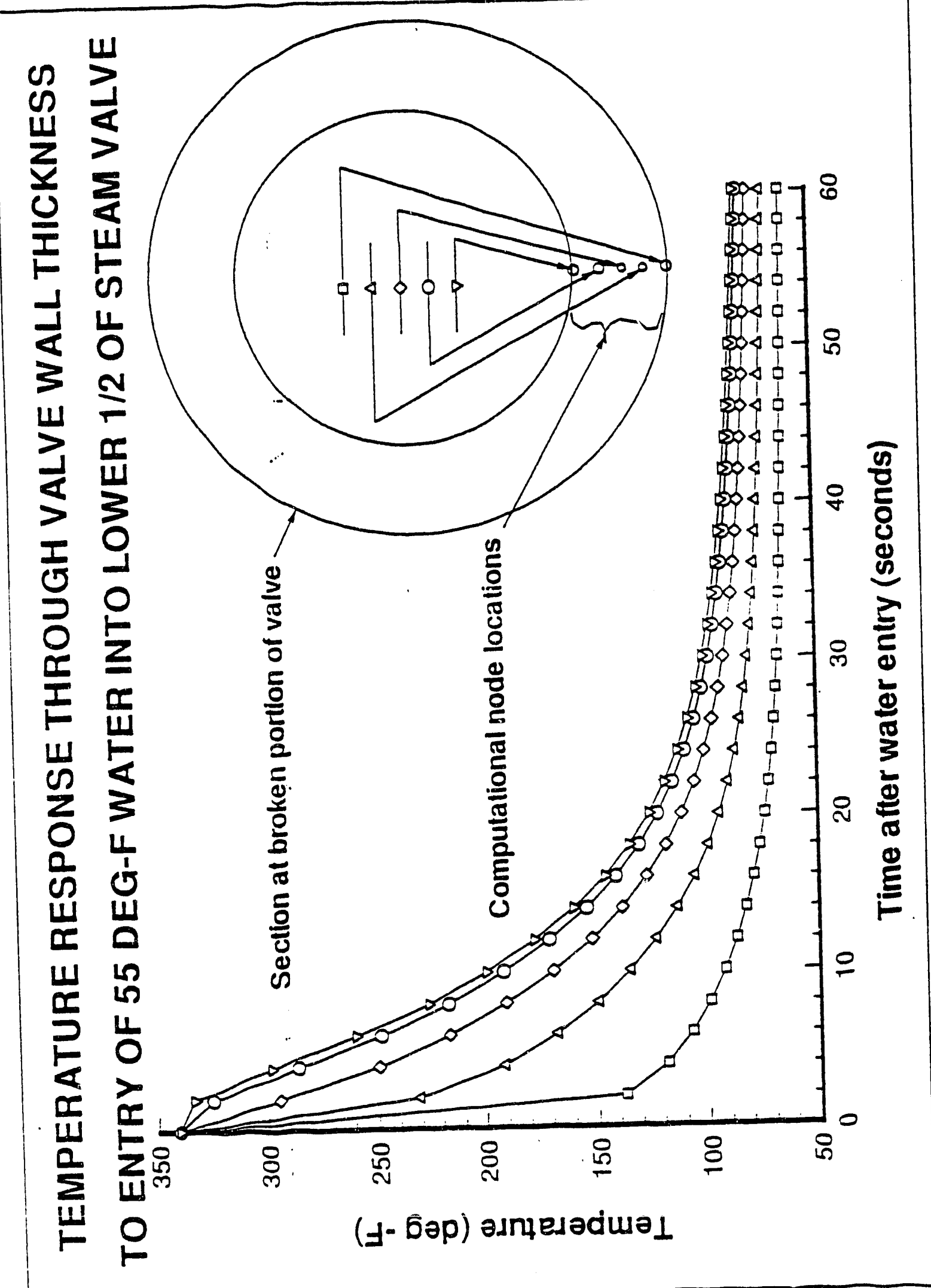


Figure 8-21. Sectional View of Valve Body (Mode1) 8 seconds After Cold Water Reaches Valve.

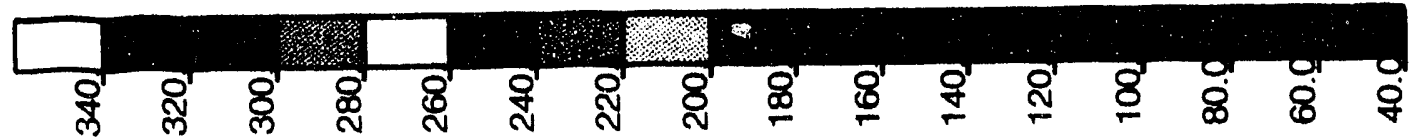

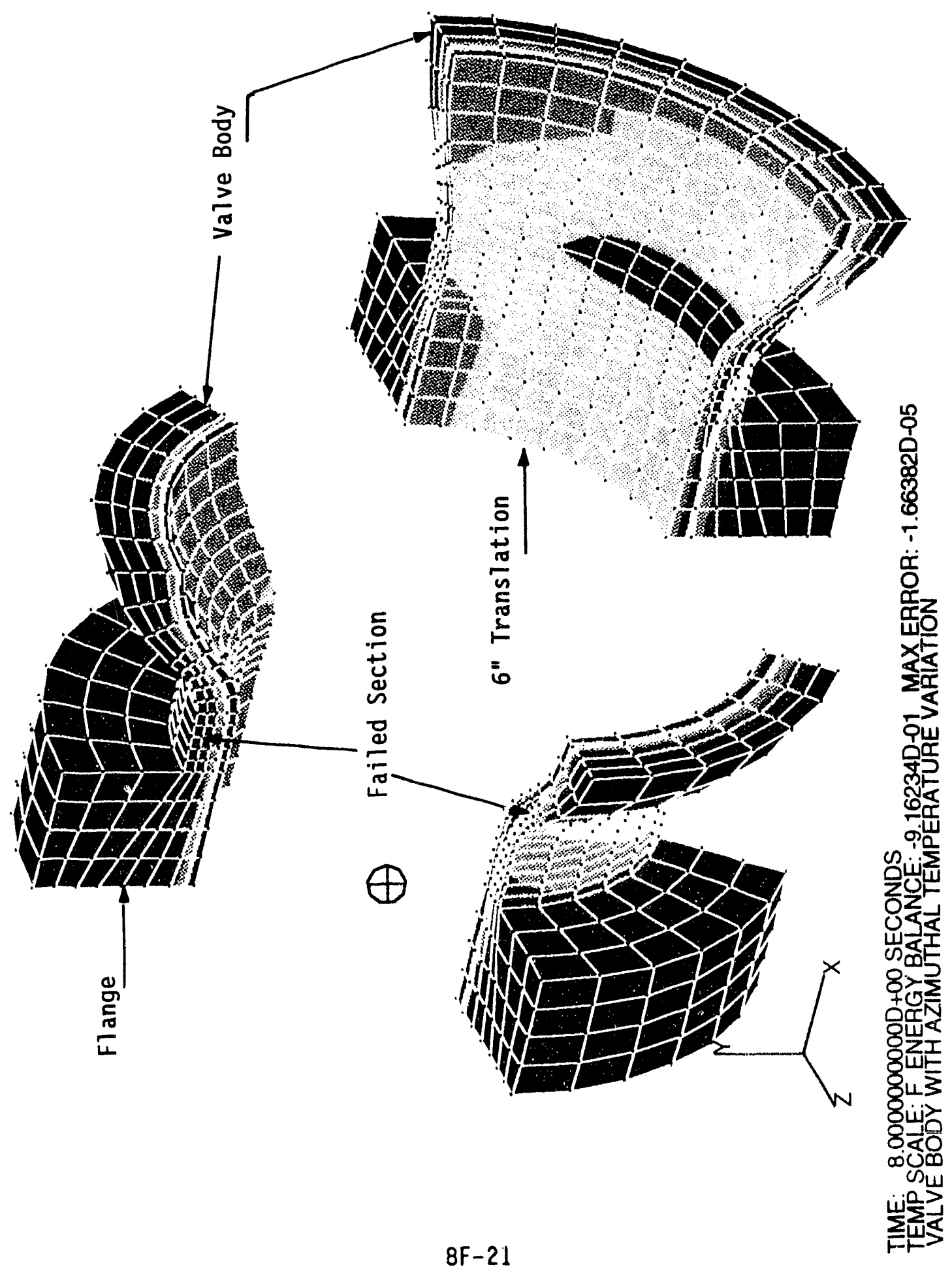


Figure 8-22. Sectional View of Valve Body (Model) 2.8 seconds After Cold Water Reaches Valve.
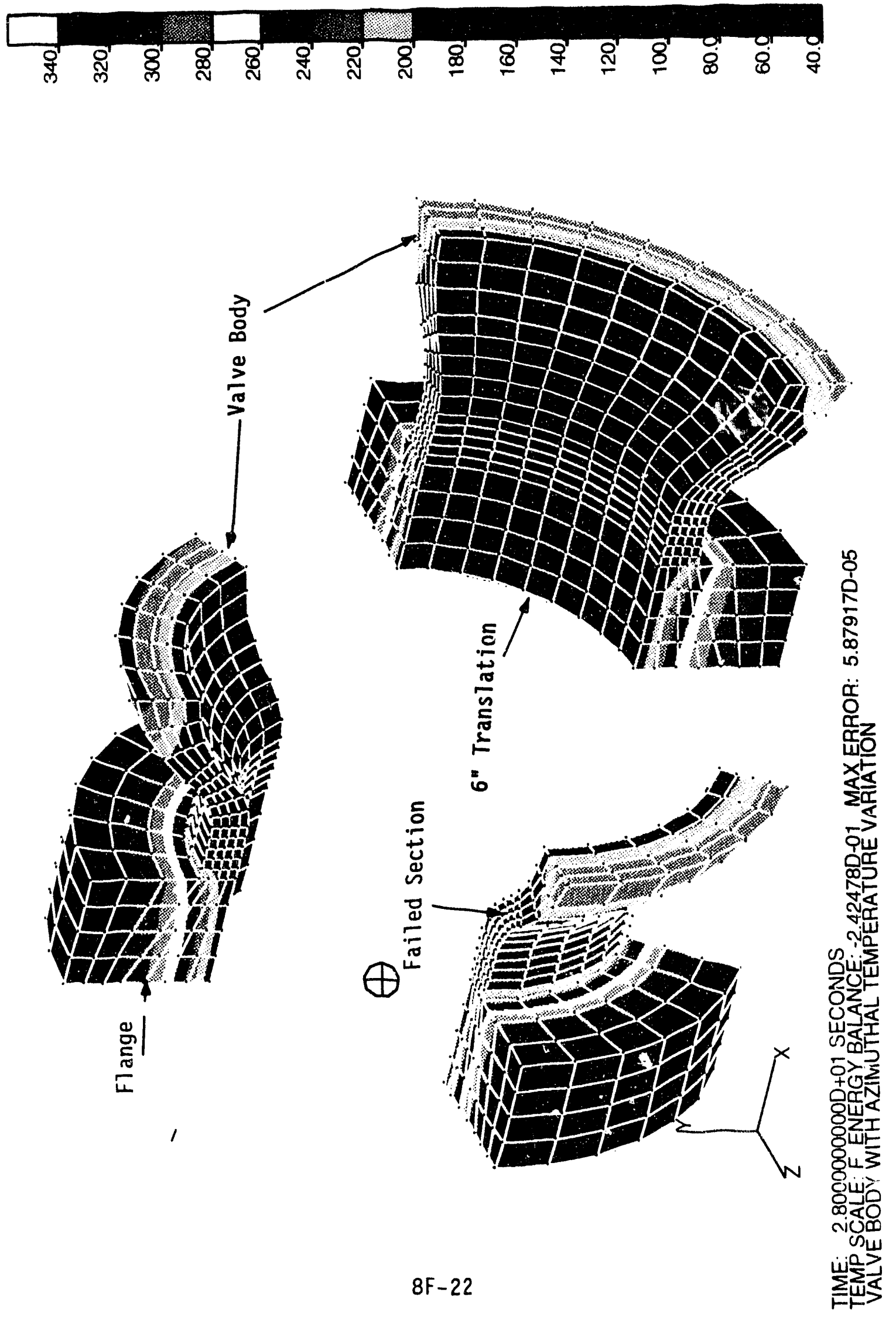
Figure 8-23. Isometric of the Upper-Elevation Piping to and from the U-3 Valve Pit.

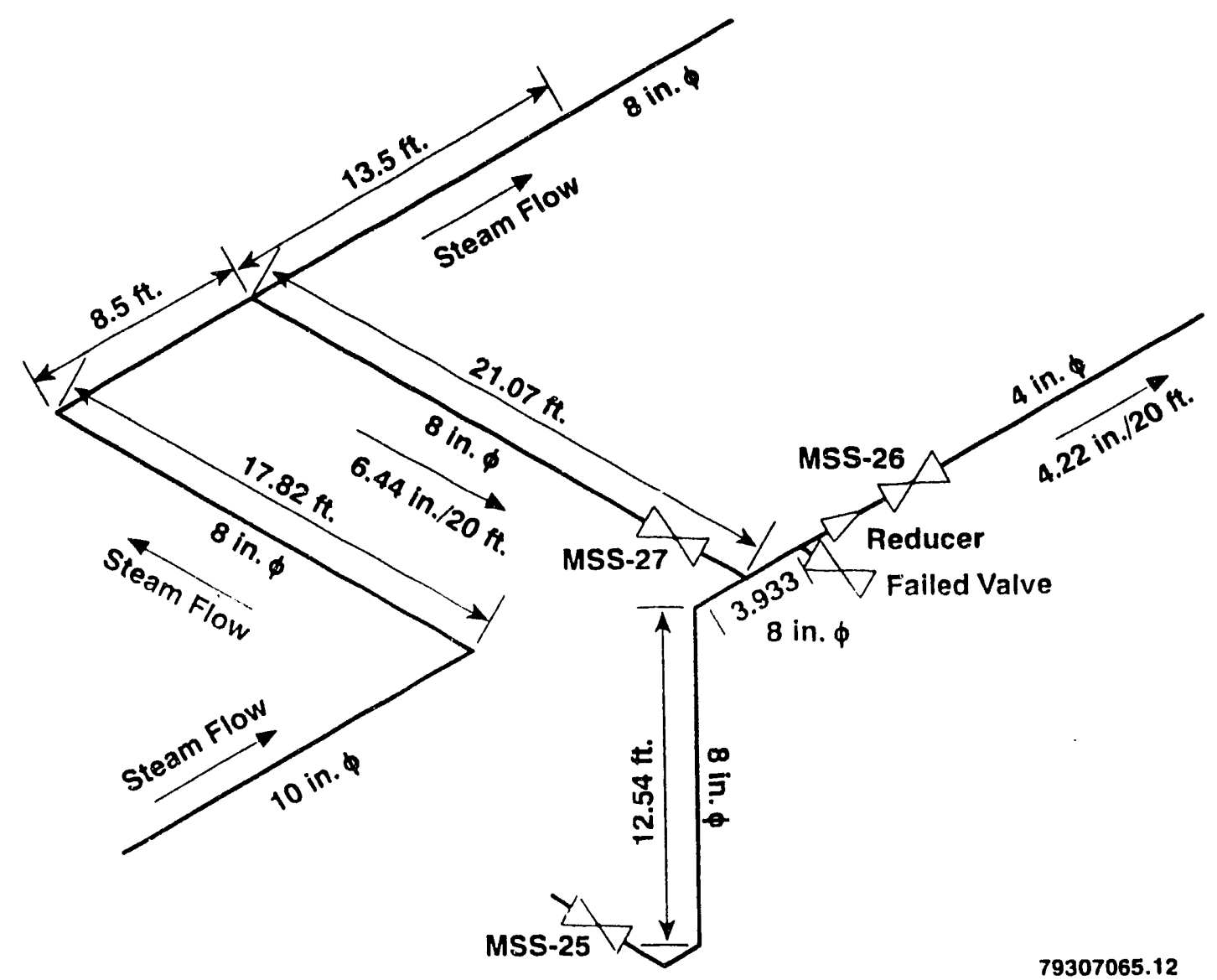




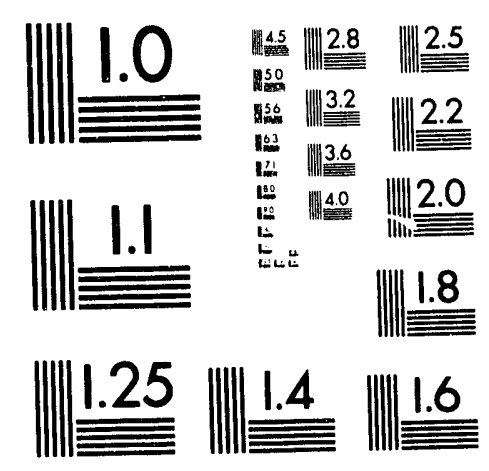



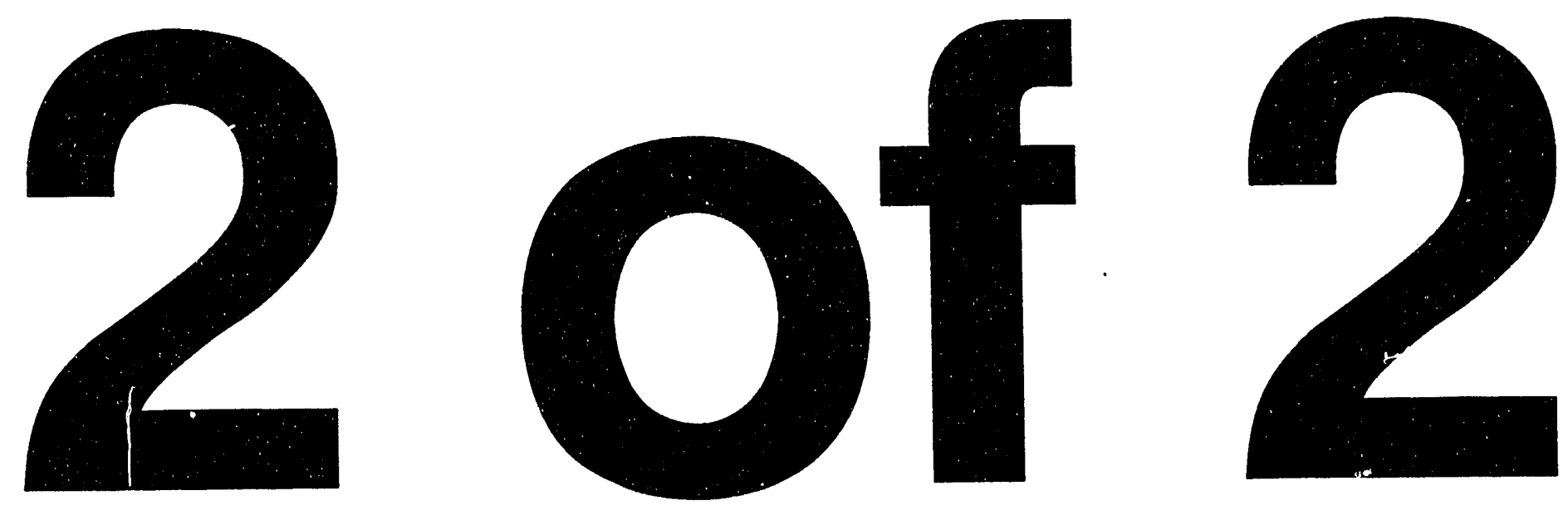
Figure 8-24. Postulated Condition of Valve Before Opened.

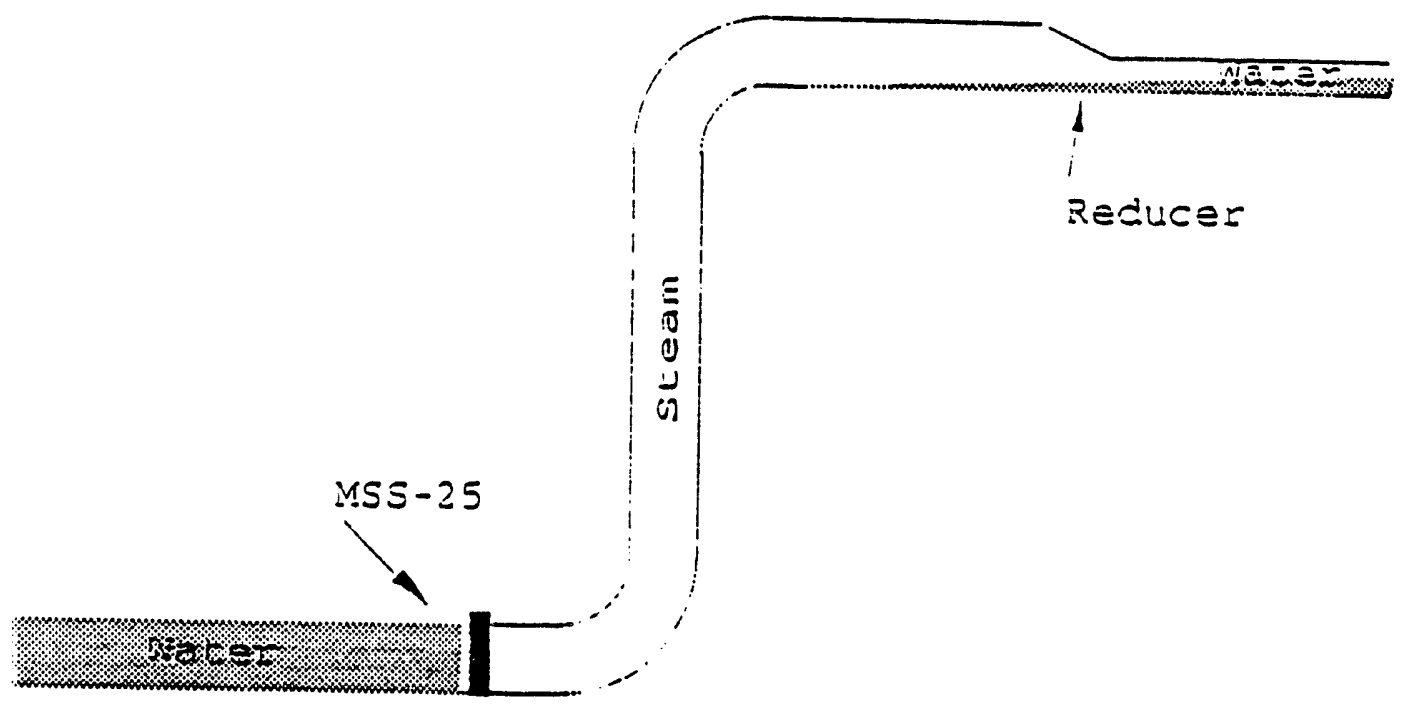

Figure 8-25. Valve Condition Shortly After Opening, with Riser Filling.

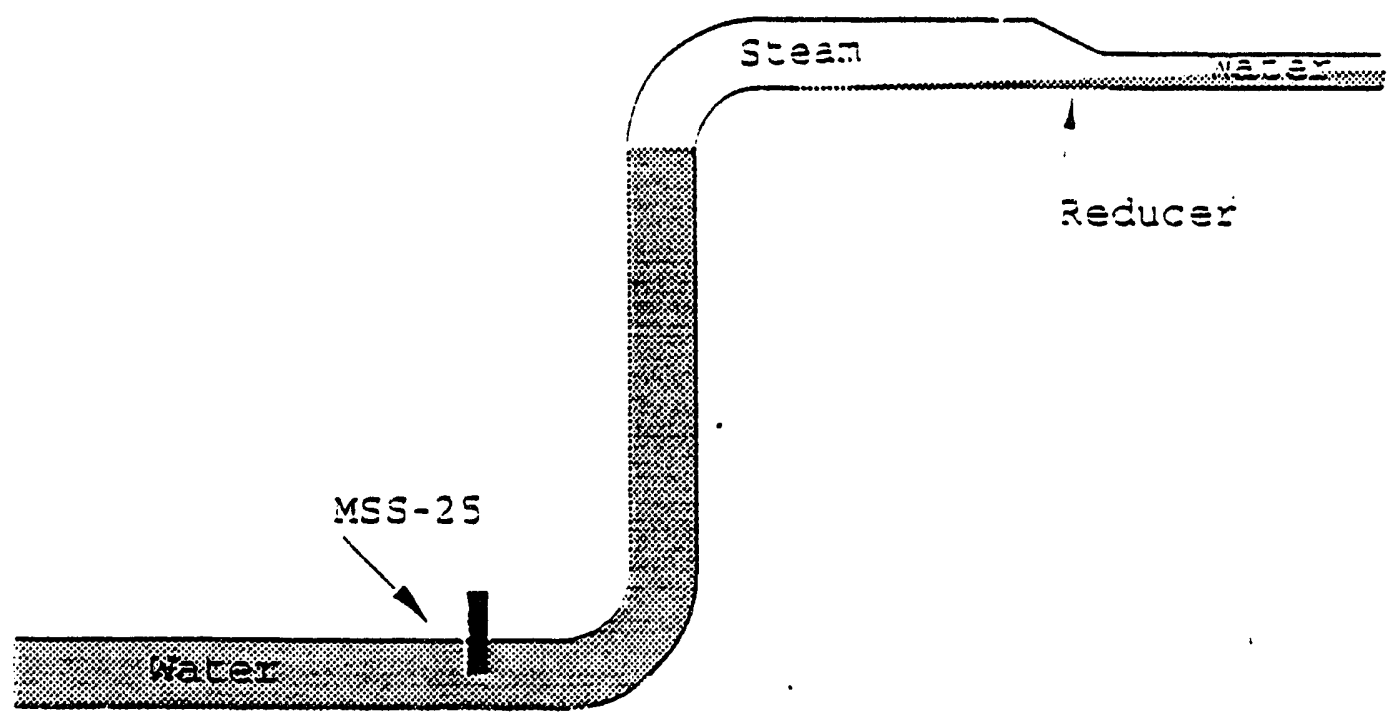


Figure 8-26. Onset of Rapid Condensation.

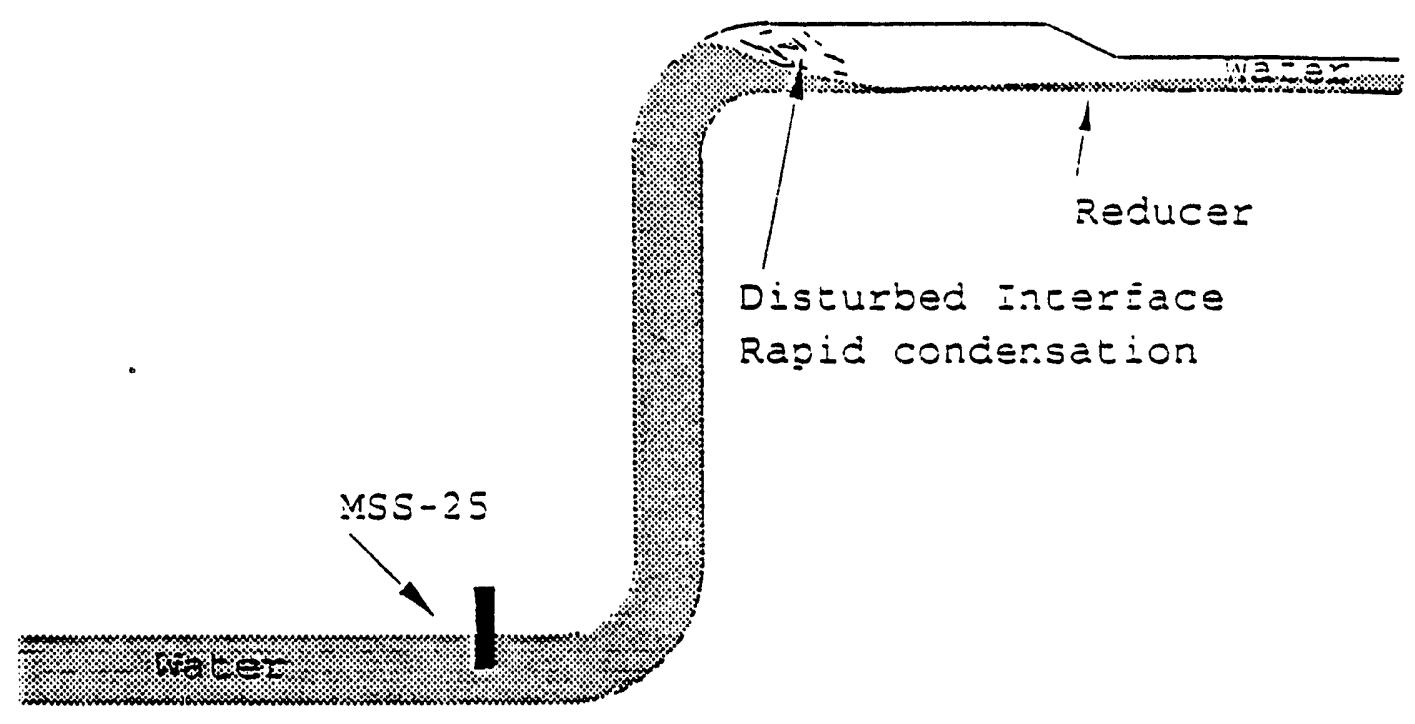

Figure 8-27. Rapid Acceleration of Water Slug.

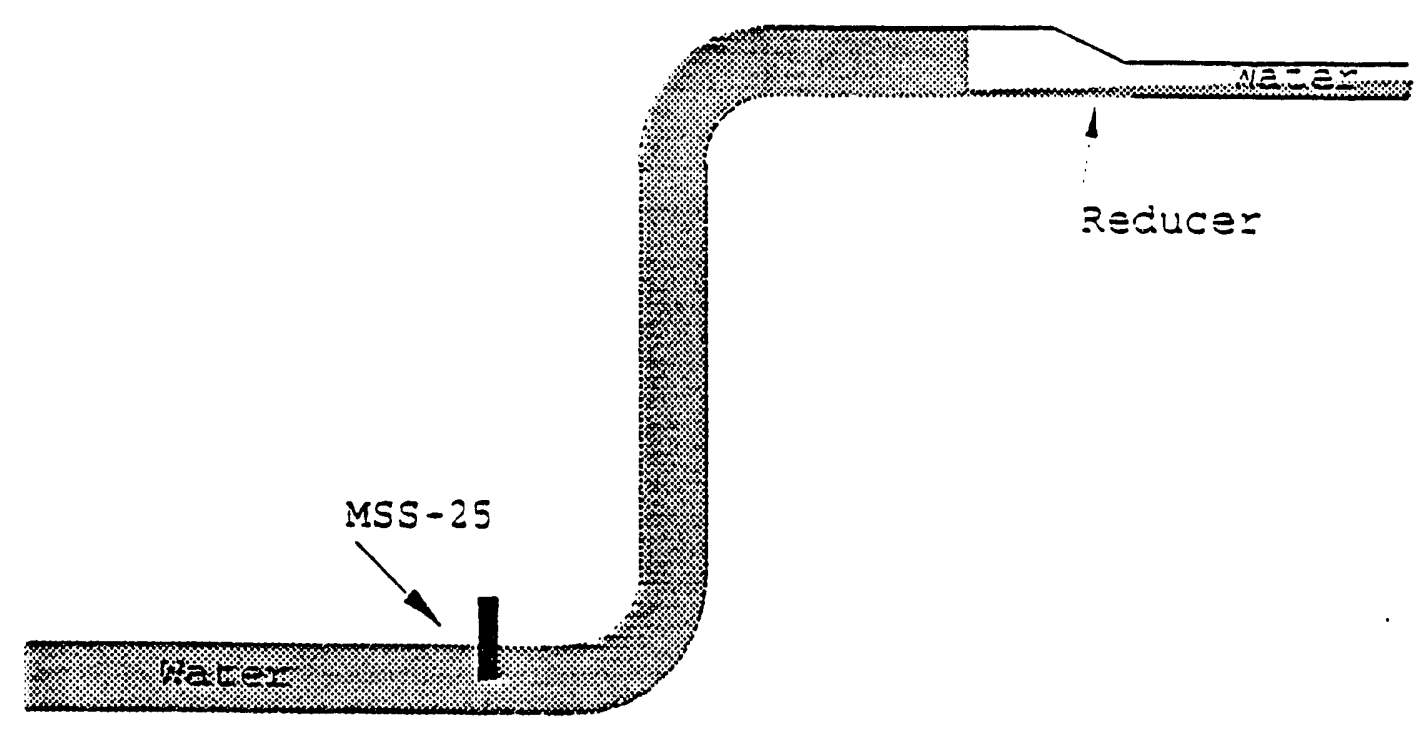




\section{WHC-EP-0667}

Figure 8-28. Slug Striking Reducer and Water-Filled 4-in. Line.

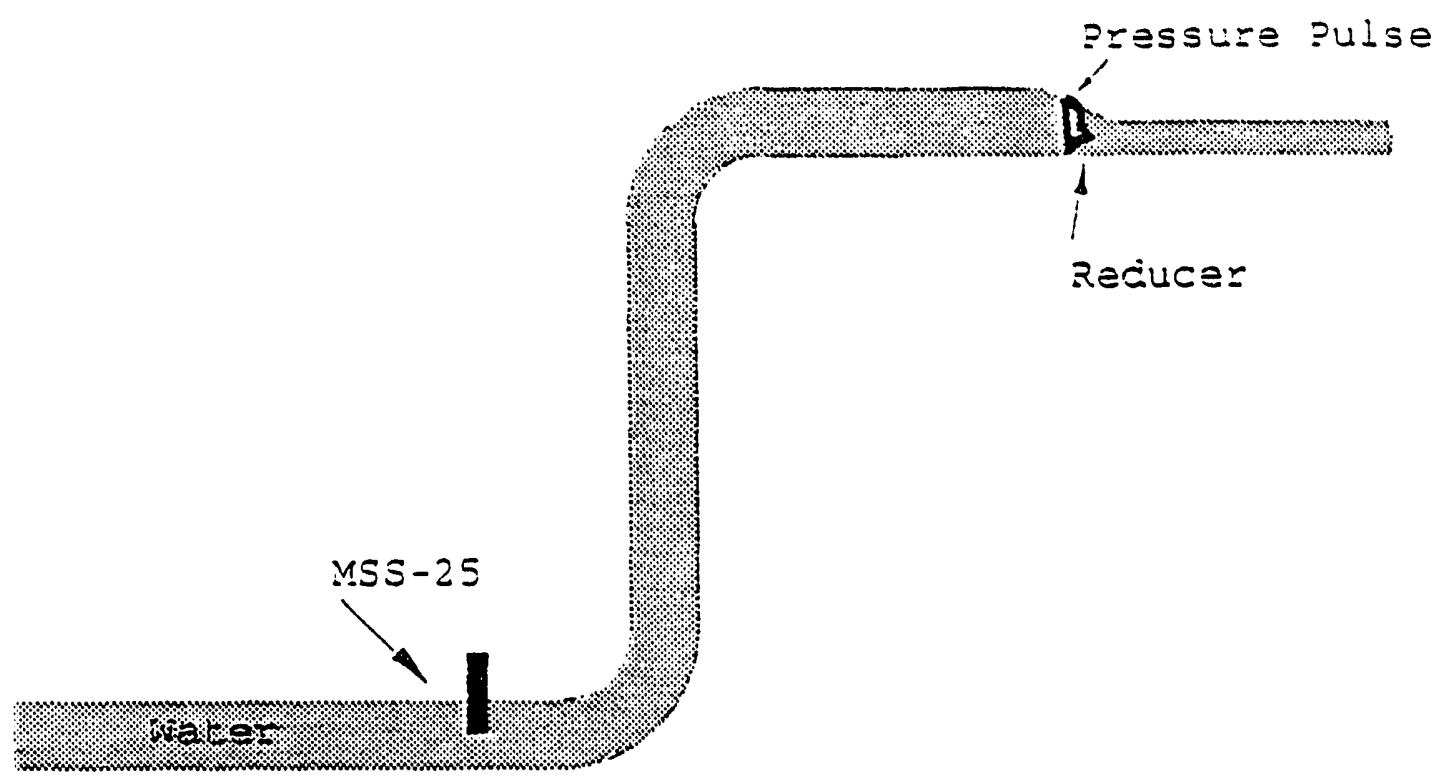

Figure 8-29. Impact of Shorter Slug on Reducer and Water-filled 4-in. Line.

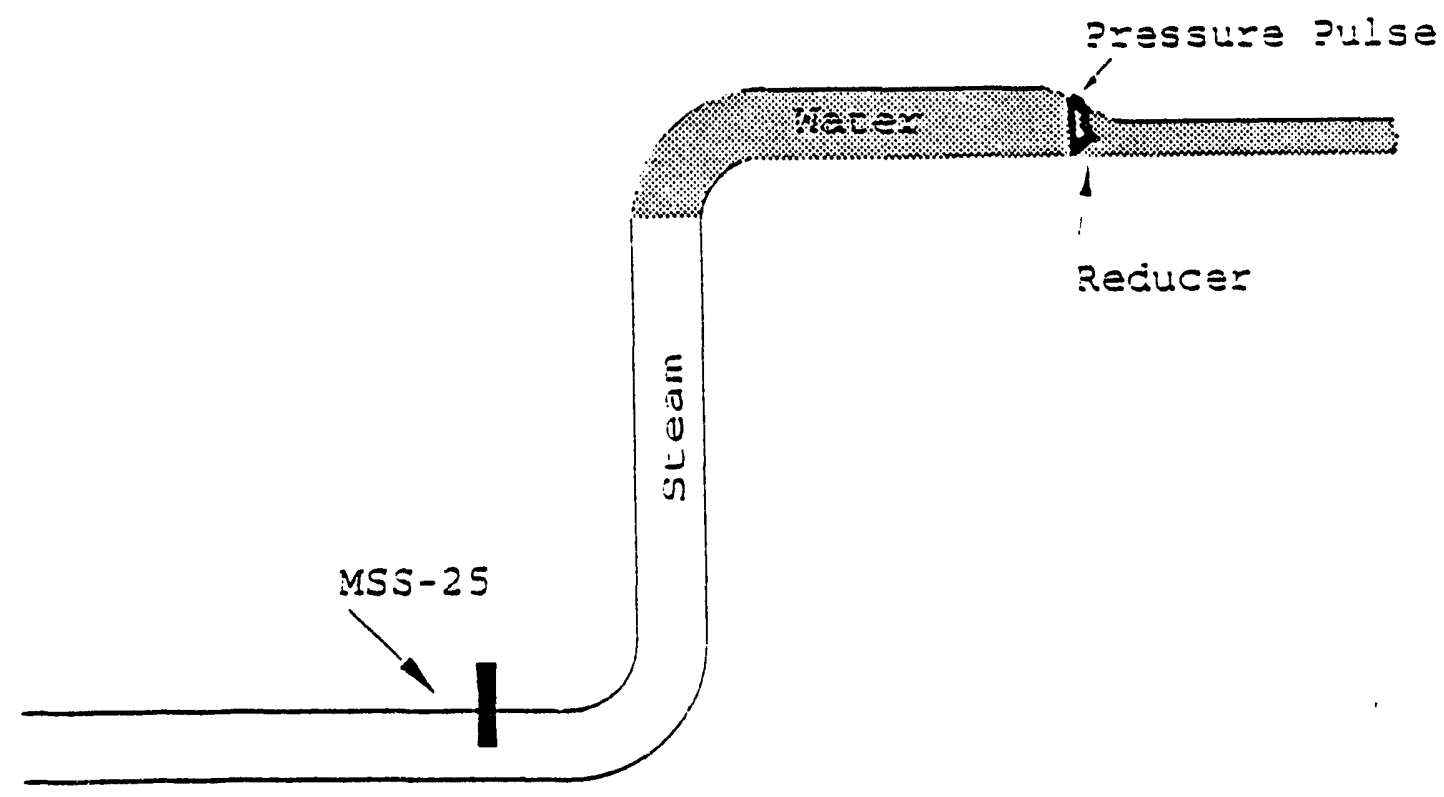


Figure 8-30. Water-Hammer Over-pressure as a Function of Slug Length (0 to $1,000 \mathrm{ft}$ ).

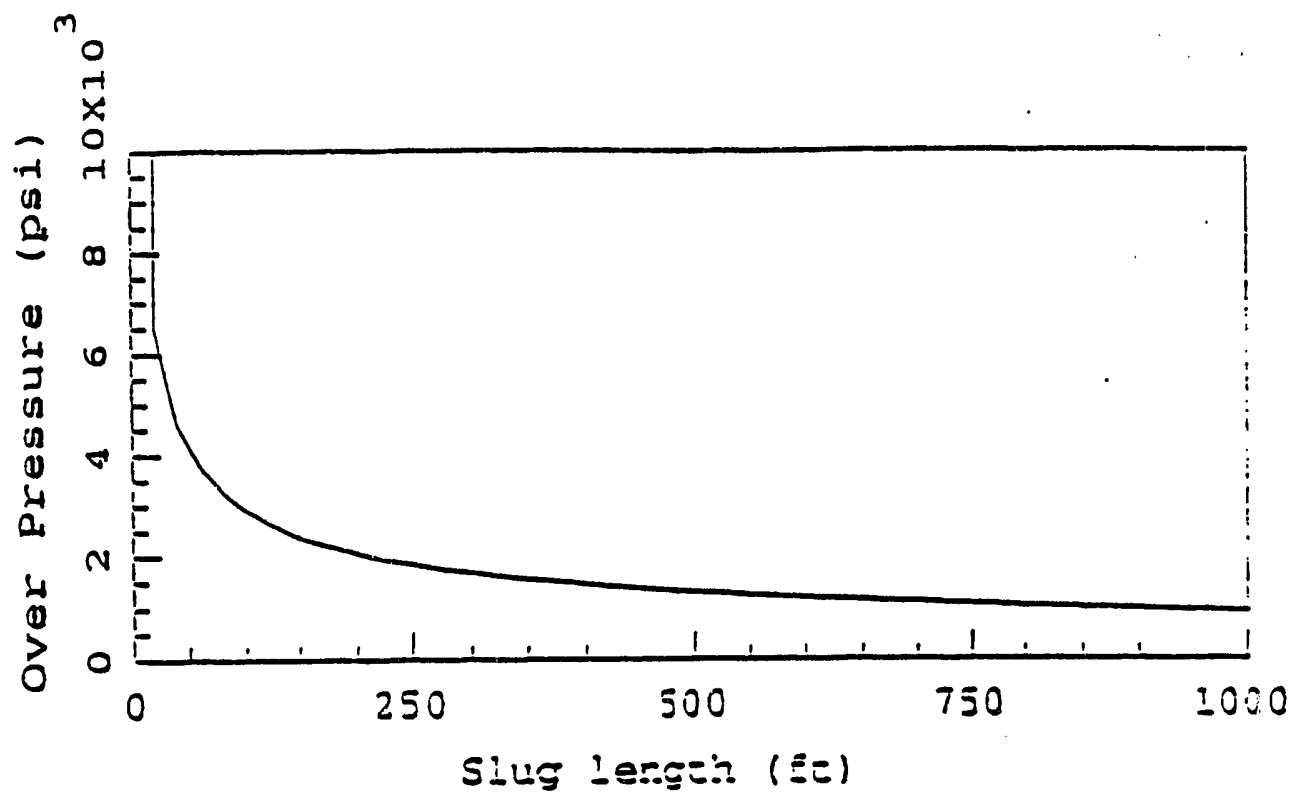

Figure 8-31. Water-Hammer Over-pressure as a Function of S7ug Length (0 to $100 \mathrm{ft}$ ).

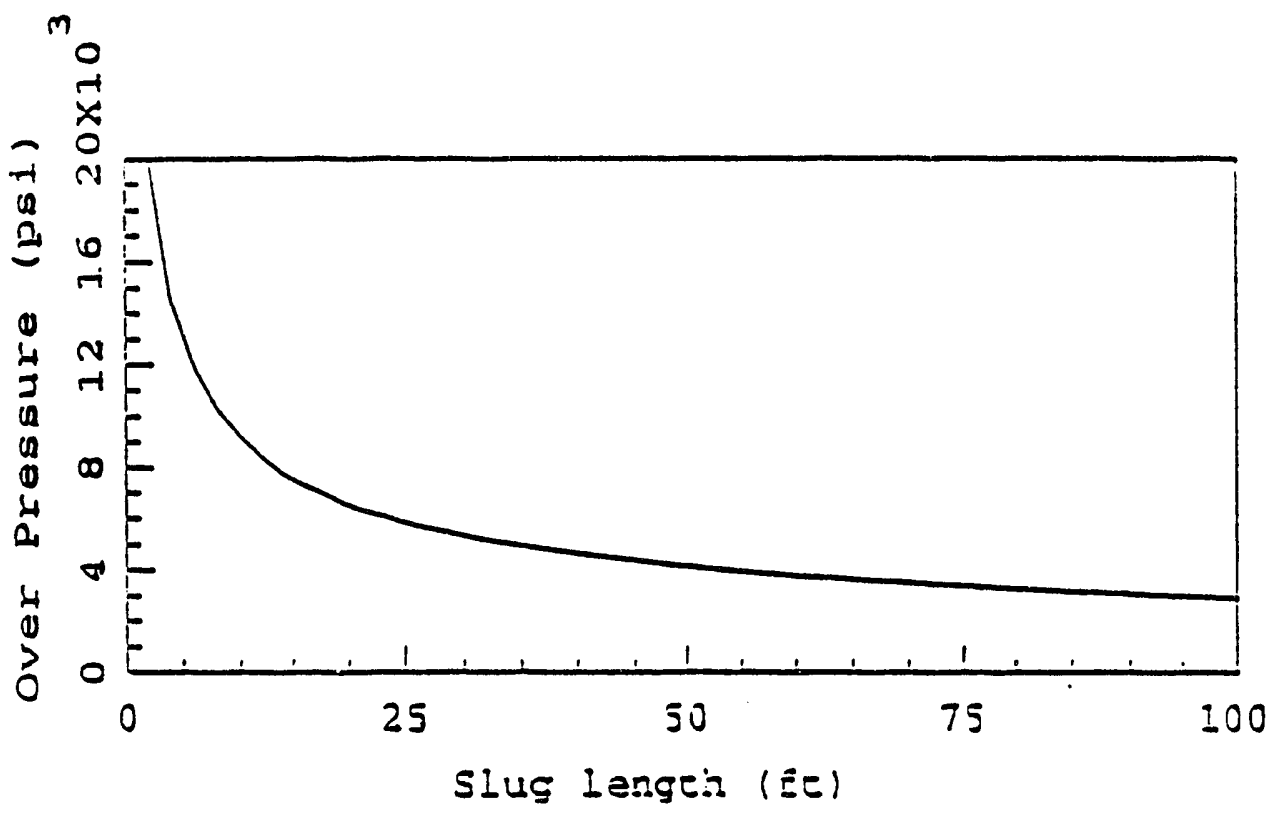


Figure 8-32. Duration of Pressure Pulse as a Function of Slug Length (0 to $1,000 \mathrm{ft}$ ).

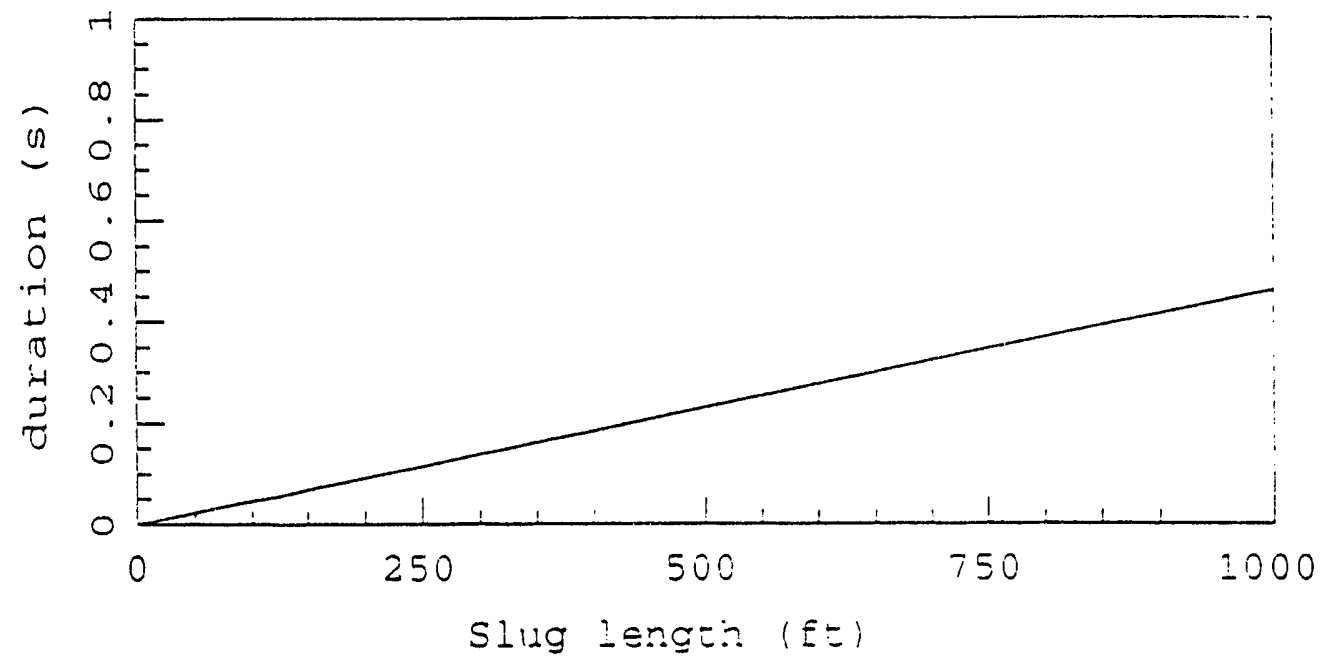

Figure 8-33. Duration of Pressure Pulse as a Function of Slug Length (0 to $100 \mathrm{ft}$ ).

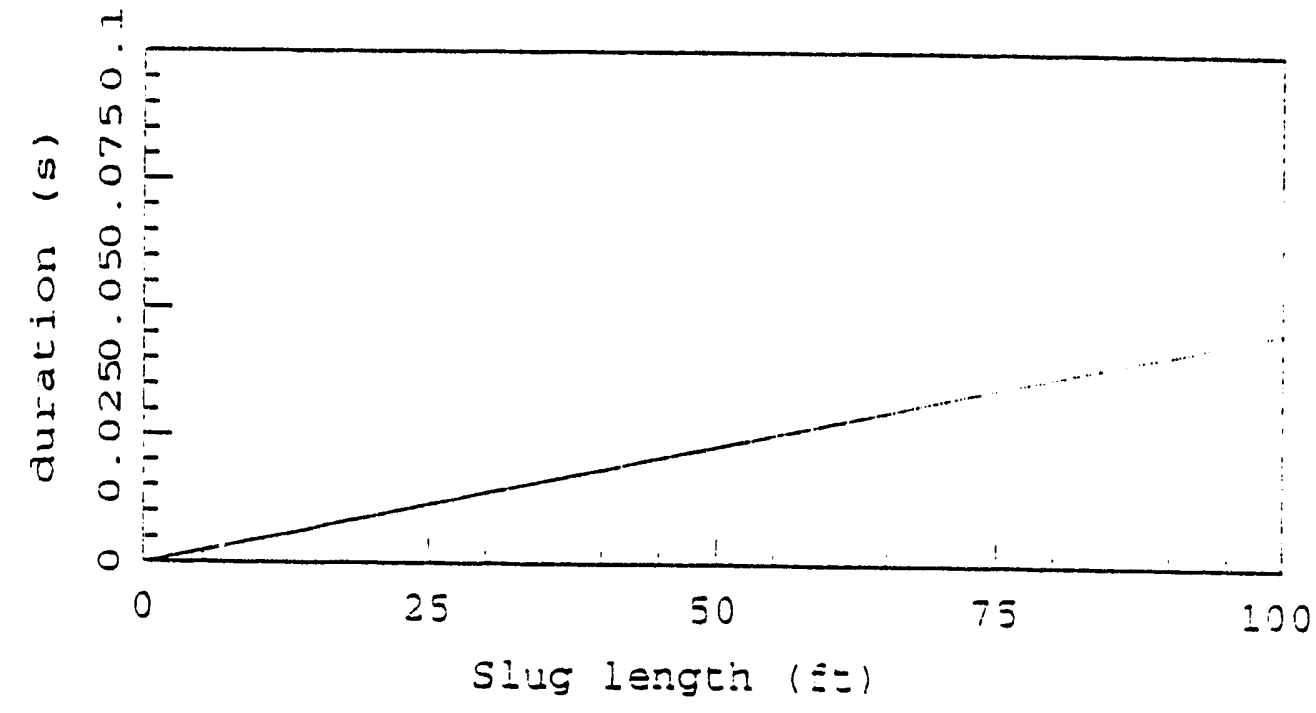


Figure 8-34. Schematic of Pipe Condition Just Before Initiation of Condensation-Induced Water Hammer.

$$
\begin{aligned}
& \text { Nater Eilled } \\
& \text { Steam Eilied }
\end{aligned}
$$

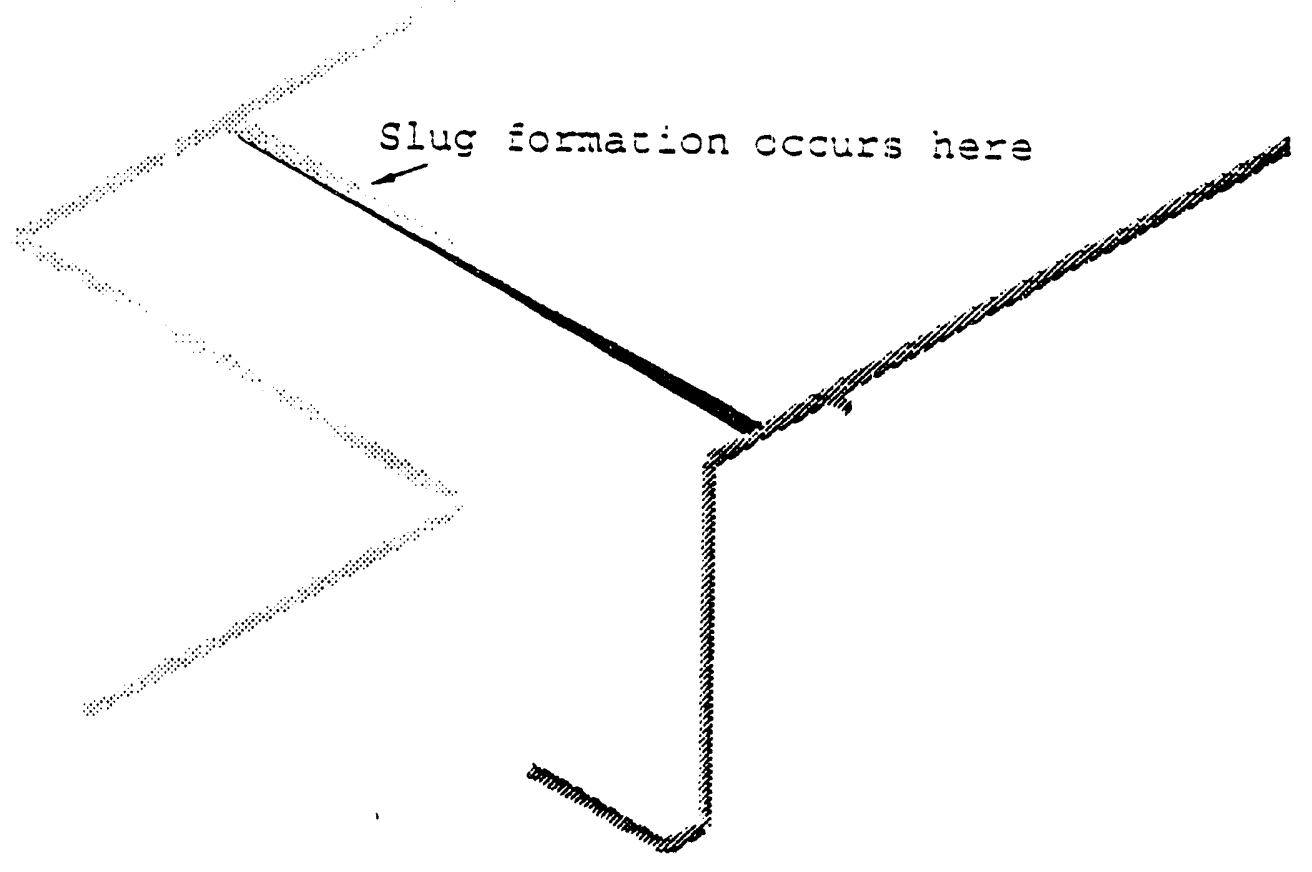


Figure 8-35. Photograph Showing Front View of lest Model.

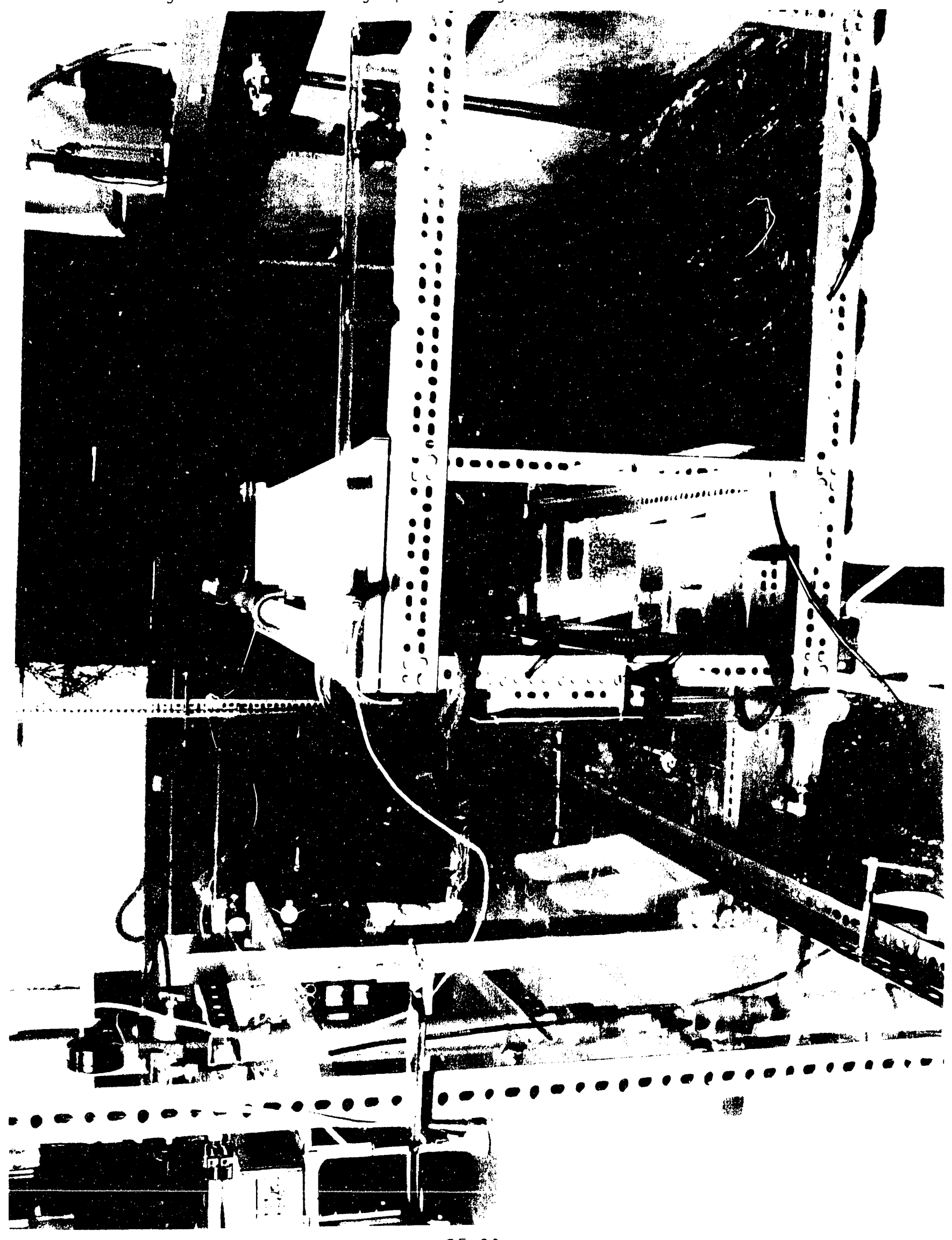


WHC-EP-066I

Figure 8-36. Photograph Showing Side View of Test Model.

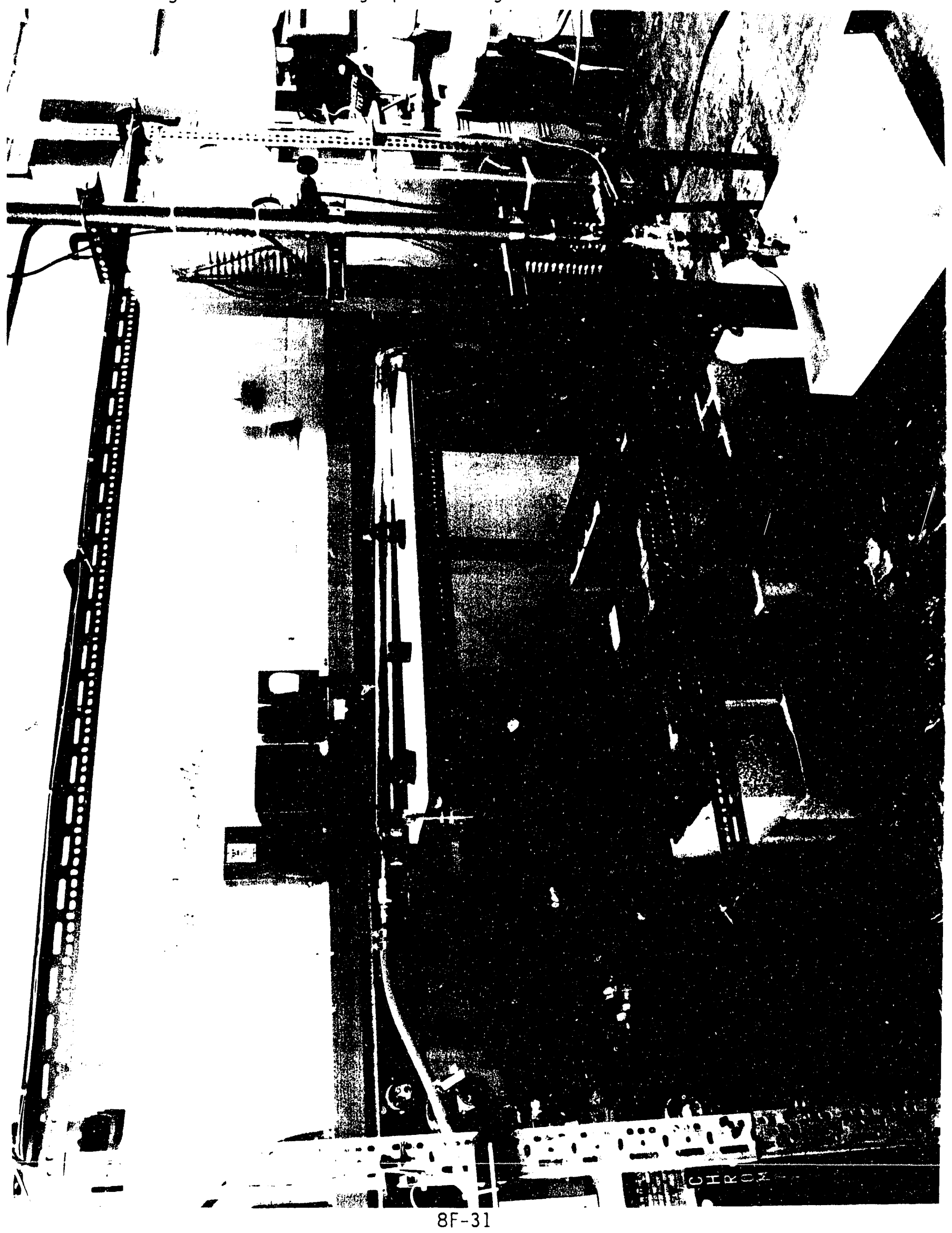


Figure 8-37. Sketch of Test Model Piping Assembly.

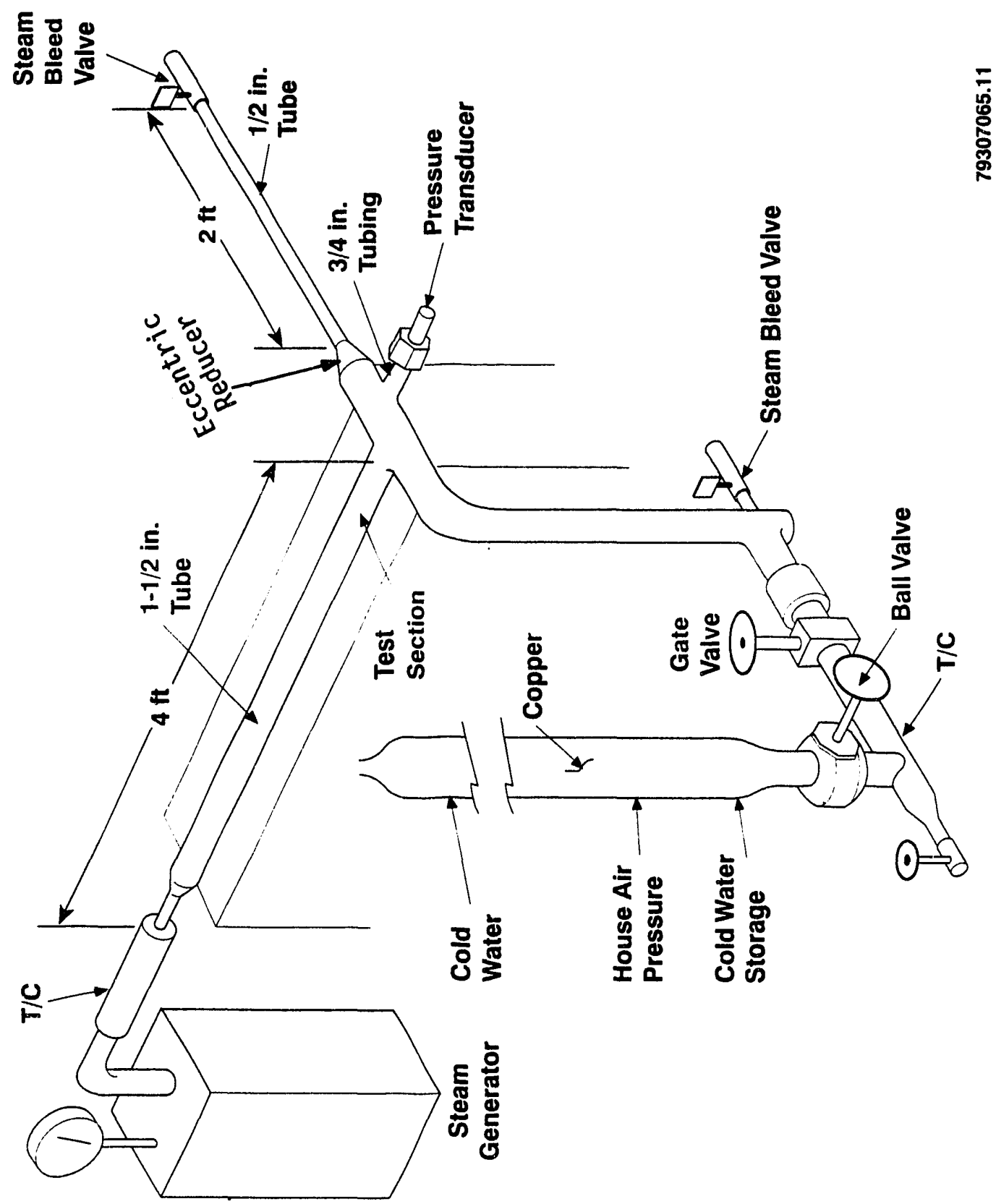


WHC-EP-0667

Table 8-1. Power House Steam Flows.

\begin{tabular}{|c|c|c|}
\hline $\begin{array}{c}\text { Time } \\
(\mathrm{p} . \mathrm{m} .)\end{array}$ & $\begin{array}{c}\text { East Export } \\
\text { (thousands of } 1 \mathrm{~b} \\
\text { per hour) }\end{array}$ & $\begin{array}{c}\text { West Export } \\
\text { (thousands of } 1 \mathrm{~b} \\
\text { per hour) }\end{array}$ \\
\hline \hline $4: 00$ p.m. & 4.1 & 3.3 \\
\hline $5: 00$ & 4.4 & 3.8 \\
\hline $6: 00$ & 4.5 & 3.7 \\
\hline & $\begin{array}{c}13.0 \\
(4.33 \text { average })\end{array}$ & $\begin{array}{c}10.8 \\
\text { average })\end{array}$ \\
\hline \hline $7: 00$ & 4.9 & 3.21 \\
\hline $8: 00$ & 4.1 & 2.3 \\
\hline $9: 00$ & 3.7 & 2.5 \\
\hline $10: 00$ & 3.8 & 2.9 \\
\hline & 11.6 & 7.7 \\
\hline & $(3.86$ average $)$ & $(2.56$ average) \\
\hline
\end{tabular}

* Accident $\approx 7: 18$ p.m. 
WHC-EP-0667

\subsection{MATERIAL EXAMINATION AND ANALYSIS}

\subsection{SCOPE OF INVESTIGATION}

The scope of the materials investigation is restricted to metallurgical analyses of the broken $6-i n$. valve and a very limited assessment of its adjoining 8 - by $4-i n$. reducer and integral 6 -in. tee leg.

\subsection{SUMMARY}

A metallurgical failure analysis was conducted on the service-ruptured 6-in. gray cast-iron gate valve. The analysis included visual observations, measurements of dimensions, limited nondestructive examination (NDE), disassembly, metal microstructural examination, scanning electron microscopy (SEM) examination of pertinent fracture surfaces, tensile tests, hardness tests, and alloy chemical analysis.

These tests indicate that the valve ruptured because it experienced loads beyond its capacity. The valve material was sound, free of any significant porosity or shrinkage, and metallurgically clean. Metallography confirmed that the valve material was gray cast iron, free of cracks, voids, or significant inclusions. Fractographic analysis indicated that the fracture mechanism was essentially the same on all fracture surfaces examined, including freshly made laboratory fracture specimens of valve material.

$V$ isual and fracture-surface examination confirmed that there was no corrosion damage or stress-corrosion cracking to reduce the load-bearing capacity. Also there were no apparent pre-existing flaws or cracks of engineering significance.

Ultimate tensile strength levels of material removed from the valve flange were about one-half of the $31 \mathrm{kip} / \mathrm{in}^{2}$ minimum value stipulated for separately cast tensile bars. Brinell hardness (BH) measurements made on the flange and in the neighborhood of the circumferential fracture were almost the same, consistent with the reduced tensile strength. Chemical composition, i.e., phosphorus and sulfur, was within specification. Microstructure, carbon and carbon-equivalent level, and maximum length of graphite flakes, all appeared to correlate with a reduced tensile strength.

\subsection{ONSITE INSPECTION FOR REMOVAL OF TEE}

Two engineers entered the pit on June 12, 1993, to inspect the steam lines and mark them for removal.

The tee/broken flange section was marked for removal by sawcutting, as shown in Figure 9-1. Several circumferential weldments were included in the tee section to be removed so that analysis could determine whether they had been affected by the same loading that fractured the 6-in. valve. Shown in Figure 9-2 are the attached valve flange and fractured area adjacent to the flange foot, as they were positioned in the pit. 
The sand and mud covering was widespread except for a narrow region of the fracture face adjacent to the place where steam exited after the break and the entire region at the bottom of the flange/fracture face area. Part of the remaining fracture face covered by sand, as well as the part of the fracture surface less covered with sand, was stained reddish-brown to purple, except for the bottom 2- to 3-in.-wide region of the flange. Speculation is that a reduced-pressure stratified steam-condensate flow or a post-shutdown remnant water flow might have washed away the lightly adherent sand and reddish-brown coloration. A faint horizontal "high-water" mark or line was observed in the interior of the tee. This line appeared to be about two-thirds of the distance above the bottom of the tee.

The broten valve, also covered with sand, was observed from the scaffold. The valve disc appeared to be seated and undamaged.

\subsection{VALVE DESCRIPTION}

Attached to the subject 6 -in. valve yoke $w-s$ a tag reading "Crane Co. Cat. 465-1/2." The valve body contained the foilowing cast-in-place designation:

46830
FS
6
CRANE
$125 S$
200 WOG

Details on various Crane valves, including the No. 465-1/2 model, can be found in Crane Catalog No. 60 dated 1960 (Crane 1960).

The 6-in. 465-1/2 valve is described as a "125 Pound Ferrosteel Wedge Gate Valve, Outside Screw and Yoke, with Bronze seat and Bronze Stem" (see al so p. 76 of the (rane catalog). The term "ferrosteel" more aptly describes a gray cast iron in accordance with American Society for Testing and Materials (ASTM) A 126 Class B, with a minimum tensile strength of $31,0001 \mathrm{bf} / \mathrm{in}^{2}$ (see p. 3 of the crane catalog). This class of cast iron covers the valve body and Donnet. The valve yoke appears to be made of a lower strength $\left(21,0001 \mathrm{bf} / \mathrm{in}^{2}\right.$ tensile strength) A 126 Class A cast iron. According to the Crane catalog, the valve is suitable for temperatures up to $450^{\circ} \mathrm{F}$.

\subsection{INVESTIGATION METHODOLOGY}

\subsubsection{Removal from Pit}

On June 14, 1993, Craft Services personnel entered the U-3 steam valve pit, removed the valve, and cut out the section of tee and pipe (Figure 9-1). The tee/pipe section was removed with a hoist, placed on a pallet, metalbanded to the pallet, and covered with several layers of clear plastic. The bands did not touch any of the fractured regions. The pallet then was transported to the $272 E$ Fabrication Shop. The photograph in Figure $9-3$ shows the banded valve and tee/reducer section after they were unloaded at Building 272E. 


\subsubsection{Initial Cleaning}

Before they were cleaned, the valve and tee/reducer sections were inspected for any unusual conditions or appearances. Sand was scraped off by fingernail in several areas on both sections. Nothing significant was found.

The valve was placed near a floor drain and a low-pressure water stream (est. <20 lbf $/ \mathrm{in}^{2}$ ) was applied to the valve (Figure 9-4). The water readily removed most of the sand. A soft-bristle brush was used periodically to remove the more tenacious sand. The valve then was dried with pressurized chop air. After the valve was dry, it was sprayed with WD-40 ${ }^{2}$ to minimize any further corrosion (Figure 9-5).

Both ends of the reducer were tared shut to prevent any water intrusion. The flange remained face down on its circle of protruding bolt ends. Lowpressure water was sprayed mainly from above the meducer to minimize any water entry. Most of the sand was removed with the low-pressure water, and some periodic brushing removed the more adherent sand. The reducer was air dried and coated with WD-40. The as-dried and WD-40-coated tee/reducer is shown in Figure 9-6.

\subsubsection{Preliminary Examinations}

Visual Examinations. The broken valve and the tee/reducer section were examined visually with a 100-W trouble light in conjunction with a 4-in.-diameter $2 X$ magnifying lens with a small, circular $4 X$ magnification insert. One of the four valve bonnet support feet for the mating valve yoke was cracked, as shown in Figure 9-7.

Dimension Measurements. The dimensions of the valve and broken flange and the tee/reducer section were taken with steel shop rulers and calibrated equipment operated by a Quality Control technician.

Disassembly. Before the critical valve components were disassembled, they were marked by vibro-etching to ensure accurate identification of all components, including their original orientation. Such marking was to ensure that areas on which subsequent finer-scale cutting or sectioning was conducted could be clearly traced to their original locations. The original orientation of each bolt and its attached nut was noted by vibro-etching the valve flange at the intersection with at least two faces of each hex-head bolt and attached nut and two faces of each square-head bolt and attached nut.

\subsubsection{Nondestructive Examination}

Magnetic particle examination at Building $272 \mathrm{E}$ indicated the presence of a crack running from the major circumferential fracture face on the valve into the body of the valve. The cracked region was sprayed with white dyepenetrant developer (no dye penetrant was used) to highlight the crack. A hand-held pen points to the crack and the white-sprayed area in Figure 9-8.

${ }^{2}$ WD-40 is a trademark of the Rocket Chemical Company. 
The presence of the secondary crack suggested a need for radiographic inspection. The valve was taken to the 300 Area NDE facility. Radiographic film, approximately 4 by 12 in., was placed through the throat of the valve. The radiographic exposures used an ${ }^{192}$ Ir source. After the film was developed, a second exposure was made on film circumferentially displaced but slightly overlapping the location of the first film. Each successive film progressed around the circumference of the circie of fracture.

The primary regions examined were the valve body adjacent to the fracture ring and its twin region that still contained its flange. The more central area of the valve body was thicker and contained bronze valve seats. These features prevented a significant exposure of the film. Because examiners believed that the other regions of interest would indicate the occurrence of any significant amount of porosity or shrinkage during casting, the central region was not re-x-rayed. Sections $B$ and $C$ of the 1.0-in.-thick flange containing half of the rracture face (see Figure 9-9) were radiographed to determine the extent of porosity. Section $A$ was not radiographed as it was used as the source for tensile specimens (see Section 9.5.5).

\subsubsection{Specimen Preparation}

Metallurgical and SEM specimen and specimen for surface chemical analysis (SCA) were marked for cutting, as shown in Figure 9-9. The radial cuts were made with a machine shop bandsaw. The cuts were made without fluid, with a slow feed.

The samples marked SEM-1 and SEM-2 were cut to obtain the respective sections of fracture face. The sample marked SEM-2 is located at the areas where the sand and coloration were apparently washed off during the steam venting following fracture. The adjacent Met-1 and Met-2 samples were cut to allow an optical microscopic view of the fracture face (major crack path) and its underlying metallurgical grain structure. The SCA-1 appeared to contain a heavier layer of surface deposit (later determined to be mainly sand) and was colored reddish-brown.

The SEM-1 and SEM-2 samples were examined as is with the SEM and also after cleaning. The SEM-3 sample was examined along with a fresh fracture of the 1 igament region between the SEM-3 fracture face and its connecting flange. The SEM-4 sample also was removed but not examined. The SEM-5 sample is the broken valve bonnet foot, also shown in Figure 9-9. The latter was cut further near its bottom hole. In addition, a fresh fracture surface was made here and an additional Met-5 section made for further microscopic observation.

Preparation of metallographic samples followed the procedure noted in ASM 1973. To expedite inspection, a quick-mount (self-setting resin) was used instead of the usual mounting material, which requires a longer curing time.

Rough and fine grinding observed the recommendation in ASM 1973 to follow grinding by light etching for each successively finer paper. The silicon carbide papers ranged from 120 to 600 grit. Final grinding was done with $3 / 0$ paper and followed by 1 ight etching. 


\section{WHC-EP-0667}

Polishing involved the use of 1 - and $\frac{1}{4}-\mu \mathrm{m}$ diamond paste on velvet cloths with low naps. Nital in a $2 \%$ concentration was used for etching. The process typically involved swab etching for 3 to 5 seconds.

Specimens selected for examination in the SEM were cleaned further by acetate tape moistened with acetone, wetting the fracture surface with acetone, pressing the tape firmly onto the fracture surface, and peeling it off after several minutes. This technique removed most, but not all, of the remaining sand and oxide film from the fracture surface.

The sections noted as $A, B$, and $C$ in Figure 9-9 were retained for possible future use. Section $B$ was sent offsite for fabrication and testing of tensile spe:imens.

The circumferential fracture face shown in Figure 9-10 was cut with a bandsaw from the valve body to determine the metallurgical characteristics of the additional subsurface crack shown in Figure 9-10. After the fracture-face ring was removed, another ring approximately $3 / 8$ to $1 / 2-i n$. thick was also sawcut from the valve body. This ring was sent to a commercial testing laboratory to determine $\mathrm{BH}$ levels at a number of centrally located azimuthal positions around the ring's circumference.

\subsection{RESULTS}

\subsubsection{Visual Examination}

Visual examination of the valve and the tee/reducer showed that visible damage was 1 imited to the valve and its mating fractured flange. No damage was apparent in the tee/reducer. The valve disc and bonnet sustained no apparent damage.

Valve damage was limited primarily to the ring of fractured material (Figure 9-9) and one completely fractured bonnet foot (Figures 9-7 and 9-9). The stem, which was bent slightly, is described in Section 9.6.3.

Some probable impact damage was found on the outer edge of the circumferential fracture face of the valve, shown at the bottom of Figure 9-10 (directly below the expressed number "6"). The apparent impact area is about 1 to $1-1 / 4$ in. long and at an angle approximately $60^{\circ}$ to the plane of the fracture face. There is no matching or similar damage on the mating fractured flange shown in Figure 9-11. Thus, the damage probably occurred when the broken (and airborne) valve struck an adjacent region in the pit before wedging itself between the vertical 8-in.-diameter pipe and the adjacent pit wall.

Another factor to be noted is the absence of reddish-brown color on the valve fracture surface (Figure 9-10) in comparison to the distinctly colored region noted on the matching fracture surface on the flange, shown in Figure 9-11. Removal of the color by further cleaning is discussed below (Section 9.6.5). The fact that it could be removed indicates strongly that the red-marked areas did not represent a crack or flaw that existed before rupture. This assessment is corroborated by SEM observations that are also described below. 
As noted earlier, the fracture face shown in Figure 9-10, was sawcut from the valve body. The additional crack that penetrated the valve body (see Figure 9-8) was apparent on both sides of the removed fracture ring. Figure $9-12$ is an approximate $2 X \mathrm{plan}$ view of the origin of the additional crack in the major fracture surface. Figure 9-13 is a photograph of the side opposite that in Figure 9-12, showing the same crack penetrating the back surface. The numbers 10 and 11 are reference numbers that were vibro-etched on the ring and its mating valve body. An attempt was made to open the crack by pulling on the sides of the ring opposite the crack, but the crack did not open appreciably.

Figure 9-14 is a higher magnification of Figure 9-13. It shows an unbroken ligament about one-fifth of the way through the thickness of the ring from the outside edge of the fracture. This unfractured ligament strongly suggests that this crack was secondary to (i.e., produced by) the primary fracture and occurred as a consequence of the way the flange separated from the valve body. Thus, the valve fracture did not originate from this region of the ring.

\subsubsection{Nondestructive Examination}

Magnetic particle examination was conducted on the valve and the tee/reducer components. Magnetic particle and some thickness measurements by ultrasonic testing (UT) were made on the tee/reducer component.

This examination indicates the presence of the secondary crack already noted in Figure 9-8, but this examination found no surface defects in the tee/reducer.

The $x$-radiography of the valve indicated that the body was sound and relatively clean. A small amount of shrinkage was noted in one area. The crack noted in Figure 9-8 also was evident in the radiograph. No porosity was detected in flange pieces $B$ and $C$.

\subsubsection{Disassembly}

Disassembly consisted mainly of unbolting the blind flange from the valve, the broken flange from its mating tee, and the bonnet from the valve body.

Each flange contained eight 3/4-in. hex-head bolts and nuts. The bonnet-body assembly contained fourteen 1/2-in.-diameter square-head bolts with hex-head nuts.

The untorquing force required for six of eight bolts in the broken flange was in the range of 150 to $2201 \mathrm{bf} \cdot \mathrm{ft}$. The two bolts whose nuts were hidden behind the flange web (see top of Figure 9-11) averaged about 25 to $30 \mathrm{lbf} \cdot \mathrm{ft}$. The untorquing force for six of the eight bolts holding the blind flange to the tee was less, ranging between about 100 and $2001 \mathrm{bf} \cdot \mathrm{ft}$. The remaining two bolts, whose nuts also were hidden by the flange web, averaged about $30 \mathrm{lbf} \cdot \mathrm{ft}$. The low-torque bolts were in the same location for each flange. The low torques do not appear related to the valve fracture. 
The $11 / 8$-in. diameter valve stem was removed and the extent of out-ofstraightness measured. The stem appeared to be bent starting at about the top of its acme thread. The disc end of the stem appeared to be bent a maximum of approximately 0.050 in.

\subsubsection{Microstructure}

The microstructures of several areas of the $f 1$ ange region adjacelit to the valve fracture face were examined microscopically. The nature and distribution of various phases in the microstructure can provide information relating to the strength and integrity of the cast iron. Furthermore, ine microstructure is affected by chemical composition. Results of chemical anaiysis appear in Section 9.6.7.

In general, the microstructure was typical of gray cast iron. The material appeared metallurgically clean and contained no significant voids or shrinkage. Further, no secondary cracks were seen, except the one noted in Figures 9-8 and 9-12 through 9-14.

The term gray iron refers to a broad class of ferrous casting alloys normally characterized by a microstructure of flake graphite in a ferrous matrix. The mechanical and physical properties of gray iron are governed in part by the shape, size, amount, and distribution of graphite flakes (mechanical property results are discussed in more detail in Section 9.6.6). In turn, the form in which the graphite flake is deposited depends on such factors as cooling speed and composition.

A method for evaluating graphite flake distribution and size is given in ASTM A 247 and is also discussed in ASM 1988. There are five graphite flake distributions, $A$ to $E$. Type A graphite flakes are distributed randomly and oriented throughout the matrix. This type of graphite is found in irons that solidify with a minimum amount of undercooling. Type B graphite is formed in irons of near-eutectic composition that solidify with a greater amount of undercooling than that associated with type $A$ graphite. Rosettes containing fine graphite are characteristic of type B. Type C graphite occurs in hypereutectic irons, particularly those with as high carbon content. Kish graphite, as it is often called, appears as straight and undistorted flakes or very thick lumpy flakes. Large flakes of graphite are associated with irons having a high carbon equivalent (See Section 9.6.7) and slow cooling rates. Small flakes are desired when maximum tensile strength is needed. For information on types D and E, see ASTM A 247 or ASM 1988.

Cooling rate is important. In general, when cooling rate decreases, pearlite decomposes progressively to a mixture of ferrite and graphite, resulting in softer and weaker iron.

The microstructure of cast irons commonly contain graphite, ferrite, cementite, and pearlite. An etching agent such as $2 \% \mathrm{Nital}$ will reveal the matrix phases in which the graphite flakes reside.

Ferrite is the soft, low-carbon, alpha iron phase that exhibits low tensile strength but high ductility. Cementite is a hard, brittle intermetallic compound of iron and carbon $\left(\mathrm{Fe}_{3} \mathrm{C}\right)$. In hyper-eutectic and eutectic irons, normal and undercooled flake graphite arises from the eutectic 
transformation and is deposited directly from the liquid and not indirectly from carbide decomposition. Pearlite is the eutectoid transformation product and consists of alternating lamellar plates of soft ferrite and hard cementite. Pearlite possesses higher hardness and tensile strength than ferrite but lower ductility. Higher values of hardness are found in pearlite with finer interlamellar spacing.

The dominant type of graphite flake distribution in Op-Met 1 (Figure 9-15) and Op-Met 2 (Figure 9-17) is primarily type $A$, referred to as "uniform distribution random orientation." A small amount of type C graphite flake, referred to as "superimposed flake size random orientation," al so appears to exist in both sections. The presence of some type $C$ graphite appears to correlate with the near-eutectic, and possibly hyper-eutectic, composition of the valve (see Section 9.6.7 for alloy chemical analysis results). The microstructure of the broken bonnet foot (noted only as SEM-5 in Figure 9-9), not shown, contained mainly type B rosette graphite flakes.

The higher magnification of Op-Met 1 and 2 (500 X, Figures 9-16 and 9-18) shows islands of soft ferrite (white areas) and pearlite (a)ternating layers of ferrite and cementite). The presence of ferrite islands may have occurred as a result of a slow cooling rate that allowed more time for carbon migration within the austenite; it is also promoted by higher silicon content, which favors the formation of graphite rather than cementite. High values of carbon equivalent (CE) also promote transformation of ferrite and graphite. As shown in Section 9.6.7, the carbon and CE levels are relatively high. The silicon level of $2.18 \%$ is about mid range (approximately 1.8 to $2.4 \%)$.

\subsubsection{Fractography}

An SEM was used to examine a range of fracture surfaces. The primary purpose of this examination was to determine general fracture topographic characteristics and to note any significant differences among the regions of the fracture surfaces. Significant differences could indicate that more than one fracture mechanism occurred or that a crack had grown slowly by one mechanism and then failed rapidly after a significant load increase.

A relatively wide range of fracture surfaces was observed in the asfailed state and later after cleaning. The surfaces were cleaned to determine whether any portion of any remaining deposits could be removed for a clearer picture of what the fracture surface looked like shortly after final fracture. A deposit that could not be removed readily might be related to fracture surface corrosion that occurred after the fracture during steam venting. Some fresh fracture surfaces were produced to provide a reference condition.

The regions or samples observed were SEM-2, SCA-1, and SEM-5 (see Figure 9-9 for sample layout). Fresh fractures were obtained from the web section of SEM-3 (body) and later from SEM-5, the broken bonnet foot. The latter was a different casting but probably the same grade of cast iron as the valve body. SEM-1 was examined for comparison with its diametrically-opposed

specimen, SEM-2. Later, SEM-1 and SEM-2 were cleaned thoroughly, primarily to remove any small amounts of remaining sand and any steam-borne corrosioninhibiting chemicals that might have been carried by the steam. Surface 
chemistry scans were conducted to help discern the differences among graphite flakes, corrosion products, and deposited oxides.

Figures 9-19 and 9-20 are fractographs taken near the inner diameter surface of SEM-2. In Figure 9-19 (150X), the gray areas were found to be graphite flakes. Much of the remaining area, as shown in Figure 9-20 (500X), appeared as an oxide covering. The next two fractographs (Figures 9-21 and 9-22) were taken in the central region of SEM-2. Here the surface appears sharper and cleaner. There was slightly less oxygen detected in the area shown in Figure 9-22. Cleaning these surfaces in soapy water, a household cleaning agent, and acetone appeared to reduce the amount of oxygen detected and made the surfaces look similar.

A fresh fracture is shown in Figure 9-23 (SEM-3). Here the graphite flakes are more obvious and the amount of oxygen is significantly less. The "blocky" character of the fracture surface in Figure 9-23 was typical of essentially all the surfaces, but was most pronounced in SEM-5 (Figure 9-24). Because the fresh fracture was produced by impact in the laboratory, this blocky structure is not a result of an intergranular stress-corrosion type of crack-growth process.

\subsubsection{Mechanical Properties}

The mechanical properties of gray iron are governed or affected by a number of factors:

- Graphite flake amount, size, shape, and distribution

- Alloy composition

- Section size, which governs cooling rate.

These factors are interrelated. For example, a required tensile strength can be achieved by more than one chemical composition, and composition alone does not determine properties. A discussion of these effects is important for qualifying the tensile strength and hardness data obtained from the broken valve.

Gray iron is usually specified entirely by tensile strengths of standard, separately cast test bars, and composition is mentioned only when some special property is required. ASTM A 126-84, the controlling standard for valves, calls out three gray-iron strength levels ( $A, B$, or $C$ which relate to nominal tensile strength levels of 21,31 and $41 \mathrm{kip} / \mathrm{in}^{2}$ ) and only maximum limits on sulfur and phosphorous. According to the crane catalog, class $B$ is the minimum strength level of the broken valve based on a separately cast tensile bar. The ASTM A 48, Standard Specification for Gray Iron Castings, which is also widely used for classifying gray irons, classifies cast irons according to the minimum tensile strength acceptable in a specific test bar. These strengths range from 20 to $60 \mathrm{kip} / \mathrm{in}^{2}$.

ASTM A $126-84$ also allows the manufacturer or foundry to substitute test specimens and testing procedures in accordance with Specification A 48. The equivalent classes in A 48 are shown in Table 9-1.

For $\mathrm{A} 126 \mathrm{Cl}$ ass $\mathrm{B}$ material, the corresponding $\mathrm{A} 48 \mathrm{class}$ materials and nominal strength levels are $35 \mathrm{kip} / \mathrm{in}^{2}$ (CTass $35 \mathrm{~A}$ ) for a 0.5 -in dia. specimen, 
$30 \mathrm{kip} / \mathrm{in}^{2}$ for 0.51 to $1.0-\mathrm{in}$. dia., and $30 \mathrm{kip} / \mathrm{in}^{2}$ for a diameter greater than 1.0 in. The tensile specimens that were removed from the $1.0-i n$. flange of the broken valve, had a 0.5-in. dia.; they are discussed later. The 1.0-in. dimension is the controlling dimension with respect to Table 9-1.

The mass effect associated with increasing section thickness or decreasing cooling rate, and its strong effect on strength, is much more pronounced in gray iron than in cast steel. The mass effects in cast steel result in increased grain size in heavy sections. This statement also applies to gray iron, but the most importint effects result ir. changes in graphite size, distribution, and the amount of combined carbon.

For any given gray-iron composition the rate of cooling from the freezing temperature to below about $650{ }^{\circ} \mathrm{C}\left(1,200{ }^{\circ} \mathrm{F}\right)$ determines the ratio of combined graphitic carbon, which controls the hardness and strength of the cast iron. Thus, the effect of section size in gray iron is considerably greater than in the more homogeneous ferrous metals in which cooling rate does not affect the form and distribution of carbon throughout the metal structure.

The range of actual strengths in class 20 and class 30 gray irons (nominally tensile strengths of 20 and $30 \mathrm{kip} / \mathrm{in}^{2}$ ) is shown in Table 9-2. Class 20 gray iron can vary from a high of $40 \mathrm{kip} / \mathrm{in}^{2}$ at about $1 / 4-\mathrm{in}$. thickness to a low of $12 \mathrm{kip} / \mathrm{in}^{2}$ at an approximate 4 -in. thickness. Similarly class 30 gray iron varies from about $45 \mathrm{kip} / \mathrm{in}^{2}(1 / 2-\mathrm{in}$. diameter) to about $20 \mathrm{kip} / \mathrm{in}^{2}$ (4-in. diameter). Ostensibly the section size at which the rated strength equals the actual strength is about $1-1 / 4$ in. In the subject broken valve, thicknesses varied from about $1.0 \mathrm{in}$. in the flange to about $5 / 8-\mathrm{in}$. at the fracture region.

Normally, the only mechanical property used to classify gray cast irons is tensile strength. Percent elongation, a measure of ductility, is known to be low, varying typically from about 0.2 to about $0.75 \%$ with an average value around $0.6 \%$. Yield strength is not well-defined because the stress-strain curve is non-linear, usually decreasing with increasing stress. Thus the modulus of elasticity is not a single number. Values of the modulus are usually estimated by either the tangent modulus or the secant modulus method.

Cast iron is also anisotropic. The modulus is higher in compression. Compression strength is often three to four times higher than the corresponding tensile strength.

Carbon affects tensile strengths in several ways. First, the effect of CE can be signifjcant, as shown in Table 9-3. Here the strength decrease ( 52 to $18 \mathrm{kip} / \mathrm{in}^{2}$ ), with increasing CE, is due primarily to an increase in the amount of ferrite in the microstructure and to pearlite coarsening. Second, increasing the maximum length of graphite flakes has a strong inverse effect on tensile strength (48 to $22 \mathrm{kip} / \mathrm{in}^{2}$ ), as shown in Table 9-4. A cursory examination of $0 p$. Met 1 and 2 (Figures $9-15$ and 9-17) shows the maximum flake lengths to be about 0.024 and 0.031 in., respectively. These lengths alone indicate that the valve strength would be at the low end of the range based on section thickness (Table 9-2). 
Hardness is important, as it can be used as a measure of cast iron strength. Hardness is a measure of the resistance of a material to surface indentation or abrasion. In metals, hardness is a measure of their resistance to permanent or plastic deformation.

One test of hardness is the static indentation test in which a ball, diamond cone, or pyramid is forced into the material being tested. The relationship of total test force to the area or depth of indentation provides the measure of hardness. The BH test is most often used because the 1arger diameter of the indentor provides an average of the various microconstituents present in the iron. Individual constituents of gray cast-iron microstructuri have $B H$ levels as shown in Table 9-5. The hardness ranges for various combination of gray iron microstructures are shown in Table 9-6.

\section{Tensile Strength and Hardness Data from Broken Valve}

Three tensile specimens of 0.5 in diameter (see Figure 9-7) were removed from flange section $B$. BH measurements were made on the tensile specimen blanks before they were machined into tensile specimens. Before tensile testing, a strain-gauged test specimen was placed in the tensile test machine to determine the amount of bending in that specimen produced by the testmachine/specimen combination. Bend stress levels for test-machine load levels of 1,200 and $2,400 \mathrm{lb}$ were all less than $10 \%$. The values ranged from 3.6 to $8.3 \%$.

The tensile strength and accompanying $\mathrm{BH}$ values are shown in Table 9-7. The average tensile strength was $15.9 \mathrm{kip} / \mathrm{in}^{2}$. This value is less than the $31 \mathrm{kip} / \mathrm{in}^{2}$ called for in A $126 \mathrm{Cl}$ ass B material including the effect of section size. The average hardness level was $B H$ 139. The average hardness level was consistent with the average tensile stress. For the same BH level, Angus (1960) showed that cast iron strength levels could range from approximately 15 to $20 \mathrm{kip} / \mathrm{in}^{2}$.

Because the tensile strength values were low, BH hardness readings were taken from a ring of material removed from the valve about $0.5 \mathrm{in}$. below the circumferentially fractured region. The $\mathrm{BH}$ readings were made adjacent to the vibro-etched valve reference numbers 0 through 9. The $\mathrm{BH}$ values were $0=130$, $1=132,2=130,3=128,4=132,5=143,6=136,7=136,8=140$ and $9=130$. The average $B H$ value was 134. Even though the material thickness in this area of the valve was approximately $5 / 8$-in., there was no significant change in hardness from the thicker l-in. section (139). In fact, the tensile strength may be the same or even a little less than the $15.9 \mathrm{kip} / \mathrm{in}^{2}$ average value obtained from the tensile specimens. These lower strength values appear to be consistent with the high CE value of the cast iron valves, the relatively long graphite flakes, and the presence of soft ferrite in the microstructure.

\subsubsection{Chemical Analysis}

Gray irons are in essence iron-carbon-silicon alloys containing small quantities of other elements. As noted earlier, the term gray iron also refers to a broad class of ferrous casting alloys normally characterized by a microstructure of flake graphite in a ferrous matrix. Alloy chemical analysis is a vital step in assessing the strength and integrity of cast iron. 
The major elements in gray iron are carbon, silicon and iron. Both carbon and silicon influence the nature of iron castings. For example, a class 20 gray iron (the number 20 referring to a nominal tensile strength of $20 \mathrm{kip} / \mathrm{in}^{2}$ ) coniains 3.4 to $3.6 \%$ rarbon and 2.3 to $2.5 \%$ silicon. Class 30 gray iron contains 3.10 to $3.30 \%$ carbon and 2.10 to $2.30 \%$ silicon. As the strength level of gray iron increases $\left(40,50\right.$, and $\left.60 \mathrm{kip} / \mathrm{in}^{2}\right)$, carbon 1 evel progressively decreases and silicon content generally decreases.

The minor elements in gray iron are phosphorous and the two interrelated elements manganese and sulfur. It is important that the sulfur content be balanced with manganese to promote the formation of manganese sulfides. Trace elements can include chromium, nickel, molybdenum, and others (ASM 1988).

The lowest melting point alloy, or eutectic, occurs with a carbon content in the neighborhood of 4.2 to $4.3 \%$ at a melting (freezing) point of $1,140{ }^{\circ} \mathrm{C}\left(2,080^{\circ} \mathrm{F}\right)$ for a pure iron-cementite alloy and about $1,125^{\circ} \mathrm{C}$ $\left(2,060^{\circ} \mathrm{F}\right)$ for an iron-graphite alloy or cast iron. Additions of silicon lower the percentage of carbon in the eutectic by about $0.33 \%$ for each $1 \%$ silicon added. With $1 \%$ silicon, the eutectic would occur at approximately $3.97 \%$ of carbon. Additions of phosphorous affect the eutectic carbon value to about the same amount as silicon. None of the other elements normally present (manganese and sulfur) affect the eutectic significantly.

A cast iron may therefore have a composition that makes it hypoeutectic, eutectic, or hyper-eutectic with regard to carbon. For example, the well known iron-carbon equilibrium or phase diagram (ASM 1973, p. 275) shows the graphical relationship between temperature and composition limits of various iron-carbon phases. When describing cast irons by carbon content, the usual method employed is the CE (Angus 1960) value in which

$$
C E=\text { Total Carbon }+1 / 3 \text { (Silicon } \%+\text { Phosphorous \%). }
$$

According to Angus, it is CE, rather than total carbon level which applies with commercial irons when using the iron-carbon phase diagram.

Alloy chemical analysis was conducted on material removed from the flange section B (Figure 9-9). Carbon level was determined by combustion. The remaining detectable elements were determined by spectroscopy. The chemical content is shown in Table 9-8.

The cast iron composition shown in Table 9-8 meets ASTM A 126 requirements for phosphorous and sulfur.

The CE value for the valve flange material is

$$
C E=3.66+1 / 3(2.18+0.132)=4.43 \% \text {. }
$$

The eutectic value of carbon from the iron-carbon phase diagram (ASM 1973) is $4.3 \%$. Thus the CE value of $4.43 \%$ is slightly hypereutectic. Hypereutectic cast irons display type $C$ graphite flakes. As noted in Section 9.6.4, a few type $C$ graphite flakes appear in the samples shown in Figures 9-15 and 9-17. Thus, the CE content appears to correlate with the few type $C$ graphite flakes. 
The lower tensile strength, described in Section 9.6.6, 2iso correlates with the higher carbon and CE levels.

\subsection{DISCUSSION}

Metallurgical failure analysis of the ruptured valve involves a progression. The steps in this progression began with a site visit to recommend those points at which the broken flange and attached tee/reducer should be removed from the steam line system. Following removal, the pieces were examined visually and dimensions were taken. This step was followed by limited NDE by magnetic particle and radiographic techniques. Radiography concentrated mainly on the fractured region and its mirror image region adjacent to the unbroken flange. Bolt untorquing levels were recorded as the flange bolts and bonnet-valve body bolts were removed. The microstructure of the fractured valve and SEM analysis of its fracture surfaces also were examined. Generally, photographs were taken at each stage of the operation. A remnant of the valve flange was sent to a commercial testing laboratory to determine tensile properties, hardness levels, and alloy chemical composition.

Visual Examination. Visual examination indicates that there were only two fractures within the valve, with the second one of minor importance. The major fracture occurred at the root of the flange adjacent to the connecting 6-in. tee/reducer (Figures 9-6 and 9-11). The steam was expelled through this opening. The minor fracture occurred in one of the feet supporting the yoke in the valve bonnet. The foot fracture probably occurred after the main rupture and probably was due to the impact of the airborne valve in the confines of the pit. No steam escaped as a result of this fracture. Some slight impact damage was noted on the edge of the valve fracture face, at the bottom of the valve. It, too, appeared to have occurred after the main rupture and probably was due to the impact of the valve in the confines of the pit. No similar damage was seen on the surface region of the mating fracture that was still attached to the tee/reducer.

The broken flange that remained attached to the tee/reducer was reddishbrown, mainly on the inner-half of the fracture circumference, except for an area approximately 2-in. wide at the lowest point of the flange. This color was removed from SEM sample surfaces by washing and was not visible on the fracture face of the mating valve body. Thus, it must have been caused by water-treatment chemicals carried in the steam that escaped in the time between the rupture of the valve and the cessation of steam and water flow in the system. Fractographic examination confirmed that this colored area did not represent either a pre-existing flaw or a different fracture mode.

Nondestructive Examination. Nondestructive examination by magnetic particle test indicated a secondary crack in the valve body; the crack appeared to emanate from the major circumferential fracture. No other cracks or defects were found either in the valve or the tee/reducer component. Radiography of the intersecting regions between the valve flange and valve body, including the fractured region, indicated that the valve material was sound and free of any significant porosity or shrinkage. One radiograph confirmed the presence of the secondary crack noted by earlier magnetic particle examination. Radiographs of portions of the broken valve flange showed no detectable porosity or shrinkage. 
Metallographic Examination. Metallographic examination of the valve body and bonnet showed no abnormalities. The microstructure was sound and relatively clean. No cracks were visible in the sections that were examined. Metallography confirmed that the valve body and bonnet were made of gray cast iron.

Further visual examination combined with optical microscopy indicated that the minor crack, leading from the outer surface of the fractured valve and progressing partway into the valve body, occurred as a consequence of the major fracture. Thus the major fracture did not originate within the body of the valve. Metallographic examinations also correlated with the high carbon and CE levels found through chemical analysis. Some Type C graphite flakes seen matched the near-eutectic to hype-eutectic level of carbon. The valve microstructure was mainly pearlite with some islands of soft ferrite.

Disassembly. Disassembly of the broken valve flange from its tee connection and of the blind flange from the unbroken portion of the valve indicated some variations, probably insignificant, in untorquing levels. The untorquing forces in the flanges were on the order of 100 to $2201 \mathrm{bf} \cdot \mathrm{ft}$. The two bolts at the top of each flange, within the shadow of the upper flange web, showed reduced untorquing forces of about $301 \mathrm{bf} \cdot \mathrm{ft}$. These 10 wer forces on two of the eight bolts in each flange did not appear related to the fracture.

Fractography. Examination of fracture surface samples in the SEM indicated that the fracture mechanism was essentially the same in diametrically opposed samples removed from the flange fracture face and in the sample removed from the broken bonnet foot. Further cleaning of the fracture faces removed deposits of oxide and sand. Fresh fracture surfaces made by impact in the laboratory indicated that some limited corrosion had occurred, as expected, on the valve fracture faces during steam venting. The colored deposit appearing only on the broken flange surface attached to the tee/reducer was identified but was easily removed from the fracture face, an indication that it came from the venting steam. No similar deposit was noted on the matching fracture face associated with the valve body. The :alve body separated during the event and thus had no further contact with system steam and water. The similarity between the laboratory impact-fracture surfaces and the valve fracture surfaces indicates that the valve experienced loadings beyond its normal load-carrying capacity.

Chemical Analysis. The chemical analysis results for the valve material met ASTM A 126 requirements. The high carbon and CE levels imply a reduced tensile strength.

Mechanical Properties and Hardness. The tensile strength of the 1.0-in. thick flange portion of the valve was low, averaging about $15.9 \mathrm{kip} / \mathrm{in}^{2}$. The $\mathrm{BH}$ levels were also low (averaging about 139 ) consistent with the lower average tensile strength. According to ASTM $A_{2} 126$, the minimum strength in a separately cast tensile bar should be $31 \mathrm{kip} / \mathrm{in}^{2}$. Allowing for section size difference is not enough to compensate for the decreased valve strength.

The $B H$ numbers also were taken in the vicinity of the approximately $5 / 8$-in.-thick circumferential fracture area. These hardness levels averaged about 134. Thus the strength of the valve in the vicinity of the valve 
fracture was about the same $\left(15.9 \mathrm{kip} / \mathrm{in}^{2}\right)$ or possibly slightly less. The reduced strength level, almost $50 \%$, also correlated with the valves relatively high CE value, relatively long maximum length of graphite flakes, and the presence of soft ferrite in the microstructure.

These results indicate that the valve failed because its pressure loading exceeded its load-bearing capacity.

\subsection{CONCLUSIONS}

The valve appears to have failed because its pressure-loading exceeded its load-bearing capacity. Values of tensile strength obtained from the flange section of the valve, coupled with $B H$ measurements in the flange and in the neighborhood of the fractured region, were lower than the minimum level stipulated by ASTM A 126 . Microstructure, chemical analysis, including carbon and carbon equivalent level, and maximum length of graphite flakes all appear to correlate with a reduced tensile strength. The valve meta? anot?red sound and free of any porosity, flaws, cracks or corrosion damage of any significance. 
Figure 9-1. Pian View Sketch of 6-in. Pipe Containing Broken Valve End.



79307065.6 
Figure 9-2. View of Sand-Covered Broken Valve Still Attached to the $6-\mathrm{in}$. Tee Leg of the 8- by $4-\mathrm{in}$. Reducer (93060714-47CN).

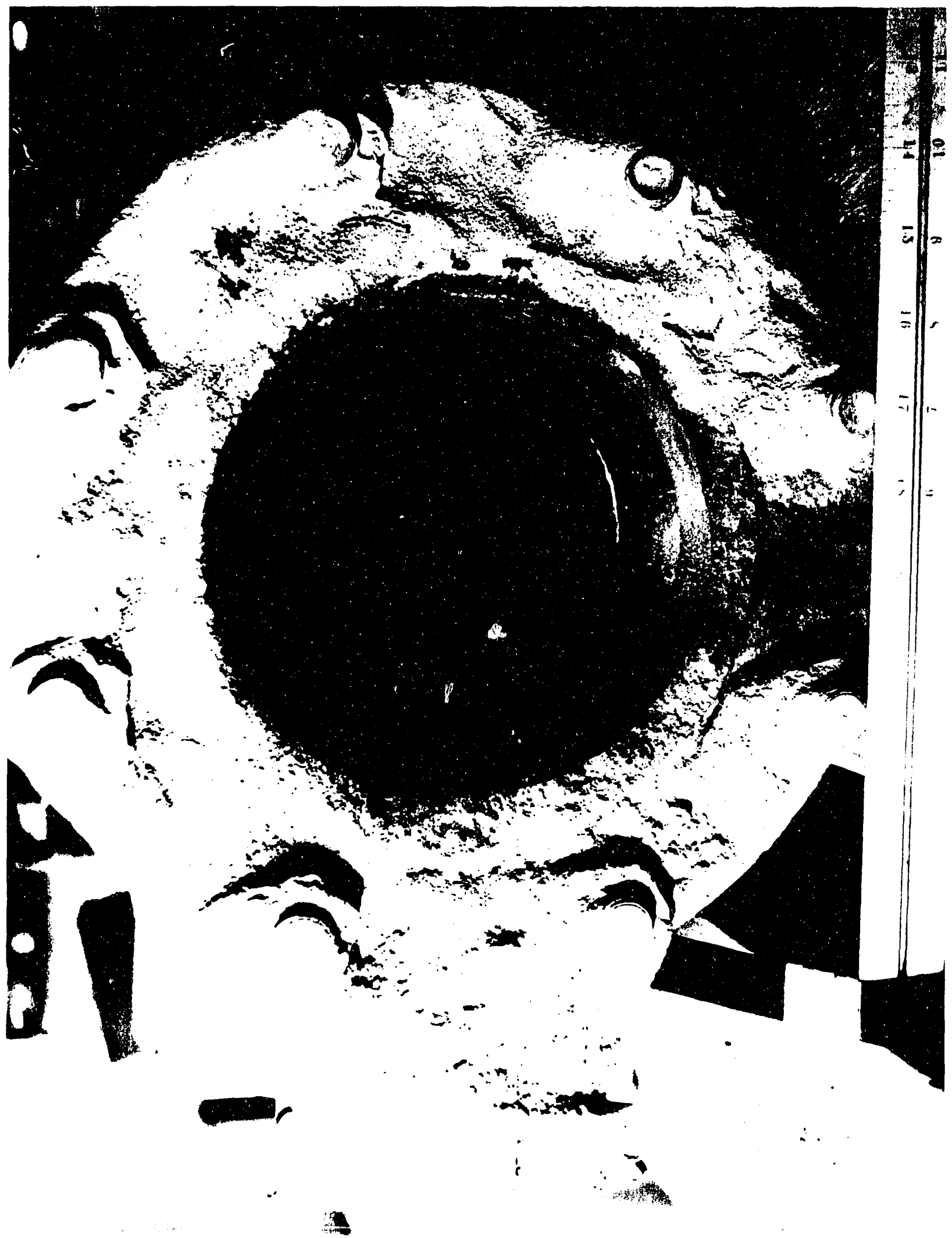


Figure 9-3. Valve and Tee Section Banded to Pallet, after Arrival at Building 272E, 200 Area. (93060714-38CN)

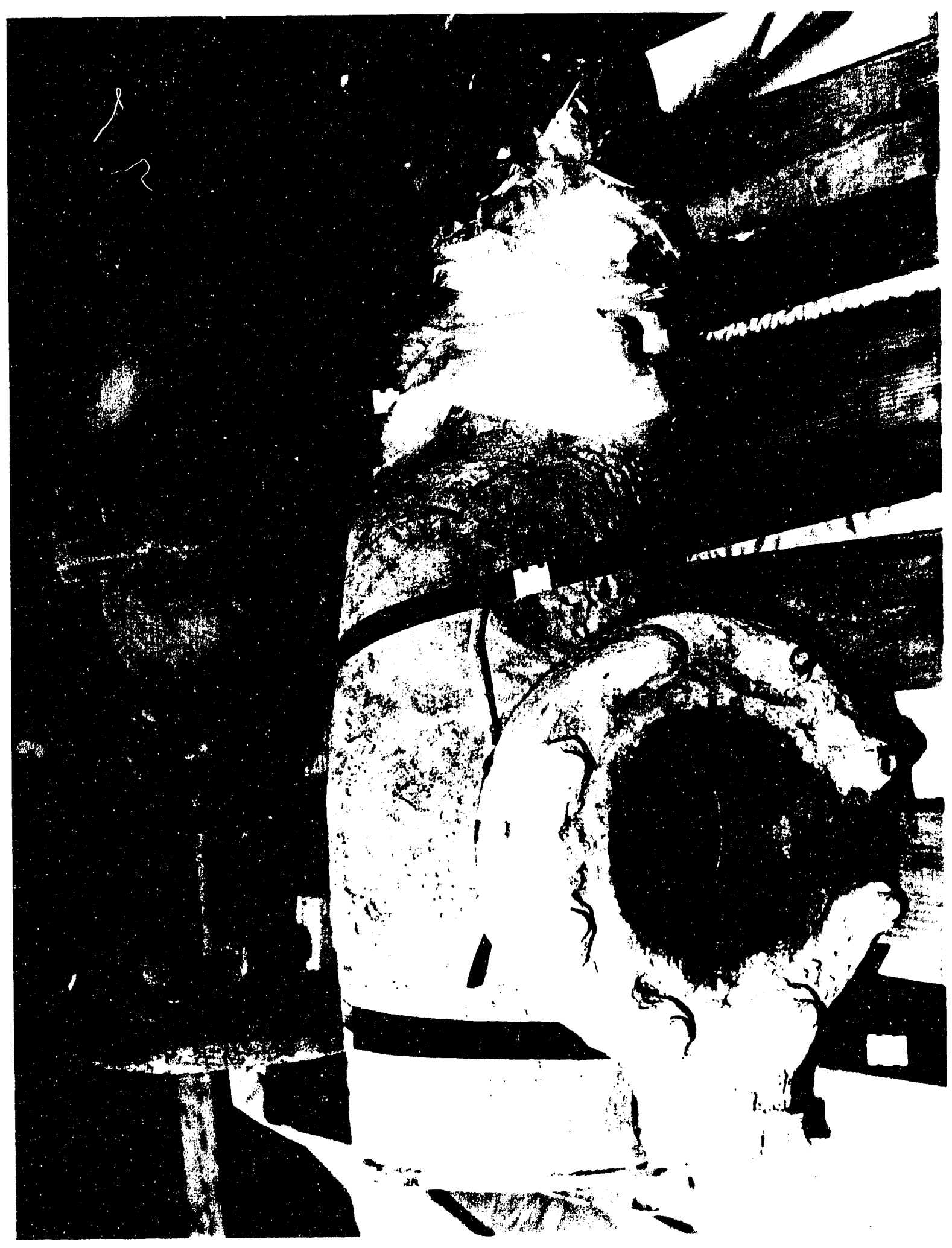


WHC-EP-0667

Figure 9 4. Low-Pressure Water Washing of Broken Valve. (930607l4 80.N)

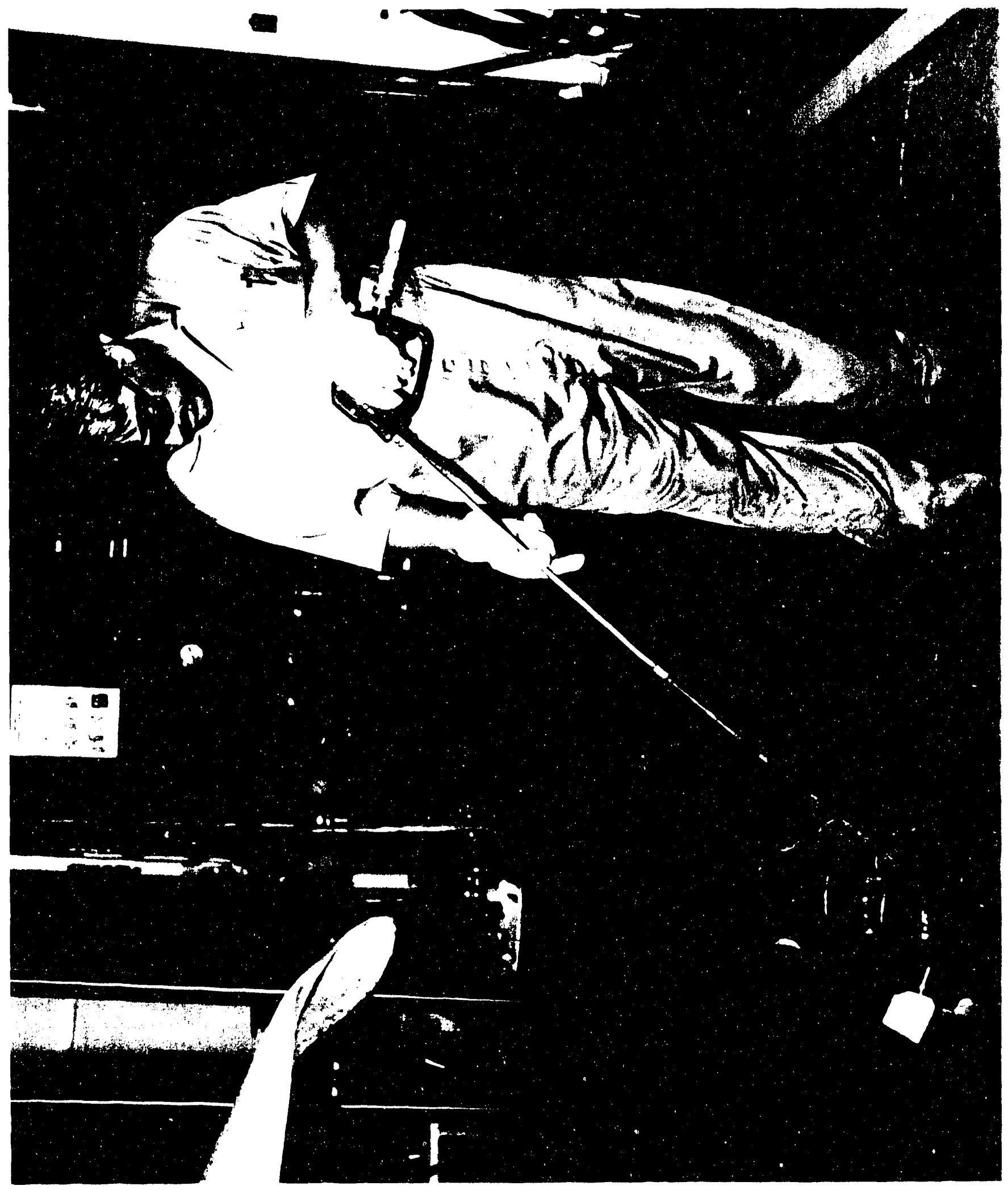


Figure 9-5. 6-in. Valve, Cleaned, Forced-Air Dried and Spray-Coated with WD-40. (93060714-12CN)

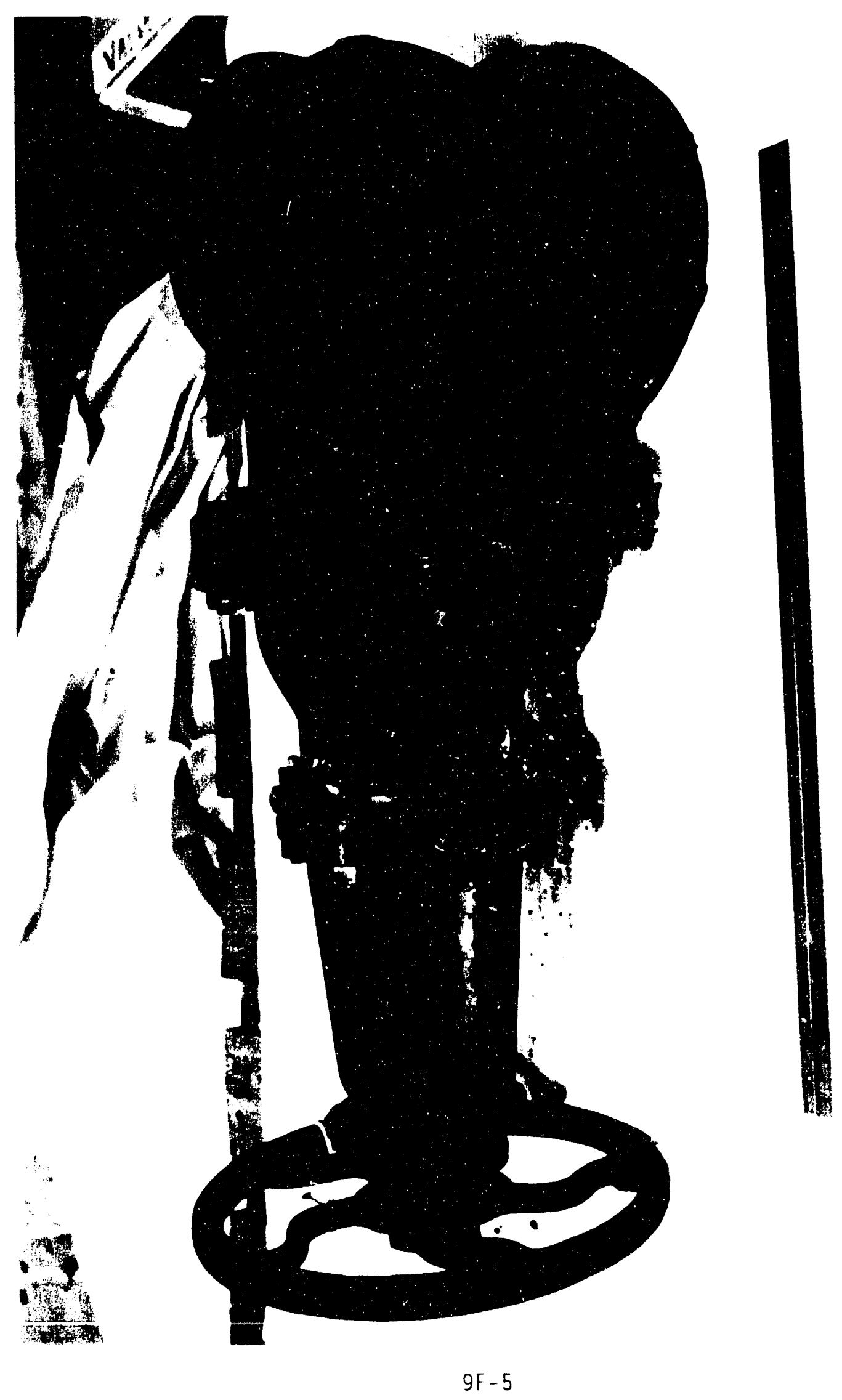


Figure 9-6. Tee/Reducer Section Cleaned, Forced-Air Dried, and Spray-Coated with WD-40. (93060714-19CN)

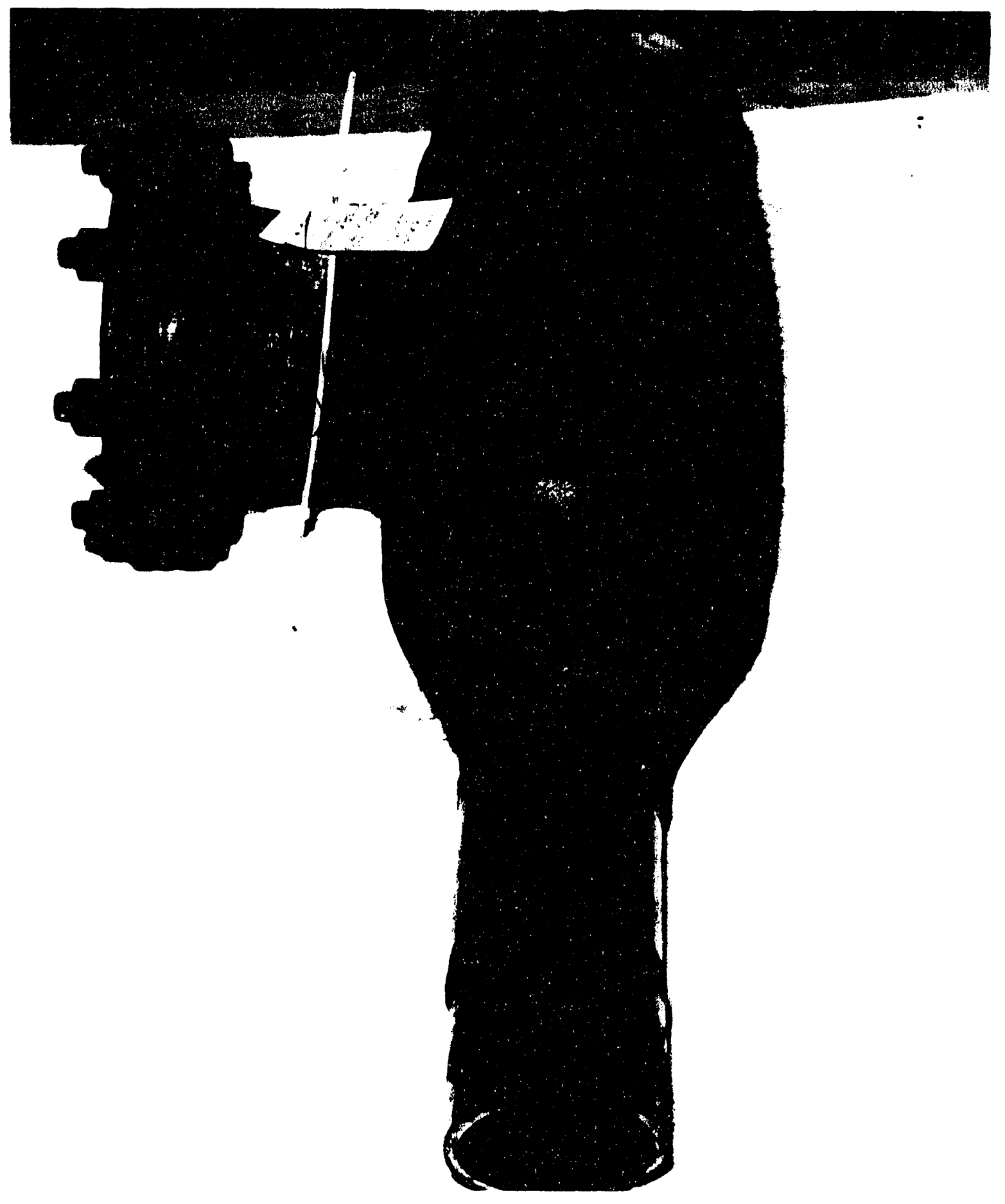




\section{WHC-EP-0667}

Figure 9-7. Cracked Valve Bonnet Foot (one of four yoke legs shown above cracked foot). (93060714-16CN)

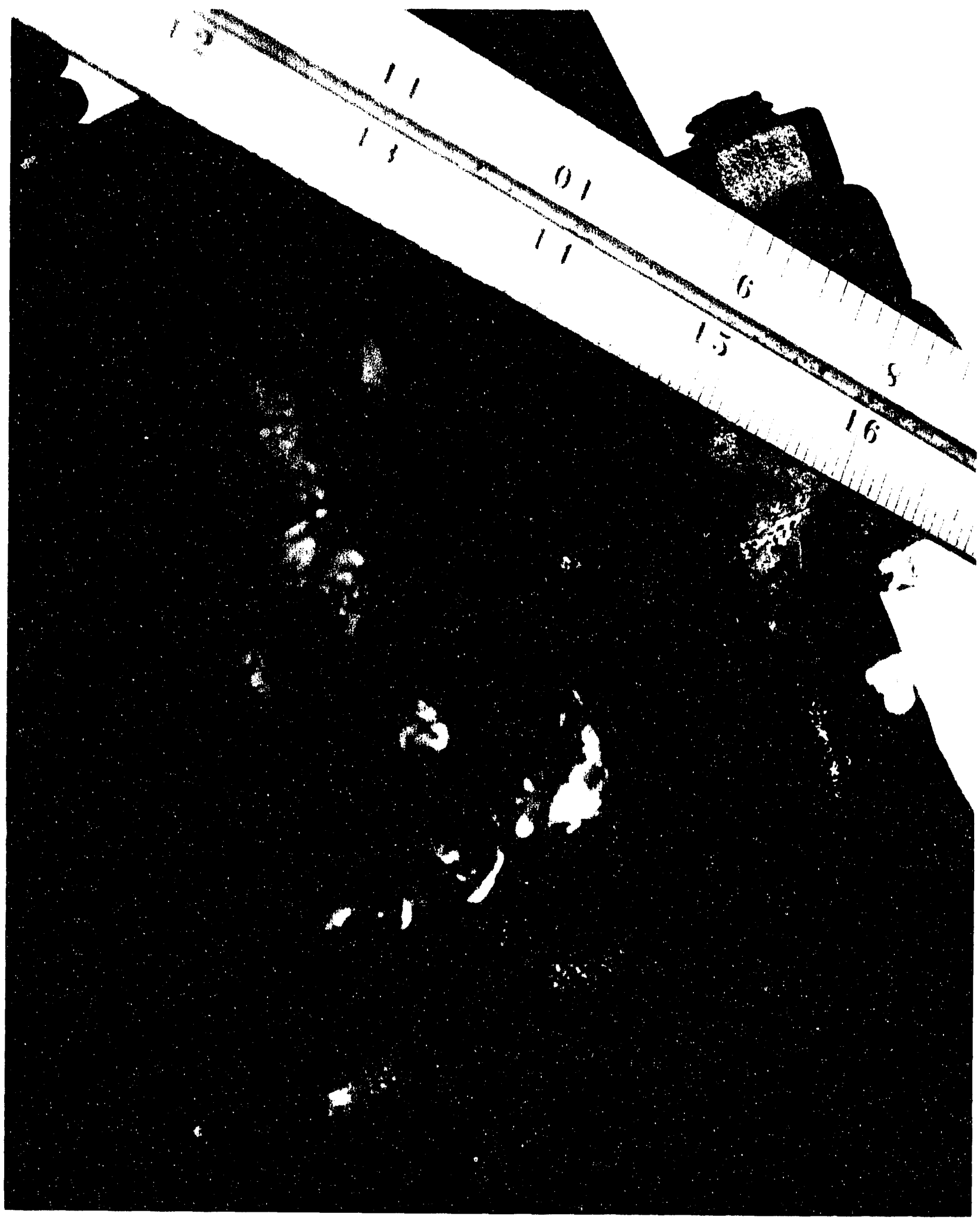


Figure 9-8. Location of an Additional Crack Penetrating the Valve Body off the Major Circumferential Fracture Surface. (93060738-3CN)

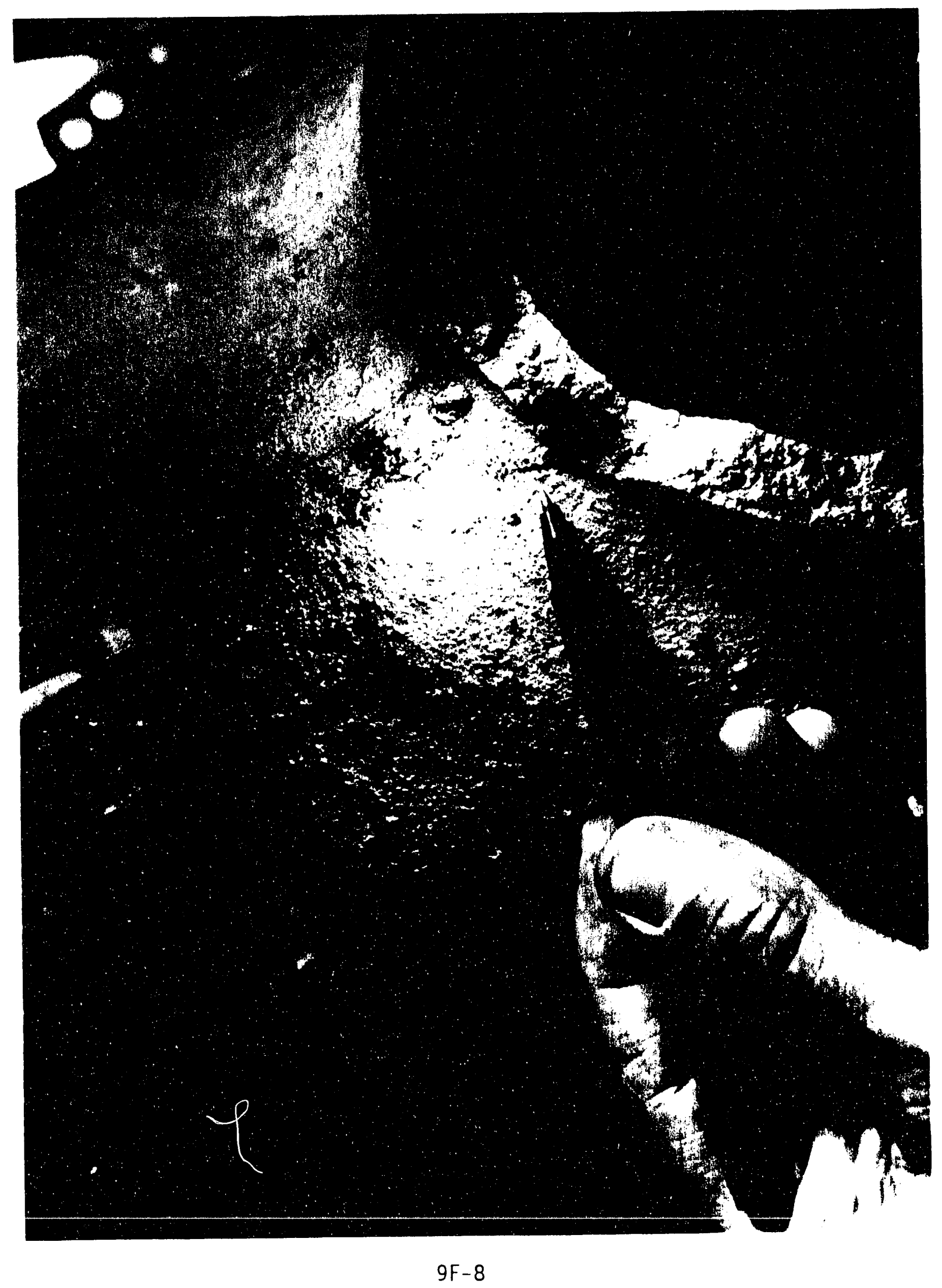


Figure 9-9. Layout of Specimens in Fractured Valve for Metallographic and Scanning Electron Microscope Observation and Surface Chemical Analysis. (93061015-1CN)

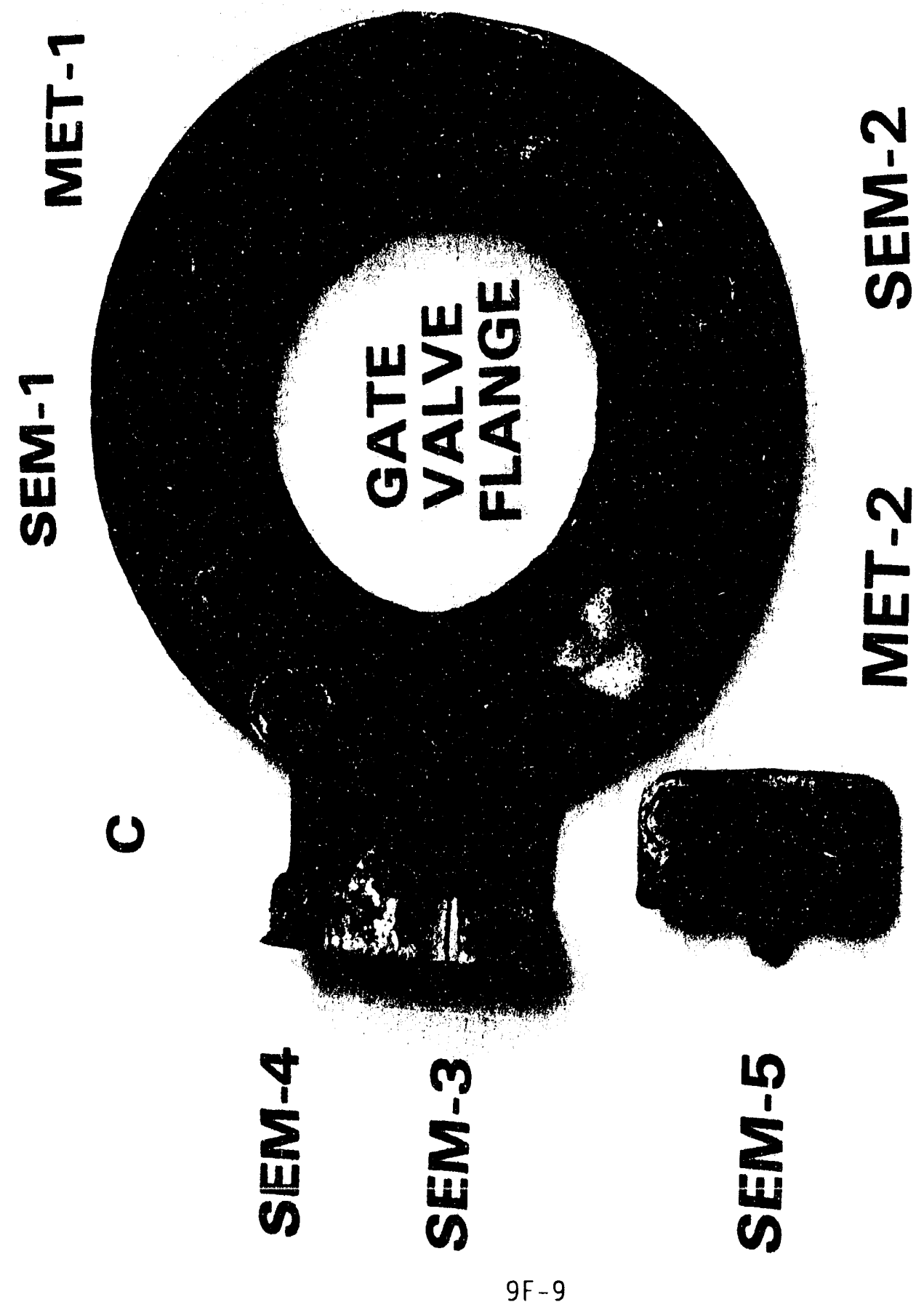




\section{WHC-EP-0667}

Figure 9-10, View of Valve Fracture Face and Probable Impact Damage Region. (93060714-18CN)

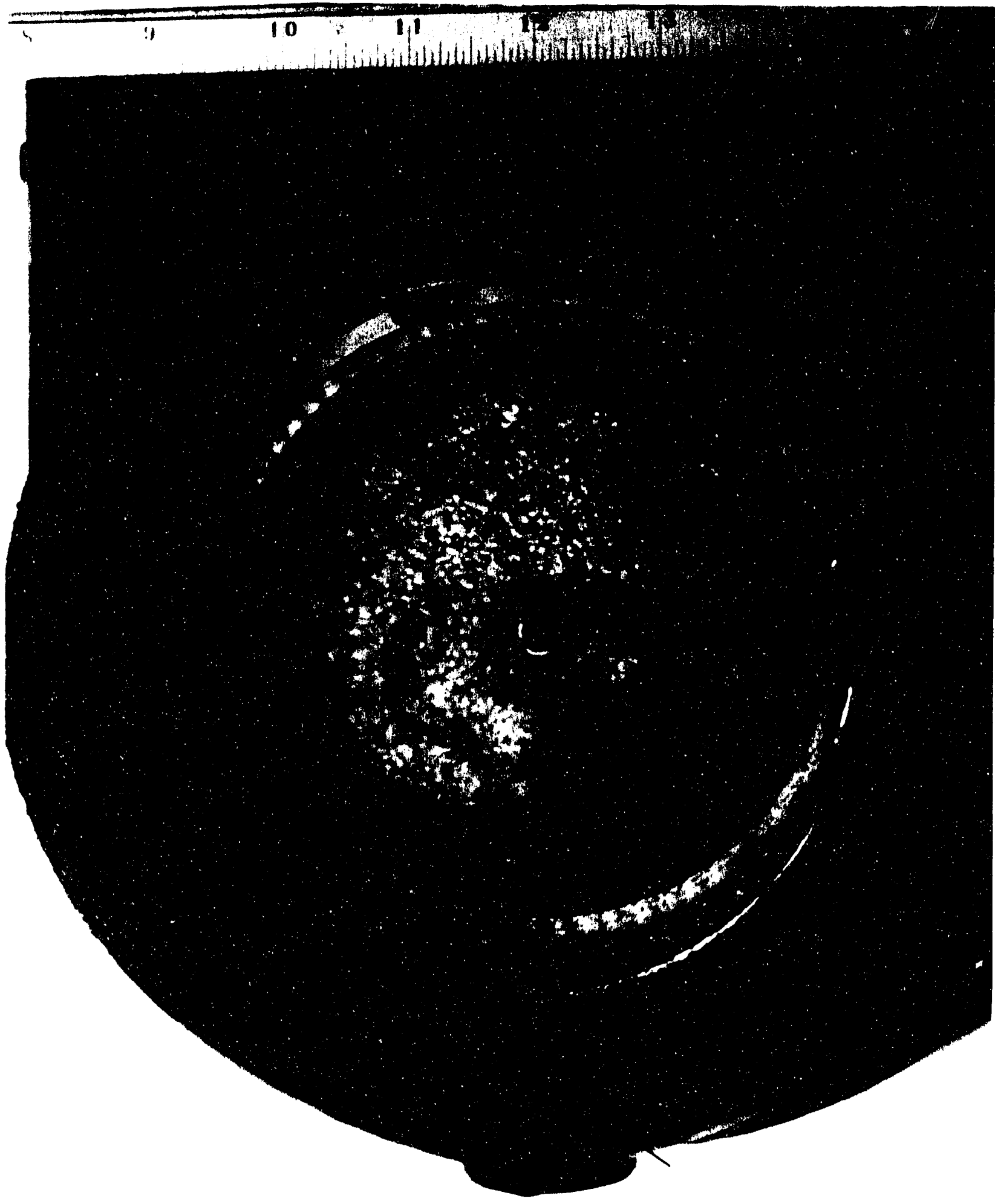


Higme 9.11. View of Mating Flange Fracture face Showing fieddich firown Stained Regions. (93060714-22CN)

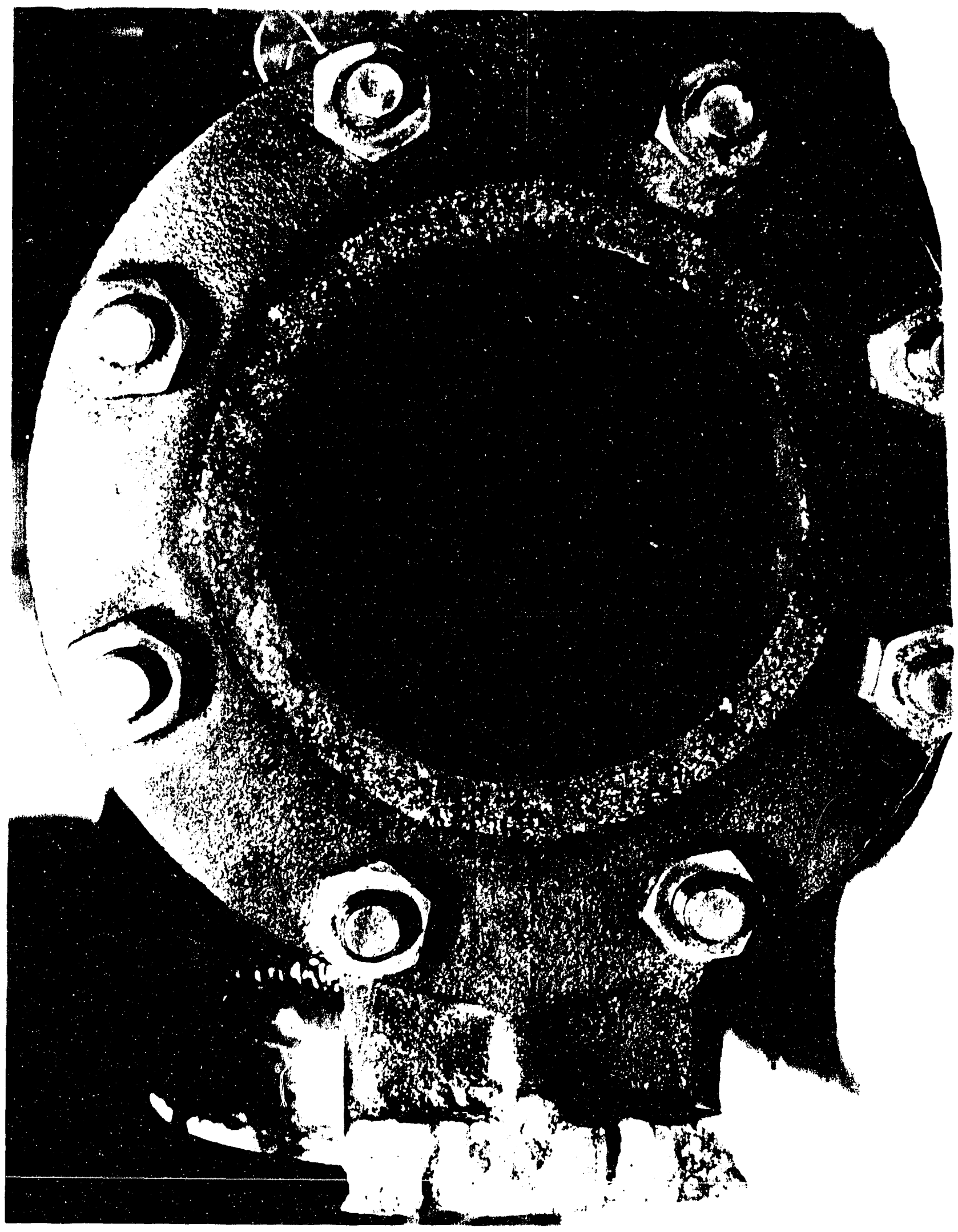


Figure 9-12. Close-Up View of Valve Fracture Face and Additional Crack. $(93223 A \quad 2 x)$

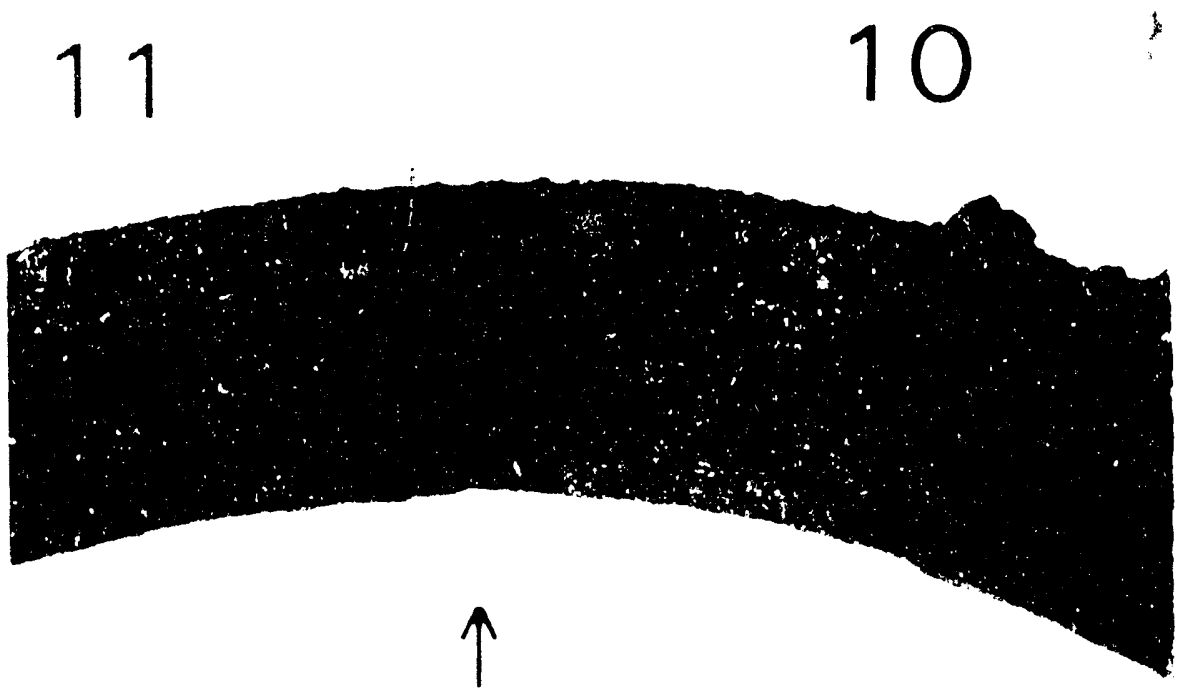

Figure 9-13. Close-Up View of Back Side of Figure 9-12 Showing Penetrating Crack. (93223B 2X)

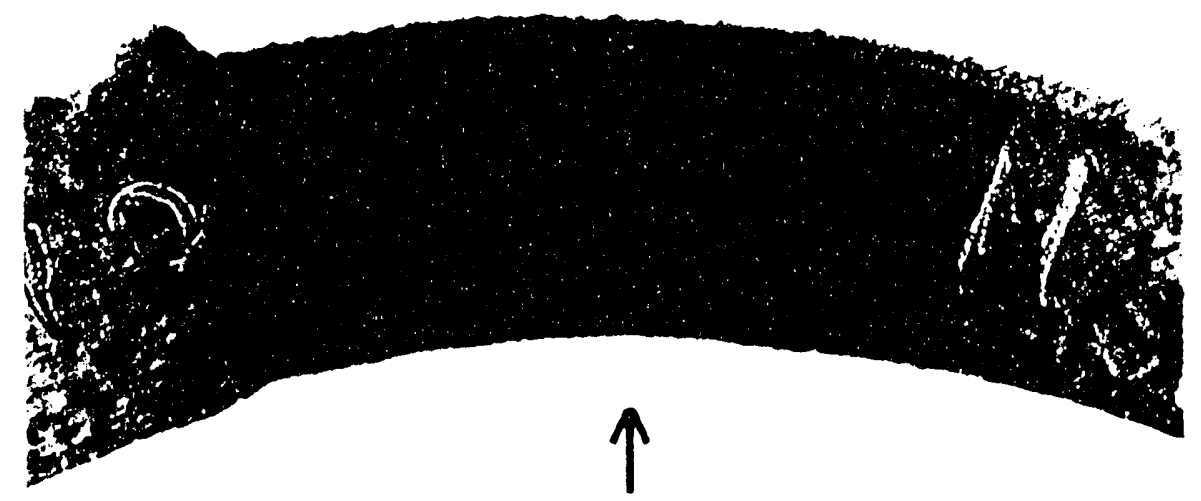


Figure 9-14. Higher Magnification View of Crack in Figure 9-13 Showing Unbroken Ligament. (93223L-4X)

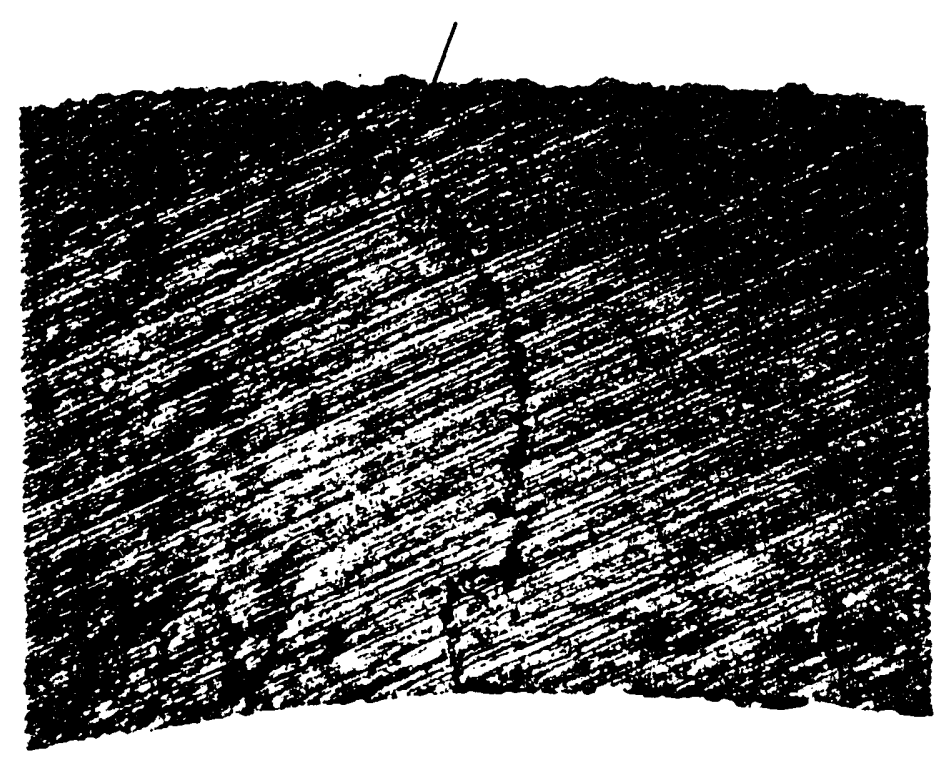

Figure 9-15. Cross Section of Fractured Valve Showing Crack Path and Microstructure, $50 \times$ ( $2 \%$ nital etch; Op Met-1). (93211A)

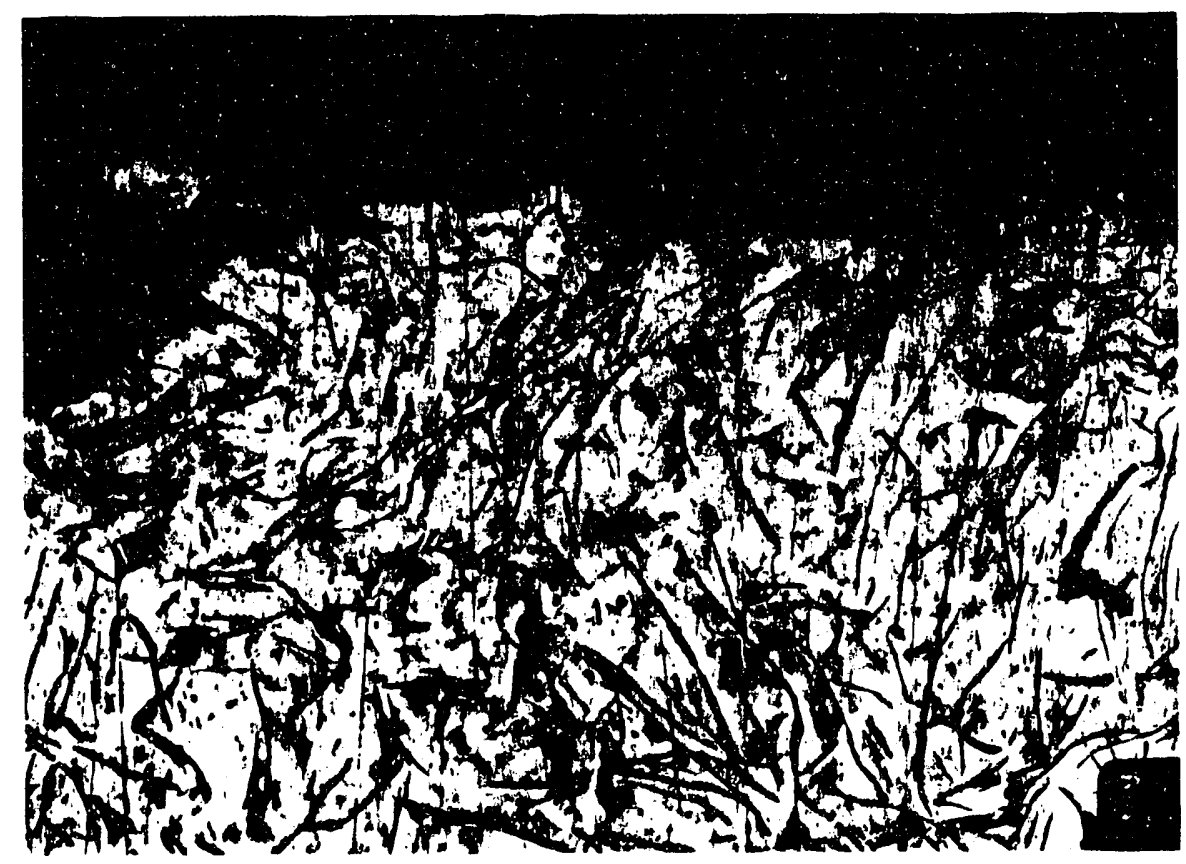




\section{THIS PAGE ACCIDENTALLY LEFT BLANK}


Figure 9-16. Higher Magnification View (500X) of Figure 9-15 Showing Graphite Flakes, Pearlite, and Ferrite (light areas)

(2\% nital etch; Op Met-1). (93211B)

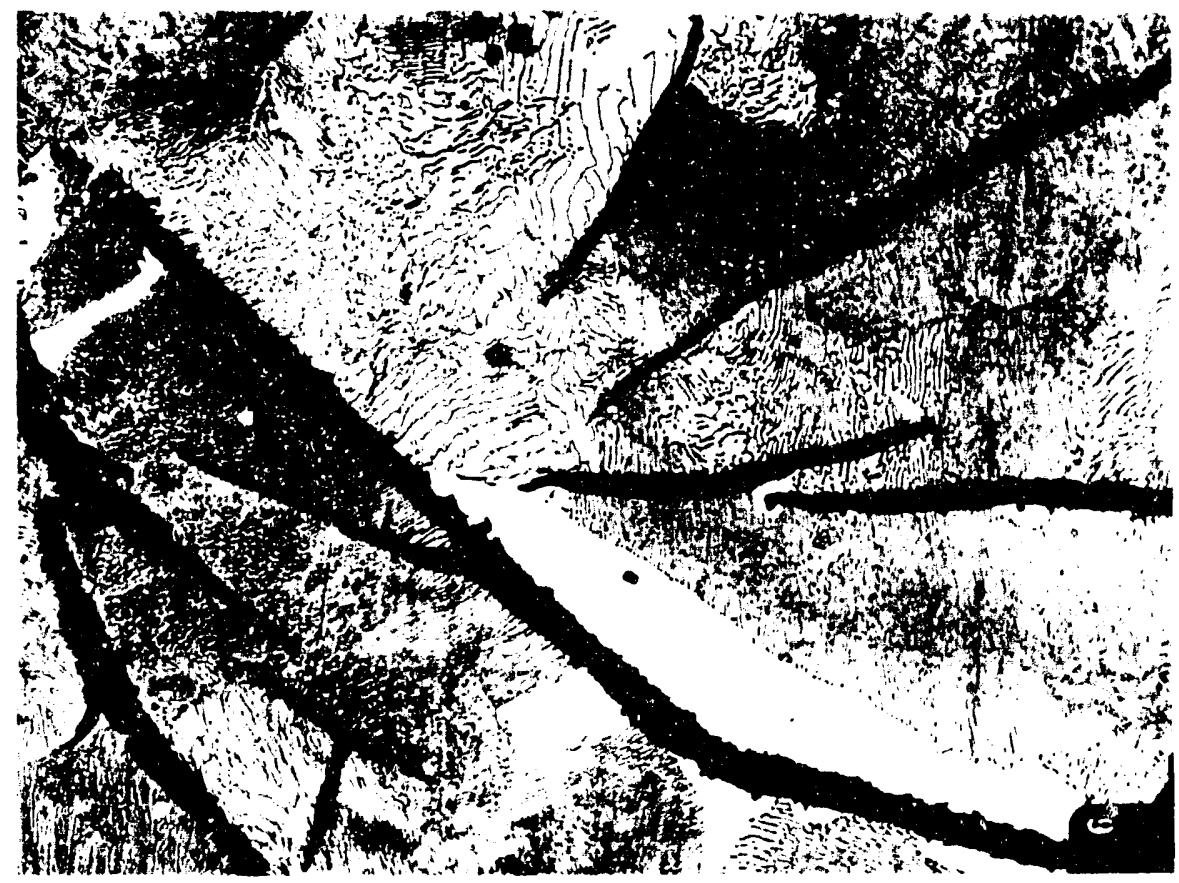

Figure 9-17. Criss Section of Fractured Valve Showing General Microstructure, $50 \times$ ( $2 \%$ nital etch; Op Met-2). (93212C)

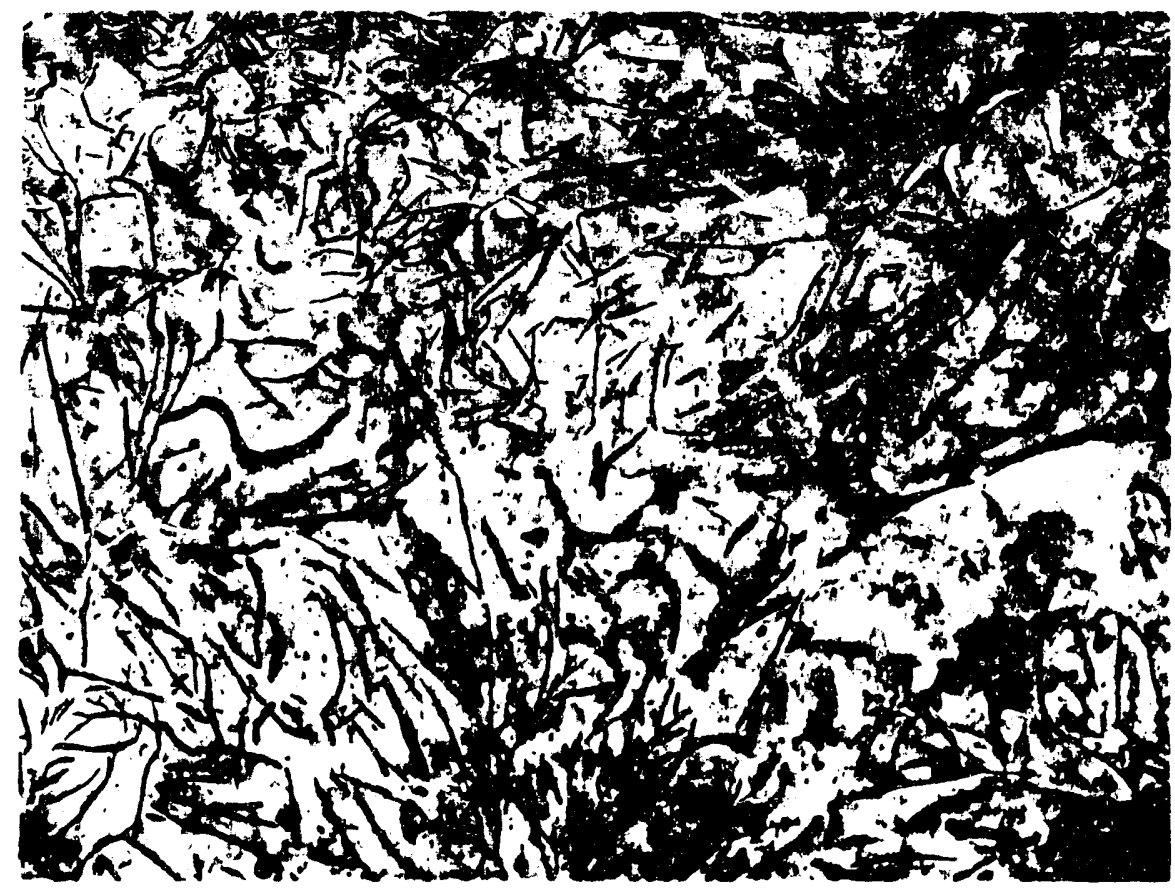


Figure 9-18. Higher Magnification View (500X) of Figure 9-17 Showing Typical Graphite Flakes, Pearlite, and Ferrite

(1 ight areas; Op Met 2). (93212B)

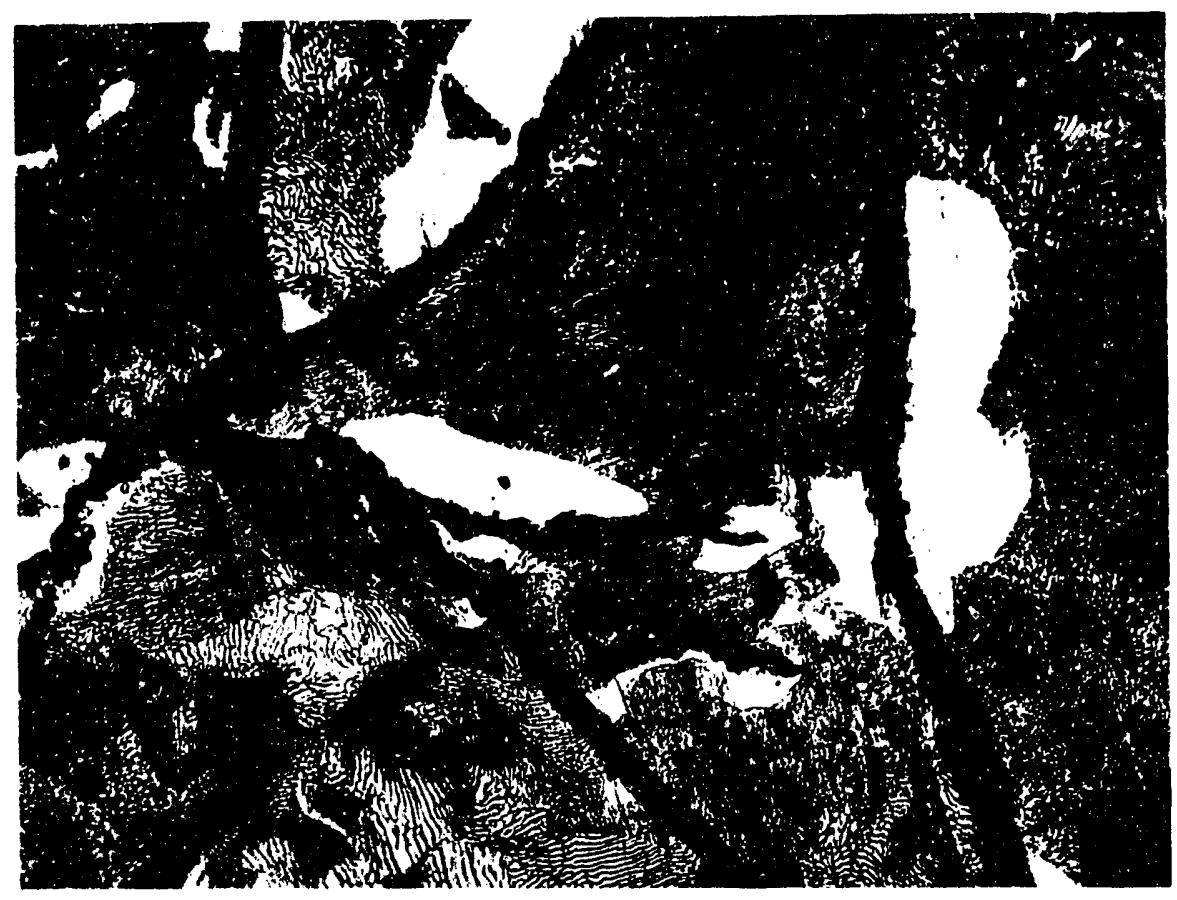


Figure 9-19. Scanning Electron Microscope-2 Fracture Surface Near the Interior Diameter Surface, 150X. (Photo 10:26)

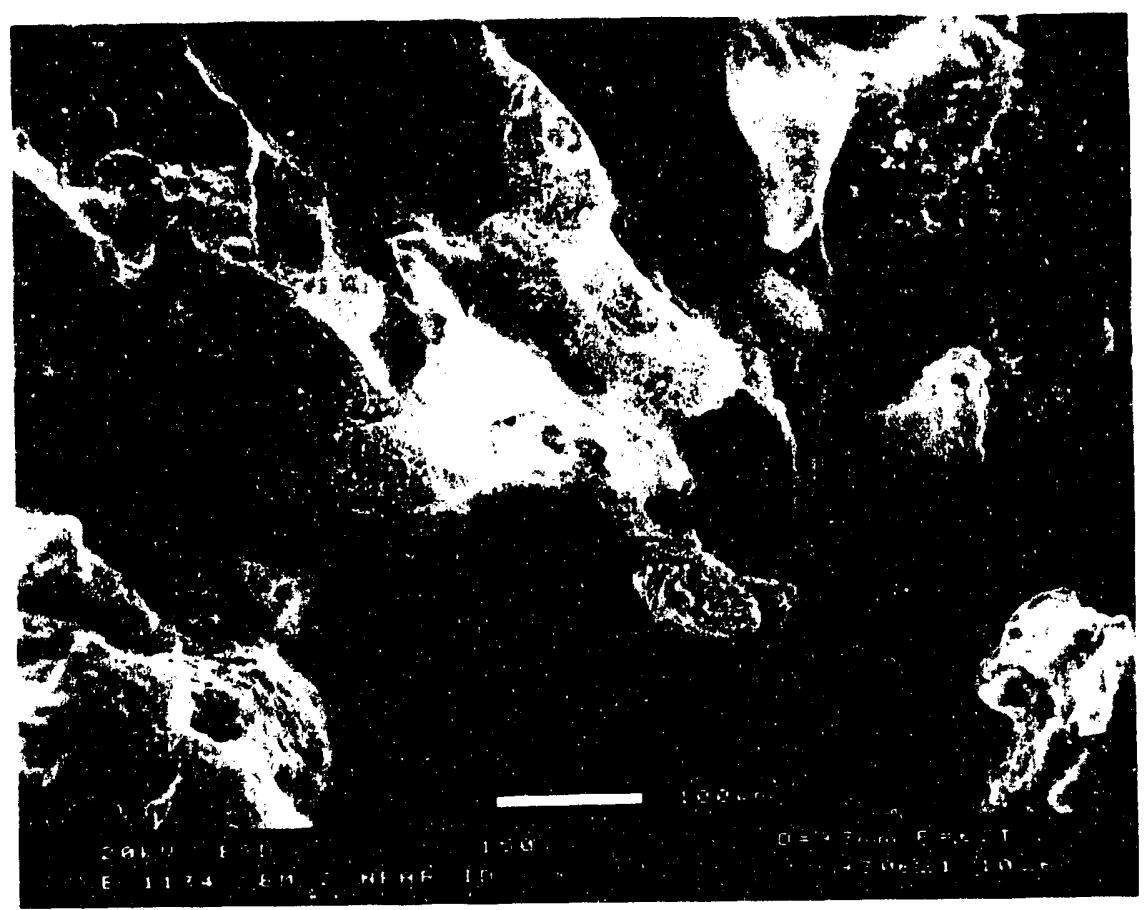

Figure 9-20. Higher Magnification View (500X) of Figure 9-19 Showing Particulate Deposits, Believed to be Mainly 0xides. (Photo 10:32)

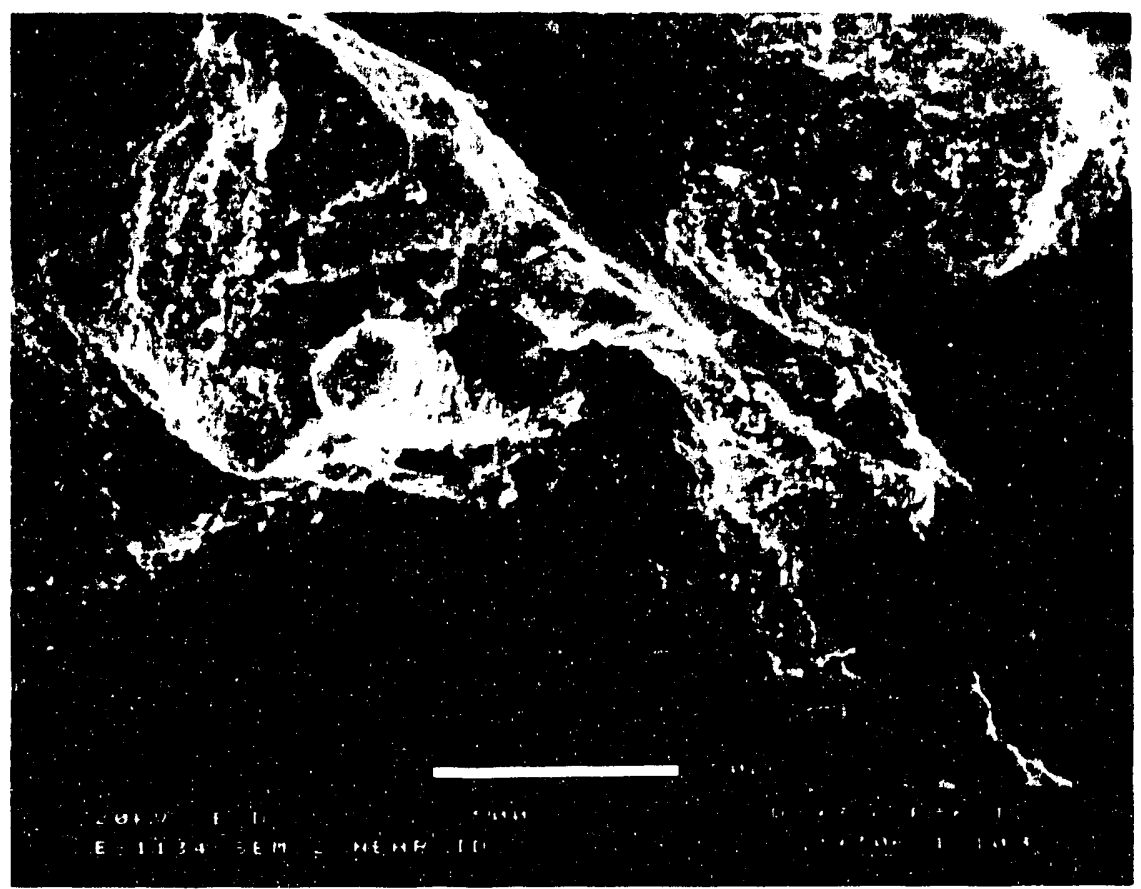


Figure 9-21. Scanning Electron Microscope-2 Fracture Surface Near the Center of SEM-2, 150X. (Photo 10:44)

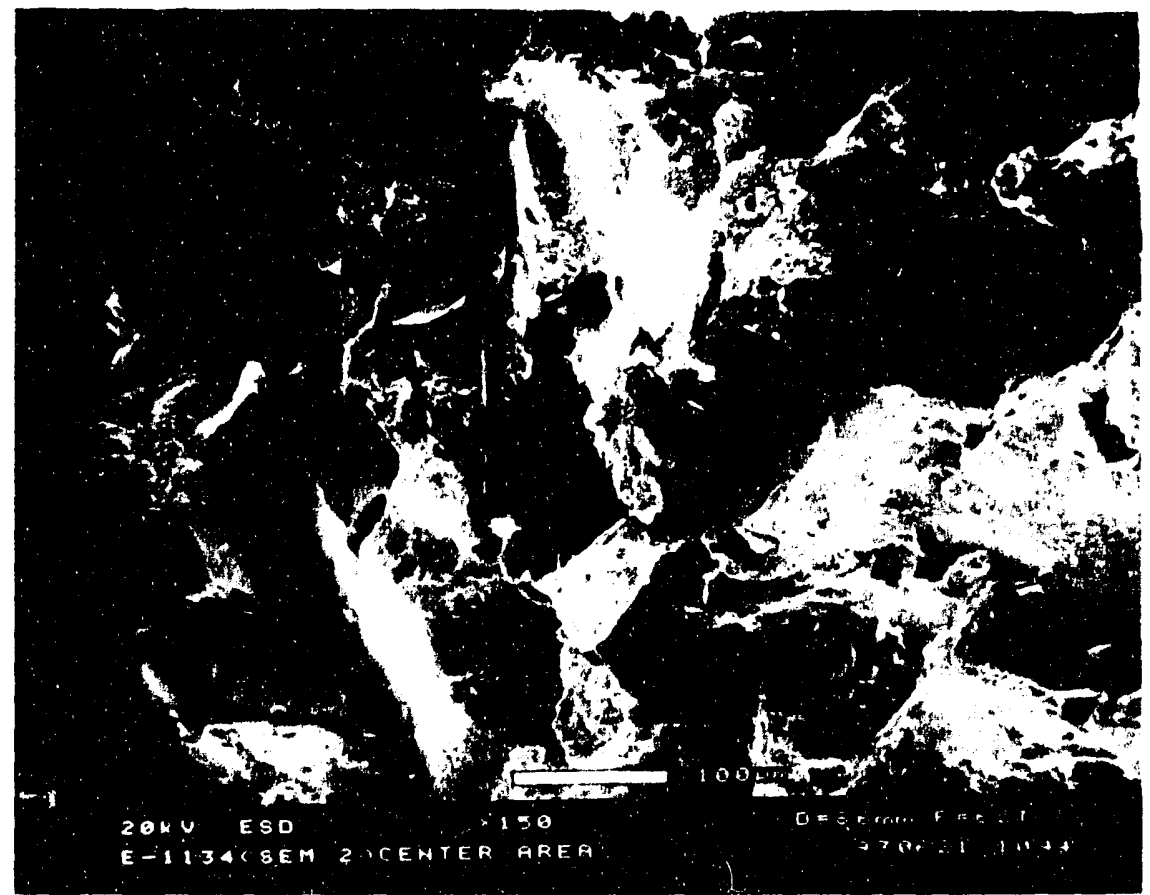

Figure 9-22. Higher Magnification View (500X) of Figure 9-21 Showing Reduced Amount of 0xide Deposit. (Photo No. 10:48)

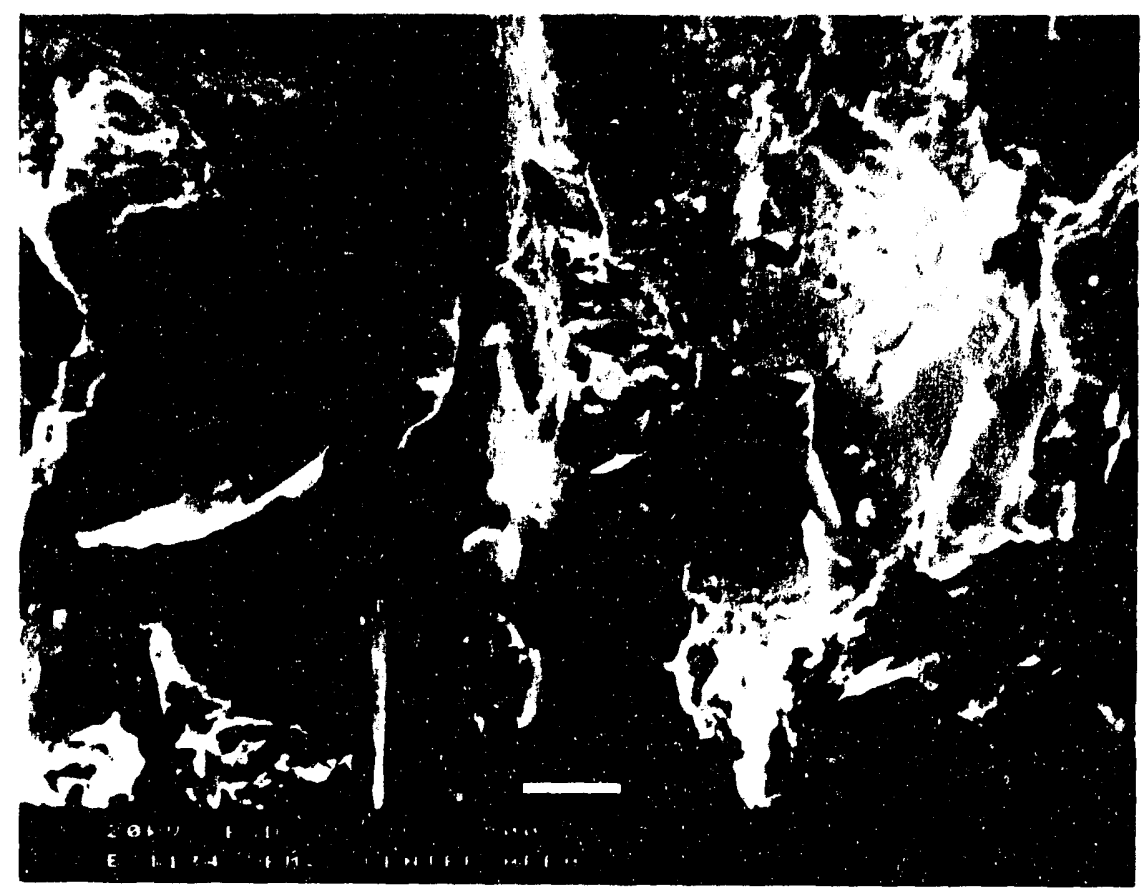


Figure 9-23. Fresh Fracture Surface, Specimen 3A-1, Near SEM-3, 150X. (Photo 11:12)

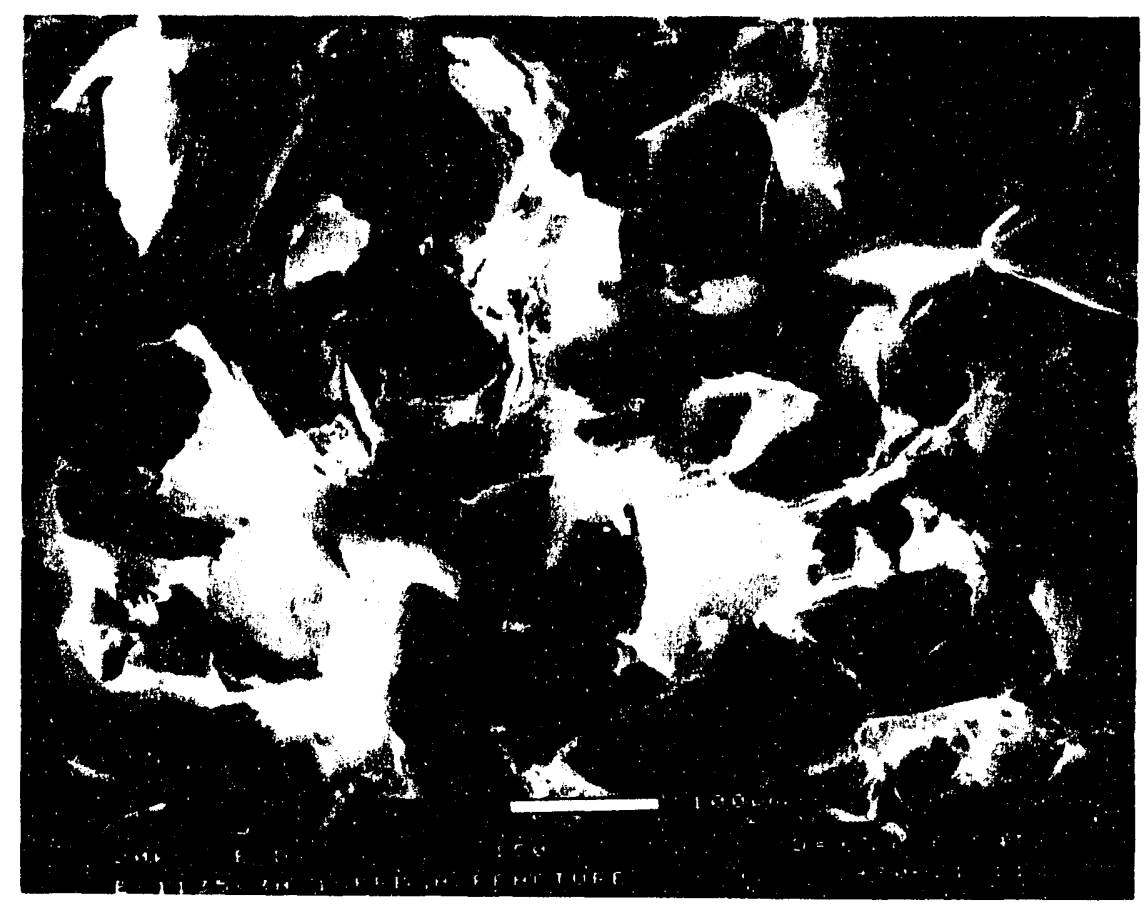

Figure 9-24. Fracture Surface, Characteristic of SEM-5, 300X. (Photo 16:16)

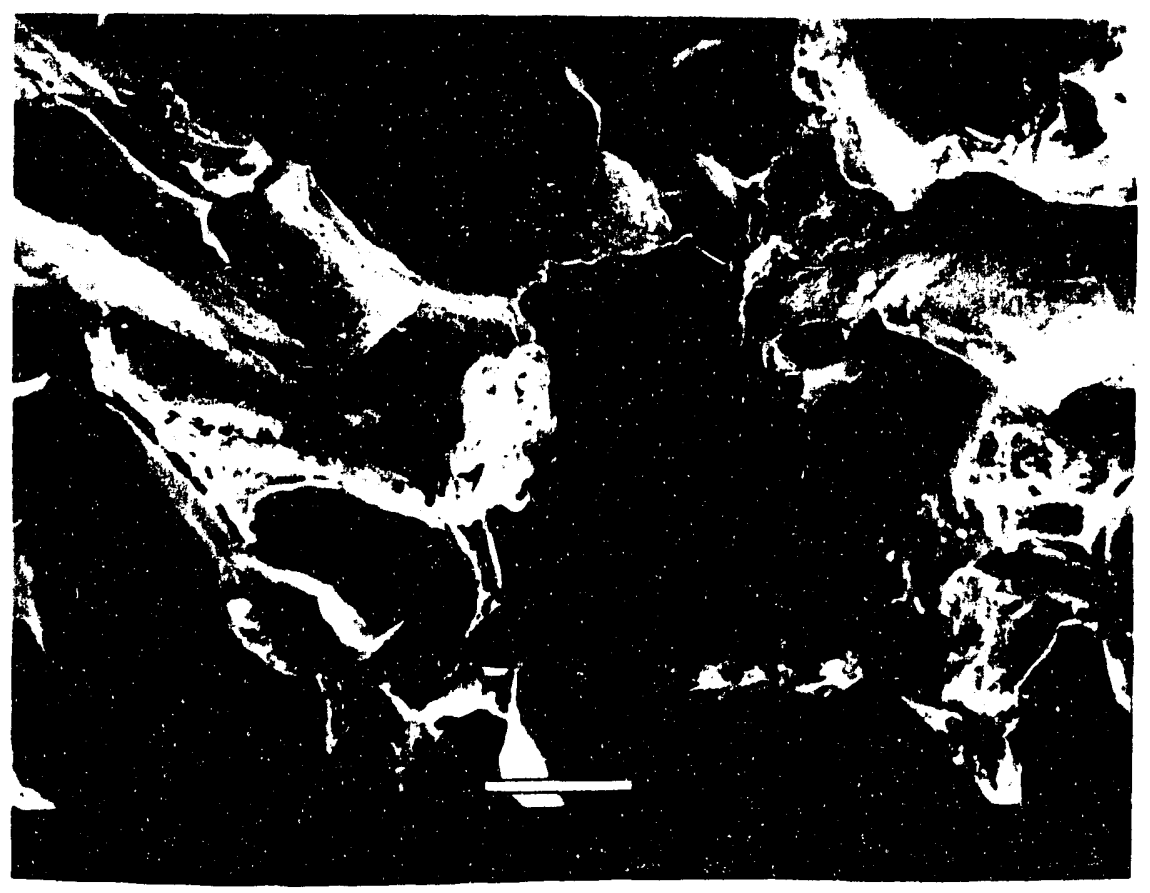


Figure 9-25. Tensile Test Specimen Geometry.

\section{Steam Valve Flange}

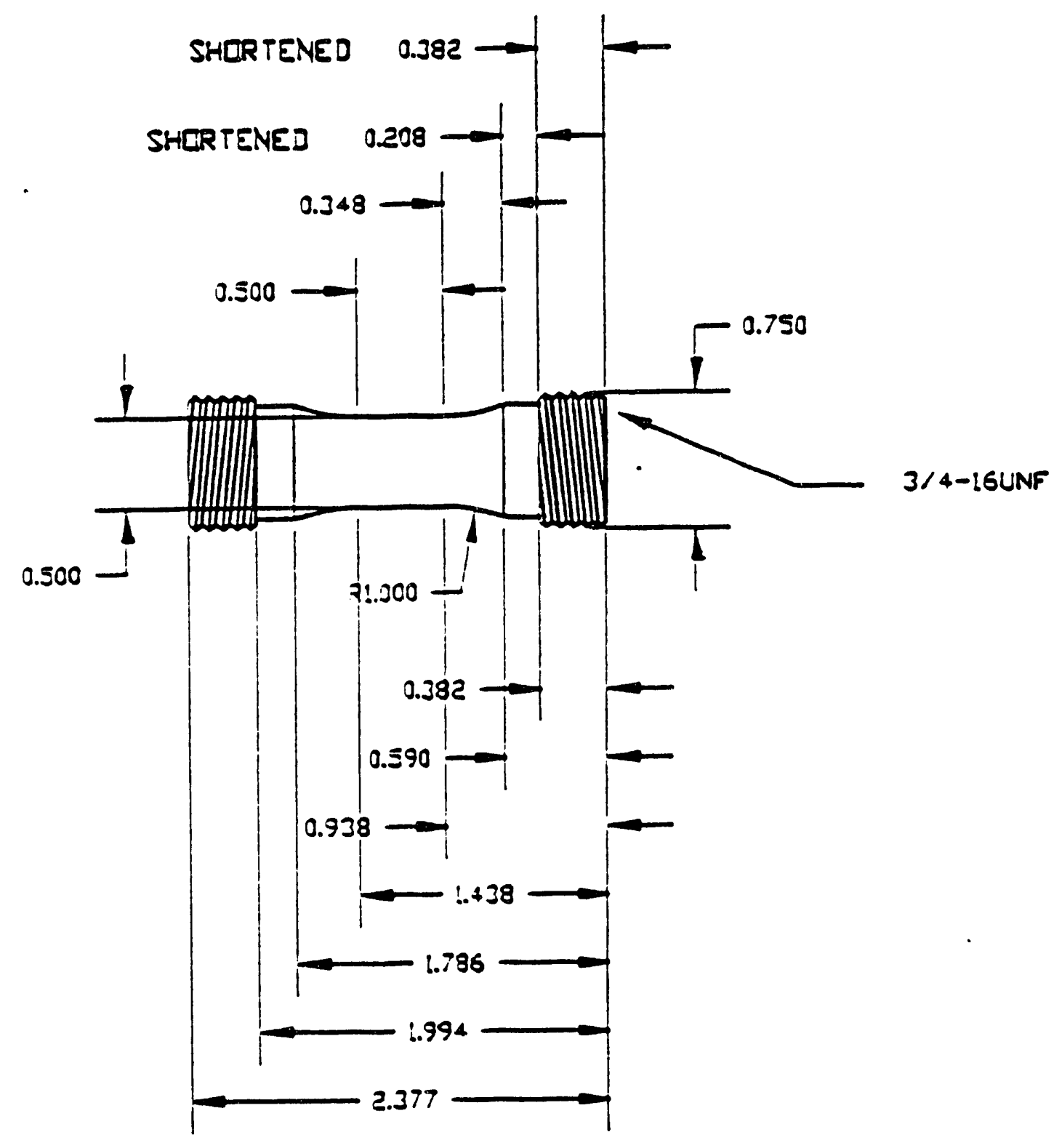

\section{Tensile Test Specimen Proposed Geometry}

Shortened ASTM A48-83 Fig. 2 Specimen A

Tension Test Specimens for Cast Iron 
Table 9-1. Equivalence of A 126 to A 48 Class Gray Cast Irons for Three Tensile Specimen Diameters.

\begin{tabular}{||c|c|c|c||}
\hline \multicolumn{4}{|c|}{ Specimen Diameters } \\
\hline \hline $\begin{array}{c}\text { Specification } \\
\text { A 126 Class }\end{array}$ & Under 0.5 in. & .51 to $1.0 \mathrm{in.}$ & Over $1.0 \mathrm{in}$. \\
\hline A & $25 \mathrm{~A}$ & $20 \mathrm{~B}$ & $20 \mathrm{C}$ \\
\hline$B$ & $35 \mathrm{~A}$ & $30 \mathrm{~B}$ & $30 \mathrm{C}$ \\
\hline C & $45 \mathrm{~A}$ & $40 \mathrm{~B}$ & $40 \mathrm{C}$ \\
\hline
\end{tabular}

Table 9-2. Effect of Specimen Diameter on Tensile Strength, Class 20 and 30 Gray Irons.

\begin{tabular}{|c|c|c|}
\hline Element & $\begin{array}{c}\text { Concentration } \\
\text { (wt. \%) }\end{array}$ & $\begin{array}{c}\text { Acceptable 1 imits } \\
\text { (max) } \\
\text { per ASTM A 126-84 }\end{array}$ \\
\hline \hline Carbon & 3.66 & -- \\
\hline Manganese & 0.87 & -- \\
\hline Silicon & 2.18 & -- \\
\hline Phosphorous & 0.132 & 0.75 \\
\hline Sulfur & 0.065 & 0.15 \\
\hline Chromium & 0.05 & -- \\
\hline Molybdenum & 0.02 & -- \\
\hline Iron & Balance & -- \\
\hline
\end{tabular}

Table 9-3. Effect of Carbon Equivalent on Gray-Iron Tensile Strength. (ASM 1990)

\begin{tabular}{||c|c|}
\hline CE (\%) & $\begin{array}{c}\text { Tensile Strength } \\
\left(\text { kip/in } \text { ( }^{2}\right.\end{array}$ \\
\hline 3.5 & 52 \\
\hline 3.75 & 45 \\
\hline 4.0 & 40 \\
\hline 4.25 & 30 \\
\hline 4.5 & 22 \\
\hline 4.6 & 18 \\
\hline
\end{tabular}




\section{WHC-EP-0667}

Table 9-4. Effect of Graphite Maximum Flake Length on Strength. (ASM 1990)

\begin{tabular}{|c|c|}
\hline $\begin{array}{c}\text { Maximum Flake Length } \\
\text { (in.) }\end{array}$ & $\begin{array}{c}\text { Tensile Strength } \\
\left(\text { kip } / \text { in }^{2} \text { ) }\right.\end{array}$ \\
\hline 0.008 & 48 \\
\hline 0.010 & 42 \\
\hline 0.015 & 35 \\
\hline 0.020 & 30 \\
\hline 0.025 & 27 \\
\hline 0.032 & 22 \\
\hline
\end{tabular}

Table 9-5. Hardness and Ductility of Basic Cast-Iron Microconstituents. (Angus 1960)

\begin{tabular}{||c|c|c|}
\hline Material & Hardness (BH) & Ductility \\
\hline \hline Ferrite & $70-150$ & Ductile \\
\hline Pearlite & $175-330$ & $\begin{array}{c}\text { Moderately } \\
\text { ductile }\end{array}$ \\
\hline Cementite & $800-1,100$ & Brittle \\
\hline
\end{tabular}

Table 9-6. Hardness Ranges for Various Combination of Gray Iron Microstructures. (ASM 1988)

\begin{tabular}{||c|c|}
\hline Microstructure & Hardness (HB) \\
\hline \hline Ferrite + Graphite & $110-140$ \\
\hline Pearlite + Graphite & $200-260$ \\
\hline
\end{tabular}


Table 9-7. Room Temperature Tensile Strength and Brinell Hardness (BH) Values from Specimens Removed from the Broken Valve Flange.

\begin{tabular}{||l|l|l|l|l||}
\hline & & \multicolumn{3}{|c||}{ Brinell Hardness (BH) } \\
\hline Specimen No. & $\begin{array}{l}\text { Tensile } \\
\text { Strength } \\
\text { (kip/in }\end{array}$ & Rdg. 1 & Rdg. 2 & Rdg. 3 \\
\hline L5794-1 & 16.3 & 125 & 137 & 150 \\
\hline L5794-2 & 15.3 & 132 & 131 & 154 \\
\hline L5794-3 & 16.2 & 135 & 131 & 152 \\
\hline
\end{tabular}

Table 9-8. Alloy Chemical Analysis Results of Valve Flange Section B. (ASM 1990)

\begin{tabular}{||c|c|c|}
\hline Class & $\begin{array}{c}\text { Diameter } \\
\text { of Tensile } \\
\text { Specimen } \\
\text { (in.) }\end{array}$ & $\begin{array}{c}\text { Tensile } \\
\text { Strength } \\
\text { (kip/in }{ }^{2} \text { ) }\end{array}$ \\
\hline 20 & $1 / 4$ & 40 \\
\hline 20 & $1 / 2$ & 34 \\
\hline 20 & 1 & 25 \\
\hline 20 & 2 & 17 \\
\hline 20 & 3 & 14 \\
\hline 20 & 4 & 12 \\
\hline & & 26 \\
\hline 30 & $1 / 2$ & 23 \\
\hline 30 & 1 & 36 \\
\hline 30 & 2 & 26 \\
\hline 30 & 3 & 23 \\
\hline 30 & 4 & \\
\hline
\end{tabular}




\subsection{STRESS ANALYSIS}

A stress analysis of the 6 -in. valve that failed in the $U-3$ valve pit was performed to estimate the over-pressure necessary to cause failure in the valve in the manner observed and to predict the tensile stress in the valve at its design pressure and temperature. The over-pressure is referred to hereafter as an abnormal condition while the design pressure is referred to as a normal condition.

\subsection{AS-BUILT CONFIGURATION}

On its removal from the U-3 valve pit, the failed 6 -in. valve was sent to the $272 E$ Fabrication Shops where its external dimensions and wall thicknesses were measured. A sketch of the valve with the appropriate dimensions is shown in Figure 10-1.

\subsection{MATERIAL. PROPERTIES}

The material used for the 6 -in. valve is cast iron, ASTM A-126, Grade B. Properties for this material at $300^{\circ} \mathrm{F}$, obtained from ANSI B31.1 (ASME 1986), ASTM (1989), and Powell (1992), are as follows:

$\begin{array}{lll}\text { Tensile strength } & S_{u l t} & =31,0001 \mathrm{bf} / \mathrm{in}^{2} \\ \begin{array}{l}\text { Coefficient of } \\ \text { thermal expansion }\end{array} & \propto & =5.93 \times 10^{-6} \mathrm{in} / \mathrm{in}^{\circ} \mathrm{F} \\ \text { Modulus of elasticity } E & =12.9 \times 10^{6} \mathrm{lbf} / \mathrm{in}^{2} \\ \text { Elongation } & =0.6 \% \\ \text { Average impact energy } & =2.6 \mathrm{lbf} \cdot \mathrm{ft} .\end{array}$

\subsection{STRESS ANALYSIS CRITERIA}

The following criteria were used to evaluate the 6-in. valve under normal and abnormal conditions.

\subsubsection{Allowable Stress for Normal Conditions}

The maximum stress allowed, as specified in Power Piping, ANSI/B31.1 (ASME 1986), for ASTM A-126 Grade B cast iron, is 3,000 $1 \mathrm{bf} / \mathrm{in}^{2}$ for temperatures up to $400^{\circ} \mathrm{F}$, which envelops the design temperature for this system of $366^{\circ} \mathrm{F}$. 


\subsubsection{Failure Stress for Abnormal Conditions}

Cast iron is a brittle material, as is evident by the low values for elongation and impact energy. Therefore, the material will fail or fracture when the maximum principal stress reaches the tensile strength for the material.

Results from tests of the actual valve material and adjustments to the test data (Section 9.6) indicate that the actual tensile strength for the valve material at the failure location is approximately $15,900 \mathrm{ibf} / \mathrm{in}^{2}$, which is less than $31,0001 \mathrm{bf} / \mathrm{in}^{2}$, the minimum value specified for ASTM A-126 Grade $B$ cast iron. Therefore, in this stress analysis, both the minimum specified value of $31,000 \mathrm{lbf} / \mathrm{in}^{2}$ and a degraded strength value of $20,000 \mathrm{lbf} / \mathrm{in}^{2}$ are used to estimate the minimum pressure required to cause the valve to fail.

\subsection{STRESS ANALYSIS}

The stress analysis of the 6 -in. gate valve involved assessing stresses on the valve body under normal operating conditions and under conditions resulting from the condensation-induced water hammer.

The methods used in the evaluation of normal conditions included hand calculations and finite-element analyses. The hand calculations evaluated the stresses at the critical sections of the valve body and gate disc as a result of deadweight and pressure loadings. The evaluation of the abnormal conditions used finite-element analysis.

The critical section consists of a circular cross section with a $6-i n$. inside diameter and a minimum wall thickness of $0.5 \mathrm{in}$.

The finite-element model used the measured wall thicknesses of the valve. The valve is a complex three-dimensional (3D) structure. However, the failed section, adjacent to the attached flange, is some distance from the $3 D$ regions, such that an axisymmetric finite-element model could be developed to simulate the critical region of the valve (Figure 10-2). The COSMOS/M computer code (SRAC 1991a) was used for the finite-element analysis.

Internal pressures were applied to study the resulting stress distributions in the valve. The following boundary conditions were applied.

- Gap elements were modelled on the face of the valve flange to simulate the connection between the valve flange and flange attached to the 8 - by 8 - by 6 -in. tee. The opening and closing of gaps was important in ensuring the proper transfer of loadings from the valve to the tee. Friction was not included in the gap elements. The nodes of gap elements on the flange from the tee were fixed.

- Because the gate was closed, internal pressure was applied to the inside surface of half of the valve body and to one side of the valve gate. The normal forces on the valve gate as a result of the pressure were calculated and applied to the valve body as axial forces. 
- The preload on the flange bolts was chosen to correspond to the yield strength of the bolt material. In this case, the bolt was loaded to an assumed tensile stress of $45,000 \mathrm{lbf} / \mathrm{in}^{2}$.

\subsubsection{Normal Conditions}

Various portions of the 6-in. valve assembly were assessed for stresses under normal operating loads. The valve body at the critical section and the valve gate disc were analyzed. The loads included deadweight and internal pressure. Normal operating loads were an internal pressure of $1251 \mathrm{bf} / \mathrm{in}^{2}$ (gauge) and $353^{\circ} \mathrm{F}$.

Hand calculations indicated a deadweight stress of $1131 \mathrm{bf} / \mathrm{in}^{2}$ at the critical cross section. Internal pressure acts on the valve body and its attached components. Finite-element analysis at the operating pressure of $125 \mathrm{lbf} / \mathrm{in}^{2}$ showed the maximum axial tensile stress to be $1,690 \mathrm{lbf} / \mathrm{in}^{2}$, which occurred at the outside surface of the critical cross section (Figure 10-3). The stress limit under normal conditions is $3,0001 \mathrm{bf} / \mathrm{in}^{2}$; thus, the valve satisfies the limits for the combination of loadings from deadweight and pressure.

By hand calculations, the shear stress in the valve gate disc is estimated conservatively to be $325,1 \mathrm{bf} / \mathrm{in}^{2}$ and the bending stress to be $4,250 \mathrm{lbf} / \mathrm{in}^{2}$ under the $125 \mathrm{lbf} / \mathrm{in}^{2}$ operating pressure. Because of the very local nature of the bending stress, the shear stress is considered to be the governing stress; it is below the stress limit. The valve did not fail at the gate disc.

Closure of the gate in the 6 -in. valve prevented pressure from reaching the blind flange attached to the end of the valve. During normal conditions, no additional stresses develop in the blind flange or the attaching bolts.

\subsubsection{Abnormal Conditions}

Stress calculations for the valve body included those from exposure to the condensation-induced water hammer. The hydraulic analysis indicates an estimated pressure pulse in the range of 1,500 to $3,0001 \mathrm{bf} / \mathrm{in}^{2}$ (gauge) for the duration of a few milliseconds.

The critical section on the valve is near the junction of the valve body and the attached flange. Relatively high local axial tensile stresses can develop under internal pressure loadings at the critical section because of the differential displacement of the stiff flange and the relatively flexible valve body. A high-pressure force exerted on the valve gate also generates a high bending moment at the critical section.

\section{Finite Element Analysis}

An internal pressure of $2,2551 \mathrm{bf} / \mathrm{in}^{2}$ (gauge) results in a maximum axial tensile stress $\left(\sigma_{y}\right)$ of $31,0001 \mathrm{bf} / \mathrm{in}^{2}$ (Figure 10-4), which is the specified minimum ultimate tensile strength of the valve body material, ASTM A-126, Grade $B$ cast iron. The maximum axial tensile stress occurs on the outside surface just off the flange junction where the valve body failed. 
An internal pressure of $1,8031 \mathrm{bf} / \mathrm{in}^{2}$ (gauge) results in a maximum axial tensile stress $\left(\sigma_{y}\right)$ of $20,000 \mathrm{lbf} / \mathrm{in}^{2}$ (Figure 10-5), which is the degraded tensile strength value applied in this analysis to represent the strength of the actual material.

The internal pressure can be separated into two loading components: the radial pressure on the inside surface of the valve body and the axial pressure on the gate disc that can be converted into axial force exerted on the valve body. The majority $\left(17,000 \mathrm{lbf} / \mathrm{in}^{2}\right)$ of the axial stress $\left(\sigma_{y}\right)$ resulting from the pressure loading at the critical section is contributed by the axial force loading because of pressure on the disk, and a much smaller stress of $3,000 \mathrm{lbf} / \mathrm{in}^{2}$ is contributed by the radial pressure on the valve body (Figures 10-6 and 10-7).

\subsubsection{Dynamic Analysis}

When a load is applied suddenly to a structure, the response of the structure to the load can be amplified beyond the effect of the same load applied in a static manner. This amplification is the result of additional inertial forces acting on the structure in combination with the load. The magnitude of this amplification depends on the duration of the load and the natural frequency of the structure. For an instantaneously applied load on a single-degree-of-freedom structural system, the maximum value for this dynamic amplification is a factor of 2 over the value that would be obtained for a static load.

The pressure load on the 6 -in. valve from the condensation-induced water hammer is a near-instantaneous impulse load. This type of loading occurs because the valve is pressurized by a pressure shock wave that travels through the piping system.

The short section of 6-in. pipe, 9-in. 1ong, that branches off the main $8-i n$. line to the $6-$ in. cast iron valve will respond primarily as a singledegree-of-freedom system in the axial direction. The main 8-in. line will act as a fixed anchor when subjected to short-duration impulse loads because of its large mass. The short 6 -in. branch section will act as a stiff spring with the mass of the 6-in. valve at the end of the spring. The natural frequency for this single-degree-of-freedom system is $1,035 \mathrm{~Hz}$, based on a valve weight of $1701 \mathrm{bf}$ and a spring rate of $1.86 \times 10^{7} \mathrm{lbf} / \mathrm{in}$. for the short section of 6-in. pipe. The weight of the water inside the valve was neglected because its mass is low compared to the mass of the valve.

The full dynamic-amplification factor of 2.0 is achieved for a singledegree-of-freedom system when an instantaneous load is applied if the ratio of the duration of the load to the system period exceeds 0.5 (Clough 1975). At a frequency of $1,035 \mathrm{~Hz}$, the period for this system is $0.97 \mathrm{~ms}$. Therefore, the duration necessary for the pressure load to develop the full dynamic amplification of the load is $0.5 \mathrm{~ms}$, or approximately $1.0 \mathrm{~ms}$, if rounded up to account for variances in the physical parameters for the system. Therefore, dynamic amplification of the pressure loading is possible since the pressure duration is $10 \mathrm{~ms}$ or greater (see Section 8.6.4). 
For this evaluation, the dynamic amplification of the pressure load is conservatively applied only to the stresses resulting from an axially applied load on the valve disk, not to the stresses resulting from a hoop-applied load. The stress analysis performed at an internal static pressure of $1,803 \mathrm{lbf} / \mathrm{in}^{2}$ showed the maximum principal stress in the valve body to be $17,000 \mathrm{lbf} / \mathrm{in}^{2}$ for an axially applied pressure load and 20,000 $1 \mathrm{bf} / \mathrm{in}^{2}$ for the axially and hoop-applied pressure load combined. Thus, the axially applied load accounts for approximately $85 \%$ of the maximum principal stress in the valve body. Therefore, a value of $0.85 \times 2=1.7$ was applied in this stress analysis to account for dynamic amplification of the pressure load.

The static pressures necessary for the maximum principal stress in the valve body to reach $20,000 \mathrm{lbf} / \mathrm{in}^{2}$ and $31,000 \mathrm{lbf} / \mathrm{in}^{2}$ (the two failure stress values evaluated in the stress analysis) were $1,803 \mathrm{lbf} / \mathrm{in}^{2}$ and $2,255 \mathrm{lbf} / \mathrm{in}^{2}$, respectively. With a dynamic amplification factor of 1.7 applied, the pressure necessary to fail the valve would be reduced to approximately $1,060 \mathrm{lbf} / \mathrm{in}^{2}$ and $1,325 \mathrm{lbf} / \mathrm{in}^{2}$, respectively, providing the duration of the pressure pulse is longer than $1.0 \mathrm{~ms}$.

\subsubsection{Discussion}

\section{Thermal stresses}

Rapid cooling (thermal shock) of the valve body by inrushing water from the water hammer can produce temperature gradients through the valve wall and result in thermal stresses. However, these thermal stresses were not included in the estimates of the pressures required to fail the valve.

A length of time is needed for the temperature gradient to develop sufficiently to affect the stresses in the outside surface of the valve, where the maximum principal tensile stress occurred from the pressure load. In addition, if the temperature change at the inside surface is prolonged, the thermal gradient through the valve will be reduced to the point that it no longer affects the stress at the outside surface.

Before the water hammer event occurred, water may have partially filled the horizontal length of pipe long enough for the through-wall temperature gradient to diminish; even so, a temperature differential would remain between the upper and lower sections of the valve. This differential would induce non-axisymetric thermal stresses that would vary at the outside surface of the valve from compressive to tensile.

During the water hammer, any volume inside the valve not previously filled with water would be subjected to a rapid thermal shock. However, the resulting thermal gradient would not have time to develop an effect at the outside surface before the maximum tensile stress occurs at the outside surface.

Thus, thermal shock to the valve varies in location, magnitude, and duration. This variability will lead to varying thermal stresses at the outside surface of the valve that are expected to be tensile at some point around the critical fracture line. Because cast iron is a brittle material, failure resulting from any loading at one point in this material would initiate failure across the entire valve section. Therefore, neglecting 
thermal stress is conservative with respect to determining the lowest pressure that could have caused the valve to fail.

\section{Fatique}

Brittle castings ran be susceptible to fatigue failures. Literature on grey cast iron (Powe11 1992) indicates that several hundred loading cycles are required to reduce the failure strength of the material substantialiy.

Additionally, no evidence of fatigue was found during the detailed examination of the valve (see Section 9.0). Therefore, fatigue failure is not expected to be a viable condition for the valve under the abnormal loading.

\subsection{FRACTU.:E MECHANIC: ANALYSIS}

The fractured valve in the U-3 stean valve pit was analyzed by means of linear elastic fracture mechanics methodology as set forth in the ASME Boiler and Pres ure Vessel Code (ASME 1992), Section X̌I, Appendix A. The purpose of the fraciure mechanics analysis was to determine the size of crack (flaw) that could be an initiator of failure under the loading conditions experienced by the valve.

First, the axial and bending stresses at the fracture surface were calculated. Two stress categories were defined: stresses caused by the pressure and stresses caused by the influence of the rigid flange close to the frar.tured surface. The closed-form solution was used for the stress analysis. The stresses were calculated for an internal pressure of $2,4001 \mathrm{bf} / \mathrm{in}^{2}$ (gauge).

Axial stress resulting from the pressure $(P R / 2 t)$ is $7,8001 b f / i n^{2}$. Bending stress resulting from flange rigidity is $24,080 \mathrm{lbf} / \mathrm{in}^{2}$. Although the stresses in the valve material used in the fracture mechanics analysis differ slightly from those obtained in the detailed finite-element analysis, the conclusions below regarding fla v-induced failure are appropriate because of the relatively large flaw sizes involved.

The fracture mechanics analysis results are summarized below.

- The stress intensity factor for postulated small cracks was calculated. The results for surface cracks varying in length from 0.02 to 0.2 in. indicate a stress intensity factor in the range of 4,021 to $11,370\left(1 \mathrm{bf} / \mathrm{in}^{2}\right)$ in. ${ }^{0.5}$. The literature reports a fracture toughness in the range of 5,000 to $25,000\left(1 \mathrm{bf} / \mathrm{in}^{2}\right)$ in. ${ }^{\circ} .5$ (Gray 1983). If an average value of 15,000 is assumed for the fracture toughness, the conclusion is that cracks of these sizes will not cause fracture.

- The critical crack size was calculated for a pressure of $2,4001 \mathrm{bf} / \mathrm{in}^{2}$ and a toughness in the range of 10,000 to $25,000\left(1 \mathrm{bf} / \mathrm{in}^{2}\right) \mathrm{in}^{0.5}$. The analysis shows the critical size (crark depth) to range from 0.123 to 0.771 in. with corresponding lengths ranging from 0.62 to $3.86 \mathrm{in}$.

Thus, the conclision is that the failure did not result from an existing crack in the valve because cracks of the size needed for failure would have been detected in the detailed post-accicent examinations. 


\subsection{SUMMARY}

Table 10-1 summarizes the pressure loading necessary to produce maximum calculated stresses of 20,000 and $31,0001 \mathrm{bf} / \mathrm{in}^{2}$ on the valve body for dynamic amplification factors of 1.0 and 1.7 . The measured tensile strength of the valve body material was $15,900 \mathrm{lbf} / \mathrm{in}^{2}$, and the thermal-hydraulic analys is (Section 8.6.4) calculates a condensation-induced water hammer pressure pulse of $1,0001 \mathrm{bf} / \mathrm{in}^{2}$ or 1,500 to $3,0001 \mathrm{bf} / \mathrm{in}^{2}$, depending upon the location and mechanism generating the over-pressure. The stress analysis, therefore, indicates that it is highly likely that dynamically-amplified condensation-induced water hammer loading was of sufficient magnitude to cause failure of the 6 -in. valve. 
Figure 10-1. Dimensions of the Failed 6-in. Valve.

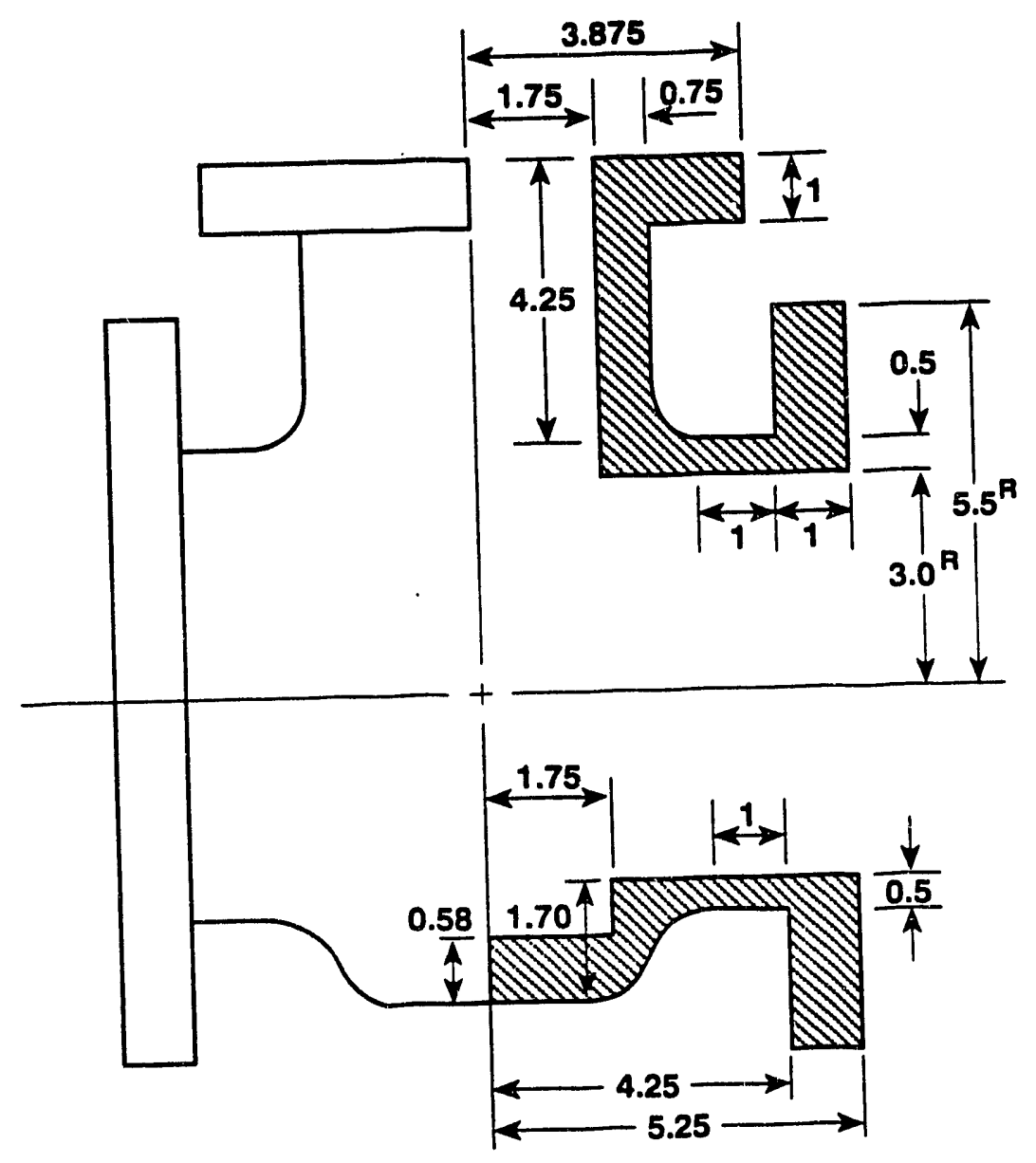

Unit = Inch

79307065.10 
Figure 10-2. Finite-Element Mode1.

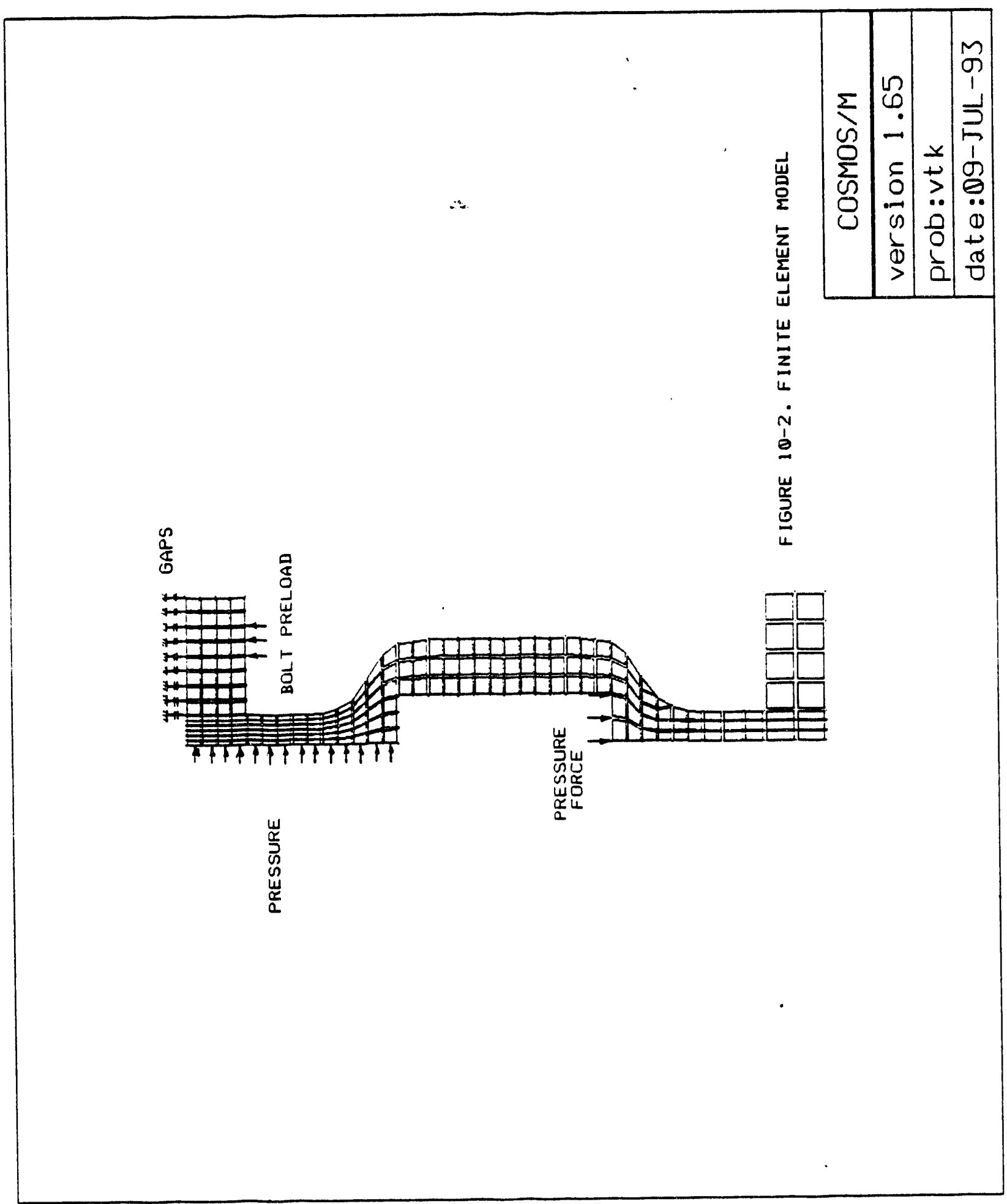


Figure 10-3. Axial Stress Distribution as a Result of an Internal Pressure of $125 \mathrm{lbf} / \mathrm{in}^{2}$ (Gauge).

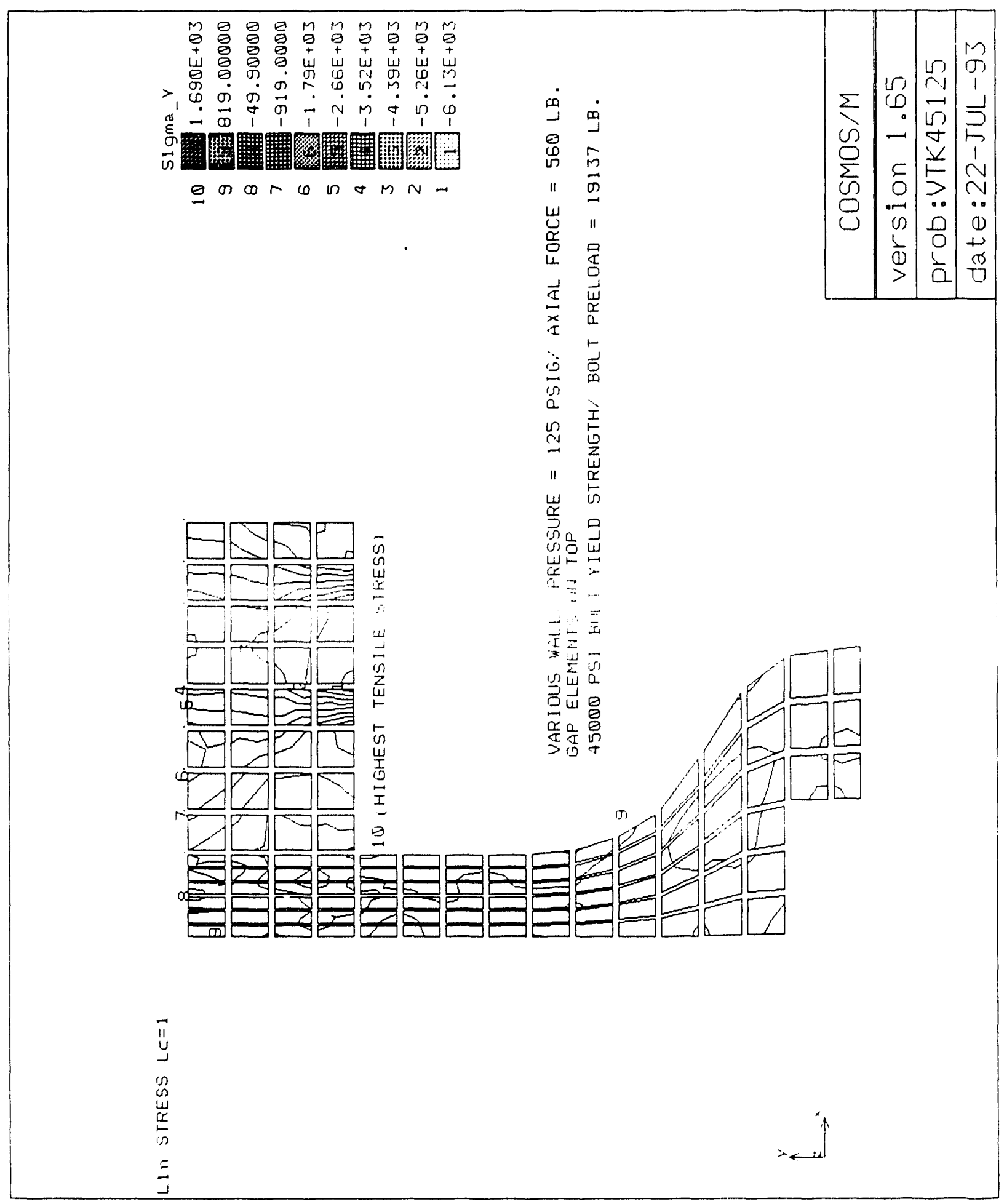


Figure 10-4. Axial Stress Distribution as a Result of an Internal Pressure of $2,250 \mathrm{lbf} / \mathrm{in}^{2}$ (Gauge).

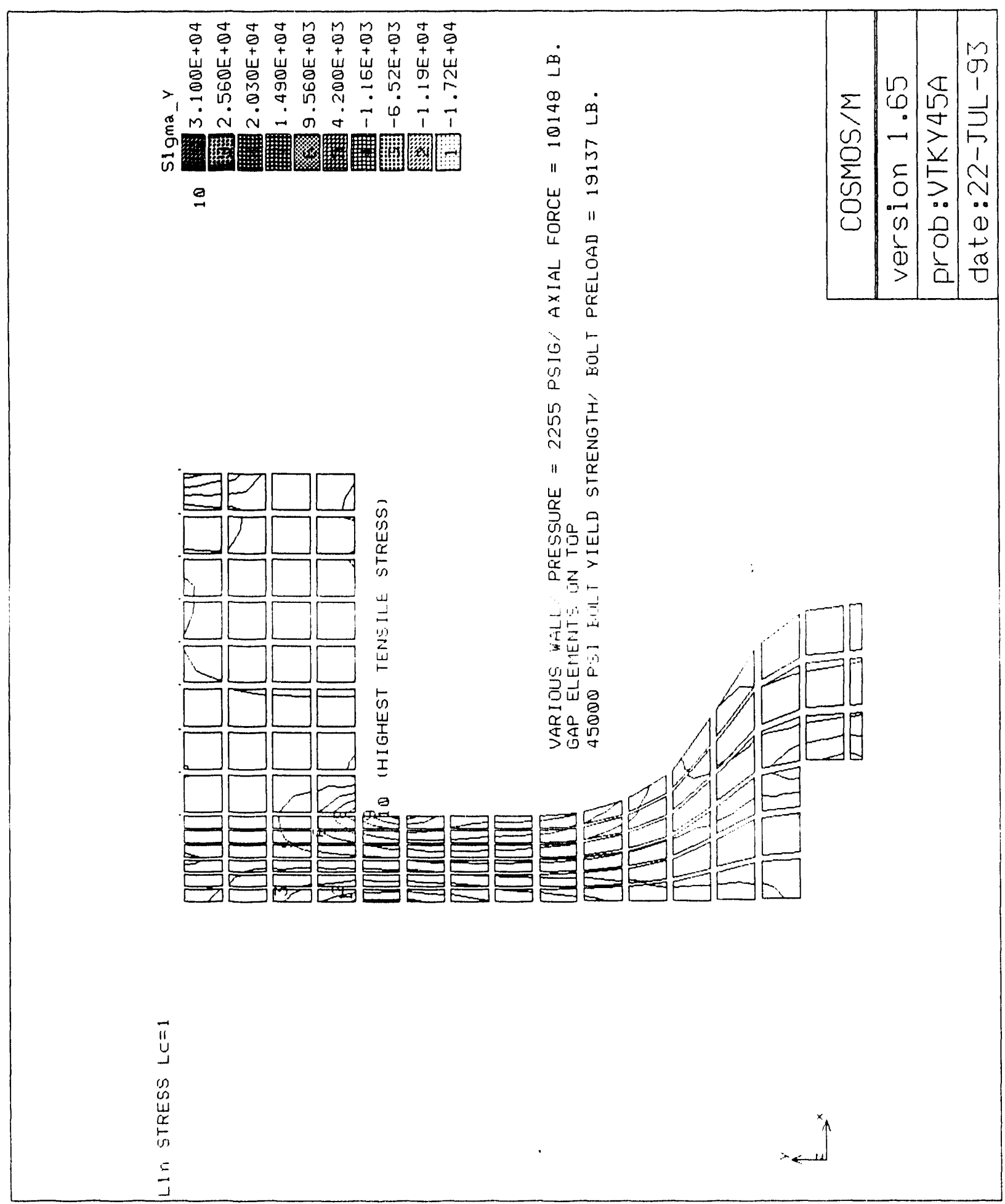


Figure 10-5. Axial Stress Distribution as a Result of an Internal Pressure of $1,8031 \mathrm{bf} / \mathrm{in}^{2}$ (Gauge).

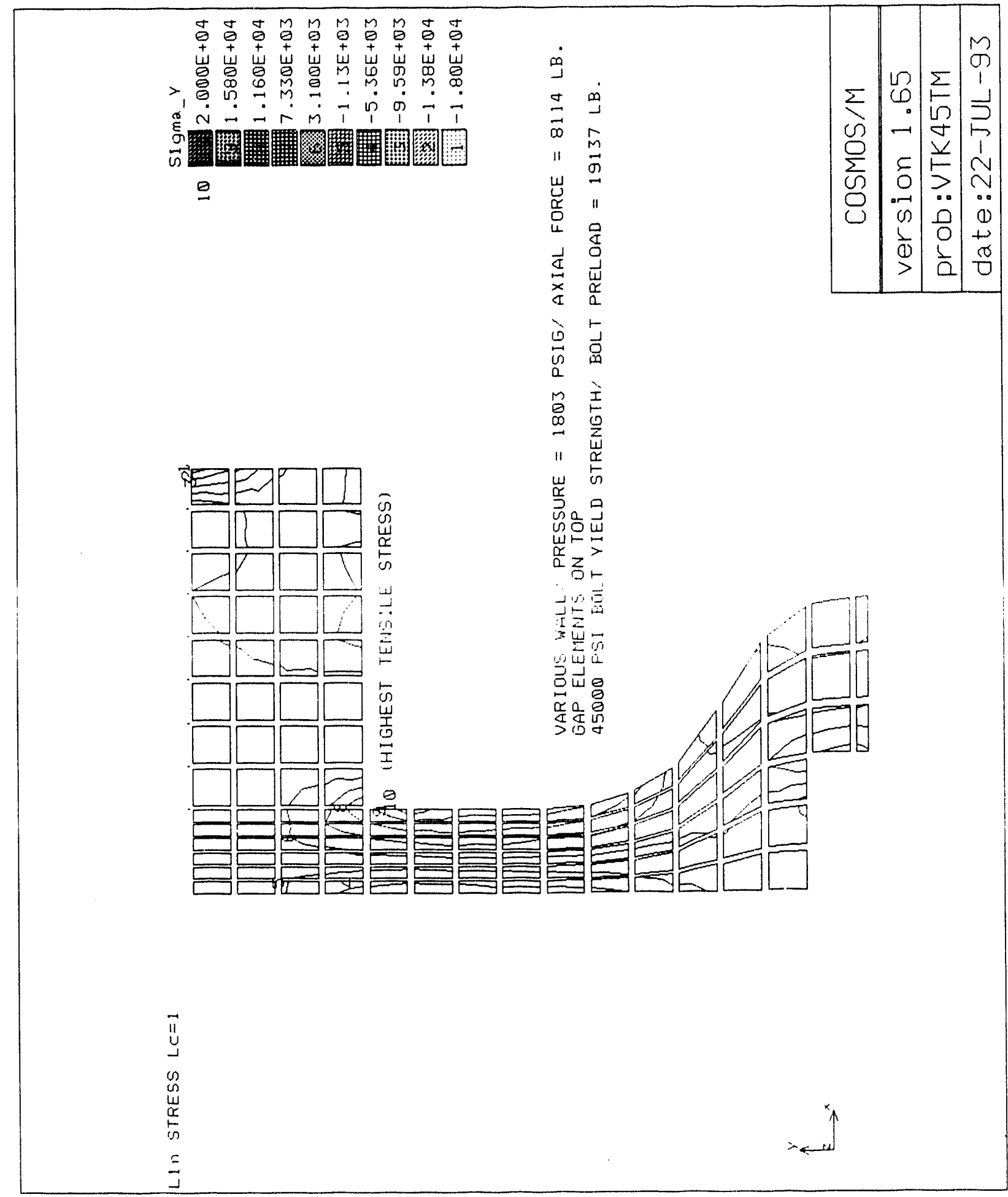


Figure 10-6. Axial Stress Distribution as a Result of an Internal Pressure of $1,803 \mathrm{lbf} / \mathrm{in}^{2}$ (Gauge) without Radial Pressure Component.

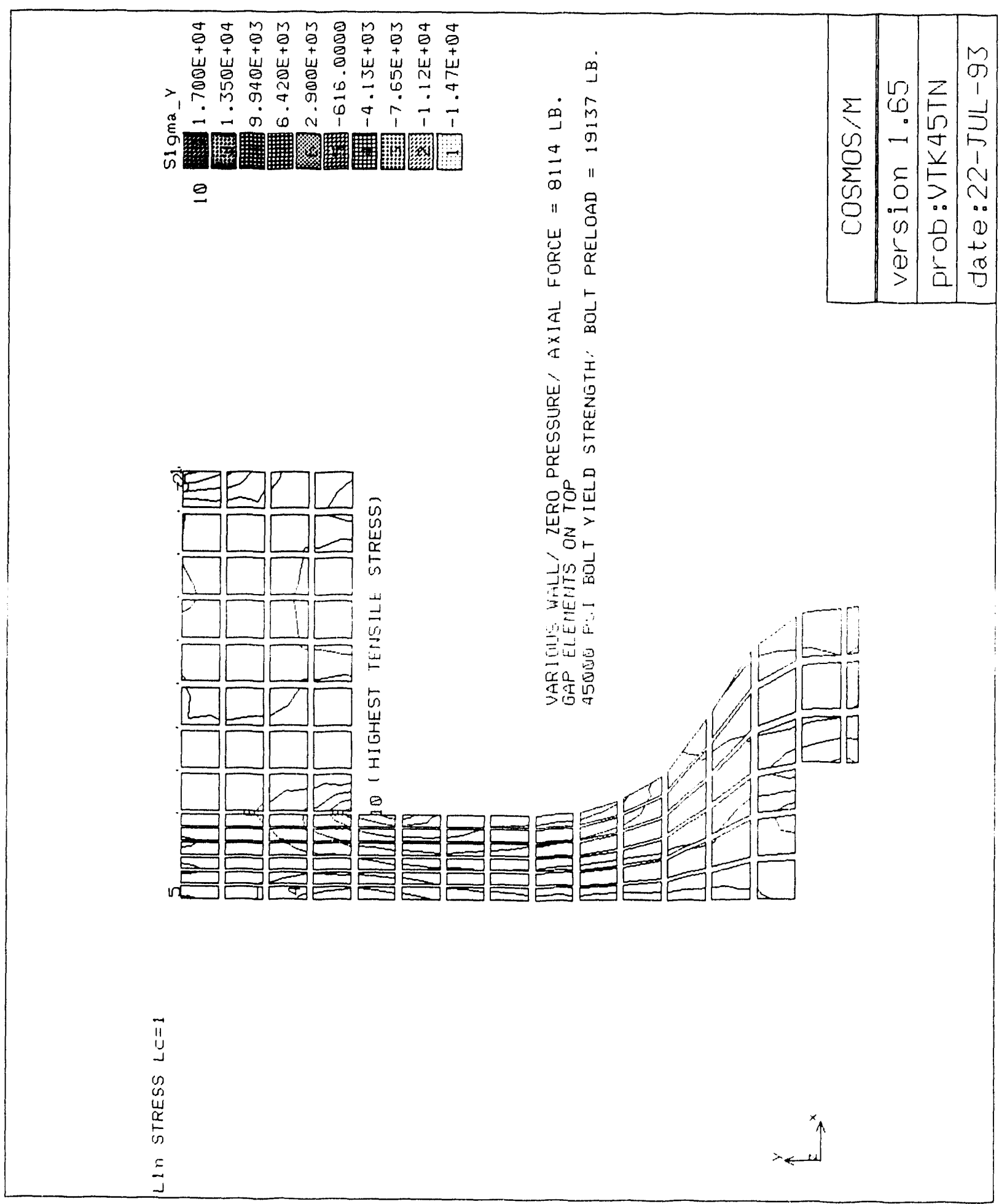


Figure 10-7. Axial Stress Distribution as a Result of an Internal Pressure of $1,803 \mathrm{lbf} / \mathrm{in}^{2}$ (Gauge) without Axial Force Component.

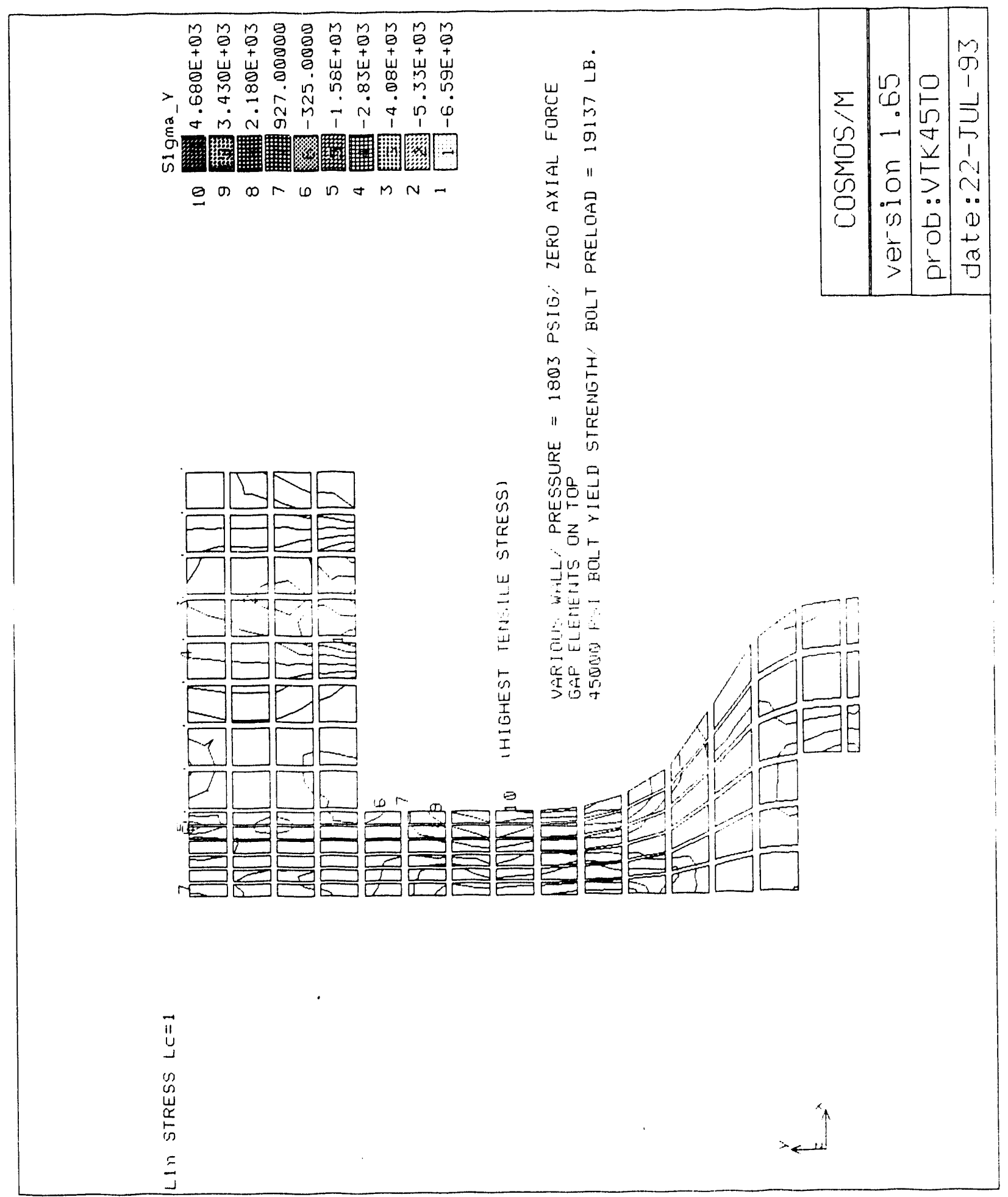


Table 10-1. Pressure Loading for Maximum Calculated Stresses for Valve Body.

\begin{tabular}{|c|c|c|}
\hline $\begin{array}{c}\text { Maximum }\left(1 \mathrm{bf} / \mathrm{in}^{2}\right) \\
\text { Stress }\end{array}$ & $\begin{array}{c}\text { Dynamic Ampl ification } \\
\text { Factor }\end{array}$ & Pressure $\left(1 \mathrm{bf} / \mathrm{in}^{2}\right)$ Load \\
\hline 31,000 & 1.0 & 2255 \\
\hline 20,000 & 1.0 & 1803 \\
\hline 31,000 & 1.7 & 1325 \\
\hline 20,000 & 1.7 & 1060 \\
\hline
\end{tabular}




\subsection{REFERENCES}

Angus, H. T. 1960, Physical and Engineering Properties of Cast Iron," British Cast Iron Research Association, Alvechurch, Birmingham, England.

ANSI, 1955, Power Piping Code, ANSI B31.1, American National Standard Institute, New York, New York.

Armstrong Machine Works, 1971, The Armstrong Steam Trap Book, Three Rivers, Michigan.

ASM, 1970, Metals Handbook, "Forging and Casting," Eighth Edition, Vol. 5, American Society for Metals, Metals Park, Ohio.

ASM, 1972, Metals Handbook, "Atlas of Microstructures," Eighth Edition, Vol. 7, pp. 81-100, American Society for Metals, Metals Park, Ohio.

ASM, 1973, Metals Handbook, "Metallography, Structures and Phase Diagrams," Eighth Edition, Vol. 8. See section on "Metallographic Techniques for Cast Irons," by J. C. Moore, pp. 86-93, American Society for Metals, Metals Park, Ohio.

ASM, 1978, "Properties and Selections: Irons and Steels," Ninth Edition, Volume 1, American Society for Metals, Metals Park, Ohio.

ASM, 1985, Metals Handbook, "Metallography and Microstructure," Ninth Edition, Vol. 9, pp. 242-256, American Society for Metals, Metals Park, Ohio.

ASM, 1988, Metals Handbook, Ninth Edition, American Society for Metals, Metals Park, Ohio.

ASM, 1990, Metals Handbook, "Properties and Selection: Irons, Steels, and High-Performance Alloys," Tenth Edition, Vol. 1, pp. 3-11 and 12-32, American Society for Metals, Metals Park, Ohio.

ASME, 1986, ASME Code for Pressure Piping, B31, "Power Piping, ANSI/ASME B31.1-1986 Edition," American Society of Mechanical Engineers, New York, New York.

ASME, 1992, ASME Boiler and Pressure Vessel Code, "Section XI," American Society of Mechanical Engineers, New York, New York.

ASTM, 1992, "Standard Specification for Gray Iron Castings," ASTM A 48, American Society for Testing and Materials, Philadelphia, Pennsylvania.

ASTM, 1989, "Annual Book of ASTM Standards," American Society for Testing and Materials, Philadelphia, Pennsylvania.

ASTM, 1984 (reapproved 1991), "Standard Specification for Gray Iron Castings for Valves, Flanges, and Pipe Fittings," ASTM A 126, American Society for Testing and Materials, Philadelphia, Pennsylvania. 
Bjorge, R. W., and P. Griffith, 1984, "Initiation of Water Hammer in Horizontal and Nearly Horizontal Pipes Containing Steam and Subcooled Water," ASME Journal of Heat Transfer, Vo1. 106, November, pp. 835-840.

Block, J. A., et a1., 1977, An Evaluation of PWR Steam Generator Water Hammer, NUREG-0291, U.S. Nuclear Regulatory Commission, Washington, D.C.

BNL, 1986, Report of Investigation of the Steam Line Accident with Fatal Injuries on October 10, 1986 at Brookhaven National Laboratory Operated by Associated Universities, Inc., Brookhaven National Laboratory, Upton, New York.

Clough, R. W., and J. Penzien, 1975, Dynamics of Structures, McGraw-Hill Book Company, New York, New York.

Crane Company, 1960, Catalog, Valves and Fittings, Chicago, Illinois.

Gray, R. J., C. W. Houck, and D. 0. Hobson, 1983, "Metallurgical Investigation of a Gray Cast Iron 16-in.-Diameter Water Line Failure at Oak Ridge National Laboratory, "Proceedings of the Fifteenth Annual Technical Meeting of the International Metallographic Society, Elsevier Science Publishing Company, New York, New York.

Papenfuss, J. N., 1982, Engineering Evaluation of Ruptured Strainer in Building 309, HEDL-TC-2273, October 1982, Westinghouse Hanford Company, Richland, Washington.

Powe11, G. W., S. Cheng, and C. E. Mobley, Jr., 1992, "A Fractography At1 as of Casting Alloys," Battelle Press, Columbus, Ohio.

Roark, R. J., and W. C. Young, 1975, Formulas for Stress and Strain, Fifth Edition, p. 465, McGraw-Hill Book Company, New York, New York.

Roidt, R. M., 1980, "Rapidly Condensing Vapor and Vapor-Air Mixtures in Steam Generators - A Summary of Experimental Findings and an Analytical Treatment of Geometric Scaling C.onsiderations," Westinghouse Research and Development Research Report 80-1E9-WAHAM-R1, Westinghouse Electric Corporation, Pittsburgh, Pennsylvania.

SRAC, 1991a, COSMOS/M Users Guide, Fifth Edition, Version 1.65, Structural Research and Analysis Corporation, Santa Monica, California.

SRAC, 1991b, Geostar Users Guide, Third Edition, Version 1.65, Structural Research and Analysis Corporation, Santa Monica, California.

Thurgood, M. J., 1977, Final Report: An Evaluation of Condensation-Induced Water Hammer during ECCS Injection in N-Reactor, NAI-8708-1, Numerical Applications Inc., Richland, Washington:

WHC-CM-4-3, Industrial Safety Manual, Westinghouse Hanford Company, Richland, Washington.

WHC-CM-4-40, Industrial Hygiene Manual, Westinghouse Hanford Company, Richland, Washington. 
WHC-IP-0384, "Supplying Steam to a Facility," SWU3-0-384-30, Rev. 0, 300 Area Utilities and Effluent Treatment Processing Administration Manual, Westinghouse Hanford Company, Richland, Washington. 


\section{DISTRIBUTION}

Number of Copies

\section{OFFSITE}

2 Westinghouse Savannah River

Project

Bldg. 183-4K

Aiken, SC 29808

P. Livingood

L. M. Polizzi

5 Westinghouse Science and Technology Center 1310 Beulah Road

Pittsburgh, PA 15235-5098
Number of Copies

ONSITE

10 U.S. Department of Energy Richland Operations office

2 Pacific Northwest Laboratory

E. L. Courtright

K3-59

L. R. Eberhardt

P7 -70

1 Kaiser Enqineers Hanford

M. S. Ruben

E6-31

54 Westinghouse Hanford Company
W. T. Alumkal
$\mathrm{R} 2-52$
T. M. Anderson
B3-01
R. J. Bliss
B3-04
W. A. Dautel
T. N. Draper
F. W. Ell is
D. J. Green (20)
A. Greenberg (10)
$\mathrm{N} 2-03$
L6-79
$\mathrm{R} 2-34$
$\mathrm{H} 5-53$
S2-66
R. K. Hansen
N2-56
H. D. Harmon
$\mathrm{R} 2-52$
G. A. Harvey
$B 4-52$
K. R. Jordan
B2 -30
HO-34
R. J. Kobelsk
R3-09
M. K. Korenko
B3-08
H. E. McGuire
B3 -63
S. R. Moreno
B3-06
L. K. Severud
H5-60
M. A. Siano
G6-02
R. G. Slocum
B5-21
D. J. Swaim
B3-51
J. D. Tow
B4-52
A. L. Trego
B3-02
Central Files (3)
L8-04 

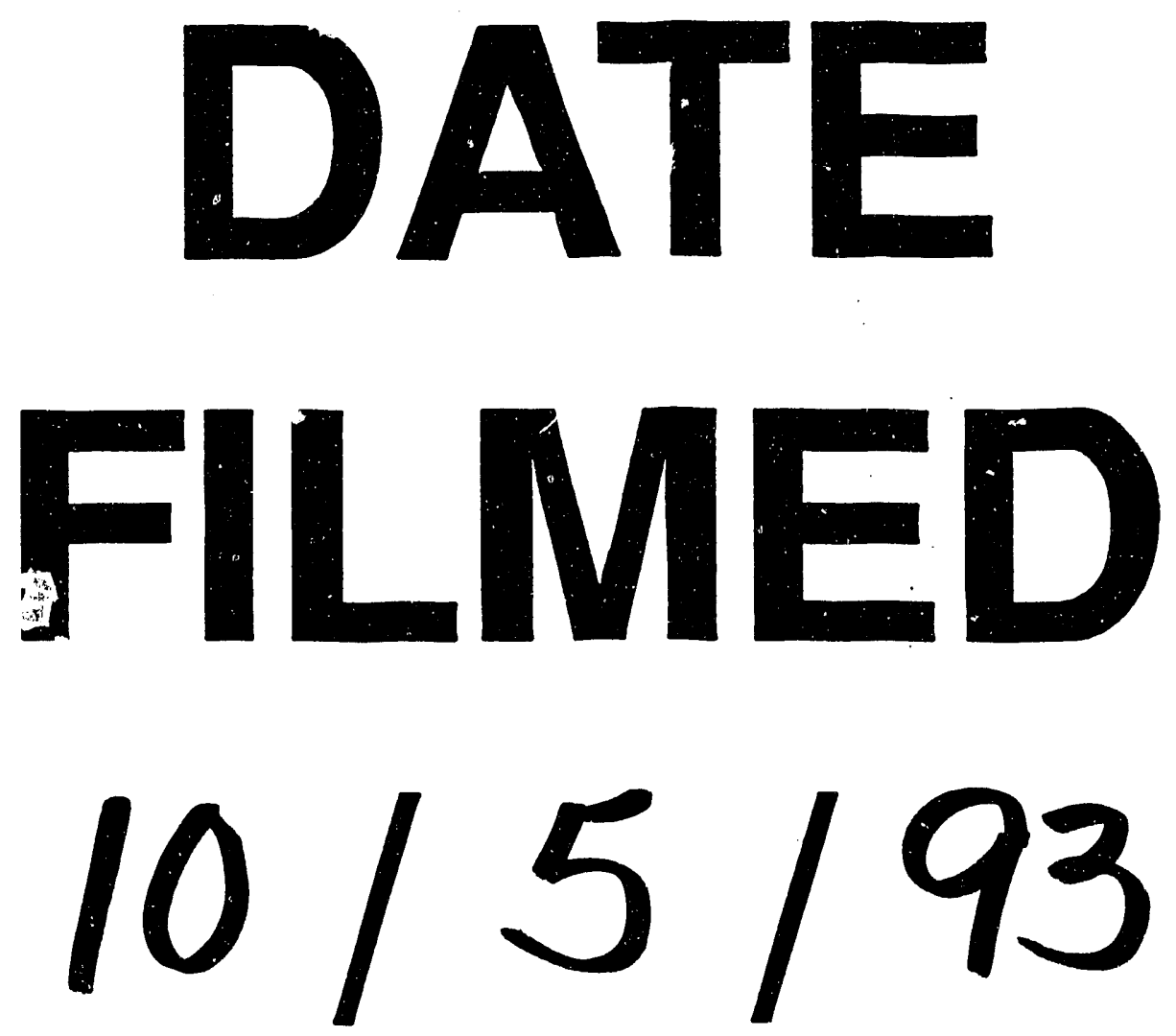

93
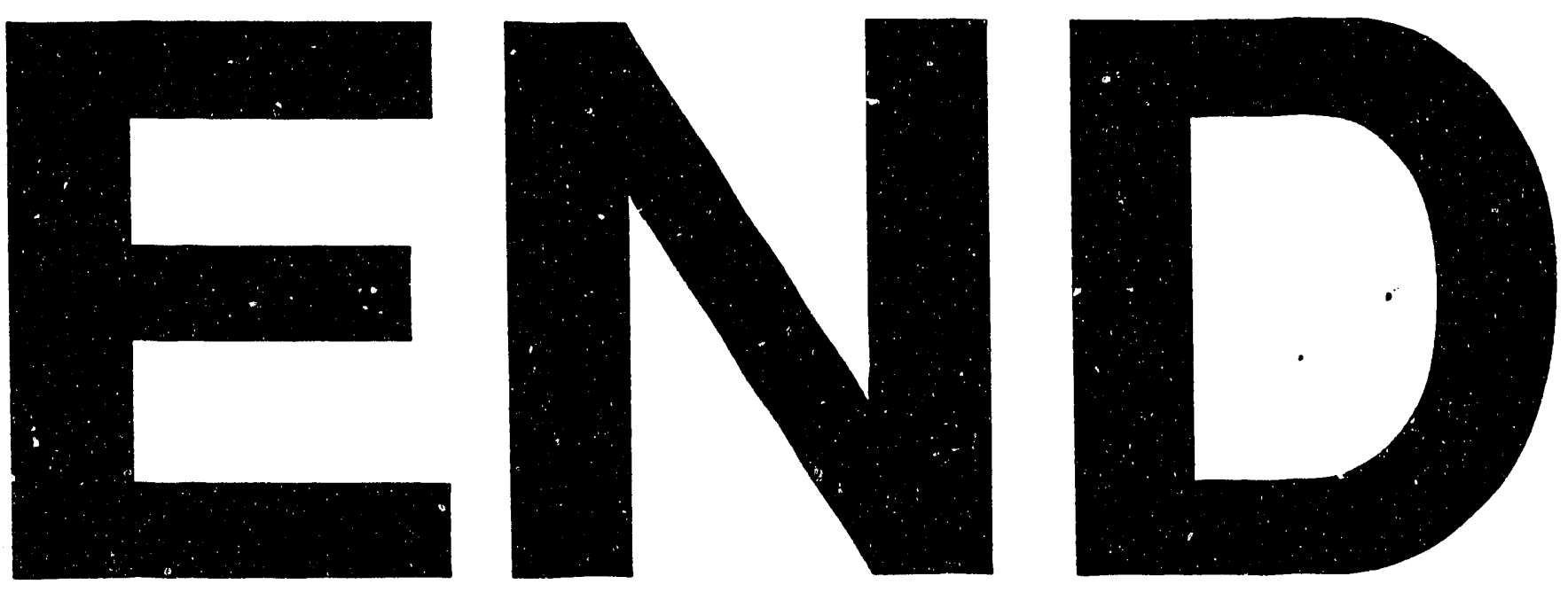
